Ronald KuRt, Klaus Näumann (Hg.)

\title{
MENSCHLICHES HANDELN ALS IMPROVISATION
}

\section{Sozial-und}

musikwissenschaftliche Perspektiven

[transcript] Kultur- und Medientheorie 
Ronald Kurt, Klaus Näumann (Hg.)

Menschliches Handeln als Improvisation 

Ronald Kurt, Klaus Näumann (Hg.)

Menschliches Handeln als Improvisation.

Sozial- und musikwissenschaftliche Perspektiven 


\section{Bibliografische Information der Deutschen Bibliothek}

Die Deutsche Bibliothek verzeichnet diese Publikation in der Deutschen Nationalbibliografie; detaillierte bibliografische Daten sind im Internet über http://dnb.ddb.de abrufbar.

(C) 2008 transcript Verlag, Bielefeld

$$
\text { (c) (1) ( }) \Theta
$$

This work is licensed under a Creative Commons Attribution-NonCommercial-NoDerivatives 3.0 License.

Umschlaggestaltung: Kordula Röckenhaus, Bielefeld Umschlagabbildung: Matthias Kunert: Kindergeburtstag (3/5),

(C) Photocase 2008

Lektorat \& Satz: Ronald Kurt, Klaus Näumann

Druck: Majuskel Medienproduktion GmbH, Wetzlar

ISBN 978-3-89942-754-7

Gedruckt auf alterungsbeständigem Papier mit chlorfrei gebleichtem Zellstoff.

Besuchen Sie uns im Internet: http://www.transcript-verlag.de

Bitte fordern Sie unser Gesamtverzeichnis und andere Broschüren an unter: info@transcript-verlag.de 


\title{
INHALT
}

\author{
Einleitung \\ RONALD KURT UND KLAUS NÄUMANN \\ 7
}

Komposition und Improvisation als Grundbegriffe einer allgemeinen Handlungstheorie

RONALD KURT

17

Theoretisch-begriffliche Anschlussstellen für ein Verständnis menschlichen Handelns als Improvisation

OLIVER KOZLAREK

47

\section{Die Form der Freiheit}

ULRICH BIELEFELD

67

>Es improvisiert < Improvisation in der nordindischen Kunstmusik

MARKUS SCHMIDT

99

Improvisation: Über ihren Gebrauch und ihre Funktion in der Geschichte des Jazz

KLAUS NÄUMANN

133

Musikalisches Improvisieren: Ein Ausdruck des

Augenblicks

SILVANA K. FIGUEROA-DREHER 
Improvisation als Merkmal und Gegenstand des Musikunterrichts

STEFAN ORGASS

183

Vom Sinn der Improvisation als Spiel

CONSTANZE RORA

215

AUTORINNEN UND AUTOREN

233 


\section{EINLEITUNG \\ RONALD KURT UND KLAUS NÄUMANN}

Improvisieren ist menschlich. Weil das Leben zum Umgang mit dem Unvorhersehbaren herausfordert, ist das Improvisieren eine Kompetenz, die nicht nur in der Kunst, sondern auch im Alltag eine wichtige Rolle spielt. Jedes menschliche Handeln enthält ein Improvisationspotential. Wenn diese Annahme richtig ist, dann müsste der Begriff Improvisation ein Kernbegriff kulturwissenschaftlichen Denkens sein - allein: er ist es nicht, jedenfalls noch nicht.

Die Autorinnen und Autoren dieses Buches nähern sich dem Phänomen des Improvisierens aus sozial- und musikwissenschaftlicher Sicht. Nicht nur das Buch, auch jeder einzelne Beitrag ist interdisziplinär konzipiert. Mit diesem Perspektiven verbindenden Vorgehen möchten wir eine fachübergreifende Diskussion zum Thema Improvisation anregen.

Den Hintergrund dieses Sammelbandes bildet die Tagung Menschliches Handeln als Improvisation. Sie fand im Rahmen des von der Deutschen Forschungsgemeinschaft geförderten Projektes Indien und Europa. Ein musiksoziologischer Kulturvergleich im Januar 2007 am Kulturwissenschaftlichen Institut in Essen statt. Die Fokussierung auf sozial- und musikwissenschaftliche Perspektiven war durch diese Rahmung vorgegeben. Traditionell der Improvisation nahe stehende Handlungsfelder wie beispielsweise Theater und Tanz können hier deshalb nicht Gegenstand der Analyse sein. Wir meinen aber, dass insbesondere das Verhältnis von Musik und Gesellschaft einen interessanten Ansatzpunkt für improvisationsbezogene Fragestellungen bietet.

Als Medium kultureller, sozialer und individueller Sinnbildung ist die gesellschaftliche Relevanz der Musik kaum zu überschätzen. Offenkundig können Menschen Klängen Sinn verleihen. Welchen Sinn Menschen mit Klängen verbinden, ist jedoch eine offene Frage, die je nach Kultur, sozialer Praxis und biografischer Prägung un- 
terschiedlich beantwortet werden kann. Kulturwissenschaftlich betrachtet birgt die Bedeutungsoffenheit der Musik gerade im Hinblick auf das Thema Improvisation viel versprechende Forschungsperspektiven. Welche Interessen, Ideologien und Ideale ranken sich um die Improvisation in der Musik? In welchen Bedeutungs- und Verwendungszusammenhängen steht improvisierte Musik in nichtwestlichen Kulturen? Welche Funktionen erfüllen musikalische Improvisationen? Wie und zu welchem Zweck lehrt und lernt man das Improvisieren? Wie sprechen und reflektieren Musiker und Wissenschaftler über Improvisationsprozesse? Welches sind die sozialen Möglichkeitsbedingungen von improvisatorischem Handeln im Allgemeinen und musikalischer Improvisation im Besonderen? Bietet die Analyse musikalischer Improvisation Anknüpfungspunkte für Theorien menschlichen Handelns? Die Beiträge dieses Buches bewegen sich im Sinnhorizont dieser Fragestellungen:

Ronald Kurt stellt in seinem Aufsatz »Komposition und Improvisation als Grundbegriffe einer allgemeinen Handlungstheorie« anhand von Kulturvergleichenden, soziologischen und musikgeschichtlichen Überlegungen die Relevanz des Improvisationsbegriffs für das Verständnis menschlichen Handelns heraus.

Oliver Kozlarek reflektiert in seinem Beitrag über »Theoretischbegriffliche Anschlussstellen für ein Verständnis menschlichen Handelns als Improvisation «. Im Hinblick auf eine kulturwissenschaftliche Konzeptionierung des Improvisationsbegriffs wird gezeigt, dass und wie Cassirers Kulturbegriff Joas' Theorie des kreativen Handelns bereichern könnte.

In seinem Aufsatz »Die Form der Freiheit« untersucht Ulrich Bielefeld, wie sich im Laufe des letzten Jahrhunderts der soziale Sinn musikalischer Improvisation gewandelt hat. Ausgehend von Adornos Musiksoziologie zeigt der Autor, dass, bedingt durch die Wechselverhältnisse zwischen Musiker, Rezipient und Technik, der Improvisation im Spannungsfeld zwischen Selbstbestimmung und Regelkonformität immer wieder neue Bedeutungen zugewiesen werden.

In seiner Kulturvergleichenden Studie »>Es improvisiert< Improvisation in der nordindischen Kunstmusik « arbeitet Markus Schmidt die inner- und außermusikalischen Strukturprinzipien indischen Improvisierens als Ausdruck der Wertvorstellungen der hinduistisch geprägten, indischen Gesellschaft heraus. 
In seinem Aufsatz »Improvisation: Über ihren Gebrauch und ihre Funktion in der Geschichte des Jazz« reflektiert Klaus Näumann über das vielgestaltige Verhältnis von Jazz und Improvisation und den daraus erwachsenden Problemen für die Gegenwart, in der die Jazz-Improvisation im universitären und schulischen Bereich mittlerweile einen festen Platz einnimmt.

Silvana K. Figueroa-Dreher fragt in ihrem Text $\gg$ Musikalisches Improvisieren: Ein Ausdruck des Augenblicks« nach den subjektiven und intersubjektiven Möglichkeitsbedingungen improvisatorischen Handelns. Auf der Grundlage einer empirischen Analyse von Free-Jazz-Improvisationen argumentiert die Verfasserin im Rahmen ihrer kritischen Auseinandersetzung mit den Handlungstheorien von Schütz und Luckmann dafür, das Improvisieren als einen eigenständigen Typus des Handelns zu betrachten.

Stefan Orgass thematisiert in seinem Aufsatz »Improvisation als Merkmal und Gegenstand des Musikunterrichts« die Improvisation aus Sicht der Kommunikativen Musikdidaktik. Der Verfasser führt aus, unter welchen Voraussetzungen und in welcher Form Improvisation im Musikunterricht relevant sein kann.

Der Beitrag von Constanze Rora handelt $»$ Vom Sinn der Improvisation als Spiel«. Die Autorin geht in musikpädagogischer Perspektive auf den $>$ Mythos Improvisation $<$ ein und stellt im Anschluss daran die Nähe zwischen Improvisation und Spiel und die Bedeutung der Improvisation für den individuellen Selbstbildungsprozess heraus.

Dass sich Musikwissenschaftlerinnen und Musikwissenschaftler - unabhängig davon, ob sie sich der historischen, der vergleichenden, der systematischen Musikwissenschaft oder der Musikpädagogik zurechnen -, mit Improvisation beschäftigen, scheint eine Selbstverständlichkeit zu sein. Tatsächlich aber hat es lange gedauert bis sich die gering geschätzte Improvisation gegenüber der hoch geschätzten Komposition zu behaupten begann und schließlich als musikwissenschaftliches Thema Anerkennung fand. Dass sich Sozialwissenschaftlerinnen und Sozialwissenschaftler nicht mit dem Thema Improvisation beschäftigen, scheint ebenfalls eine Selbstverständlichkeit zu sein. So wie das Denken insbesondere der historischen Musikwissenschaft von den Kategorien Komposition und Werk beherrscht wurde (und zum Teil noch immer wird), so ist auch in durchaus vergleichbarer Weise die Geschichte der Soziologie geprägt von Begriffen, die der durchorganisierten Ordnung 
und/oder dem souveränen schöpferischen Subjekt höchste Wertschätzung beimessen. Diese Leitkategorien legen es nahe zu übersehen, dass Ordnung nur das halbe Leben ist und dass menschliches Handeln sich nicht auf das Realisieren von Entwürfen reduzieren lässt. Bis heute gibt es in der Soziologie keinen Theorieansatz, der menschliches Handeln mit dem Vermögen zu improvisieren in Verbindung bringt.

In den Texten zum Thema Improvisation, die in den letzten Jahren veröffentlicht wurden, dominieren musikwissenschaftliche Perspektiven. Aber auch andere Disziplinen nehmen Teil am Improvisationsdiskurs: Theater-, Kunst- und Tanzwissenschaft, Psychologie, Linguistik, Architektur etc. Alle mischen ihre Stimme ein - fast alle, wie gesagt, soziologische Beiträge liegen bislang keine vor (vgl. hierzu beispielhaft die von Walter Fähndrich herausgegebene Reihe Improvisation I bis V; Fähndrich 1992, 1994, 1998, 2001, 2003). Wir würden uns freuen, wenn dieses Buch den Anfang vom Ende soziologischer Diskursabstinenz markierte. Anknüpfungspunkte für die Soziologie gibt es viele. Schon vor Jahrzehnten schlug Carl Dahlhaus vor, Improvisation als eine »kulturwissenschaftliche Kategorie « aufzufassen (Dahlhaus 1979: 23), die nur im Kontext von Geschichte und Gesellschaft angemessen zu definieren sei. In diesem Sinne betont auch Bert Noglik, dass sich Improvisationen nicht in einem »kulturellen Vakuum« abspielen (Noglik 1992: 116). Aus soziologischer Sicht wäre demgemäß also nicht zu fragen, was Improvisation als solche ist, sondern was Menschen als Mitglieder bestimmter Gemeinschaften praktisch und theoretisch unter Improvisation verstehen.

Im weiten Spektrum dieser Verstehensweisen ist unter anderem die Meinung zu finden, dass sich das Improvisieren wissenschaftlich nicht erfassen lasse. So schreibt der Musiker Derek Bailey in der Einleitung seines Buchs Musikalische Improvisation. Kunst ohne Werk:

»Improvisation ist ständig im Fluss, niemals stabil und festgeschrieben; sie entzieht sich exakter Beschreibung und Analyse, sie ist von Hause aus unakademisch. Mehr noch: Jeder Versuch, Improvisation zu beschreiben, stellt in gewisser Weise eine Verfälschung dar, denn der Wesenskern spontaner Improvisation läuft dieser Absicht zuwider und steht im Gegensatz zum Gedanken der Dokumentation.«(Bailey 1987: 7) 
Mythologisierende Denkverbote motivieren Reflexionen. Ob bzw. inwieweit sich das Improvisieren akademischer Reflexion entzieht, wird hier soziologisch und musikwissenschaftlich zu prüfen sein. Dabei ist nicht auszuschließen, dass Bailey Recht behält und sich die Wissen wollende Hinwendung zur Improvisation als orphischer Bezug entpuppt (vgl. Hogrebe 2006). Die Musik eröffnete Orpheus die Möglichkeit, seine geliebte Eurydike aus dem Schattenreich des Todes in die Oberwelt zurückzuführen. Doch das Wissen wollen ließ ihn scheitern. So wie Orpheus Eurydike verlor, indem er sich Vergewisserung suchend nach ihr umsah, so könnte auch der Versuch, das flüchtige Phänomen der Improvisation mit wissenschaftlichen Mitteln begreifen zu wollen, den Gegenstand unseres Erkenntnisinteresses zum Verschwinden bringen. Wie gewonnen, durch die Kunst, so zerronnen, durch die Wissenschaft. Auch auf die Gefahr hin, dass die Improvisation nun für immer in das dunkle Schattenreich des Unfassbaren und Unverstehbaren zurückweicht, wollen wir hier eine erste Bezugnahme wagen und den Beiträgen dieses Bandes einige Assoziationen zur Etymologie des Wortes $>$ Improvisation< voranstellen.

Das Wort >Improvisation< entstammt dem Lateinischen >improvisus< und lässt sich in drei Sinneinheiten zerlegen: $>\operatorname{Im}<->$ pro $<-$ $>$ videre $<$. $>$ Videre $<$ heißt $>$ sehen $<$, $>$ pro $<$ bedeutet hier $>$ vor $<$ und impliziert einen Zukunftsbezug, >im< ist eine Negation und lässt sich ins Deutsche als >nicht< oder >un< übersetzen (vgl. Widmer 1994: 9f.). In der Verbindung der drei Worte >nicht $<->$ vor $<->$ sehen $<$ wird ein Sehen verneint, das sich auf Zukünftiges bezieht. Das leuchtet unmittelbar ein: wir wissen nicht, wie es weitergeht. Dieses Nichtwissen deutet aber auch ein Wissen an, nämlich das Wissen, dass wir nicht wissen, was zukünftig der Fall sein wird. Die Zukunft ist ungewiss. Mit dieser Gewissheit müssen wir leben.

Nicht wissend wie es weitergeht, können wir nur ahnen, was geschehen wird. Wir überschreiten in unseren Gedanken die Gegenwart in Richtung Zukunft und nehmen diese dadurch hypothetisch vorweg. So gehen wir der prinzipiell ungewissen Zukunft mit Antizipationen entgegen. Diese Zukunftsvorzeichnungen bilden den Sinnhorizont für die Ausrichtung unserer Lebenspläne. In diese vorentworfene Zukunft hinein handeln wir. Das unterscheidet Marx zufolge den Menschen vom Tier: 
»Eine Spinne verrichtet Operationen, die denen des Webers ähneln, und eine Biene beschämt durch den Bau ihrer Wachszellen manchen menschlichen Baumeister. Was aber von vornherein den schlechtesten Baumeister vor der Biene auszeichnet, ist, daß er die Zelle in seinem Kopf gebaut hat, bevor er sie in Wachs baut. Am Ende des Arbeitsprozesses kommt ein Resultat heraus, das beim Beginn desselben schon in der Vorstellung des Arbeiters, also schon ideell vorhanden war.« (Marx 1984: 193)

Dass wir uns selbst immer schon planend und projektierend voraus sind, ist sicher wahr, aber daraus folgt nicht zwangsläufig, dass jeder Bau die Realisierung seines Bauplans ist. Das Problem ist: meist kommt es anders als wir dachten. Oft ereignet sich etwas, das wir nicht vorhergesehen haben - wobei der Vorgriff des Vorhersehens als logische Voraussetzung für das Unvorhergesehene fungiert. Nur so ist es überhaupt möglich, dass wir überrascht werden können, von Ereignissen, von anderen und nicht zuletzt auch von uns selbst. Das Unvorhersehbare ist so gesehen eine Erwartungsenttäuschung, die Negation einer Transzendenz.

Das Unvorhersehbare hat eine andere Qualität, wenn Zukunftsantizipationen nicht lückenlos und präzise, sondern umrisshaft und vage sind. Je ungefährer die Zielsetzungen und Handlungspläne, desto mehr müssen wir nolens volens das Unvorhersehbare in unser Handeln mit einbeziehen. Wir suchen dann die Situation, in die wir uns begeben haben bzw. in die wir irgendwie hineingeraten sind, nach Zwecken, Mitteln, Risiken und Chancen ab. Hier, wenn wir den Unwägbarkeiten des Lebens erwartungsoffen gegenübertreten, zählen wir auf das Unvorhersehbare - im anderen Fall, wenn wir der perfekten Realisierung detailgenauer Pläne entgegenstreben, müssen wir mit dem Unvorhersehbaren rechnen (indem wir beispielsweise Versicherungen abschließen).

Zurück zur Etymologie. Das lateinische >improvisus< hat Eingang ins Italienische (>improvvisare $<$ ), Französische (>improviser $<$, $>$ improviste $<$ ) und Englische (>improvise $<$ ) gefunden, nicht aber ins Deutsche. Das deutsche Wort, das dem Ausdruck >Improvisation< sinngemäß am nächsten steht, lautet 〉Stegreif $<$. Das Wörterbuch der Brüder Grimm widmet ihm neun Spalten (vgl. Grimm 1999: 13861394).

Der Stegreif ist der Steigbügel des Reitpferdes. Das ist der sachliche Bedeutungskern eines vielschichtigen Bedeutungsfelds. Es reicht vom Grobmotorisch-Kriegerischen bis zum Feinsinnig-Künst- 
lerischen. Jacob und Wilhelm Grimms Erläuterungen bleiben zunächst auf den Bereich des Reitens bezogen: »sich im stegreif nehren« bedeutet »sich auf reyterei legen, vom Sattel leben«, »als berittener wegelagerer vom strassenraub leben« (ebd.: 1389). Vom Bedeutungsfeld des Reitens ausgehend betonen die Grimms dann den bildlichen Sinn: »aus dem stegreife, ohne große vorbereitung, ohne lange überlegung, keck, eilig, gleichsam, wie der fröhliche reitersmann schnell noch etwas erledigt, auch wenn er schon im Sattel sitzt und ohne abzusteigen « (ebd.: 1390). Die nächste Bedeutungsübertragung führt vom Rittertum ins Bürgertum. Aus dem Stegreif sprechen heißt »ohne grosse vorbereitung und ohne manuscript « (ebd.: 1391). Aus dem Stegreif schreiben heißt »ohne große vorbereitung keck seine ansichten niederschreiben « (ebd.: 1391). Die Kunst darf schließlich auch nicht fehlen. Goethe: »wenn der hauptbegriff gegeben war, so arbeitete der künstler wohl auch aus dem stegreife«(ebd.: 1391). Für die Musik wird E.T.A. Hoffmann zitiert: »er weiss einen gegebenen satz aus dem stegreif so oft man will, und in allen Tönen abzuändern« (ebd.: 1391). Im Zusammenhang mit Shakespeare und Theater taucht sogar das Wort >improvisieren< auf: »stegreifschauspielkunst, die improvisiert« (ebd.: 1392). An anderen Stellen wird es genannt, um als Äquivalent für >improvisator< die deutschen Ausdrücke >stegreifdichter $<$ und $>$ stegreifredner $<$ anzuführen (vgl. ebd.: 1393f.). Von der Kunst führt der Weg dann wieder zum Alltag zurück, wenn das Wort >Stegreif< zur Beschreibung einer bestimmten Lebensweise herangezogen wird: »aus dem stegreif leben, d.h. ohne das künftige stark zu bedenken, ohne bestimmten lebensplan « (ebd.: 1392).

Die genannten Verwendungsweisen des Wortes $\gg$ Stegreif $<$ verweisen darauf, dass Menschen im Prozess des Handelns ohne große Vorbereitung - aber nicht gänzlich ohne Vorbereitung! - produktiv sein können. Das für die Improvisation Entscheidende ist hier, dass der Handelnde dem Jetzt das Ja-Wort gibt und im Angesicht des Augenblicks auf selbst gesetzte, situativ sich ergebende oder von anderen auferlegte Ansprüche so schnell und so angemessen wie möglich zu antworten versucht.

Für eine Definition des Improvisationsbegriffs ist diese Einleitung sicherlich nicht der rechte Ort. Den folgenden Bestimmungsversuch möchten wir den Lesern dieses Buches gleichwohl nicht vorenthalten. $\mathrm{Ob}$ die improvisierte Improvisationsdefinition des Saxophonisten Steve Lacy nicht doch eher als Aufführung eines 
durchkomponierten Werks zu verstehen ist, bleibt hier dahingestellt. Der Anekdote zufolge wurde Lacy gebeten, aus dem Stegreif in 15 Sekunden zu beschreiben, was den Unterschied zwischen Komposition und Improvisation ausmache.

»In 15 Sekunden zusammengefasst, besteht der Unterschied zwischen Komposition und Improvisation darin, dass man bei der Komposition so viel Zeit hat, wie man sich nur wünscht, um sich zu entscheiden, was man in 15 Sekunden sagen will; während einem bei der Improvisation 15 Sekunden zur Verfügung stehen.«(Lacy in Fähndrich 1994: 82)

In ebendiesem Sinne möchten wir uns nun in 15 Sekunden bei den Autorinnen und Autoren dieses Buches, der Deutschen Forschungsgemeinschaft (DFG), dem Kulturwissenschaftlichen Institut (KWI) und dem transcript-Verlag, insbesondere bei Karin Werner und Jörg Burkhard, für ihr Mitwirken bedanken.

\section{Literatur}

Bailey, Derek (1987): Musikalische Improvisation. Kunst ohne Werk. Hofheim: Wolke.

Dahlhaus, Carl (1979): »Was heißt Improvisation?« In: Reinhold Brinkmann (Hg.): Improvisation und neue Musik, Mainz et al.: Schott, S. 9-23.

Fähndrich, Walter (Hg.) (1992): Improvisation I. Winterthur: Amadeus Verlag.

Fähndrich, Walter (Hg.) (1994): Improvisation II. Winterthur: Amadeus Verlag.

Fähndrich, Walter (Hg.) (1998): Improvisation III. Winterthur: Amadeus Verlag.

Fähndrich, Walter (Hg.) (2001): Improvisation IV. Winterthur: Amadeus Verlag.

Fähndrich, Walter (Hg.) (2003): Improvisation V. Winterthur: Amadeus Verlag.

Grimm, Jacob und Wilhelm (1999): Deutsches Wörterbuch, Band 17. München: dtv.

Hogrebe, Wolfram (2006): »Orphische Bezüge«. In: ders., Echo des Nichtwissens, Berlin: Akademie Verlag, S. 144-155.

Marx, Karl (1984): Das Kapital. Kritik der politischen Ökonomie. Erster Band. (MEW 23). Berlin: Dietz Verlag. 
Noglik, Bert (1992): »Improvisation als kulturelle Herausforderung «. In: Walter Fähndrich (Hg.), Improvisation I, Winterthur: Amadeus Verlag, S.112-132.

Widmer, Peter (1994): »Aus dem Mangel heraus«. In: Walter Fähndrich (Hg.), Improvisation II, Winterthur: Amadeus Verlag, S. 9-20. 



\title{
KOMPOSITION UND IMPROVISATION ALS GRUNDBEGRIFFE EINER ALLGEMEINEN HANDLUNGSTHEORIE
}

\author{
RONALD KURT
}

\section{Improvisation in Europa}

Die Jazzsaxofonistin Angelika Niescier erklärt Schülern, was Improvisation ist. ">Beim Improvisieren muss man sich auf eine neue Situation einstellen. Wenn man sich verfährt, muss man neue Wege finden, um ans Ziel zu kommen. Oder lügen, das ist auch eine Art der Improvisation.< >Ja<, warf ein Schüler ein, >wenn ich meine Hausaufgaben vergessen habe und mir eine Ausrede ausdenken muss.« (in Rheinische Post 01.08. 2007: B10)

Improvisation in Indien

Der indische Politikwissenschaftler Sunil Khilnani wirbt dafür, »das, was charakteristisch indisch ist oder sein kann, als eine Fähigkeit zu sehen: als die Fähigkeit zu improvisieren, als eine Art Geschicklichkeit im historischen Überleben, als eine Kunst, auf jede Frage, die gestellt werden könnte, eine Antwort zu finden. In den Musikformen Indiens wie auch in seinen literarischen Traditionen ist es nicht die Beständigkeit, das Dogma des singulären Textes, was geschätzt wird, sondern die Fähigkeit zu improvisieren und zu variieren.« (Khilnani 2006: 23)

Dort dient der Begriff der Improvisation als Inbegriff indischer Identität, hier scheint er mehr auf Profanes zu verweisen. Auch wenn Improvisationstheater mittlerweile Kultstatus genießen und auf Jazzimprovisationen rituell mit Applaus reagiert wird, ins Hochkulturschema hat es die Kunst der Improvisation bei uns nie so recht geschafft. Dem Improvisieren haftet im Westen ein Makel an: 
es ist Mangelmanagement, unperfekter Notbehelf, Mittel für einen höheren Zweck.

In der abendländischen Kulturgeschichte steht die Improvisation im Schatten der Komposition. Gegenüber dem Werk ist alles andere irgendwie immer weniger wert. Nicht nur in der Kunst, auch in den Wissenschaften hat sich die Wertschätzung des perfekt durchkomponierten Werks tief in unsere Art des Denkens eingezeichnet, unter anderem in unsere Handlungstheorien. Im Bezug auf diese Theorietradition argumentiere ich in diesem Text für ein Modell, das menschliches Handeln als Verhältnis aus Komposition und Improvisation begreift. Diese Auffassung soll hier durch soziologische und musikgeschichtliche Überlegungen hergeleitet und begründet werden. In Kulturvergleichender Perspektive werden auch Aspekte des indischen Musik- und Kultur(er)lebens miteinbezogen. Schließlich werden die Sonderwege der abendländischen Musik- und Wissenschaftsgeschichte ja erst dann als solche wahrnehmbar, wenn sie vor dem Hintergrund alternativer Kulturentwicklungen gespiegelt werden. Schlägt der Blick vom Eigenen auf das Fremde um in einen Blick vom Fremden auf das Eigene, dann gelingt es mitunter mit anderen Augen zu sehen.

\section{Genesis eines Menschenbildes}

»Zu Anbeginn hat Gott erschaffen den Himmel und die Erde. Die Erde aber war wüst und wirr, und auf der Urflut lag Finsternis. Gottes Geist aber schwebte über den Gewässern. Da sprach Gott: >Licht werde! < Und Licht ward. Und Gott sah: Das Licht war gut. «(Genesis 1. Kap. 1-4) Natürlich war das Licht gut! Von Gott erschaffen konnte es ja nicht anders als perfekt sein. Nach der sechstägigen Arbeit, »die Gott zu tun geplant hatte (Genesis 2. Kap. 3) war das Schöpfungswerk vollbracht. Dass es »sehr gut war « (Genesis 1. Kap. 31), versteht sich von selbst: Die Schöpfung war die perfekte Realisierung eines vollkommenen göttlichen Plans. Die Schöpfung als Improvisation zu bezeichnen wäre Blasphemie. Gott improvisiert nicht!

Und der Mensch? Wenn zur Beantwortung dieser Frage das Menschenbild sozialwissenschaftlicher Handlungstheorien zugrunde gelegt würde, dann improvisiert auch er nicht. In den auf Max We- 
ber und Alfred Schütz zurückgehenden soziologischen Handlungstheorien scheint ein nach dem Bilde Gottes modellierter Mensch gleichsam als >Vize-Gott< (Cusanus) oder >second maker $<$ (Shaftesbury) die Rolle des allmächtigen Schöpfers eingenommen zu haben. Insbesondere bei der Handlungstheorie von Alfred Schütz scheint der Mensch in eine gottgleiche Position gerückt: Der Geist des Menschen schwebt über der sozialen Wirklichkeit, entwirft Zielvorstellungen und Handlungspläne, um dann, nach dem >fiat $<$, dem biblischen >es geschehe!<, seinen Körper die Realisierung des Geplanten erledigen zu lassen - und nach dem Vollzug sieht der Mensch, ob es gut war.

\section{Die Handlung und das Handeln}

Menschliches Handeln vollzieht sich entwurfsbezogen (vgl. Schütz 2004: 155). Der Mensch setzt sich Ziele, bedenkt die Mittel, kalkuliert die Folgen, richtet sich an Werten, Normen, Menschen und Dingen aus, aktiviert das jeweils relevante Wissen, berücksichtigt Gewohnheits- und Gefühlsmäßiges und versucht dann im Rahmen dieses Orientierungsnetzes einen Handlungsplan zu komponieren, den es schließlich im praktischen Handeln entsprechend umzusetzen gilt. Das Ganze lässt sich mit Alfred Schütz in die Phasen Zielsetzung, Handlungsentwurf, Entschluss, Vollzug zergliedern. Das Verhältnis von Entwurf und Vollzug bestimmt Schütz mit den Begriffen Handlung und Handeln: Das, was entworfen wird, ist die Handlung, während Handeln das an diesem Entwurf orientierte Verhalten ist. Der Entschluss, der Willensakt des >fiat $<$ fungiert dabei gleichsam als Startschuss, um das Vorentworfene in einem Tun (oder auch Nichttun) zu verwirklichen. So gesehen steht das Handeln voll und ganz im Dienst der Handlung. Die Handlung ist das Maß des Handelns, das als Erfüllungsgehilfe des Entwurfs das Ideal in der Praxis realisieren soll. Der $»$ Sinn des Handelns ist die vorher entworfene Handlung « (Schütz 2004: 157).

Am Entwurfcharakter menschlichen Handelns ist unbedingt festzuhalten, weil es ansonsten kein Kriterium gäbe, zwischen sinnhaftem Handeln und bloßem Verhalten zu unterscheiden (vgl. Schütz 2004: 157). Ob aber an der engen Bestimmung des Entwurfs als ein dem Handeln vorausgehender Handlungsplan und an der ein- 
seitigen funktionalen Differenzierung zwischen Handlung und Handeln festgehalten werden kann, ist hingegen fraglich.

Die Voraussetzungen, auf denen das hier skizzierte Handlungsmodell beruht, wurzeln einerseits im christlichen Schöpfungsmythos, andererseits in den aufklärerischen Attitüden des 18. und 19. Jahrhunderts, insbesondere in der Idee des autonomen Subjekts, das selbstbestimmt und vernunftgemäß denken und Welt gestaltend wirken kann. In diese Subjektauffassung sind mehrere Dualismen eingewoben: Die Trennung von Ich und Welt, Idee und Wirklichkeit, Geist und Körper. Dazwischen tritt vermittelnd ein die Willenskraft: Sie bringt das Ich zur Welt, die Idee zur Verwirklichung und den Körper unter Kontrolle (und in Bewegung). Die zeitliche Trennung von Handlung, Entschluss und Handeln ist eine logische Konsequenz dieser Denktradition. In dieses kantisch-cartesianische Koordinatensystem setzte Max Weber den Typus des rational denkenden Menschen ein, dessen Handeln »an die Kategorien >Zweck und >Mittel ( gebunden)« ist (Weber 1973: 149). Diesem von der Nationalökonomie inspirierten Credo schlossen sich im Anschluss an Weber auch Schütz und Parsons an. Das Schema der Rationalität ließ die nutzen- und/oder vernunftorientierten Aspekte menschlichen Handelns in den Vordergrund treten. Das in diesem Sinne Nicht- bzw. Irrationale - das Gefühls- und Gewohnheitsmäßige, das Unbewusste, Spontane, Improvisatorische, Spielerische und Kreative - rückte dadurch in den Hintergrund (was auch Vilfredo Pareto mit seiner Kategorie des nicht-logischen Handelns nicht ändern konnte). Die Erfolgsgeschichte des zweckrationalen homo oeconomicus und des normenkonformen homo sociologicus reicht bis in die Soziologie der Gegenwart. So unbestreitbar die Nützlichkeit dieser Modelle ist, so unbestreitbar ist aber auch, dass sie die nichtrationalen Aspekte des Handelns bestenfalls als Abweichung vom Rationalen, »als defiziente Modi des rationalen Handelns « (Joas 1996: 63) erfassen können. Hinzu kommt, dass rationalitätszentrierte Handlungstheorien kaum in der Lage sind, menschliches Handeln als Prozess zu verstehen. Schließlich kann der Prozess des Handelns nur im Ausnahmefall die 1:1-Verwirklichung eines vorfabrizierten Entwurfs sein. In der Regel geht unserem Handeln, das sich ohnehin nur analytisch in einzelne Handlungsatome zergliedern lässt, kein sorgfältig in aller Ruhe durchdachter Handlungsplan voraus. Oft sind es nur vage Vorhaben, mit denen wir durchs Leben schreiten bzw. stolpern. Mitunter vergessen wir unterwegs, was wir uns vor- 
genommen hatten, manchmal entwickeln wir Ziele und Pläne spontan aus der Situation heraus und nicht selten überraschen wir uns selbst mit unserem Tun. Schon diese ganz alltäglichen Erfahrungen passen nicht in das Schema von Handlungstheorien, in denen das Handeln im Rahmen der Vorgaben der Handlung zu verbleiben hat.

Die >Erst-Denken-dann-Handeln<-Theorie sagt wenig über die soziale Praxis, aber viel über die Entstehungssituation der Theorie aus: die Studierzimmeratmosphäre des einsam brütenden (vorzugsweise deutschen) Denkers, der fernab vom Weltlichen Masterpläne für die Menschheit schafft.

\section{Komposition und Schriftlichkeit}

Der christlich fundierte und aufklärerisch konfirmierte Glaube an das schöpferische Subjekt spiegelt sich am stärksten in der hervorragenden Rolle, die der Komponist in der abendländischen Musikgeschichte gespielt hat (und in der massenwirksamen Hochkulturverwaltung noch immer spielt).

Im 18. und 19. Jahrhundert wurden die Komponisten mit symbolischen Sinnzuweisungen nur so überschüttet. Sie haben »erschaffen, wie der Herr, aus dem Nichts « (Tieck über Mozart), sie folgten göttlicher Eingebung - »von oben muss es kommen « (Beethoven) -, sie schöpften aus ihren Träumen (E.T.A. Hoffmanns Ritter Gluck), aus dem Unterbewusstsein (vgl. Brahms in Bullerjahn 2004: 127) und, so noch in Thomas Manns Dr. Faustus, aus dem Pakt mit dem Teufel. In den Werken der Komponisten fand das Bürgertum all das ausgedrückt, was ihm seinerzeit wertvoll und wichtig erschien: das Innerste (Herder), die Affekte (Carl Philipp Emanuel Bach), »das Ach und Oh des Gemüts « (Hegel), den Willen (Schopenhauer), menschliche Subjektivität, mathematische Objektivität, Natur, Allgemeinmenschliches, Genie.

So sehr die Ansichten über das Wesen des Schöpferischen und den Gehalt der Werke ideologisch auch variieren mochten, das Verhältnis zwischen Täter und Tat blieb formal konstant: Hier die Subjektivität des Komponisten, dort die Objektivität des Werks, im individuellen Akt des schriftlichen Komponierens in die rationale Form einer Notation gebracht. Der wie auch immer inspirierte Komponist bringt seine musikalischen Gedanken auf dem Notenpa- 
pier in eine schriftliche Form und hinterlässt der Welt damit ein in sich geschlossenes Werk, das es so aufzuführen gilt, wie es durch die Notenschrift vorgegeben ist. Die Interdependenz von Komposition und Notation ist Max Weber zufolge das Resultat eines Rationalisierungsprozesses. »Erst die Erhebung der mehrstimmigen Musik zur Schriftkunst schuf so den eigentlichen >Komponisten « (Weber 2004: 237f.; vgl. auch Kurt 2006a). (Erhöhungen können erniedrigend wirken: Auf der Rückseite der Wertschätzung von Komponist und Notation nistete sich zugleich die Haltung ein, nichtschriftliche Musik mit Geringschätzung zu behandeln.) Im Kult der Komponistenverehrung bildete sich in der klassischen und romantischen Musik der folgende kategorische Imperativ heraus: Folge Ton für Ton dem fix und fertig vorliegenden Handlungsplan der Partitur und verwirkliche ihn im Sinne seines Schöpfers. Das Wesentliche des Werkes ist so gesehen die Partitur und nicht die Aufführung. Diese ist zuallererst als $\gg$ Dienst an der graphisch einzigartigen Fixierung « zu verstehen (Mauser 1994: 48). Adornesk zugespitzt: »Partituren sind nicht nur fast stets besser als die Aufführungen, sondern mehr als nur Anweisungen zu diesen; mehr die Sache selbst.« (Adorno 1973: 153)

Der Mythos vom heiligen Werk und seiner gottgleichen Schöpfung durch den mit der Welt und seinem Selbst ringenden Komponisten ist im 20. Jahrhundert durch Komponisten wie Strawinsky, Schönberg und Cage entzaubert worden. Ein Rest von Aura mag dem Komponistendasein gleichwohl erhalten geblieben sein. Heute sind es im E-Musikbetrieb aber doch eher die charismatischen Dirigenten und Virtuosen, die dem westlichen Glauben an souveräne Subjektivität noch Nahrung geben können.

\section{Komposition und Improvisation als Gegensatz}

Für die Musikwissenschaftler des 19. Jahrhunderts war das Improvisieren lediglich eine musikalische Marginalie. Das 1938 erschienene Buch von Ernst Ferand Die Improvisation in der Musik brach mit dieser Tradition. Ferand rekonstruiert, wie mit der Verschriftlichung der mehrstimmigen Musik im 11. Jh. ein Rationalisierungsprozess einsetzte, der den Spielraum für musikalische Improvisationen zu- 
nehmend eingrenzte. Die fortschreitende Verbesserung des Notationssystems, das schriftliche Fixieren frei fantasierter Variationen und die Forderung, sich an die vorgeschriebenen Noten zu halten, begünstigten das kompositorische Gestalten und begrenzten zugleich die Möglichkeiten musikalischer »Augenblicksäußerungen« (Ferand 1938: 1) - nicht ohne Widerstand:

»Daß gerade in der deutschen Choralpraxis noch bis ins 15. Jh. hinein gegen Improvisationsgelüste der Sänger angekämpft werden musste, zeigt recht deutlich die Anweisung >De modo bene cantandi choralem cantum in multitudine personarum< usw. des Conrad von Zabern aus dem Jahre 1474, in der die Sänger nachdrücklichst ermahnt werden, sich streng an die Noten zu halten, wie sie dastünden, und nicht einzelne Noten zu zerlegen (verzieren), Kadenzen (caudae) anzubringen, in die Quinte (!) oder in eine andere Konsonanz (!) überzuspringen oder gar nach Art eines Diskantus von den vorgeschriebenen Noten abzuweichen.«(Ferand 1938: 110f.)

Schließlich räumte auch die musikalische Praxis - von Ausnahmen wie der Orgelimprovisation einmal abgesehen - der Komposition den Vorrang ein. Wenn man improvisierte, dann vornehmlich deshalb, um Ideen für Kompositionen zu generieren.

»Um 8 Uhr nahm Haydn sein Frühmahl. Gleich nachher setzte er sich ans Klavier und phantasierte solange, bis er zu seiner Absicht dienende Gedanken fand, die er sogleich zu Papier brachte: so entstanden die ersten Skizzen von seinen Kompositionen.« (Albert Christoph Dies in Ferand 1938: 30)

Auch die anderen beiden Wiener Klassiker, Mozart und Beethoven, improvisierten viel, und gut, aber das hat sie nicht berühmt gemacht. Dem »Improvisator flicht die Nachwelt keine Kränze« (Ferand 1938: IX).

Ferand rekonstruiert das Verhältnis von Komposition und Improvisation vor dem Hintergrund einer entwicklungstheoretischen Annahme: Die Improvisation bildet das Anfangsstadium, die Komposition den End- und Höhepunkt. Mit dieser Unterscheidung ist entschieden, wie das Improvisieren zu bewerten ist. Es ist triebhaft, instinktiv, reflexhaft, unüberlegt, unvorbereitet, spontan, gefühlsmäßig und spielerisch. Die Komposition fasst Ferand hierzu als Gegensatz. Sie ist prämeditiert, planmäßig und durchdacht (vgl. Ferand 
1938: 14). So wird die Musik und mit ihr der Mensch in zwei Hälften zerlegt: eine irrationale und eine rationale. Die Irrationalität der Improvisation sieht Ferand als kindlich, die Rationalität der Komposition als erwachsen an. Wie es dem Geist der Zeit entsprach, wendete Ferand dieses Schema auch auf Gesellschaften an. Als entwicklungsgeschichtlich frühe Stufe der Musik ist die Improvisationspraxis seiner Meinung nach kennzeichnend für primitive und exotische Gesellschaften. In diesem Sinne setzt Ferand »der triebhaften, wild wuchernden Phantasie des Morgenlandes « »die männliche Komponente des ordnenden lateinischen Intellekts entgegen « (Ferand 1938: 84). Ferands Ethnozentrismus gibt seiner Argumentation einen bizarren Dreh. Indem er die Improvisation ins Zentrum seines musikwissenschaftlichen Denkens stellt, drängt er sie als Vorstufe zur Komposition zugleich wieder an den Rand zurück.

Die musikpädagogische Pointe seines Früher/Später-Schemas besteht darin, dass eine kindgerechte Musikerziehung mit dem Improvisieren beginnen sollte. Als Gewährsmann seiner Auffassung, dass der Weg zur Komposition über die Improvisation führe, gibt Ferand Lodovico Zacconi (1555-1627) an:

") Wo andere die Absicht hatten, einen Schüler auf Papier auszubilden, d.h. einen, der gut zwei-, drei-, vier- und mehrstimmig zu komponieren versteht, habe ich ... nur das Ziel gehabt, einen guten Stegreifkontrapunktisten zu erziehen, aus welcher Übung dann [!!] der gute Komponist hervorgeht.< In diesem Sinne ist Zacconi als der erste Musikpädagoge zu betrachten, der entsprechend dem biogenetischen Grundgesetz auf dem Gebiete der Kompositionslehre die Improvisation als Vorstufe zur Komposition fordert.« (Ferand 1938: 236, Hervorhebungen und Ausrufungszeichen im Original!)

Im letzten Abschnitt seines Buches gelingt es Ferand dann doch noch, die Improvisation von der Komposition zu emanzipieren.

»Stellt auf der einen Seite die abstrakte Komposition eine rein geistige Schöpfung dar, der gegenüber der extreme Virtuose das technische Prinzip verkörpert, so zeichnet sich die improvisatorische Äußerung durch die Verschmelzung beider Prinzipien aus, indem in ihr das geistige, ideelle Moment des musikalischen Schaffens mit dem materiellen der körperlichen Realisierung zur untrennbaren Einheit wird.« (Ferand 1938: 426) 


\section{Komposition und Improvisation als Kontinuum}

Der amerikanische Musikwissenschaftler Bruno Nettl würdigt Ferand als den ersten Theoretiker, der sich mit dem in der Musikwissenschaft vernachlässigten Thema der Improvisation systematisch beschäftigt hat. In seinen Thoughts on Improvisation (vgl. Nettl 1974: 1) formuliert Nettl dann allerdings eine Gegenposition. Er sieht in der Entgegensetzung von Komposition und Improvisation kulturalistische Kurzschlüsse wirken.

Erstens: Aus der historischen Tatsache, dass Komposition und Schriftlichkeit im Westen traditionell als zusammengehörig betrachtet werden, folgt nicht im Umkehrschluss, dass nicht-notierte Musik notwendigerweise nicht-komponierte Musik ist. Gerade mündlich vermittelte Musik kann sich durch einen sehr hohen Grad an kompositorischer Verbindlichkeit auszeichnen. Die face-to-face-Kommunikation zwischen Lehrer und Schüler gestattet eine mimetische Genauigkeit, die durch das Notieren von Tonhöhen und Zeitwerten nicht erreicht werden kann; auch dann nicht, wenn zusätzliche Schriftzeichen Lautstärke, Artikulation und Klangfarbe präzisieren (vgl. Frisius 1998: 12).

Zweitens: Die Degradierung des Improvisierens zu einem spontanen Ausbruch von Natur wiederum entstammt der typisch abendländischen Eigenschaft, das Prädikat >Kultur < nur solchen Produkten zu verleihen, die auf hoch- und tiefgeistiger Kopfarbeit beruhen.

Nettl begreift Komposition und Improvisation nicht als Gegensätze, sondern als die beiden Endpunkte eines Kontinuums (Nettl 1974: 6). Am einen Ende dieses Kontinuums sieht er die schnelle und spontane Arbeitsweise eines Schuberts, am anderen Ende den langsam arbeitenden, bewusst mit Stift und Papier nach Neuem drängenden Beethoven (vgl. Nettl 1998: 9). Diese Differenz ist Nettl zufolge keine qualitative, sondern eine quantitative. Demnach hieße $>$ improvisieren $<>$ schnell komponieren $<$, aus der Situation heraus beziehungsweise in die Situation hinein. In diese Richtung zielen auch die meisten Lexikon-Definitionen: »Improvisation [...] besteht musikalisch im Erfinden und gleichzeitigen klanglichen Realisieren von Musik; sie schließt die schriftliche Fixierung (Komposition) ebenso aus wie das Realisieren eines Werkes (Aufführung, Wiedergabe, Interpretation)«(Riemann Musiklexikon 1967: 390). In diesem Sinne beruht die Improvisation auf der Simultanität von Pro- 
duktion und Performanz und die Komposition auf der Sukzessivität von Konstruktion und Exekution.

Aber gleich ob > vorgefertigt $<$ oder $>$ jetzt gemacht $<$, Komposition und Improvisation haben Nettl zufolge die gleiche Wissenswurzel. Beide Formen der Musikerfahrung verbindet, dass sie auf musikalischen Schemata beziehungsweise models beruhen (vgl. Nettl 1974: 11). Die Grundlage jedweden Musizierens ist kulturell erworbenes Musikwissen. Der Bezug auf Bekanntes und das Vorgegebensein von Formen sind dem Komponieren und Improvisieren demnach grundsätzlich. Dieses Argument hilft zwei Mythen zu entzaubern. Zum einen: Komponieren ist keine creatio ex nihilo. Zum anderen: Improvisieren ist kein Naturereignis.

\section{Komposition und Improvisation im interkulturellen Vergleich}

Für Ferand und Nettl gehört das Phänomen der Improvisation zu den Universalien der Musik. Ferands Universalismus ist allerdings ein Partikularismus, der das Verstehen des Fremden mit den Maßen eines verallgemeinerten Eigenen angeht. Nettls Universalismus beruht demgegenüber auf einer vergleichenden Herangehensweise, die Eigenes und Fremdes kulturrelativ nebeneinander stellt; nach dem Motto: improvisiert wird überall, hier so und dort anders. In dieser Perspektive fällt aber auf, dass sich die Formenvielfalt des Improvisierens nicht auf den Nenner einer eindeutigen Definition bringen lässt. Das vergleichende Vorgehen fordert vielmehr dazu auf, die kulturspezifischen Formen musikalischer Improvisation als Bestandteile einer sozialen Praxis zu sehen, in der Musikalisches und Gesellschaftliches vielfädig ineinander verwoben sind. In dieser Perspektive fällt zum Beispiel auf, dass in Indien das Improvisieren nicht nur musiktheoretisch, sondern auch gesellschaftspraktisch einen viel höheren Stellenwert besitzt als im Westen.

Das indische Klassik-Publikum bevorzugt improvisierte Musik. Der detailgenauen Wiedergabe durchkomponierter Musik kann es nichts abgewinnen. Und wenn ein Musiker Vorkomponiertes zu reproduzieren wagt, dann sollte es für das Publikum wenigstens so klingen als ob es improvisiert wäre - das gilt auch für die westliche klassische Musik, nur umgekehrt. Wenn Musik als Ausdruck von 
Kultur verstanden werden kann, dann ließe sich dieser Gegensatz so verallgemeinern: Klassische indische Musik spiegelt das Konzept der Improvisation als Kulturideal - klassische europäische Musik spiegelt das Konzept der Komposition als Kulturideal. Aus dem unterschiedlichen Umgang mit den Konzepten Improvisation und Komposition lassen sich zusätzlich zwei Denkrichtungen abstrahieren: Hier tendiert man zur Verfestigung des Flüssigen, dort zur Verflüssigung des Festen. Das heißt: in der klassischen Musik des Westens wird die Improvisation oft als Mittel für den Zweck der Komposition eingesetzt, in der klassischen indischen Musik ist die Komposition ein Mittel für den Zweck, Vorgefertigtes in Improvisationen aufzulösen.

Die Vorliebe für Komponiertes und Vorhersehbares und die Wertschätzung der Selbstkontrolle, die für das disziplinierte (Re-) Produzieren und regungslos stille Hören klassischer Musik erforderlich ist, kommen im Westen, insbesondere in Deutschland, nicht von ungefähr. »Es ist nicht überraschend, dass die Musikwissenschaft, ein Fach, das sich in Deutschland entwickelte, die in der deutschen Kultur geschätzten Werte Disziplin und Vorhersagbarkeit hervorhebt und Musik, die mit diesen Konzepten verbunden ist, privilegiert hat.«(Nettl 1998: 8, Übersetzung v.V.) So gesehen sind auch die Akzeptanzprobleme des Jazz alles andere als verwunderlich. Der Jazz, eine Musikrichtung mit traditionell hohem Improvisationsgehalt, ließ sich aus der Sicht der weißen Mittelklassekultur leicht mit den Merkmalen >schwarz $<$ und >Dritte Welt $<$ etikettieren - eine Stigmatisierung, die den Jazzern dann später als Stilmittel zur Selbstmythisierung diente. So oder so, die Abgrenzung von improvisierter bzw. komponierter klassischer Musik versprach in beiden Richtungen einen hohen Distinktionsgewinn (vgl. Nettl 1998: 7).

\section{Der Raga}

Auf Indien ist dieses Schema nicht anwendbar. Dort kommt das Improvisieren nicht aus dem unteren, sondern aus dem oberen Segment der Sozialhierarchie. Es ist traditionellerweise der gottgleiche Guru, der den Musik Lernenden das Improvisieren beibringt. Für die klassische indische Musik ist der Stellenwert der Improvisation kaum zu überschätzen. Das Improvisieren-Können ist geradezu die 
Kernkompetenz, um klassische indische Musik, also einen Raga, zu spielen. Ein Raga ist eine melodische Form. Sie besteht aus bestimmten Tönen bzw. Tonverbindungen, die nach festgelegten Regeln zu spielen sind (vgl. hierzu Schmidt in diesem Buch). RagaMusik ist immer improvisierte Musik. In einer Raga-Aufführung werden zwar auch Kompositionen verwandt, aber der Musiker wird stets danach drängen, das Starre und Feste der Kompositionen in Improvisationen zerfließen zu lassen. Einen Raga vom Blatt oder auswendig zu spielen, wäre ein Widerspruch in sich. So wie das Improvisieren eines Raga einerseits strikten Regeln folgt, so fordern andererseits die Regeln zum ständigen Improvisieren heraus. Das eine ist die Voraussetzung des anderen. Regelbefolgung und Improvisationszwang sind die zwei Seiten derselben Medaille.

Die Funktion der Improvisation besteht darin, die objektive Persönlichkeit des Raga - und nicht etwa die subjektive Persönlichkeit des Musikers - zum Ausdruck zu bringen (vgl. Kurt 2007). JazzMusiker und frei improvisierende Musiker betonen nicht nur oft, dass sie sich selbst bzw. ihre Gefühle oder ihre Persönlichkeit in der Improvisation zum Ausdruck bringen (vgl. Jost 1979: 64), sie betonen auch sehr häufig, dass sie mit der Improvisation Altes überwinden und Neues entstehen lassen wollen. Im Sinne dieser Selbstverpflichtung auf endloses Revolutionieren wird das Improvisieren auch als Weg in die Freiheit beschrieben. »Ich glaube, dass es im Jazz, von seinen ersten Anfängen an, eigentlich immer um die Erweiterung der Freiheit ging « (Steve Lacy in Bailey 1987: 96). Auf der Gegenseite dieses Freiheitsstrebens steht die Angst vor dem Klischee und der Nicht-Originalität: »Nach einer Minute ist schon die Gefahr da, dass man sich wiederholt « (Misha Mengelberg in Wilson 1999: 153). Das Paradox der freien Improvisation besteht darin, dass sie, wie jedes Musizieren, einerseits auf Schemata beruht, andererseits diese Schemata aber zu vernichten versucht. Anders gesagt: Man schlägt sich das Standbein mit seinem Spielbein weg, aber nicht, um sich zu Fall zu bringen, sondern um fliegen oder zumindest für kurze Zeit schweben zu können - bis man schließlich wieder auf seine Füße, oder aber zu Boden fällt.

Über ein derart radikales Freiheitsstreben können sich indische Musiker nur wundern. Für revolutionäre Ansprüche ist in der traditionsbewussten indischen Musikkultur kein Platz. Das Improvisieren folgt dort anderen Idealen. Der indische Musiker improvisiert nicht über einen Raga wie ein Jazzmusiker über die Harmonien ei- 
nes Standards, sondern immer in einem Raga (vgl. Nettl 1974: 9). Jazzstandardimprovisationen kommen Raga-Improvisationen zwar insofern nahe als beiden Formen der Improvisation ein überliefertes (und von einer Expertengemeinde überwachtes) Set von Schemata, Regeln und Konventionen zugrunde liegt, das den Improvisierenden verhältnismäßig viel Freiraum lässt. Die Grenzen dieser Freiheit werden als fraglos gegeben hingenommen. »Es käme einem indischen Musiker nicht in den Sinn, die Grundlagen des Raga in Frage zu stellen, ebenso wenig hat man einen Jazzmusiker je einen Blues mit 11 oder 13 Takten spielen hören«(Globokar 1979: 38f.). Hier wie dort spielt der Improvisierende in die Selbstverständlichkeiten einer mit anderen geteilten Musikkultur hinein. Die Differenz liegt auf einer anderen Ebene. Zugespitzt formuliert: Bei einer Jazzstandardimprovisation dient der Standard als Material für den Musiker. Bei einer Raga-Improvisation ist es umgekehrt: Hier nimmt sich der Musiker als Material oder Medium des Ragas wahr. »Be a medium«, oder »The raga is singing through you «, so drückten es der Sitar-Spieler Sanjoy Bandopadyay bzw. der Sänger Ashish Sankritayan im Gespräch mit mir aus. Der Musiker darf sich in der Improvisation nie außerhalb der Wesensgrenzen des von ihm gespielten Ragas bewegen. Mit den Regeln eines Ragas zu brechen, ist für den indischen Musiker keine Option. Für den indischen Musikwissenschaftler Moutal manifestiert sich hier ein Ost/West-Gegensatz:

»Während sich der westliche Mensch gemäß seiner Lebensart zu befreien hofft, indem er, wie beispielsweise in der avantgardistischen Musik, mit den traditionellen Regeln bricht, versteht der Inder, dass sich Freiheit im Leben und in den Künsten eher dann erreichen lässt, wenn man die Regeln akzeptiert und das Beste aus ihnen macht.« (Moutal 1991: 46, übersetzt v.V.)

Gesetz und Freiheit bilden im indischen Musik- und Kultur(er)leben keine Anti-, sondern eine Synthese. Ihre Ausdrucksform ist die Improvisation.

Indes: Im Unterschied zur westlichen Improvisationskultur ist der indischen Art des Improvisierens die Kreation von Neuem nicht wesentlich. Gemessen am westlichen Kreativitätsideal sind indische Musiker weder originell noch schöpferisch. Vorgegebene Ordnungen zu verneinen und Bestehendes zugunsten von Neuem zu zerstören ist ihre Sache nicht. Sie erfinden nicht, sondern entdecken und entfalten nur, was im Raga immer schon der Möglichkeit nach ent- 
halten war. Sie verbleiben in den vorgegebenen Formen eines Raga und bewegen sich in diesem mit einem reichen Repertoire von Verzierungsformeln, melodischen und rhythmischen Variationen und permutativen (auf Kombinier- und Vertauschbarkeit beruhenden) Verknüpfungen. Die oben aufgestellte Gleichung >Improvisieren ist instantanes Komponieren< geht hier nicht auf. Improvisation kann kreativ sein, muss es aber nicht. In der indischen Musik ist es mehr das virtuose Verfügen über Jahrzehnte lang bis zur Bewusstlosigkeit eingeübte melodische und rhythmische Muster, was die Improvisation konstituiert und in potentiell unendlich vielen Variationen möglichst ohne Wiederholungen - kontinuiert. Die indische Improvisation ist ein Spielen mit den Beständen, das Regeln folgt - nicht in blindem Gehorsam, sondern mit Witz; etwa so, wie man Wittgenstein zufolge den Regeln eines Sprachspiels folgt. Variatio delectat - die Wiederholung jedoch nicht. Im Westen will man sich nicht wiederholen, weil man weiter muss. Warum Zeit vertändeln mit Dingen, die man schon kennt? »Dem Geist ist die Wiederholung schrecklich« (Valéry 1989: 215). Anders im Osten: In Indien holt man sich dasselbe immer wieder anders wieder. Form geworden ist die ewige Wiederkehr des Gleichen als Nicht-Gleiches in der indischen Ästhetik des Andeutens, Umspielens und Verzierens.

Auch die im Westen übliche Zurechnung der Improvisation auf ein hierfür verantwortliches Individuum ist nicht ohne weiteres auf den indischen Kontext anwendbar. Traditionsbewusste indische Musiker würden hier jeden Ichbezug von sich weisen - der Raga gilt in Indien ja als Mittel zur Überwindung des Ich - und stattdessen behaupten, dass andere Kräfte als das Ich für das Improvisieren verantwortlich sind. Da, wo viele westliche Musiker höchste Ichaktivität veranschlagen, da sehen sich indische Musiker vornehmlich in einer Gefäßfunktion. Das indische Pendant zum westlichen >ich improvisiere < lautet: >es improvisiert< oder noch ichloser: >hier wird improvisiert $<$. Die Grenzerfahrung des passiven Geschehenlassens und Mittlerseins, die im übrigen auch von frei improvisierenden Musikern als Kernaspekt der Improvisation angeführt wird (vgl. Ronnie Scott in Bailey 1987: 90), lässt sich nicht nur kulturell, sondern auch psychologisch begründen. Je mehr sich ein Musiker der Situation und seinem reichen Repertoire an Reaktionsmöglichkeiten überlässt, desto weniger wird er bewusst eindeutige Entscheidungen treffen können. Wenn die Kontingenz des musikalisch Möglichen nicht mehr rational reduzierbar ist und das Ich nicht mehr Herr im 
eigenen Haus sein kann, dann ereignet sich vieles zwangsläufig unbedacht und unbewusst - in einer Art kalkuliertem Kontrollverlust. Man lässt sich/es gehen, um sich/es kommen zu lassen. Gerade in der indischen Musik sind diese Momente durch das viele Jahrzehnte lange Einüben vielseitig einsetzbarer Improvisationspatterns geradezu vorprogrammiert. Unter Umständen stellen sich auf diese Weise auch wieder längst vergessene musikalische Gedanken ein. Kreativität ist oftmals nur eine Maske der Vergesslichkeit. Was ist schon wirklich neu auf Erden? »Was einst gewesen, das ist jetzt, und was geschehen, das geschieht. Nichts Neues gibt es unter dieser Sonne« (Der Prediger/Ekklesiastes 1.9).

Dass viele indische Musiker trotz ihres Anspruchs auf Ichlosigkeit zugleich nach einem unverwechselbaren Ausdruck ihrer Person und ihres Stils streben, steht hierzu nur scheinbar im Widerspruch. In der klassischen indischen Musik geht der Musiker in seiner Improvisation nicht über das Bestehende hinaus, sondern er fügt etwas Besonderes ins Allgemeine ein. Da in der indischen Musikkultur ein Raga etwas Ewiges ist, kann es beim Improvisieren nicht darum gehen, den Raga zu verändern oder ihn gar für den Ausdruck von Menschlichem oder Persönlichem zu missbrauchen, sondern einzig und allein darum, ihn durch die und in der Improvisation zu verwirklichen. Die Praxis mag sich oft vom Ideal der Theorie entfernen - schon seit vielen Jahren beklagen Puristen die Tendenz der Szene, sich durch selbstdarstellerisches Virtuosentum auf dem globalisierten Musikmarkt zu etablieren -, der hohe symbolische Wert der Improvisation scheint davon jedoch unberührt. In einer oft bemühten Redensart heißt es, dass die Improvisation eines Raga auf kürzestem Wege zum Göttlichen führe: >Indian Classical Music is the shortest way to God<. Hier wird der Improvisation indirekt ein religiöser Sinn verliehen - so wie im Westen der Komposition.

In den hier verglichenen Musiktraditionen stehen Improvisation und Komposition in völlig verschiedenen Bedeutungs- und Funktionszusammenhängen. In der klassischen europäischen Musik kreist alles um den schöpferischen Komponisten und sein notiertes Werk. Im Zentrum der klassischen indischen Musik steht der Raga und seine Realisierung im Hier und Jetzt einer Improvisation. Die relative Geringschätzung der Improvisation in der westlichen und der Komposition in der indischen Musik sind Folgen dieser kulturell bedingten Relevanzsetzungen. Für eine Improvisationskultur nach indischem Vorbild >fehlen< der westlichen Musik die Voraussetzun- 
gen. Und für Kompositionen nach westlichem Muster >fehlen< in der indischen Musik die Voraussetzungen. Es $>$ fehlt $<$ dort nicht nur an einer exakten Notenschrift, es >fehlen< auch die kulturellen Bedingungen für die Möglichkeit, schöpferisch und originell zu sein. »In India, it is next to impossible to be >original« (Ranade 2002: Preface). In Indien kann Kunst weder, wie in der westlichen Klassik, schöpferisch, noch, wie in der griechischen Antike, nachahmend sein. Die Kunst der musikalischen Improvisation hat in Indien eine andere Funktion. Im Hier und Jetzt soll sie dem ewigen Sein des Ragas eine lebendige musikalische Gestalt verleihen.

\section{Situationssensibilität}

Für eine Raga-Improvisation bedarf es einer Reihe von Zutaten. In ihrem Essay The Cooking of Music vergleicht die indische Schriftstellerin und Musikerin Sheila Dhar die Aufgabe des Musikers mit der eines Kochs.

»Das Gericht muss nach altbewährten Rezepten zubereitet werden, es muss kreativ sein und die persönliche Signatur des Koches in sich tragen, es muss die Frische und den ursprünglichen Geschmack aller Zutaten bewahren, es muss sicherstellen, dass alle Gewürze und Zutaten in einer einmaligen Mischung zusammenkommen, und vor allem muss die Erfahrung, der Geschmack und der Genuss im Geiste des Empfangenden zu Leben gelangen, es sollte pakka sein - welches das Antonym zu kaccha ist, und das bedeutet: ungekocht, schwach, brechbar und fragil.« (Dhar 2001: 38, übersetzt v.V.)

Die Wahlverwandtschaft zwischen indischer Küche und indischer Musik beruht auf ihrer gemeinsamen Nähe zur Improvisation. Hier wie da geht es nicht um die rezeptgetreue Reproduktion des ewig Gleichen (wie etwa bei McDonalds), sondern darum, ein essentiell Gleiches mit einmaligen Variationen und Verzierungen zu würzen und nach Art des Hauses bzw. der Familientradition frisch zu servieren. Das Produkt muss wiedererkennbar und doch einmalig sein. So sehr das Kochen und Musizieren auch auf fraglos geltenden Grundregeln basiert, letztlich kommt es darauf an, wie gut der Produzent improvisieren kann. In beiden Fällen »hängt die Qualität eher an der Spontaneität und dem Gespür für den Augenblick als an 
irgendeinem rigiden Rezept « (Dhar 2001: 38, übersetzt v.V.). Der Geschmack eines indischen Gerichts und der Klang eines indischen Ragas werden sehr stark von der Sensibilität für das Situative geprägt. In diesem Sinne betont auch der Sitar-Spieler Sanjoy Bandopadhyay die Bedeutung der Situation für das Funktionieren einer Improvisation. Er beschreibt, was geschieht, wenn er den Alap, die erste Phase eines Ragas, improvisiert:

»Was passiert, wenn ich den Alap spiele? Ich habe ihn bisher etwa 200 oder 300 Stunden gespielt. Dadurch bin ich programmiert. Mein Gehirn bietet mir nun während des Spielens 20 alternative Vorschläge an. Dann, bedingt durch den Einfluss der Gesamtsituation (total environment), sticht ein Vorschlag heraus. « (Sanjoy Bandopadhyay in Kurt 2006b: 41:39 - 42:13, übersetzt v.V.)

Die Konzentration auf das, was gerade in und außerhalb der Musik geschieht, eröffnet dem Musiker unvorhergesehene Möglichkeiten. Eine Raga-Realisierung geht alle Sinne an, nicht nur das Hören. Aufmerksam auf alles achtend und eingebettet in das Regelwerk des Ragas - ein unerlaubter Ton und schon ist der Improvisierende raus aus dem Raga! - kann der Musiker Richtungswechsel vornehmen, neue Wendungen ausprobieren und in Dimensionen des Raga vordringen, die ihm bis zu diesem Zeitpunkt noch unerreichbar schienen. Sich der Situation zu überlassen, ist natürlich immer risikoreich. Schnell stellen sich Fehler, Kontrollverluste und Orientierungsschwierigkeiten ein. Aber es gibt andererseits auch Gefahrvermeidungsstrategien, nicht nur für Raga-Improvisationen, sondern für alle Situationen, in denen sich Menschen auf das Abenteuer des Augenblicks einlassen. Man muss sich nicht unvorbereitet in den Prozess der Improvisation begeben. Klaus-Ernst Behne führt eine Reihe von Techniken an, mit denen sich die Risiken des Improvisierens reduzieren lassen:

»Man kann sich entscheiden: 1) nichts zu spielen (konzentrierte Improvisationen können sich durch viele Pausen auszeichnen); 2) ein bestimmtes Muster zu spielen (erfahrene Musiker verfügen über ein groBes Repertoire von abrufbaren Mustern); 3) das zuvor gespielte Muster zu wiederholen oder zu variieren.«(Behne 1992: 47)

Erlernbare Regeln wie diese helfen das Improvisieren zu strukturieren - das Gelingen einer Improvisation garantieren, können sie frei- 
lich nicht. Alle Techniken und Tricks bewirken nichts, wenn sich der Improvisator gegenüber den Möglichkeiten des Moments nicht offen zeigt. Die Forderung an den Improvisierenden, im Hier und Jetzt zu leben, hat in diesem Zusammenhang keinen spirituellen, sondern einen zutiefst praktischen Sinn. Menschen leben ja in Situationen; nicht hin und wieder, sondern unausgesetzt ihr ganzes Leben lang. Und wie immer man die Situation, in der man sich gerade befindet, auch definiert, dass man sich in einer Situation zu dieser Situation verhält, ist ein Grundzug des Menschseins - der kulturell allerdings unterschiedlich beurteilt und bearbeitet wird.

Im westlichen Denken dominiert traditionell die Auffassung, dass der Mensch nicht zur Situation gehört, sondern ihr gegenübersteht oder, noch besser, über ihr steht. Kennzeichnend für diese Haltung der Distanz ist das Streben, die Situation zu kontrollieren und unabhängig von den jeweiligen Besonderheiten der Situation gemäß allgemein gültiger Prinzipien planmäßig und zielführend handeln zu können.

In Indien scheint man für Situatives sensibler zu sein. Die Achtsamkeit auf das Spezifische der Situation bezeichnet der indische Psychoanalytiker Sudir Kakar als Kontextsensitivität (vgl. Kakar 2006: 184). Kakar erkennt in der kontextsensitiven Einstellung etwas typisch Indisches. Ob diese Verallgemeinerung zutreffend ist, bleibt hier dahingestellt. Soviel ist allerdings sicher: Für eine RagaImprovisation ist Kontextsensibilität eine conditio sine qua non.

Die Sensibilität für das Situative zeigt sich bei Raga-Improvisationen insbesondere in der Interaktion zwischen Musikern und Zuhörern. Je näher sich Musiker und Publikum während des Konzerts gegenübersitzen, desto höher das Feedbackpotential. Der Musiker agiert und die Zuhörer reagieren, zum Beispiel mit zustimmendem Kopfschütteln oder mit Zwischenrufen wie »Wahwah « (frei übersetzt etwa: sehr schön, sehr schön). An Resonanzen wie diesen richtet der Musiker sein Improvisieren aus. Im Idealfall entsteht in diesem wechselseitigen Aufeinander-Eingehen die für den jeweiligen Raga typische Stimmungslage. Im Wechselverhältnis zwischen Sozialem und Musikalischem findet dann eine atmosphärische Verdichtung statt, die der Situation eine Farbe gibt: Raga ist das, was den Geist färbt - »Raga: that which colors the mind « (Shankar 1969: 24).

In einem klassischen Sinfoniekonzert sind die Rollen bekanntlich anders verteilt. Hier ist der Zuhörer nicht als Koproduzent, son- 
dern als stiller Rezipient gefragt. Solange wie das Werk erklingt, solange muss man schweigen. Das Werk kann nur wirken, wenn es seinen Gehalt ohne situative Störungen entfalten kann. Dementsprechend sind Sinfoniekonzerte klassischerweise so strukturiert, dass unmittelbar wechselseitige Interaktionen entlang der Achsen Publikum-Publikum, Publikum-Musiker, Musiker-Musiker so gut wie gar nicht stattfinden können. Den Mittelpunkt dieser sozialen Ordnung bildet die kommunikative Haltung des Dirigenten: er wendet den Zuhörern seinen Rücken zu.

Bei freien Improvisationen hat das Publikum demgegenüber größere Mitgestaltungsmöglichkeiten, weil es »durch seine Art der Reaktion, durch seine Hör- und Sehweisen, den Ablauf mehr oder weniger beeinflusst «(Globokar 1979: 35). In eine gemeinsame Gefühlslage - wie im Fall des Ragas - bringen sich Musiker und Publikum dabei aber wohl eher selten. Erstens kann eine freie Improvisation, die es mit der Freiheit wirklich ernst meint, HörerErwartungen weder erfüllen noch enttäuschen, weil sie sich allem Erwartbaren und Wiedererkennbaren verweigern will. Zweitens vollzieht sich das Improvisieren hier in der Regel nicht publikums-, sondern selbstbezogen, im Sinne einer Selbstbereicherung, Selbsterforschung oder Selbstbefreiung (vgl. Globokar 1979: 34), die für den Zuhörer dann im Extremfall nur noch die Rolle des Voyeurs übrig lässt.

\section{Improvisation als Kulturtechnik}

In Indien ist Improvisation eine Kulturtechnik von hohem symbolischen Wert. Dabei lässt sich anhand der indischen Musikkultur zeigen, dass sich das indische Verständnis von Improvisation mit der westlichen Auffassung von Improvisation nicht zur Deckung bringen lässt. Kulturgeschichtlich bedingt wird das Improvisieren im Westen allzu schnell mit den Kategorienfeldern >natürlich, triebhaft, irrational< und ssubjektiv, schöpferisch, freiheitlich< in Verbindung gebracht. In Indien steht das Improvisieren unter anderen kulturellen Vorzeichen: Es dient dem Traditionserhalt, der Gemeinschaft und dem Variieren und Verzieren von vorgegebenen Ordnungsformen. Es führt auch nicht zur Befreiung des Ich, sondern zur Befreiung vom Ich, und es ist auch nicht revolutionär. Aber es fördert die lang- 
same Veränderung von innen her, nicht nur in der Musik, wo sich die Regeln für das Spielen eines Raga nicht von einem Tag auf den anderen, sondern immer nur sehr allmählich ändern (vgl. Neuhoff 1995), sondern auch in der Gesellschaft. Das gemeinhin trotz seiner religiösen Vielfalt und seiner vielen historischen Transformationen als starr und traditionsverhaftet geltende Indien hätte sich weltgeschichtlich nicht behaupten können, wenn es den dort lebenden Menschen nicht möglich gewesen wäre, vorgegebene Normen und Werte zu verändern. Menschliche Denk- und Handlungsweisen in »Kasten zu versteinern« (Marx 1984: 359) wäre widermenschlich. Menschen verändern die Welt, in der sie leben: durch Revolution, durch Innovation oder, das ist möglicherweise der indische Weg, durch Improvisation. Weil sich diese Wandlungsprozesse stets langsam und immer von innen heraus vollziehen, werden sie in der Regel nicht als Traditionsbruch wahrgenommen. Demgegenüber gilt in der abendländischen Kultur- und Musikgeschichte der Bruch mit der Tradition als Bedingung künstlerischen und gesellschaftlichen Fortschritts.

Interkulturelle Vergleiche beginnen mit dem Blick vom Eigenen aufs Andere. Kippt die Perspektive, dann ist es unter Umständen möglich, vom Anderen her auf das Eigene zu sehen. Dieser Blick kann bereichernd sein. In diesem Sinne denke ich, dass sich von der indischen Improvisationskultur vieles lernen lässt, nicht nur, aber eben auch für eine allgemeine Handlungstheorie.

\section{Die Situation im Westen}

Im Hinblick auf eine Handlungstheorie, in welcher Improvisation und Komposition gleichrangig neben einander stehen, hält Hans Joas' Buch Die Kreativität des Handelns viel versprechende Anschlussmöglichkeiten bereit. Hans Joas hat in seinem Buch Die Kreativität des Handelns gezeigt, dass der rationalistische Reduktionismus der europäischen Handlungstheorien mit Ansätzen des amerikanischen Pragmatismus überwunden werden kann. Es ist wahrscheinlich kein Zufall, dass diese Impulse von den USA ausgingen, bezeichnenderweise von dem Land also, in dem sich auch der Jazz entwickelte - und nach »abendländischer Auffassung gilt Improvisation als Synonym für Jazz« (Globokar 1979: 37). Jazz und 
Pragmatismus sind so etwas wie eine musikalisch-wissenschaftliche Parallelaktion: sie richten sich beide am situativ handelnden Menschen aus. Gegenüber dem Typus des Handelnden, der fernab der sozialen Praxis Handlungswerke komponiert, die genauso wie geplant zu realisieren sind, reifte im amerikanischen Pragmatismus ein Menschenbild, das nicht das souveräne Subjekt, sondern das Situative in den Mittelpunkt stellte.

Handeln ist ein Prozess, dem neben seinem Bezug zum Entwurf auch noch andere Qualitäten eigen sind. Der Grund hierfür liegt im Prozess des Handelns selbst, genauer gesagt: in der Situation, in der sich Handelnde befinden. Zwar gehen Menschen nicht frei von Vorurteilen, Interessen und Entwürfen in eine Situation hinein, aber diese intentionalen Mitbringsel »enthalten noch keine erschöpfende Antwort auf die Herausforderungen dieser Situation« (Joas 1996: 237). Die Situation steht uns dabei nicht als ein Objekt gegenüber, das erst sinnlich und verstandesmäßig zu erschließen wäre. Die Wahrnehmung der Situation beinhaltet bereits Reaktionspotentiale. Sie ist eine Art Auslöser für Antwortmuster, die auf früheren Erfahrungen beruhen. Die Situation ist uns »im Modus möglicher Handlungen (gegeben)« (Joas 1996: 233), sie aktiviert Erwartungen und augenblicklich abrufbare Reaktionsschemata. Das Handeln wird dadurch nicht determiniert, sondern dynamisiert. Wie reagiert der Handelnde in der Situation auf die Situation und auf das, was er in sie an Vorstellungen hineingebracht hat? Diese Frage ist immer eine offene. Webers Zweck/Mittel-Rationalität und Schütz' strikte schematische Unterscheidung zwischen Handlungsplan, Entschluss und Vollzug der Handlung durch das Handeln ist vom Standpunkt einer Handlungstheorie, die von der Situation und nicht von souveräner Subjektivität ausgeht, nicht aufrecht zu halten. »So verstanden, ist der Begriff der >Situation ` geeignet, an die Stelle des Zweck/MittelSchemas als erster Grundkategorie einer Handlungstheorie zu treten.«(Joas 1996: 235)

\section{Das kreative Ich}

Die Auffassung des Handelns als kreativ zieht die Frage nach sich, auf wen oder was diese Qualität zurückzuführen ist. Joas bringt hier George Herbert Mead ins Spiel. Der amerikanische Sozialpsycholo- 
ge beantwortet die Frage nach der Quelle der Kreativität mit seinem Konzept des I and Me bzw. >Ich< und >ICH<. Das Me definiert Mead als denjenigen Aspekt des Selbst, der die (durch Rollenübernahmen) verinnerlichten Erwartungshaltungen anderer enthält (vgl. Mead 1973: 216f.). Das I steht in der Meadschen Konzeption für die unmittelbar spontane »Reaktion des Organismus auf die Haltungen anderer « (Mead 1973: 218). Charakteristisch für die Reaktion des I sind die Attribute >unvorhersehbar< und >überraschend<. Dieses unberechenbare Ich ist der Grund dafür, »daß wir uns niemals ganz unserer selbst bewußt sind, daß wir uns durch unsere eigenen Aktionen überraschen« (Mead 1973: 217). »Das >Ich< liefert das Gefühl der Freiheit und Initiative« (Mead 1973: 121). Letztlich fasst Mead das I als eine Funktionsweise des Organismus: bewusstlos, impulsiv, triebhaft, Es-ähnlich, aber auch initiativ und schöpferisch. Verglichen mit dem selbstbewussten Super-Ich des neuzeitlichen Europas scheint hier das Pendel in Gestalt des I sehr weit in Richtung Körper auszuschlagen. Losgelöst aber vom bewussten Planen und Entwerfen kann das Handeln nicht mehr als sinnhaft gelten. Beide Handlungstheorien driften entgegengesetzten Polen zu: Die europäische tendiert sehr zur Reflexion, die amerikanische sehr zum Reflex. Hans Joas versucht diese beiden Theorietraditionen mit dem Konzept der Kreativität zu überwölben. In diesem Sinne fordert er, »Kreativität als eine analytische Dimension allen menschlichen Handelns aufzufassen « (Joas 1996:173). So erscheint das menschliche Handeln in einem neuen Licht - die Lichtquelle selbst ist allerdings nicht ganz so neu. Denn Joas entwickelt seinen Begriff des kreativen Handelns aus den abendländischen Kreativitätsmetaphern $>$ Ausdruck $<$, >Produktion $<$, >Revolution $<$ und $>$ Leben $<$. Das Phänomen der Improvisation bleibt in dieser Rekonstruktionskette außen vor; wie schon so oft in der Geschichte der westlichen Wissenschaft. Im Register des Buches Die Kreativität des Handelns ist das Wort Improvisation konsequenterweise auch nicht aufgeführt.

Ebenfalls wie Joas vom Begriff der Situation ausgehend, möchte ich nun versuchen, die hier im Zusammenhang mit der indischen und europäischen Musikkultur thematisierten Facetten des Improvisierens in ein handlungstheoretisches Modell zu integrieren. 


\section{Improvisation als handlungstheoretischer Grundbegriff}

Den Thesen, dass jedes Handeln in einer Situation stattfindet und Kreativität »als Leistung innerhalb von Situationen « (Joas 1996: 190) ein Potential ist, das Handlungsprobleme lösen hilft, ist meiner Meinung nach unbedingt zuzustimmen. In der Tat: Krisensituationen machen mitunter erfinderisch und nicht selten enthalten sie für das handelnde Individuum auch Wachstums- und Entwicklungschancen. Diesen handlungstheoretischen Ansatz mit westlichen Werten wie Kreativität, Fortschritt, Freiheit, Individualität, Kunst und Demokratie in Verbindung zu bringen, muss für Mead, Dewey und nicht zuletzt auch für Joas sehr nahe liegend gewesen sein. Krise, Kreativität und Kunst verweben sich in ihren Interpretationen jedoch zu einem undurchsichtigen Wertgeflecht, das den Blick auf das Handeln an einem zentralen Punkt verstellt. Der Begriff der Kreativität scheint mir bei Joas allzu sehr die fast schon obsessive Fixierung des Westens auf das Schöpferische, Neue, Originelle zu bedienen (und die Schraube der sozialen Forderung nach Kreativität noch eine Windung weiter zu drehen). Indem Joas das menschliche Handeln als potentiell künstlerisch adelt, rückt seine Theorie in die Tradition ein, von der er sich eigentlich absetzen wollte. In Joas' Kreativität des Handelns erscheint der homo secundus deus nicht als souveräner Rationalist, sondern von seiner anderen Seite her: als Künstler, der aus der Situation heraus schöpferisch tätig wird.

Das reiche Bedeutungsspektrum des Begriffs Improvisation bietet hier möglicherweise einen Ausweg an, weil es neben dem Kreativen auch noch eine Reihe anderer Aspekte mit einbezieht. Mit Edward T. Hall »glaube (ich), dass in jeder menschlichen Tätigkeit ein Potential für Improvisation [...] steckt« (Hall 1992: 38). Das Improvisieren-Können ist eine Fähigkeit des Menschen, deren Erscheinungsform je nach Kultur, sozialer Rahmung und individuellem Vermögen variieren kann. Die Kontrastierung der Musikkulturen hat gezeigt, dass und wie das Improvisieren in kulturell geprägte Denk- und Handlungsweisen eingebettet ist. Vor dem Hintergrund dieses musiksoziologischen Kulturvergleichs, der für eine Theorie des Handelns natürlich nicht mehr als eine interkulturelle Heuristik sein kann, gilt es nun die Klärung der Bedeutungsdimensionen des Improvisationsbegriffes anzugehen - nicht um den Begriff der Improvisation auf seinen vermeintlich kleinsten inter- bzw. transkultu- 
rellen Nenner zu bringen, sondern um die Universalität wie auch die Kulturrelativität des Improvisierens in einem Modell des Handelns zusammenzuführen, in dem Improvisation und Komposition in einem Wechselverhältnis aufeinander bezogen sind.

\section{Vom Umgang mit dem Unvorhersehbaren}

Für eine Improvisation müssen drei Voraussetzungen gegeben sein:

- erstens, dass man in einer Situation ist,

- zweitens, dass in dieser Situation Unvorhersehbares geschieht (bzw. geschehen soll),

- drittens, dass die Reaktion auf das Unvorhersehbare (bzw. die Produktion von Unvorhersehbarem) aus dem Moment heraus erfolgt.

Die Situation, das Unvorhersehbare und die unmittelbare Reaktion darauf sind keine objektiven, sondern subjektive Kategorien. Wie eine Situation definiert ist, was als unvorhersehbar gilt und wie reagiert wird, hängt davon ab, welchen Sinn der Handelnde seinem Inder-Situation-Sein verleiht und mit welchem Wissen und Können er den Gegebenheiten des Augenblicks begegnen kann. Das wiederum ist abhängig von der kulturellen Prägung, der sozialen Situiertheit und der individuellen Entwicklungsgeschichte des Handelnden. Meinungen zum Improvisieren gibt es dementsprechend sehr, sehr viele:

Wird der gerade nicht zuhandene Hammer durch ein funktionales Äquivalent ersetzt, dann ist das Improvisieren eine Mangelkompensationskompetenz. Jazzimprovisationen können als Ausdruck von Persönlichkeit gewürdigt werden. Manch frei improvisierender Musiker strebt nach Zuständen der Absichts-, Bindungs- und Regellosigkeit. Indische Musiker wiederum schätzen ihre Raga-Improvisation in aller Regel als spirituelle Erfahrung ein. Ob das Ich, ein Es oder etwas Göttliches für das Improvisieren verantwortlich gemacht wird, ist dabei genauso kultur- und kontextabhängig wie die Charakterisierung des Improvisierens als: Flow, Spiel, Wagnis, Rausch, Entscheidungskette, Suchprozess, kreatives Regel brechen, schöpferische Gestaltung des Hier und Jetzt, motorischer Automa- 
tismus, lustvolle Selbsterfahrung, irrationales Sichtreibenlassen und des Ungleichen mehr.

Improvisation findet also nicht in einem sinnfreien Vakuum, sondern in kulturspezifischen Bedeutungszusammenhängen statt. Diese Kulturrelativität verweist wiederum auf etwas Universales: Jedwedes Improvisieren ist an Kompositionen rückgebunden; es geschieht nicht voraussetzungsfrei. Der Improvisierende erschafft sein Handeln schließlich nicht spontan aus dem Nichts, sondern er schöpft aus einem Repertoire vorkomponierter Handlungsmuster, die er (bewusst oder auch nichtbewusst) aus dem Stegreif situationsbezogen appliziert, variiert, kombiniert, modifiziert.

Das erklärt auch, warum sich die Augenblicksaktion der Improvisation ihrer Möglichkeit nach zwischen Chaos und Klischee bewegt. Wenn es schnell gehen muss, ist der Griff zur Phrase naheliegenderweise die erste Wahl. Sind aber alle Formeln aufgebraucht, dann steigt die Chance auf Überraschungen.

Improvisation und Komposition bilden so gesehen keinen Gegensatz, sondern die beiden Pole eines Verhältnisses. Einerseits setzt das Nicht-voraus-sehbare (lat.: in-pro-videre) immer schon das Zusammen-Gefügte (lat.: com-ponere) voraus. Ohne vorgefertigte Situationsdefinitionen und abrufbereite Reaktionsschemata wären wir nicht nur erkenntnis- und handlungsunfähig, wir wären schlichtweg unfähig, etwas als unvorhersehbar zu erfahren - weil das Unvorhersehbare logischerweise immer etwas Vorausgesehenes zur Voraussetzung hat. So führt das Voraussehen und Vorausplanen immer wieder in ein Hier und Jetzt, das anders als erwartet ist. So entsteht zwischen Antizipation und aktuell Gegebenem ein Abstand, der Raum für Improvisationen lässt, in denen wiederum auf vorkomponierte Problemlösungen zurückgegriffen wird. Dieses dialektische Verhältnis zwischen Nichtvoraussehbarem und Zusammengefügtem ist ein steter Quell für die Reproduktion von Altbewährtem und die Produktion von Variabilität und Veränderung.

Wenn Unvorhergesehenes geschieht (oder geschehen soll), verschiebt sich das Handeln in Richtung Improvisation, geschieht nichts Unvorhergesehenes (oder soll nichts Unvorhergesehenes geschehen), dann verläuft das Handeln eher kompositionsorientiert. Beim improvisatorischen Handeln liegt der Schwerpunkt auf der Gegenwart, beim kompositionsorientierten auf der Vergangenheit. Das eine vom anderen loszulösen, scheint schwerlich möglich zu sein, »weil es sich streng genommen überhaupt nicht um isolierbare, 
gegeneinander abgeschlossene Bereiche, sondern um eine Skala von Möglichkeiten handelt, eine Skala, auf der es sozusagen nichts als Übergänge und Zwischenformen gibt und deren Extreme, die absolute Komposition und die absolute Improvisation, sich ins Irreale, Ungreifbare verlieren « (Dahlhaus 1979: 15). Was Dahlhaus für die Musik behauptet, das gilt meiner Meinung nach für menschliches Handeln generell. Komposition und Improvisationen liegen nahezu immer in Mischverhältnissen vor. $\mathrm{Zu}$ welchem Pol das Handeln tendiert, hängt von den Umständen ab, und von der Einstellung.

»Dem typischen Improvisator [...] wird es schwer fallen, nach einem vorgefaßten Plane vorzugehen; und selbst in Fällen, wo er dies tut, wird sich seine improvisatorische Phantasie, sein improvisatorisches Temperament nur allzu leicht von den Fesseln eines im voraus festgelegten Gedankenganges befreien wollen.«(Ferand 1938:15)

Wer gerne improvisiert, wird an der detailgenauen Durchführung eines perfekt geplanten Handlungsentwurfs wenig Interesse haben. Auch der Macht seiner Gewohnheiten und dem routinenreproduktiven >Und so weiter des Alltags wird er nicht immer folgen wollen. Auf Gleiches immer wieder gleich zu reagieren ist seine Sache nicht. Er neigt eher dazu, auf das Gleiche immer wieder anders zu reagieren. Den Jazzmusiker Steve Lacy reizt die Improvisation, weil sie eine bestimmte Haltung provoziert: »Es hat etwas mit der >Kante $<\mathrm{zu}$ tun. Immer am Rande des Unbekannten zu stehen und ständig zum Sprung bereit sein « (Lacy in Bailey 1987: 98).

$\mathrm{Ob}$ man Improvisationssituationen sucht oder meidet, ist jedoch nicht nur eine Frage der Haltung, sondern auch eine Frage der sozialen Atmosphäre. Jedenfalls macht es einen großen Unterschied, ob man nur für sich, oder in erster Linie für andere improvisiert. Die Präsenz anderer lädt die Situation mit Erwartungen auf. Diese Erwartungen bestimmen, ob bzw. in welchem Rahmen improvisiert werden kann, soll oder muss. Je nach dem, ob die Stimmung improvisationsfreundlich oder improvisationsfeindlich ist, wird die Handlungsorientierung des Improvisierenden zwischen Vorsicht und Vertrauen schwanken. Wie hoch ist die soziale Erwünschtheit des Improvisierens hier? Muss man Angst vor Fehlern haben? Sind die anderen offen und entgegenkommend? Oder nimmt jemand eine verunglückte Improvisation mit der Videokamera auf?

Dass und wie die Qualität der Improvisation von der Gegenwart anderer Menschen abhängt, hat schon Heinrich von Kleist in seiner 
Schrift Über die allmähliche Verfertigung der Gedanken beim Reden beschrieben. »Wenn du etwas wissen willst und es durch Meditation nicht finden kannst, so rate ich dir [...] darüber zu sprechen « (Kleist 1978: 454). Die Gegenwart des anderen kann im Gespräch beflügelnd wirken und aus dunklen Vorstellungen klare werden lassen:

»[W]enn ich nur dreist damit den Anfang mache, (so prägt) das Gemüt, während die Rede fortschreitet, in der Notwendigkeit, dem Anfang auch ein Ende zu finden, jene verworrene Vorstellung zur völligen Deutlichkeit aus, dergestalt, daß die Erkenntnis, zu meinem Erstaunen, mit der Periode fertig ist. Ich mische unartikulierte Töne ein, ziehe die Verbindungswörter in die Länge, gebrauche auch wohl eine Apposition, wo sie nicht nötig wäre, und bediene mich anderer, die Rede ausdehnender, Kunstgriffe, zur Fabrikation meiner Idee auf der Werkstätte der Vernunft, die gehörige Zeit zu gewinnen.«(Kleist 1978: 454)

Das Gelingen einer solchen Improvisation hängt maßgeblich von den spontanen Reaktionen ab, mit denen der andere uns auf unserem Gedankenweg begleitet. »Es liegt ein sonderbarer Quell der Begeisterung für denjenigen, der spricht, in einem menschlichen Antlitz, das ihm gegenübersteht; und ein Blick, der uns einen halbausgedrückten Gedanken schon als begriffen ankündigt, schenkt uns oft den Ausdruck für die ganze andere Hälfte desselben« (Kleist 1978: 454).

So gesehen könnte uns das Improvisieren in vielen Lebenslagen als eine Art sozialer Mäeutik dienen: »Denn nicht wir wissen, es ist allererst ein gewisser Zustand unsrer, welcher weiß « (Kleist 1978: 458). Wenn wir in diesem Sinne mehr über uns und unsere Mitmenschen erfahren wollen, dann sollten wir uns um eine für Improvisationen günstige Atmosphäre bemühen.

\section{Literatur}

Adorno, Theodor W. (1973): Ästhetische Theorie. Frankfurt a.M.: Suhrkamp.

Bailey, Derek (1987): Musikalische Improvisation. Kunst ohne Werk. Hofheim: Wolke. 
Behne, Klaus-Ernst (1992): »Zur Psychologie der (freien) Improvisation«. In: Walter Fähndrich (Hg.), Improvisation I, Winterthur: Amadeus, S. 42-62.

Bullerjahn, Claudia (2004): »Der Mythos um das kreative Genie: Einfall und schöpferischer Drang «. In: Claudia Bullerjahn/ Wolfgang Löffler (Hg.), Musikermythen. Alltagstheorien, Legenden und Medieninszenierungen, Hildesheim et al.: Georg Olms Verlag, S. 125-162.

Dahlhaus, Carl (1979): »Was heißt Improvisation?« In: Reinhold Brinkmann (Hg.), Improvisation und neue Musik, Mainz et al.: Schott, S. 9-23.

Dhar, Sheila (2001): The Cooking of Music. New Delhi: Permanent Black.

Ferand, Ernst (1938): Die Improvisation in der Musik. Eine entwicklungsgeschichtliche und psychologische Untersuchung. Zürich: Rhein-Verlag.

Frisius, Rudolf (1998): »Fixiertes und nicht Fixiertes: diesseits und jenseits des Klischees? «In: Walter Fähndrich (Hg.), Improvisation III, Winterthur: Amadeus, S. 9-46.

Globokar, Vinko (1979): »Reflexionen über Improvisation«. In: Reinhold Brinkmann (Hg.): Improvisation und neue Musik, Mainz et al.: Schott, S. 24-41.

Gruber, Gernot/Mauser, Siegfried (1994): »Entwurf einer Grundlegung musikalischer Hermeneutik «. In: Siegfried Mauser (Hg.), Musikalische Hermeneutik im Entwurf. Thesen und Diskussionen, Laaber: Laaber-Verlag, S. 47-54.

Hall, Edward T. (1998): »Improvisation - Ein Prozess aus mehreren Ebenen«. In: Walter Fähndrich (Hg.), Improvisation I, Winterthur: Amadeus, S. 24-41.

Hoffmann, E.T.A (1976): »Ritter Gluck«. In: ders., Fantasiestücke in Callots Manier, Gesammelte Werke 1, Berlin und Weimar: Aufbau-Verlag, S. 16-28.

Joas, Hans (1996): Die Kreativität des Handelns. Frankfurt a.M.: Suhrkamp.

Jost, Ekkehard (1979): »Über Jazzimprovisation«. In: Reinhold Brinkmann (Hg.), Improvisation und neue Musik, Mainz et al.: Schott, S. 55-65.

Kakar, Sudhir/Kakar, Katharina (2006): Die Inder. Porträt einer Gesellschaft. München: Beck. 
Khilnani, Sunil (2006): »Die Mannigfaltigkeit der Geschichte«. In: Claudia Wenner (Hg.), Die Geister Indiens. Ein Kaleidoskop, Frankfurt a.M: Fischer, S. 15-24.

Kleist, Heinrich von (1978): »Über die allmähliche Verfertigung der Gedanken beim Reden«. In: ders., Werke und Briefe in vier Bänden. Band 3, hg. von Siegfried Streller, Berlin und Weimar: Aufbau-Verlag, S. 453-459.

Kurt, Ronald (2006a): »Max Weber und Indien. Perspektiven und Probleme der Kulturvergleichenden Musiksoziologie«. In: Jörn Rüsen (Hg.), KWI-Jahrbuch 2005, Bielefeld: transcript, S. 299312.

Kurt, Ronald (2006b): Be A Medium. Teaching and Learning Indian Classical Music. Dokumentarfilm mit deutschen Untertiteln, 45 Minuten, München: Allary Film TV \& Media.

Kurt, Ronald (2007): »Klangkulturen in Indien und Europa. Vom objektiven und subjektiven Sinn musikalischen Handelns«. In: Karl-Siegbert Rehberg (Hg.), Die Natur der Gesellschaft. Verhandlungen des 32. Kongresses der Deutschen Gesellschaft für Soziologie in Kassel, Frankfurt a.M.: Campus, im Druck.

Marx, Karl (1984): »Das Kapital. Kritik der politischen Ökonomie. Erster Band«. In Karl Marx/Friedrich Engels, Werke Band 23, Berlin: Dietz.

Mead, George Herbert (1973): Geist, Identität und Gesellschaft aus dem Geist des Sozialbehaviorismus. Frankfurt a.M.: Suhrkamp.

Moutal, Patrick (1991): A Comparative Study of Selected Hindustani Ragas. New Delhi: Munshiram Manoharlal Publishers.

Nettl, Bruno (1974): »Thoughts on Improvisation: A Comparative Approach«. In: The Musical Quarterly Vol. LX, No.1, S. 1-19.

Nettl, Bruno (1998): »An Art Neglected in Scholarship«. In: Bruno Nettl/Melinda Russell (Hg.), In the Course of Performance. Studies in the World of Musical Improvisation, Chicago, London: University of Chicago Press, S. 1-23.

Neuhoff, Hans (1995): Yaman und Multani. Konstanz, Variabilität und Veränderung in zwei nordindischen Ragas. Frankfurt a.M.: Peter Lang.

Ranade, Ashok Da. (2002): Hindustani Music. New Delhi: National Book Trust.

Riemann Musiklexikon (1967): Sachteil. Mainz et al.: Schott. 
Schütz, Alfred (2004): »Der sinnhafte Aufbau der sozialen Welt. Eine Einleitung in die verstehende Soziologie«. In: Martin Endreß/Joachim Renn (Hg.), ASW II, Konstanz: UVK.

Shankar, Ravi (1969): My Music, My Life. New Delhi: Vikas Publishing House.

Valéry, Paul (1989): Cahiers/Hefte, Band 3. Frankfurt a.M.: Fischer.

Weber, Max (1973): »Die >Objektivität< sozialwissenschaftlicher und sozialpolitischer Erkenntnis«. In: ders., Gesammelte Aufsätze zur Wissenschaftslehre, Tübingen: Mohr.

Weber, Max (2004): »Zur Musiksoziologie«. In: Christoph Braun/ Ludwig Finscher, $M W G$ I/14, Tübingen: Mohr.

Wilson, Peter Niklas (1999): Hear and Now: Gedanken zur improvisierten Musik. Hofheim: Wolke. 


\title{
THEORETISCH-BEGRIFFLICHE ANSCHLUSSSTELLEN FÜR EIN VERSTÄNDNIS MENSCHLICHEN HANDELNS ALS IMPROVISATION
}

\author{
OLIVER KOZLAREK
}

In The New Grove Dictionary of Music and Musicians heißt es: »To some extent every performance involves elements of improvisation, though its degree varies according to period and place; and to some extent every improvisation rests upon a series of conventions or implicit rules. " (Horsley et al. 1980: 32) Bleibt diese Aussage aber auf die performativen Künste - allen voran Musik, Tanz und Schauspiel - beschränkt, oder offenbart der Blick durch das begriffliche Prisma der »Improvisation « Erkenntnisse über den Charakter des menschlichen Handelns allgemein? Die folgenden Ausführungen wollen deutlich machen, dass Improvisation eine grundsätzliche Qualität des menschlichen Handelns darstellt.

Dazu muss nach theoretisch-begrifflichen Anschlussstellen gesucht werden. Diese lassen sich in der Handlungstheorie, die Hans Joas unter dem Stichwort der Kreativität artikuliert hat, finden. Ausgangspunkt ist bei Joas ein anthropologisches Verständnis »menschlichen Handelns«, das als universelle Grundlage für Soziabilität schlechthin angenommen wird. Attraktiv ist Joas' Theorie des kreativen Handelns, weil sie den Begriff der Kreativität von subjektphilosophischen Voraussetzungen befreit und die Quelle der Kreativität nicht im autonom handelnden und schöpferischen Subjekt, sondern in intersubjektiven und konkreten Situationen des Handelns vermutet. Außerdem verbindet Joas den Begriff der Kreativität mit dem der Kontingenz ${ }^{1}$ (vgl. Joas 2002). Genau diese Verbindung zwischen freier Kombinatorik und der Unmöglichkeit, die

1 Der Begriff der Kontingenz ist sehr eng mit Joas' Theorie verbunden. Er taucht aber vor allem im Zusammenhang mit makrosoziologischen Überlegungen auf. 
jeweiligen Resultate genauestens voraussehen zu können, deckt sich mit der Bedeutung des Wortes Improvisation.

Joas stellt seinen Vorschlag für eine Theorie menschlichen Handelns aber unter den Begriff der Kreativität, dessen semantische Schwerkraft Missverständnisse vorprogrammiert. Ist Joas' Theorie nicht vielleicht doch noch viel tiefer in der Tradition der europäischen Subjektphilosophie, die er mit Hilfe des US-amerikanischen Pragmatismus zu überwinden trachtet, verankert?

Der Versuch, den Begriff der Improvisation im Sinne einer Alternative zu Joas' Begriff der Kreativität zu vermessen, offenbart auch eine inhaltliche Schwäche in seiner Theorie: Da der Begriff der Improvisation aus dem Bereich der Kultur stammt, stellt sich die Frage, ob und wie Joas die Beziehung zwischen menschlichem Handeln und Kultur thematisiert. Die kritische Rekonstruktion seiner Handlungstheorie soll zeigen, dass sein Begriffsapparat »Kultur « nur sehr indirekt ins Blickfeld bekommt. Die Kulturphilosophie Cassirers als Ergänzung zu Joas' Handlungstheorie gelesen - was sich schon deshalb anbietet, weil sie selbst auf handlungstheoretischen Prämissen aufbaut - offenbart nicht nur eine gewisse Kompatibilität, sondern verfestigt auch die Annahme, dass der Begriff der Improvisation die semantische Alternative darstellen könnte, nach der hier gefragt wird.

\section{Kreativität des Handelns jenseits von Funktionalismus und Rationalismus}

Die Theorie des kreativen Handelns von Hans Joas lässt sich als Versuch verstehen, die Kontingenz des menschlichen Handelns in den Mittelpunkt der Aufmerksamkeit zu stellen. Wichtige Referenzpunkte seines Denkens sind der US-amerikanische Pragmatismus im Allgemeinen und die Schriften von George Herbert Mead im Besonderen. In letzteren findet Joas drei dicht miteinander verwobene Themenbereiche, die auch seinem eigenen Werk die charakteristische Note verleihen: 1. das Problem des menschlichen Handelns, 2. die Frage nach der Normativität und 3. die Problematisierung der Funktion einer Wissenschaft sozialer Phänomene (vgl. Joas 1980). Ich möchte diese drei Themen etwas ausführlicher erörtern: 
1. Meads Theorie ist nicht einfach als eine Theorie des Handelns zu verstehen. Handeln, und zwar soziales Handeln, wird darin vielmehr zum Schlüssel für das Verständnis des Menschen. Was den Menschen von anderen Lebewesen unterscheidet, ist zunächst die einzigartige Vielfalt von Handlungsmöglichkeiten, die bereits die unerschöpfliche Kreativität des menschlichen Handelns erahnen lässt. Joas offenbart sein Interesse für diese Thematik bereits in einem Buch, das er zusammen mit seinem Freund Axel Honneth, und schon damals deutlich beeinflusst durch die Lektüre von Mead, 1980 veröffentlichte. Dabei ging es beiden darum, eine nicht-essentialistische und anti-funktionalistische Anthropologie als Grundlage für die Sozialwissenschaften zu entwickeln. Doch auch damals wusste Joas schon, dass ein solches Vorhaben vor allem auf die nahezu unerschöpflichen Handlungsmöglichkeiten menschlichen Handelns eingehen müsse (vgl. Honneth/Joas 1980: 13).

2. Auch das Thema der Normativität erscheint durch das Prisma einer solchen Handlungstheorie in einem anderen Licht. Die Vorstellung, dass sich menschliches Handeln an einem externen Regelwerk von Werten und Normen orientiert, lässt sich danach nicht mehr halten. Meads Entscheidung, Handeln aus der Perspektive des Akteurs zu betrachten (vgl. Joas 1992: 281ff.), verpflichtet dazu, zu verstehen, wie Akteure auch moralische und ethische Probleme in konkreten Situationen des Handelns bewältigen. Der Perspektivenwechsel macht deutlich, dass es nicht darum gehen kann, die Identifikation von Werten und Normen vor das Verständnis des konkreten Handelns zu setzen. Vielmehr manifestiert die Akteurperspektive, dass Handeln auch, bzw. gerade, vor dem Hintergrund von Werten und Normen kontingent und kreativ sein kann. Wird Kreativität also als Grundlage des Verständnisses menschlichen Handelns angenommen, wird der Fokus einer Theorie der Normativität auf die »Konstruktion von moralischen Handlungsmöglichkeiten « eingestellt sein, nicht auf ihre »Anwendung « (vgl. Joas 1992: 300).

3. Schließlich lässt sich mit Mead die Frage nach der Funktion der Sozialwissenschaften vor dem Hintergrund der Zentrierung auf Kreativität beantworten. Gegen die bekannten Versuche, die Sozialwissenschaften an den theoretischen und methodologischen Imperativen der Naturwissenschaften auszurichten, trat schon Mead dafür ein, Wissenschaft allgemein als Dispositiv der Problembewältigung in bestimmten politischen und gesellschaftlichen Prozessen und Zusammenhängen zu verstehen: 
»Indem der Pragmatismus die Wissenschaft als den Typus systematischer Lösung kognitiver Handlungsprobleme auffasst, macht er das praktische Fundament aller Wissenschaft deutlich. Weder ein spezifisches Aussagesystem noch eine eindeutig beschreibbare Methode, sondern nur das relativ erfolgreichste Verfahren zur Lösung von spezifischen Erkenntnisproblemen: das ist Wissenschaft. Wissenschaft und Ethik oder Politik sind nicht scharf voneinander zu trennen, sondern ebenso miteinander verschränkt wie es in der Handlungskonzeption der Pragmatisten die Suche nach angemessenen Mitteln und die Reflexion auf die Angebrachtheit der Zwecke in praktischen Situationen sind.« (Joas 1992: 304)

Deshalb sieht sich Mead nicht gezwungen, Sozialwissenschaften und Naturwissenschaften als zwei völlig unterschiedliche »Kulturen« (C.P. Snow) zu begreifen. Vielmehr ergänzten sie sich in ihren Ansprüchen praktische Probleme zu lösen, wodurch sie beide zum Ausdruck einer »wissenschaftlich-technisch geprägten Zivilisation« würden (Joas 1992: 304).

Die Forschung über Mead hat den Weg für ein Buch geebnet, das 1992 veröffentlicht wurde, und in dem Joas der Aufgabe nachgeht, »den amerikanischen Pragmatismus einmal in Hinsicht auf die heutigen Folgerungen für Handlungs- und Gesellschaftstheorie $\mathrm{zu}$ artikulieren « (Joas 1996: 9). Konsequenterweise nimmt er in Die Kreativität des Handelns - so der Titel des Buches - die bereits genannten und bei Mead entdeckten Gedanken auf und baut um sie herum seine eigene Handlungstheorie.

Als Ausgangspunkt wählt er, sich von den konventionellen Handlungstheorien abzusetzen. Diese fasst er in zwei Gruppen zusammen. Die eine wird von Theorien des rationalen Handelns gebildet, während die zweite Gruppe sich aus Theorien des normativ orientierten Handelns zusammensetzt. In beiden Fällen wird der Blick auf das menschliche Handeln nur durch zwei Brillen, der des rational handelnden Subjektes oder der der vermeintlich vorgegebenen Werte und Normen, möglich.

Dabei werden drei Problemfelder sichtbar: 1. Handeln wird grundsätzlich als teleologisch verstanden. 2. Dichotomien wie Theorie-Praxis, Geist-Körper, Subjekt-Objekt, Individuum-Gesellschaft bringen ein dualistisches (»cartesianisches«) Weltbild zum Ausdruck, in dem davon ausgegangen wird, dass dem konkreten Handeln immer eine Idee, ein Plan, eine Theorie oder eine Strategie voraus geht, und dass Handeln folglich einen Prozess darstellt, in 
dem der Körper von den »geistigen « Kräften kontrolliert und bezwungen wurde. 3. Schließlich wird der Mensch als »Individuum « und »Subjekt« als ein grundsätzlich vorsoziales Wesen verstanden.

Alle drei Punkte machen deutlich, wie weitreichend die handlungstheoretischen Ambitionen Joas' gehen; sie wollen nicht nur eine neue Handlungstheorie neben bisherige Versuche stellen. Impliziert wird vielmehr eine Kritik des >westlichen< Denkens, die bis tief in die epistemologischen, ontologischen und die, für Joas besonders wichtigen, anthropologischen Fundamente hineinreicht.

In negativer Weise zeichnen sich an den herausgearbeiteten Problemen der konventionellen Handlungstheorien schon die Koordinaten für Joas' eigene Theorie ab. Diese wird entsprechend in drei Schritten entwickelt, in denen »der intentionale Charakter menschlichen Handelns, die spezifische Körperlichkeit und die ursprüngliche Sozialität der menschlichen Handlungsfähigkeit analysiert « werden sollen (Joas 196: 217).

1. Handeln als teleologisch zu verstehen bedeutet, davon auszugehen, dass es ein intendierter Ablauf ist, der auf bestimmte Ziele hin ausgerichtet ist. Dadurch wird Handeln selbst aber eigentlich als zweitrangig betrachtet, denn in ihm wird nur noch ein Prozess gesehen, der dazu dient, bestimmte Zwecke zu erreichen. Gegen eine solche Degradierung des Handelns protestiert Joas energisch. Er sieht die Aufgabe der Sozialtheorie darin, ihr Interesse kompromisslos und vorrangig auf das Handeln zu richten. John Dewey folgend unterscheidet er zwei analytisch trennbare Aspekte menschlichen Handelns: Zum einen die Orientierung an bestimmten Handlungszielen, zum anderen die Resultate. Dabei würde deutlich, dass Ziele nicht als zukünftige Wirklichkeiten verstanden werden dürften, die das Handeln nur zu konkretisieren hat. Für Dewey befinden sich auch die Ziele des Handelns im Hier und Jetzt der jeweiligen Handlungssituation. Noch als Voraussicht sind Handlungsziele ein Teil der aktuellen noch nicht vollendeten Handlungen selbst. Nach dieser Logik muss ebenfalls die Beziehung zwischen Mitteln und Zielen des Handelns überdacht werden. Sie lässt sich nun als reziprok verstehen. Ziele können auch als Resultate der zur Verfügung stehenden Mittel begriffen werden.

Beispielhaft für diese Art des Handelns ist das Spielen von Kindern. Mit diesem Verweis soll keineswegs auf eine koordinationslose Art des Handelns angespielt werden. Am Spielen von Kindern kann vielmehr jene Flexibilität im Umgang mit Handlungszielen 
und Zwecken exemplifiziert werden, die Erwachsene eher verlernt $\mathrm{zu}$ haben scheinen. Kinder besitzen (noch) eine viel ausgeprägtere Gabe, bestimmte Ziele im Verlauf ihrer Handlungen aufzugeben und durch andere zu ersetzen, die den vorhandenen Mitteln eher entsprechen. »Das Spielen enthält, so Dewey, durchaus Zwecke im Sinne einer inneren Handlungsregulation; es besteht nicht in beliebigen Bewegungen [...]«(Joas 1996: 228).

Joas' an Mead und Dewey geschulte Handlungstheorie will also nicht einfach jede Reflexion über Handlungsziele eliminieren. Er möchte die Handlungstheorie aber an einer anderen Frage orientieren: Wie lassen sich die Prozesse, in denen Handlungsziele entstehen, besser erklären? Voraussetzung dafür ist eine deutliche Kritik an den »cartesianischen « Dualismen, nach denen die Intentionalität des Handelns der Dimension des Geistes (res cogitans) zugeschrieben wird, während die Ausführung zum Gegenstand des Körpers (res extensa) werden soll. Die Alternative, die Joas anbietet, versucht diese strikte Trennung dadurch aufzuheben, dass sie den Handlungsbegriff weiter fasst. Auch die kognitiven Momente fallen damit in den Bereich des Handelns und werden nicht mehr als etwas verstanden, was dem Handeln vorausgeht. Das bedeutet einerseits, dass jede menschliche Handlung permanent mit dem kognitiven Apparat verbunden ist, dass sie nicht einmal kommandiert wird und dann blind abläuft, sondern dass sie permanente Steuerungs- und Gegensteuerungsmechanismen impliziert, die sich der Eingebundenheit in konkrete Situationen zu jedem Zeitpunkt vergewissern. Andererseits bedeutet es aber auch, dass Intentionalität nicht aus einer, von den jeweiligen Handlungskontexten und -situationen unabhängigen und übergeordneten, Schaltstelle abgefeuert wird, sondern dass sie vielmehr das Resultat der vielen, »vor-reflexiven Strebungen und Gerichtetheiten« (Joas 1996: 232) unseres Körpers ist.

»[Der] Ort [dieser Strebungen und Gerichtetheiten, d.V.] ist unser Körper: seine Fertigkeiten, Gewohnheiten und Weisen des Bezugs auf die Umwelt stellen den Hintergrund aller bewussten Zwecksetzung, unserer Intentionalität, dar. Die Intentionalität selbst besteht dann in einer selbstreflexiven Steuerung unseres laufenden Verhaltens.«(Joas 1996: 232)

Wir sind danach keine Subjekte, die von der objektiven Welt getrennt sind. Vielmehr befinden wir uns mit unseren Körpern immer 
bereits in situ, sind immer schon Teil komplexer Situationen, ohne dass diese allerdings unser Tun absolut determinieren würden.

2. Im nächsten Schritt entwickelt Joas eine detaillierte Argumentation gegen das im modernen Denken weit verbreitete Vorurteil, dass Handeln eine Art Kontrolle des Körpers impliziere. Ziel auch dieses Teils der Argumentation ist es, die Handlungstheorie wieder für die leiblichen Bedingungen des Handelns zu sensibilisieren. Dies hält Joas deshalb für wichtig, weil sich nur so ihr Universalitätsanspruch fortschreiben ließe. Die Berücksichtigung der Leiblichkeit macht es möglich, weiterhin an das allen Menschen Gemeinsame zu glauben, ohne dafür einen extremen Formalismus in Kauf nehmen zu müssen.

Nun ließe sich zwar behaupten, dass das Thema der Körperlichkeit alles andere als neu ist. Joas weiß das. Er selbst nennt Elias und Foucault, in denen er Wegbereiter für die >körperliche Wende< im soziologischen Denken sieht. Dennoch glaubt er, dass sich in Elias und Foucault letztendlich doch noch die Idee fortsetzen würde, dass die Geschichte der Zivilisation vor allem die Geschichte des rationalen Akteurs nacherzähle.

Die Herausforderung für eine tatsächlich alternative Handlungstheorie bestünde konsequenterweise darin, die Aufmerksamkeit nicht nur auf die rationale Kontrolle des Körpers zu legen, zumal diese doch eher einen Ausnahmefall darzustellen scheint. Hervorgehoben werden müssten vielmehr die Momente, in denen sich dem Handelnden die Körperkontrolle verneint. Joas lenkt sein Augenmerk auf vor-reflexives Handeln, dass sich zum Beispiel beim Lächeln, Weinen oder auch beim durch Scham ausgelösten Rotwerden Ausdruck verschafft. In all diesen Beispielen erfahre der Akteur so etwas wie einen $>$ sinnhaften Verlust der Intentionalität $<$. Das bedeute keineswegs, dass Intentionalität definitiv suspendiert würde und dass an ihre Stelle externe Faktoren wie kulturelle, physiologische oder psychologische Bedingungen das Geschehen steuern und beherrschen würden. Im Gegenteil, auch vor-reflexives Handeln manifestiert nach wie vor eine gewisse Intentionalität auf Seiten des Akteurs. Nur hat diese ihren Sitz nicht in der Vernunft, sondern im Körper des Handelnden:

»Der sinnhafte Verlust der Intentionalität liegt nicht dort vor, wo körperliche Phänomene zum Indikator für uneingestandene Intentionen werden: wenn wir etwa vor Scham erröten. Unsere Fähigkeit zu intenti- 
onalem Handeln ist dabei nicht prinzipiell in Frage gestellt; unser Körper verrät nur andere Intentionen als wir intentional gerne mitgeteilt hätten.«(Joas 1996: 249)

Mit den Begriffen des »Körperschemas« und des »Körperbildes«, die Joas von Paul Schilder, Maurice Merleau-Ponty und einmal mehr von George Herbert Mead übernimmt, schließt er seine Argumentation in diesem zweiten Schritt ab. Während nach dem cartesianischen Denken davon ausgegangen wird, dass sich der Mensch ein Bild von der Welt - ein »Weltbild « - macht, wobei die vorausgesetzte Trennung von Körper und Geist, Objekt und Subjekt usw. dafür verantwortlich gemacht wird, dass die »Welt« als etwas, vom Menschen Getrenntes in Erscheinung treten kann, glaubt Joas, dass die Erfahrung von Subjektivität auf das leibliche Eingebundensein in die natürliche und soziale Umwelt zurückgeht.

3. Schließlich, in einem dritten Schritt, argumentiert Joas gegen den cartesianischen Solipsismus. Selbst die Konstitution eines »Körperschemas « unterliegt noch der Tatsache, dass Menschen immer schon mit anderen Menschen, das heißt auch: mit anderen Körpern, interagieren. Joas geht davon aus, dass es immer schon so etwas wie eine »primäre Sozialität« gibt, das heißt: eine vorreflexive Interaktion zwischen Körpern, die sich bis zur »präödipalen Mutter-Kind-Interaktion« zurückverfolgen lässt (Joas 1996: 277).

\section{Die Grenzen der Theorie kreativen Handelns und die Notwenigkeit einer Kulturtheorie}

Joas' Theorie der Kreativität des menschlichen Handelns setzt sich nicht nur bewusst von funktionalistischen und rationalistischen Handlungstheorien ab, sondern geht auch zu kulturalistischen Reduktionen auf Distanz. Kultur als ultimative Handlungserklärung oder gar -Rechtfertigung einzusetzen, lehnt er kategorisch ab. Dies wird besonders im Rahmen seiner Wertediskussion (vgl. Joas 2002: 1997) deutlich. Gerade dort soll der Verdacht entkräftet werden, als verfolge er eine kulturrelativistische Absicht. Die im Zusammenhang moralphilosophischer und ethischer Debatten immer wieder thematisierte Alternative »Relativismus versus Universalismus« hält er für falsch: 
»[I]n unseren Tagen halten die meisten diese zwei vermeintlich alternativen Positionen für attraktiv. Man findet (oder vielleicht sollte ich sagen >wir finden<), den Wertepluralismus attraktiv, weil wir uns von einem Ethos der Toleranz leiten lassen und weil wir eine Neigung haben, über unsere eigene Nation und unsere eigene Kultur zu urteilen. Das ist auch der Grund dafür, dass wir dem Universalismus gegenüber skeptisch eingestellt sind, der mit dem Anspruch kulturell unabhängig zu sein, auftritt. Selbst dann noch, wenn er sich im kontraktualistischen Gewand zeigt, erfahren wir eine Aversion gegenüber den reinen Partikularismen und sind uns der politischen Gefahr bewusst, die sie darstellen. $\ll^{2}$ (Joas 2002: 49)

Joas spielt in diesem Zitat auf jenen Diskussionszusammenhang an, der vor allem in den 80er Jahren des vergangenen Jahrhunderts unter den Stichwörtern Liberalismus und Kommunitarismus stand. Genau in diesen Zusammenhang fühlt er sich aber befugt, mit seiner eigenen Theorie eine Art »dritten Weg« einzuflechten. Danach liegt der normative Handlungsrahmen weder in universellen und formalen Prinzipien begründet, noch in kulturell vorgegebenen Vorstellungen, sondern aktualisiert sich - ebenfalls nach Gesichtspunkten der Kreativität - immer wieder in konkreten Handlungssituationen. Menschliches Handeln lässt sich so gesehen auch in normativer Hinsicht als Laboratorium des Experimentierens verstehen. So gibt es keine absolute Sicherheit, dass das zur Verfügung stehende normative Wissen vor Irrtümern bewahrt. Kein »kategorischer Imperativ« entlastet die Akteure, die in jeweils neuen Situationen immer wieder neue Entscheidungen treffen müssen. Vor allem gegen Talcott Parsons richtet sich Joas, wenn er behauptet, dass Handeln nicht nur eine Konkretisierung der Werte darstelle, die den Handelnden schon eingelagert in ihren »Diskursen« - zur Verfügung stünden. Vielmehr befänden sich die Handelnden immer wieder erneut vor der Aufgabe, in konkreten Situationen ihr Handeln mit anderen auch in normativer Hinsicht zu koordinieren. Die jeweils verfügbaren »Diskurse« stehen für Joas damit auf einer untergeordneten Ebene:

»Selbstverständlich, sowohl ein Wert, als auch die Anwendung eines Wertes können sich an einen Rechtfertigungsdiskurs anschließen. Aber die pragmatistische Ethik stellt eine Distanz zwischen der Perspektive

2 Rückübersetzung aus dem Spanischen durch Oliver Kozlarek. 
des Diskurses und der existentiellen Perspektive desjenigen, der handelt, her.«(Joas 2002: 58)

Entsprechend dieser bewusst antikulturalistischen Position muss Joas auch auf eine klare Unterscheidung zwischen sozialer und kultureller Integration bestehen. Er erinnert explizit an Talcott Parsons, für den diese beiden Dimensionen zu verschmelzen schienen. Zwar wird die kulturelle Verwurzelung der Werte und Normen nicht geleugnet,

»[a]ber das bedeutet nicht, dass [die normative Regulierung der sozialen Integration, d.V.] einfach aus [den kulturellen Werten, d.V.] hervorgingen, sondern, dass sie aus einem reflexiven Gleichgewicht zwischen dem Bewusstsein, das die Akteure von ihrer Kooperation haben, und den kulturellen Interpretationen hervorgehen.« (Joas 2002: 64)

Dass Joas nun in diesem Zusammenhang und trotz aller Kritik am Rationalismus den Begriff des »reflexiven Gleichgewichts« verwendet, mag auf den ersten Blick überraschen. Es könnte aber auch symptomatisch dafür sein, dass seine eigene Theorie kaum über begriffliche Werkzeuge verfügt, um sich mit dem Thema der Kultur gebührend auseinanderzusetzen. So wichtig seine Erinnerung an das leibliche Eingebundensein des Menschen in konkreten Situationen ist und so erhellend seine Gedanken an vor-reflexive Formen der Sozialität auch sein mögen, so sehr fehlt doch eine genauere Analyse der Beziehung zwischen dem menschlichen Handeln und der Kultur. Immer wieder entsteht bei der Lektüre von Joas Schriften der Eindruck, als stünde Kultur auf einer der »primären Sozialität « untergeordneten Ebene. Eindrucksvoll und überzeugend zugleich verweist er auf die Mutter-Kind-Beziehung, die seiner Ansicht nach eine prototypisch vorkulturelle Form sozialer Interaktion darstellt (vgl. Joas 1996: 277). Vor dem Hintergrund aktueller Debatten, in denen der kulturelle Einfluss bereits auf Ungeborene vermutet wird, lässt sich diese Argumentation aber genauso plausibel in Frage stellen.

Ein weiterer Grund für die Notwendigkeit der Thematisierung von Kultur lässt sich aus einer begrifflichen Überlegung ableiten, die Jürgen Straub in sehr überzeugender Weise angestellt hat: Kreativität könne, so Straub, eigentlich nur dann sinnfällig werden, wenn man berücksichtige, wogegen sich dieser Begriff absetzt. Für Straub 
ist dies ein immer schon vorausgesetzter Ordnungsbegriff. »Kreatives Handeln ist nicht ohne die Ordnung denkbar, die es verwirft [...]« (Straub 1999: 157). Dabei dürfe allerdings der Aspekt des Bruchs nicht radikalisiert werden, wie dies in der Vergangenheit vor allem im Zusammenhang mit der Vorstellung sozialen Wandels zum Beispiel in den, auch von Joas kritisierten Revolutionstheorien - immer wieder geschehen ist.

»Es ist eine Binsenweisheit, daß die innovative Veränderung sozialer und psychischer Ordnungen ihre Zeit braucht. Damit ist nicht nur der rechte Zeitpunkt, der Kairos kreativen Handelns gemeint, sondern auch die Langwierigkeit der Transformation von Ordnungen. Bisweilen beginnt der Wandel eher beiläufig, mit einem ersten >harmlosen< Vorstoß gegen eine eingeschliffene Regel hier, der Unachtsamkeit gegenüber einem bislang verbindlichen Ziel dort.« (Straub 1999: 155)

Wie das Zitat deutlich macht, ist die kreative Umgestaltung einer Gesellschaft also weder mit einer radikalen Negation jeder Ordnung zu verwechseln, noch als etwas grundsätzlich Unmögliches zu verstehen. Kreatives Handeln ist also auch nicht

»das > ganz andere< der Ordnung. Vielmehr nutzt es die überschüssigen Möglichkeiten in einer Ordnung, es schließt an einen Riß, an einer Frage in einer Ordnung an und >antwortet< auf diese, um schließlich über sie hinauszuführen. Eine creatio ex nihilo ist das kreative Handeln niemals.«(Straub 1999: 157)

Wenn also Kreativität immer schon Ordnung impliziert, wäre es eine »begrifflich-logische Unmöglichkeit (Straub 1999: 158), die eine ohne die andere zu denken. Auch für Straub ist Kultur einer der ordnungsstiftenden »Bestimmungsgründe menschlichen Handelns« (Straub 1999: 163). Dabei darf die ordnungsstiftende Qualität der Kultur aber nicht so stark sein, dass sie die Kreativität des menschlichen Handelns neutralisieren würde. Wie muss Kultur aber beschaffen sein, wenn sie genauso ordnungsstiftend wie kreativitätsfördernd sein soll? Dies lässt sich von Ernst Cassirers Philosophie der symbolischen Formen lernen, die ich im Folgenden kurz skizzieren möchte. 


\section{Ernst Cassirers Philosophie der symbolischen Formen}

Schon in den ersten beiden Bänden seines Das Erkenntnisproblem in der Philosophie und Wissenschaft der neueren Zeit $(1906,1907)$ sieht Cassirer den Ursprung der neuzeitlichen Wissenschaften in der Mathematik. Im zweiten Band gesteht er Leibniz den Verdienst zu, eine in diesem Zusammenhang ganz wesentliche Entdeckung gemacht zu haben: Die mathematischen Begriffe haben keine substanzielle Bedeutung, sondern eine funktionale. Dieses Thema steht auch im Mittelpunkt eines 1910 veröffentlichten Buches mit dem Titel Substanzbegriff und Funktionsbegriff (Cassirer 2000). Das Buch lässt sich als eine Darlegung Cassirers eigener Epistemologie verstehen (vgl. Paetzold 1995: 24). Begriffe sind hier keine Abstraktionen von etwas »substantiell« Gegebenen, sondern relativ autonome Konstruktionen. »Relativ autonom« ist der jeweilige Begriff deshalb, weil er in einer »funktionalen « Beziehung $\mathrm{zu}$ anderen Begriffen steht. Zusammen konstituieren bestimmte Begriffe »Felder der Phänomene«, deren »Logik « nicht nur von Korrespondenzen zu empirischen Grundlagen abhängt. Dies macht das Beispiel der negativen Zahlen deutlich: diese erschließen offensichtlich eine nicht-empirische Welt, indem sie einer relationalen oder »funktionalen « Logik der Begriffe folgend die Linien der positiven Zahlen verlängern. Die Voraussetzung dafür, negative Zahlen denken zu können, liegt nicht in der Existenz negativer Objekte, sondern in der Eigenlogik des begrifflichen Feldes der Mathematik.

Aber Cassirer glaubt auch, dass diese Logik in denjenigen Wissenschaften Anwendung findet, die sich mit Naturphänomenen beschäftigen, wie die zu seiner Zeit noch über allen anderen Naturwissenschaften thronende Physik. Ähnlich wie Charles S. Pierce oder Werner Heisenberg geht Cassirer davon aus, dass auch in den Naturwissenschaften die Theoriebildung und das heißt: die Errichtung bestimmter Begriffsordnungen, eine ganz zentrale Rolle spielt. Somit erklärt er Kohärenz und nicht Korrespondenz zum wichtigeren Kriterium. Frédéric Vandenberghe fasst dies wie folgt zusammen:

»By stressing the constructive and synthetic character of science, Cassirer develops a post-positive theory of knowledge that breaks with all correspondence theories of truth. Against the positivists and other naïve empiricists, he forcefully argues that the function of science does not 
consist in proposing a copy or a reflection of sensible reality. (Vandenberghe 2001: 483)

Obwohl das Buch Substanzbegriff und Funktionsbegriff noch eindeutig als Ergebnis von Cassirers Forschung über das »Erkenntnisproblem « zu bewerten ist, bereitet es den Weg zu einer sehr originellen Form der Kulturphilosophie vor, die Cassirer später unter den Titel der Philosophie der symbolischen Formen stellen sollte. ${ }^{3}$

Sobald einmal grundsätzlich die Relativität wissenschaftlicher Inhalte angenommen wird, ist es nur konsequent auch andere Formen der Erkenntnis mit denen der modernen Wissenschaften zu vergleichen. Cassirer ist sich dessen bewusst und folgt in seinem Hauptwerk Philosophie der symbolischen Formen (1923-29) dieser Einsicht konsequent. Unter dem Begriff der »symbolischen Formen« werden nun Sprache, Mythos und Wissenschaft als Felder verstanden, die trotz aller Unterschiede doch auch ganz ähnlich »funktionieren«. Dabei geht es Cassirer aber nicht bloß um eine vergleichende Epistemologie wie Vandenberghe zu glauben scheint (vgl. Vandenberghe 2001: 484). Die Fragestellung ändert sich vielmehr in dramatischer Weise. So hat Hans Blumenberg hervorgehoben, dass die Leitfrage, an der sich Cassirers Forschung nun orientiert, nicht mehr die Frage »Was können wir wissen?«, sondern die Frage »Was wollen wir wissen?« (vgl. Blumenberg 1996: 164) ist. Schon dadurch, dass hierbei Wissen und Erkenntnis an Intentionalität rückgebunden werden, zeigt sich, dass epistemologische Fragen in den Bereich der praktischen Philosophie, ja der Sozialtheorie führen. Konkreter lassen sich drei Schnittstellen mit der praktischen Philosophie und der Sozialtheorie ausmachen: 1. handlungstheoretische, 2. zeitdiagnostische und 3. ethische. Ich werde mich im Folgenden vor allem auf die erste beschränken. ${ }^{4}$

Der Vergleich mit Joas drängt sich dort auf, wo Cassirers Überlegungen handlungstheoretische Ansprüche offenbaren. Es ist allerdings fraglich, ob die Art und Weise, in der Cassirer Handeln the-

3 Zwar ist erst in einem 1921 veröffentlichten Buch über Einsteins Relativitätstheorie von »symbolischen Formen« die Rede (vgl. Cassirer 2001a), doch die Weichen dafür legt Cassirer tatsächlich schon in seinen erkenntnistheoretischen Studien um.

4 Ausführlicher habe ich die anderen beiden Themen an anderer Stelle diskutiert (vgl. Kozlarek 2004). 
matisiert, zu Joas Vorstellung auch wirklich kompatibel ist. Joas hat in seinem Buch von 1992 ja schon darauf bestanden, dass nicht jeder Versuch eine Handlungstheorie zu konstruieren, gleichwertig ist. Seiner Meinung nach stellt das Thema seit geraumer Zeit bereits eine Art Kulminationspunkt dar, auf den die meisten Überlegungen in den Sozialwissenschaften und der Philosophie hinauszulaufen scheinen. Genauso ließe sich zeigen, dass dem menschlichen Handeln dabei in sehr vielen Versuchen eine gewisse Kreativität unterstellt werde. Dies zeige sich deutlich an den von Joas so genannten »Metaphern der Kreativität« - Ausdruck, Produktion, Revolution, Leben, Intelligenz und Rekonstruktion (vgl. Joas 1996: 113ff.) -, nach denen sich verschiedene handlungstheoretische Richtungen kategorisieren lassen sollen. Vor allem die ersten drei Metaphern seien aber auch symptomatisch für das Problem, das Joas sich anschickt zu überwinden: sie erlaubten es nicht, Kreativität als grundsätzliche Qualität des menschlichen Handelns zu verstehen, sondern beschränkten sie auf bestimmte Bereiche: Die Rede vom »Ausdruck« verweise auf die Dimension des Subjektes und suggeriere, dass Kreativität eben auf diesen Bereich beschränkt bleibe. »Produktion« fokussiere hingegen den Umgang mit der objektiven Welt, und »Revolution« auf kreative Eingriffe in der sozialen Welt. Dagegen sucht Joas nach einer integrativen Theorie menschlichen Handelns im Zeichen der Kreativität.

Die zentrale Stellung des Symbolbegriffs in Cassirers Philosophie ließe vermuten, dass hier eher ein weiterer Versuch unternommen wurde, eine um den subjektiven »Ausdruck « zentrierte Theorie der Kreativität auf den Weg zu bringen. Diese Annahme ließe sich dadurch verhärten, dass Cassirer ja aus der Tradition des Neukantianismus kommt, und dass ihm Kants Subjektphilosophie besonders nah gestanden hat. So bliebe Cassirers Eigenleistung aber völlig missverstanden. Sie besteht darin, Kants Subjektphilosophie - seine $»$ Kritik der reinen Vernunft « - in Kulturphilosophie - eine »Kritik der Kultur« (Cassirer 2001b: 9) - überführt zu haben; ein Schritt so weitreichend, dass er als eine neue »kopernikanische« Wende interpretiert werden könnte. »Kultur« wird von Cassirer nicht als das verstanden, was von Subjekten produziert wird, sondern es handelt sich um eine Art der »Zwischenwelt «, in dem sich die Dimensionen 
Subjekt und Objekt überhaupt erst konstituieren und ausdifferenzieren. $^{5}$

Ein weiterer Vorwurf, den Joas an Cassirers Philosophie richten könnte, ist der des »Konstruktivismus«. Vor kurzem schrieb er:

»Während der letzten zwanzig Jahre sind die Sozialwissenschaften teilweise durch einen interdisziplinären (oder nicht-disziplinären) Komplex mit dem Namen >cultural studies< ersetzt worden. Außerdem wurden diese >cultural studies` zur Domäne einer spezifischen intellektuellen Orientierung, nämlich eines radikalen und umfassenden >Sozialkonstruktivismus<. Ich glaube, daß es höchste Zeit für die Sozialwissenschaften ist, eine Gegenoffensive zu starten.«(Joas 2005: 91)

Gegen diese Vorwürfe wäre Cassirers Kulturphilosophie aber schon deshalb gefeit, weil sie, ebenso wie Joas', auf ein im emphatischen Sinne handlungstheoretisches Programm setzt:

»Nicht das bloße Betrachten, sondern das Tun bildet vielmehr den Mittelpunkt, von dem für den Menschen die geistige Organisation der Wirklichkeit ihren Ausgang nimmt. Hier zuerst beginnen sich die Kreise des Objektiven und Subjektiven, beginnt sich die Welt des Ich von der der Dinge zu scheiden. Je weiter das Bewußtsein des Tuns fortschreitet, um so schärfer prägt sich diese Scheidung aus, um so klarer treten die Grenzen zwischen >Ich< und >Nicht-Ich< hervor.« (Cassirer 2002: 183)

Der an der Humboldt-Universität lehrende Philosoph Oswald Schwemmer schreibt:

»Unser gesamtes geistig-kulturelles $>$ Sein $<-$ so kann man die These zusammenfassen - ist in unserem Handeln und Wirken, ist praktisch fundiert.«(Schwemmer 1997: 27)

Über die Qualität dieses »Tuns«, das in Cassirers Kulturphilosophie eine so zentrale Rolle spielt, lässt sich folgendes sagen: 1. Es ist kreativ und kontingent, denn obgleich es sich aus dem symbolischen Material nährt, das die Welt, in der der Mensch hineingeboren wird,

5 Cassirer macht diese Idee besonders in seiner Kritik an Georg Simmels Aufsatz »Der Begriff und Tragödie der Kultur« (1911/12) deutlich (vgl. Cassirer 1994). 
immer schon bildet, wird es diese Welt nie einfach reproduzieren, sondern aus dem Vorhandenen nicht-determiniertes Neues schaffen. 2. Es verweist immer auch auf die leibliche Wirklichkeit des Menschen, worauf ich noch genauer eingehen werde. 3. Und schließlich ist es intersubjektiv. Das heißt, es lässt sich immer als Handeln zwischen Menschen verstehen. Und auch dieser Aspekt der Intersubjektivität verbindet sich mit der Idee der Leiblichkeit: Auch für Cassirer stellt Interaktion eine interkorporale Beziehung dar.

Wie sich gezeigt hat, spielt für Joas die Leiblichkeit des menschlichen Handelns eine besonders große Rolle. Für den Vergleich mit Cassirer ergibt sich daraus die Frage, wie dieser das Verhältnis zwischen Kultur und Leiblichkeit versteht. Klar ist, dass Cassirer kein Naturalist ist. Aber auch eine Reduktion zum GeistigIdeellen findet sich in seinem Denken nicht. Stattdessen glaubt er, dass die jeweiligen Interaktionen zwischen Körpern sowie zwischen Körpern und Objekten immer schon durch Kultur, das heißt, durch symbolisch fixierte Bedeutungen, vermittelt werden. Dabei ist Kultur kein nur äußerlicher, die originäre Beziehung des Menschen zu seiner natürlichen und mitmenschlichen Umwelt entfremdender Faktor, sondern eine ganz wesentliche Eigenschaft des menschlichen Handelns.

»Indem die Aktion sich gleichsam aus der unmittelbaren Form des Wirkens zurückzieht, gewinnt sie damit für sich selbst einen neuen Spielraum und eine neue Freiheit; steht sie damit bereits an dem Übergang vom bloß Pragmatischen $<$ zum >Theoretischen $<$, von dem physischen zum ideellen Tun.«(Cassirer 2001b: 125)

Jedes Beispiel menschlichen Handelns lässt sich gemäß dieser Betrachtung irgendwo auf dem Kontinuum zwischen dem rein Pragmatischen und dem rein Theoretischen verorten. Letztendlich lässt sich Kultur auch so verstehen, dass es die leiblichen Fähigkeiten des menschlichen Handelns erweitert. Erst durch Kultur konnte es zu jener einzigartigen Ausdehnung in Raum und Zeit kommen, für die menschliches Handeln steht. Kultur und Körperlichkeit sind ganz wesentlich miteinander verschränkt: daher ist Cassirers anthropologische Formel vom »animal symbolicum « (vgl. Cassirer 1970) keineswegs reduktionistisch. Sie bezieht sich nicht nur auf die geistigtheoretischen Fähigkeiten des Menschen, sondern sieht diese immer schon mit den körperlich-praktischen vereint. 
Ist Cassirers Kulturphilosophie relativistisch? Wie Gerald Hartung kürzlich dargelegt hat, geht es in Cassirers Anthropologie nicht mehr nur um die Frage »Was ist der Mensch?«, sondern: »Gibt es eine Einheit der menschlichen Kultur? (Hartung 2003: 344). Motiviert wurde diese Frage vermutlich durch die zeitgeschichtlichen Erfahrungen des radikalisierten Nationalismus, der sich auf kulturelle Unterschiede berief und für zwei Weltkriege verantwortlich war. Für Cassirer stand fest, dass es gelingen müsse, die Einheit des Menschen trotz der Vielfalt seiner kulturellen Möglichkeiten zu definieren. Da der Mensch sich aber gerade auch durch seine nahezu unerschöpfliche Vielfalt von Handlungsmöglichkeiten charakterisiert, ist eine inhaltliche Definition eine unabschließbare Aufgabe:

»Dementsprechend folgt die kulturphilosophische Bestimmung des Menschen auch einer bloß regulativen Idee, an der sich die Analyse der einzelnen symbolischen Formen orientieren muß, die sie allerdings weder als konstitutiv voraussetzen noch als faktisch erreichbar denken darf.« (Hartung 2003: 346)

Ist auf der Grundlage einer solchen radikal prozessualen Definition eine auch sozial oder politisch verlässliche Vorstellung von der Einheit des Menschen denkbar? Mit Schwemmer können wir resümieren:

»Damit entsteht eine >Öffentlichkeit< des interindividuellen Handelns, mit der ein >Gemeinschaftsgefühl< begründet und die Formen des Miteinanderumgehens und der gegenseitigen Verständigung gesichert werden. Im Tun als leibliches Handeln wird daher der Gebrauch unserer geistigen Unterscheidungen in einer gemeinschaftlichen Versicherung befestigt. Sprachliche - wie überhaupt symbolische - Bedeutung ist in den Unterschieden, die uns unser Handeln erschließt, verankert, und die sprachlichen Unterscheidungen - wie überhaupt die symbolischen Differenzierungen - sind durch ihre Einbettung in unser (Miteinander-) Handeln in ihrem gemeinschaftlichen Gebrauch gesichert.« (Schwemmer 1997: 28f.)

Der Horizont dieser anthropologisch-politischen Handlungstheorie ist kein geringerer als die Weltgemeinschaft des Menschen. Cassirer hat sich an einem weltoffenen und einschließenden Kosmopolitismus orientiert, in dem der Mensch in seiner Gesamtheit - unabhängig kultureller, nationaler oder gar ethnischer Unterschiede - im 
Mittelpunkt steht. Vor diesem Hintergrund lässt sich folgender Satz aus Cassirers Anthropologie verstehen: »[...] we must affirm that humanity is not be explained by man, but man by humanity.« (Cassirer in Hartung 2003: 346) Es geht also nicht um den Begriff »Mensch«, sondern um all das, was der konkrete Mensch zu schaffen imstande ist.

Mit diesem Verweis auf das Politische geht erneut ein Verweis auf Ordnung einher. Aber durch das Filter der cassirerschen Kulturphilosophie erscheint auch die politische - ja kosmopolitische! Ordnung ganz im Zeichen des kreativen und kulturvermittelten Handelns. Ordnung und Kreativität gehören auch hier unzertrennlich zusammen. Da sich die Kreativität durch die Ordnung hindurch realisiert und dabei immer wieder neue Ordnungen entstehen, lässt sich an einer emphatischen Vorstellung des Schöpferischen im Menschen auch ohne Subjektphilosophie und Theologie festhalten: »Die Mannigfaltigkeit des bloßen Wirkens wird jetzt zur Einheit des Schaffens, in der immer bestimmter die Einheit des schöpferischen Prinzips sichtbar wird.«(Cassirer 2002: 256)

\section{Kreativität oder Improvisation?}

Dennoch: Pierre Bourdieu hat darauf hingewiesen, dass im Wort »Kreativität« immer schon eine intentionalistische und damit eine auf subjektphilosophische Grundlagen zurückgehende Idee einer »kreativen Absicht « mitschwingt (Bourdieu 2001: 176). Joas' Theorie des kreativen Handelns versteht sich als Kritik an solchen Vorstellungen, und - wie gesehen - auch Cassirer distanziert sich überzeugend von ihnen. Damit stellt sich allerdings die Frage, ob der gewählte Begriff glücklich ist. Gerade der mit dem Rekurs auf Cassirers Philosophie der symbolischen Formen beabsichtigte Verweis auf die in Joas' Theorie unterdeterminierte Dimension der Kultur lässt sich in diesem Zusammenhang auch als Öffnen eines semantischen Raums verstehen, der terminologische Alternativen parat halten könnte. Eine solche aus der Semantik der Kunst stammende Alternative sehe ich im Begriff der Improvisation, in dem die Bedeutungen von Kreativität und Kontingenz zusammenfließen. Ist nicht menschliches Handeln selbst dort, wo es sich in aller Strenge den Regeln konform verhalten möchte, diesem Folgen nur in beschränkter Weise fähig? Und ist es nicht auch gleichzeitig dort, wo es als 
besonders frei und ungebunden verstanden wird, immer auch von den Vorgaben, die ihm durch die jeweilige Kultur auferlegt sind, abhängig? Menschliches Handeln grundsätzlich als Improvisation zu verstehen würde diesen Ambivalenzen Rechnung tragen.

\section{Literatur}

Blumenberg, Hans (1996): Wirklichkeiten in denen wir leben. Stuttgart: Reclam.

Bourdieu, Pierre (2001): Meditationen. Zur Kritik der scholastischen Vernunft. Frankfurt a.M.: Suhrkamp.

Cassirer, Ernst (1970): An Essay on Man. New Haven/London: Yale University Press.

Cassirer, Ernst (1994): »Die >Tragödie der Kultur ««. In: ders., Zur Logik der Kulturwissenschaften, Darmstadt: Wissenschaftliche Buchgesellschaft, S. 103-127.

Cassirer, Ernst (2000): Substanzbegriff und Funktionsbegriff. Untersuchungen über die Grundfragen der Erkenntniskritik. Darmstadt: Wissenschaftliche Buchgesellschaft.

Cassirer, Ernst (2001a): Zur Einsteinschen Relativitätstheorie. Darmstadt: Wissenschaftliche Buchgesellschaft.

Cassirer, Ernst (2001b): Philosophie der Symbolischen Formen. Erster Teil. Die Sprache. Darmstadt: Wissenschaftliche Buchgesellschaft.

Cassirer, Ernst (2002): Philosophie der Symbolischen Formen. Zweiter Teil. Das mythische Denken. Darmstadt: Wissenschaftliche Buchgesellschaft.

Hartung, Gerald (2003): Das Maß des Menschen. Aporien der philosophischen Anthropologie und ihre Auflösung in der Kulturphilosophie Ernst Cassirers. Weilerswist: Velbrück.

Honneth, Axel/Joas, Hans (1980): Soziales Handeln und menschliche Natur. Anthropologische Grundlagen der Sozialwissenschaften. Frankfurt a.M./New York: Campus.

Horsley, Imogene/Collins, Michael/Badura-Skoda, Eva/Libby, Dennis/Jairazbhoy, Nazir A. (1980): »Improvisation«. In: Stanley Sadie (Hg.), The New Grove Dictionary of Music and Musicians, Bd. 9, London, Washington, Hong Kong: Macmillian Publishers, S. 31-56. 
Joas, Hans (1980): Praktische Intersubjektivität. Die Entwicklung des Werkes von G.H. Mead. Frankfurt a.M.: Suhrkamp.

Joas, Hans (1992): Pragmatismus und Gesellschaftstheorie. Frankfurt a.M.: Suhrkamp.

Joas, Hans (1996): Die Kreativität des Handelns. Frankfurt a.M.: Suhrkamp.

Joas, Hans (1997): Die Entstehung der Werte. Frankfurt a.M.: Suhrkamp.

Joas, Hans (2002): »Pluralismo de valores y universalismo moral«. In: ders., Creatividad, acción y valores. Hacia una teoría sociológica de la contingencia, Mexiko-Stadt: UAM-Porrúa, S. 4966.

Joas, Hans (2005): »Neue Aufgaben für die Sozialwissenschaften. Eine handlungstheoretische Perspektive«. In: Hans Joas/Hans G. Kippenberg (Hg.), Interdisziplinarität als Lernprozeß. Erfahrungen mit einem handlungstheoretischen Forschungsprogramm, Göttingen: Wallstein Verlag, S. 79-93.

Kozlarek, Oliver (2004): »Cultura y acción como referencias complementarias para una teoría de la modernidad «. In: ders., Crítica, acción y modernidad, Mexiko-Stadt: Dríada, S. 177206.

Paetzold, Heinz (1995): Ernst Cassirer - Von Marburg nach New York. Eine philosophische Biographie. Darmstadt: Wissenschaftliche Buchgesellschaft.

Schwemmer, Oswald (1997): Ernst Cassirer. Ein Philosoph der europäischen Moderne. Berlin: Akademie Verlag.

Snow, C.P. (1993): The Two Cultures. Cambridge: Cambridge University Press.

Straub, Jürgen (1999): Handlung, Interpretation, Kritik. Grundzüge einer textwissenschaftlichen Handlungs- und Kulturpsychologie. Berlin, New York: Walter de Gruyter.

Vandenberghe, Frédéric (2001): »From Structuralism to Culturalism. Ernst Cassirer's Philosophy of Symbolic Forms«. European Journal of Social Theory 4/4, S. 479-497. 


\section{DIE FORM DER FREIHEIT *}

ULRICH BIELEFELD

Musik ist überall. Nicht wenigen bedeutet sie viel, wenn auch jeweils ganz Unterschiedliches. Es ist unklar, was sie, gern als universale Sprache ohne festen Begriff bezeichnet, denn »bedeutet ${ }^{1}{ }^{1}$ Die universale Kraft der Musik aber ist institutionalisiertes und manchmal politisches Feiertagsgerede. Wenn auch ohne festen Begriff und ohne einheitliches, nicht aber: ohne System, kann sie Bestimmtes bedeuten und hat, wie es die aktuelle Hirnforschung mit ihren Mitteln zeigt (vgl. Baumgartner et al. 2006), die Fähigkeit, emotionales Erleben zu potenzieren.

Das Musikerlebnis wird dabei schnell, so wird gesagt, zum Gemeinschaftserlebnis. Wo gesungen wird, da lasse man sich nieder, ist ein hieran anschließender Allgemeinplatz, der auf die vermeintliche Unschuld des gern als rein, als unmittelbar Bezeichneten zielt. Es ist jedoch keineswegs belanglos, was und wie gespielt, gesungen und auch mitgesungen wird. Musik entzieht sich nicht der Gesellschaft, dem Kontext, und sie ist dennoch nicht darauf zu reduzieren. Es gibt, so meine These, einen Geist der Musik, den es herauszuarbeiten gilt.

Musik ist systematisch und wird gleichzeitig mit Gefühl, Ausdruck, Emotion und Rausch verbunden. Musik umfasst, durchaus nicht zufällig, zwei meist als Gegensatz konstruierte Dimensionen: Systematik und Rationalisierung einerseits, das Reich der Freiheit und des unmittelbaren Ausdrucks andererseits. Beispielhaft dafür steht der in der zweiten Hälfte des 20. Jahrhunderts ausgetragene Streit, bei dem es um die Trennung zwischen der sogenannten Eund U-Musik, um Kunst und Nichtkunst, um bürgerlich und nicht bürgerlich, um wertvoll und nicht wertvoll ging. Es war ein Kampf

1 »Tatsächlich ist sie eine universale Sprache und doch kein Esperanto: sie unterdrückt keine qualitativen Eigentümlichkeiten.« (Adorno 1973c: 350) 
um die Rechtfertigung von keineswegs nur musikalischen, aber sich in Musik ausdrückenden Haltungen der »Größe«, um die Regeln, nach denen etwas als »groß« bezeichnet und wahrgenommen werden konnte oder sollte (vgl. Boltanski et al. 2007). ${ }^{2}$ Hatte sich das »Ganze« der Gesellschaft für Adorno auch aufgelöst, so fand er es doch im »Werk «, in der Analyse der Partitur, weniger in ihrer musikalischen Reproduktion. ${ }^{3}$ Musiksoziologisch relevant ist der Kontext, in dem gearbeitet wurde und in dem die Werke entstanden - in dem etwa Debussy sich durch die »kleine Form« als französischer Komponist auszeichnet, der das »pathetische « der »deutschen « Musik, die »große Form« mithin, gegenübergestellt werden kann, aber auch, so ebenfalls Adorno, das fast völlige Verschwinden der $\mathrm{Mu}$ sik, also von Komponist und Werk, in England (vgl. Adorno 1973c: Kapitel X, Nation). ${ }^{4}$ Der Autor/Komponist entwirft ein Werk, schöpft die Möglichkeiten einer Systematik aus und erweitert, erneuert, dekonstruiert und rekonstruiert sie. Werk und Autor verhalten sich in einer Weise zueinander, wie sie Michel Foucault für den Text analysiert hat (vgl. Foucault 2001). Das Werk verweist zunächst auf den Willen des Subjekts, lässt als strukturell zu Analysierendes jedoch den Autor verschwinden

Adorno selbst war ein Autor der so genannten Ersten Moderne oder des »ästhetischen Essentialismus« (Bühl 1994). Er trauerte um das verloren gegangene Ganze, und sah im Werk eine letzte Möglichkeit einer individualisierten und doch objektivierbaren Rettung.

»Die Einheit der beiden Sphären der Musik ist danach die des ungelösten Widerspruchs. Sie hängen nicht zusammen etwa derart, dass die untere eine Art volkstümlicher Propädeutik für die obere ausmachte oder

2 Boltanski und Thévenot unterscheiden verschiedene Rechtfertigungsordnungen, die je eigene Gültigkeitsregeln besitzen und festlegen, was, d.h. welche Dinge, und wer, welche Subjekte, innerhalb ihres Anwendungsbereichs, ihrer »cité« mit »Größe« oder »Würde« ausgestattet werden (vgl. Boltanski/Thévenot 2007). Wie wichtig es ist, Dinge in diese Rechtfertigungsordnungen einzubeziehen, zeigt sich am Beispiel der Musik eindrücklich.

3 »Partituren sind nicht nur fast stets besser als die Aufführungen, sondern mehr als nur Anweisungen zu diesen; mehr die Sache selbst.« (Adorno 1973b: 153)

4 Die Bemerkungen Adornos finden sich im Kapitel X über die Nation. 
dass die obere ihre verlorene kollektive Kraft von der unteren ausborgen könnte. Aus den zersprungenen Hälften lässt das Ganze sich nicht zusammenaddieren, aber in jeder erscheinen, (wie sehr auch perspektivisch), die Veränderungen des Ganzen, [...]«(Adorno 1973g: 20).

Das Werk, so sehr Adorno an ihm festhielt, hatte seine tatsächliche oder ihm zugeschriebene Kraft der Repräsentation verloren, ohne dass eine andere Form an seine Stelle getreten wäre. Aus einer Welt, die Adorno verachtete, aber besser kannte, als ihm seine Kritiker attestieren, wurde ein neuer gesellschaftlicher Anspruch formuliert. Improvisation, das Reich des virtuos Improvisierenden »galt als Reich der Freiheit; hier war offenbar die starre Wand zwischen Produktion und Reproduktion gesprengt, die ersehnte Unmittelbarkeit wiederhergestellt, die Entfremdung von Mensch und Musik gemeistert aus vitaler Kraft« (Adorno 1973a: 796f.). Eine Freiheit, die Adorno zufolge nichts als Trug war, was er im Übrigen nicht nur für die Improvisation des Jazz konstatierte, sondern auch für den improvisierenden Orgelspieler. ${ }^{5}$

Der Hörer, der Amateur und der Jazzkenner, der Stile und Bands differenziert, deren Geschichte kennt und sich identifiziert, »als handele es sich um die Heilsgeschichte«, werden von Adorno in diesen Taumel der vorgestellten und behaupteten Freiheit, die doch nichts als Anpassung sei und gerade deshalb seinem Verdikt verfällt, einbezogen. Denn der Amateur wie der Experte

»steht dem Sportsmann am nächsten: wenn nicht dem Fußballspieler selbst, dann dem schwadronierenden Gesellen, der die Tribünen beherrscht. Er glänzt durch Fähigkeit zur rüden Improvisation, selbst wenn er insgeheim stundenlang Klavier üben muß, um die widerspenstigen Rhythmen zusammenzubringen. Er gibt sich als der Unabhängige, der auf die Welt pfeift. Aber was er pfeift, ist ihre Melodie, und seine Kniffe sind weniger Erfindungen des Augenblicks als aufgespeicherte Erfahrung aus dem Umgang mit den umworbenen technischen Dingen.

5 So schreibt er zum in der leer gewordenen Kirche improvisierenden Organisten: »[...] anstatt mit der Kraft der Improvisation, wenn sie noch Kraft ist, hinüber zu schlagen in ein frisches Phantasiebereich der Freiheit, konserviert er die Formen, die ihn nicht mehr tragen und die er nicht mehr füllt, gießt die breiten improvisatorischen Ströme hinein, die nicht die Wände schmelzen, sondern zäh darin erkalten« (Adorno 1973d [1927]: 94). 
Seine Improvisationen sind allemal Gesten der behenden Unterordnung unter das, was der Apparat von ihm verlangt. Der Chauffeur ist das Vorbild für den Hörtyp des patenten Kerls. Sein Einverständnis mit allem Herrschenden geht so weit, daß er gar nicht erst mehr Widerstände produziert, sondern von sich aus bereits je und je das leistet, was von ihm verlangt wird um des zuverlässigen Funktionierens willen. Er lügt sich die Vollkommenheit seiner Unterordnung unter den verdinglichten Mechanismus in dessen Beherrschung um. So ist die souveräne Routine des Jazzamateurs nichts anderes als die passive Fähigkeit, in der Adaption der Modelle von nichts sich irremachen zu lassen. Er ist das wahre Jazzsubjekt: seine Improvisationen kommen aus dem Schema, und das Schema steuert er, die Zigarette im Mund, so nachlässig, als hätte er es gerade selber erfunden.« (Adorno 1973g: 43)

Nichts als »rüde Improvisation«, stundenlang eingeübte und reproduzierte Synkopen, nichts als Schema. Adorno erkennt nicht die erst nach beständigem Training individuell und elegant werdende Flanke, sieht nur rüde Fouls, nicht die Abweichung von der Regel, die durch deren Beherrschung erst möglich wird. Noch in der Dissonanz sieht er nur eine die Regel bestätigende Verletzung.

»Wohl kommen in der Jazzpraxis Dissonanzen vor, und selbst Techniken des absichtsvollen Falschspielens haben sich herausgebildet. Aber allen diesen Gepflogenheiten ist eine Unbedenklichkeitsbescheinigung mitgegeben: jeder extravagante Klang muß so beschaffen sein, dass der Hörer ihn als Substitut für einen >normalen< erkennen kann; und während er sich an der Misshandlung freut, welche die Dissonanz der Konsonanz angedeihen lässt, für die sie eintritt, garantiert die virtuelle Konsonanz zugleich, dass man im Kreise verbleibt.« (ebd.: 38)

\section{Auf der Suche nach einem Ausweg}

Axel Honneth hat jüngst Adorno als eine Fortschreibung Max Webers gelesen (Honneth 2005). Liest man Weber mit gutem Recht als Beschreibung und Analyse einer fortschreitenden und ausweglosen Rationalisierung und Bürokratisierung und lässt man auch Adornos Analysen im Verhängnis des zur Unfreiheit aufgelösten Ganzen enden, ließe sich dieser Befund auf eine unbefriedigende Art bestätigen. Aber es lässt sich mehr Münze aus beiden schlagen. Denn Max Weber greift das Problem des Zusammenhangs von Freiheit und Ra- 
tionalität an einem überraschenden Punkt auf: in seiner Fragment gebliebenen Musiksoziologie. ${ }^{6}$ Bestätigt ein erster Blick zunächst die Fähigkeit Webers, sich die zeitgenössische Musiktheorie und Harmonielehre anzueignen, auch einen kulturvergleichenden Blick auf Formen mehrstimmiger Musik zu werfen und schließlich am musiktheoretischen Material seine Rationalisierungsthese zu verifizieren, so weist er doch darauf hin, dass gerade die Rationalisierungsvariante der europäischen Musik einen nicht rationalisierbaren Kern enthält. Es stellen sich immer wieder Spannungen in der Beziehung von (musikalischer) Rationalisierung und ihr widerstrebendem (musikalischem) Leben der Töne ein. Wie Christoph Braun gezeigt hat, sind es die »Widersprüche und Spannungen zwischen Ratio und Emotion, Akkordharmonik und Melodik, Theorie und Praxis, ja selbst einzelnen (benachbarten) Tönen « (Braun 1994: 11), die die Musikstudie charakterisieren. Mathematisch genau lässt sich fassen, dass die abendländisch rationalisierte Musik nur noch ein reines Intervall - die Oktave - beinhaltet. Die Unreinheiten verteilen sich durch den Kompromiss der temperierten Stimmung auf die Töne innerhalb der Oktav. Noch die als »rein« bezeichneten Intervalle, »reine Quart « und »reine Quint«, sind dies nicht im mathematisch/physikalischen Sinn. Ihre Bezeichnung ist Sprachkonvention. Der nicht rationalisierbare Rest ist es, der Weber fasziniert. ${ }^{7} \gg$ Die Musik wird für die Webers zur Metapher für das Leben « (Radkau 2005: 546). Marianne Weber beschrieb das musikalische Gesetz als »nicht in Formeln zu fassen und nicht definierbar doch in jeder

6 Max Webers musiksoziologische Schrift wurde zunächst 1921 unter dem Titel: Die rationalen und soziologischen Grundlagen der Musik veröffentlicht. Ein Manuskript existiert nicht. Von 1925 bis 1956 wurde es als Anhang von Wirtschaft und Gesellschaft gedruckt, ab der fünften Auflage aber entfernt und 1972 separat veröffentlicht. Diese Ausgabe allerdings ist seit längerem vergriffen. Eine amerikanische Übersetzung erschien 1958, die jüngste kommentierte und eingeleitete Ausgabe ist ein großer Fortschritt (siehe Weber 2004 [1921]). Auf die Arbeit von Braun muss hingewiesen werden, da sie Webers Musikschrift endlich den Platz eingeräumt hat, der ihr zusteht und ohne die ich diese kurzen Anmerkungen gar nicht hätte machen können (vgl. Braun 1992).

7 Weber geht immer wieder auf antike und nicht-europäische Tonsysteme ein. Aber auch in der Musiksoziologie interessiert ihn der europäische Fall. Vgl. hierzu in Bezug auf die Musiksoziologie Kurt (2006). 
Composition walte[nd]« (ebd.). Für Max Weber aber war es das Gesetz selbst, das an seine rationalen Grenzen stieß. Die Form des sich im zwölften Schritt zum Kreis schließenden Quintenzirkels entspricht nicht der Schichtung mathematisch/physikalisch reiner Quinten, die sich eben nicht zur siebten Oktave schließen. Die mäBig grobe Verstimmung der temperierten Quint ist eine Scheinlösung. Und schließlich entsteht Musik im Umgang mit der Regel, nicht durch deren bloße Ausführung, durch Veränderungen, die auch eine Verletzung der Regel einschließen. ${ }^{8}$ Sie enthält in sich selbst das Material zur Freiheit. Form und Freiheit, so kann man es kurz zusammenfassen, bilden einen Zusammenhang.

Max Weber bezog sich in seinem Fragment zur Musiksoziologie auf »Texte«, nicht auf musikalische Praxis. Theodor W. Adorno stellte das Werk und damit letztlich die Partitur als Text in den Mittelpunkt. Auch bei ihm lassen sich Andeutungen finden, die den $\mathrm{Zu}-$ sammenhang von Regeln und Handeln, von Form und Freiheit betreffen. Sein Misstrauen gegen die angebliche Freiheit der Improvisation war sachlich durchaus berechtigt. Es gibt Improvisation nicht ohne Regel, ohne Regelbezug, ohne Form. Adorno wurde dies zum Vorwurf an die Improvisation im Jazz, die doch nur zur Konvention und Standardisierung führe (und teilweise geführt hat) und Marktgesetzen gehorche. Er konnte das Verhältnis von Regel/ System/Form und Improvisation nur in ihrer Gegenüberstellung deuten und warf der Improvisation Mangel an Freiheit vor, der schließlich noch in der Dissonanz die Harmonie bestätige.

Dabei setzte Adorno das Mittel der Improvisation selbst als Schreibtechnik ein, als Einfall und Variation mit durchaus systematischem Anspruch. Hierfür steht seine Textsammlung, die unter dem Titel »Improvisationen « seinem Fragment über Musik und Sprache eingegliedert ist, kurz und prägnant geschrieben, im Moment abgefasst, über die Jahre gesammelt und schließlich zusammengesetzt. $\mathrm{Zu}$ erwähnen sind auch die Assoziationen und Improvisationen, die unter dem Titel Minima Moralia berühmt wurden. In diesen findet

$8 \gg$ Regel« ist noch nicht »Recht «, das zu seiner Durchsetzung »Personal« verlangt, noch sind »Regel « und »Recht « schon »soziales Leben«. Weber richtet sich gerade gegen die »stete Gefahr der hoffnungslosen Konfusion des Empirischen mit dem Normativen« (Weber ${ }^{4}$ 1973: 343). Regeln sind nicht schon selbst die Form des Sozialen, sondern Bestandteil, Komponente sozialer Wirklichkeit. 
sich der Satz: »Die älteren, nicht auf Massenproduktion berechneten Medien gewinnen neue Aktualität: die des Unerfaßten und der Improvisation. Sie allein könnten der Einheitsfront von Trust und Technik ausweichen.« (Adorno 1973e: 56) Hier, Adorno-typisch eben: nur hier, ließe sich ein Ausweg als ein eventuelles Ausweichen erkennen, ein Weg, den Adorno allerdings nicht in der im 20. Jahrhundert schließlich bekanntesten und erfolgreichsten Improvisationsmusik, dem Jazz, verwirklicht sah. Aber das »Unerfasste und die Improvisation « wurden gleichwohl in der neuen Welt der sich verwirklichenden Moderne zu wichtigen Ausdrucksmitteln und geradezu zu notwendigen Fähigkeiten. In der flüssigen und flüchtigen Welt (vgl. Baumann 2003, 2007) entstanden neue Formen der $»$ musikalischen Leidenschaft« (Hennion 1993). Einerseits bildeten sich die Muster des ästhetischen Urteils und der Praxis des Hörens in der Produktion gesellschaftlicher Differenzen ab, und andererseits veränderte sich die Praxis des Musikmachens, der Produktion und Reproduktion. Die Einheitlichkeit des rationalisierten europäischen Systems globalisierte und veränderte sich in ebendiesem Prozess. Die bürgerliche Praxis des von Alfred Schütz beschriebenen »Making Music Together « (Schütz 1951) verschwand in eine Nische; es entstanden viele weitere Nischen, und einige Musikstile wurden geradezu zu Identitätsmarkern sich ausdifferenzierender Gruppen.

\section{Zum Verhältnis von Regeln und Freiheit}

Das Thema kann nun genauer formuliert werden. Die Beschreibung von Regeln ist noch nicht die Beschreibung des Handelns und der Praxis. Handeln ist eingebettet in teils explizite Regeln, ganz deutlich etwa in Vorschriften, und in Praktiken, die mit mehr oder weniger impliziten Erwartungen und schließlich Erwartungserwartungen verbunden sind. Über die Gültigkeit der Regeln entscheiden Herrschaft als Möglichkeit, ein bestimmtes Handeln anderer regelmäßig bewirken zu können, und Anerkennung als Einverständnis. Wenn auch in unterschiedlicher Weise, so teilen die soziologischen Handlungstheorien den Blick auf wodurch auch immer bedingtes, aber schließlich zu erwartendes Handeln, auf Wiederholungen, Wiederkehrendes und Typisches, auf Kulturen, zu denen man gehört, Systeme, die ihre spezifische Form der Kommunikation und Codierung 
und der Inklusion und Exklusion ausbilden, Gruppen, in die man hinein sozialisiert wird oder die sich auflösen.

So sehr auf den subjektiv gemeinten Sinn abgestellt wurde, war er doch typologisch aufzulösen. In der Typologie war für die Überraschung kein Platz und schließlich wurde auch die Individualisierung als strukturelles Phänomen der entwickelten Moderne beschrieben. Es ist die Anforderung an den Einzelnen, sich als Individuum zu entwerfen und sich aus den Bausteinen, die von der Illusion des Ganzen der Gesellschaft übrig blieben, zusammenzusetzen. Hieraus aber ergibt sich eine weitergehende Anforderung für die Handelnden und für die soziologische Analyse. Handeln ergibt sich nicht, zumindest nicht mehr ausschließlich, aus der Analyse des Kontexts, aus den Märkten, Institutionen, Organisationen, vorgegebenen Handlungsentwürfen, schließlich auch den sozialen Gruppen und Kulturen, sondern beinhaltet zudem eine »aktive und reflexive Selbstproduktion von Werten« (Hennion et al. 2000: 348). In der modernen, nationalen Gesellschaft war Selbstthematisierung zu einer notwendigen und systematischen Anforderung geworden, die zunächst von Wissenschaft, Literatur und Kunst übernommen wurde, die, obwohl sie sich vor allem auf sich selbst beziehen, beständig die Frage nach dem »Ich« und dem »Wir« nicht nur stellten, sondern verbindlich und autoritativ $\mathrm{zu}$ beantworten suchten (vgl. Bielefeld 2003). Die Anforderung zur Selbstthematisierung ist nicht verschwunden, sondern verlagerte sich von der Passivität der Ausführung zur Aktivität der Selbstproduktion und verallgemeinerte sich im gleichen Prozess als eine Anforderung, die nun zumindest im Prinzip jeder erfüllen sollte. Sie wurde zu einer Aufgabe des Einzelnen.

Nunmehr ist es nicht das bürgerliche Subjekt z.B. des Komponisten als »Meister«, der System, Entwurf und Ausführung aus sich selbst heraus entwirft und beherrscht, und auch nicht mehr ein System, das in diesem Fall die musikalische Praxis bestimmt. Die klassische Moderne als organisierte Moderne, als eine, die versuchte, Regel, System, Entwurf einerseits, Praxis, Handeln, Ausführung andererseits möglichst nah zueinander zu bringen und vielerlei Anstrengungen unternahm, diese zur Deckung zu bringen, brachte konsequenterweise eine Avantgarde hervor, die bei aller Kritik das Prinzip nicht nur teilte, sondern zu perfektionieren suchte. Im Fall der Musik kann beispielhaft auf die Zwölftonmusik als großem Systematisierungsentwurf hingewiesen werden. Das Musikerlebnis, von 
Alphons Silbermann in den Mittelpunkt der Musiksoziologie gestellt, war auch hier an den möglichst genauen Nachvollzug des Entwurfs durch die Musiker, und, idealerweise, eine partiturlesende Hörerschaft gebunden. Das Ideal der technischen und gesellschaftlichen Rationalität als Modell der Gesellschaft der klassischen Moderne bildet sich exemplarisch in Form eines ästhetischen Modernismus ab. Auch in dieser Situation findet sich der »gelungene Moment«, von dem Musiker und Zuhörer berichten und den man bei einigem Glück und wiederholten Versuchen, an ihm teilzunehmen oder ihn (mit anderen) herzustellen, selbst erfahren kann. Musik und auch musikalisches Handeln als Musizieren und Hören scheinen Universalität und Partikularität auf besondere Art verbinden zu können. Ihre besondere Form einer immateriellen Materialität eröffnet weite Felder, die mit »Wahrheit«, mit dem »wahren Moment des als richtig empfundenen Tons oder gar mit der des abendländischen $»$ Werks « verbunden werden konnte und gleichzeitig das individuelle »Musikerlebnis« und die Erfahrung des »Wir-Gefühls« in der Erlebnisgemeinschaft ermöglicht. Das Ideal der Avantgarde entfernte sich von dieser Situation. Der Konstruktivismus etwa der seriellen Musik der 50er und 60er Jahre wurde gerade durch seinen Rationalismus esoterisch, d.h. entfernte sich sowohl von Ausdruck als auch vom Publikum. ${ }^{9}$ Er kann als Höhepunkt der klassischen Moderne verstanden werden, realisiert zu einer Zeit, als dessen Niederlage in anderen Bereichen nicht nur eingeleitet, sondern längst aktenkundig geworden war.

»Neotonale « Konzeptionen können als eine interne Reaktion auf diese Entwicklung verstanden werden, in der Intensität, Ausdruck und Hörerlebnis erneut Bedeutung bekommen. Ganz unabhängig hiervon aber hatte sich die moderne gesellschaftliche Situation selbst verändert und mit ihr das moderne Ideal des Verhältnisses von Form und Freiheit, von Regeln und Handeln. Ganz entscheidend veränderte sich der gesellschaftlich und kulturell bestimmte Entwurf dessen, was ein Subjekt ist. Ist es für die organisierte Moderne der Begriff der Souveränität, der einerseits politisch behauptet und realisiert werden soll und sein Ideal im souveränen Staat gefun-

9 Den Bruch von »großer Musik und Gebrauch« legte Adorno schon in die Mitte des 19. Jahrhunderts. Verantwortlich machte er die »manipulierten und zugleich selbstzufriedenen Bedürfnisse des bürgerlichen Publikums « (Adorno 1973f: 15). 
den hat, der andererseits aber auch das Ideal des unabhängigen, über sich selbst bestimmenden Subjektes ausmacht, ein Verhältnis, das noch durch das sich im souveränen Staat realisierende Kollektivsubjekt als souveränes Volk gesteigert werden konnte, so erodieren beide Strukturen in der zweiten Hälfte des 20. Jahrhunderts. Blieb das Souveränitätskonzept auf der Ebene der nationalstaatlichen Ordnung institutionell erhalten und wurde gar zum allein gültigen weltgesellschaftlichen Modell der Anerkennung verallgemeinert, so verändert es sich dennoch faktisch auf allen Ebenen, d.h. militärisch, ökonomisch und kulturell. Kurz gefasst handelt es sich um eine Verschiebung vom Konzept der Selbstbestimmung zu dem der Selbstverwirklichung als soziale Anforderung. Die Form der Selbstthematisierung verändert sich und das Subjekt selbst wird zu einem ihrer Akteure. Es ist nicht mehr das sich über die Aneignung einer allgemeinen Moral, Bildung und Verantwortung realisierende souveräne und universale bürgerliche Subjekt, sondern das sich schließlich in Gruppenzusammenhängen verwirklichende Individuum, das sich in Differenzierung (von anderen Gruppen) und einer nun gruppenbestimmten Selbstbeobachtung entwerfen muss. Es kommt nun auf die Performance an, den öffentlichen Selbstentwurf, der nach außen gerichtet zeigt, dass man dazugehört, weil man sich unterscheidet.

Musik bekommt in dieser Form von Gesellschaft nicht nur deshalb eine besondere Bedeutung, weil sie zu einem wichtigen ökonomischen Bestandteil der Kulturindustrie wurde, und - etwa im Falle Englands - sogar das Potential hatte, die klassische Industrie in ihrer strukturellen Bedeutung abzulösen, oder weil sie nun ubiquitär vorhanden war, sondern auf Grund ihrer strukturellen Bedingungen, ihrer eigenen spezifischen Form der Materialität. Denn sie ist keine Sprache, aber man kann trotzdem mit ihr kommunizieren; sie ist je unterschiedlich äußerst rationalisiert und ihre Ausübung fordert meist lange Sozialisations- und Lernprozesse, doch geht sie nicht in dieser Rationalisierung auf; Musik kann konzipiert werden als »unmittelbar den Willen selbst « darstellend, als »universalia ante rem «, wobei das »unaussprechlich Innige aller Musik « dann darauf beruht, »dass sie alle Regungen unseres innersten Wesens wiedergibt, aber ganz ohne die Wirklichkeit und ohne die Qual« (Schopenhauer 1971: 310f.). Sie kann, wie im abendländischen Fall der akademischen Musik, sich in der Überhöhung des Werks eines Individuums, eines Werks, das sich in der Partitur exemplarisch mate- 
rialisierte und im Komponisten den exemplarischen Typus des bürgerlichen Subjekts als souveränem Schöpfersubjekt fand, realisieren, aber sie verselbständigt sich doch in der Aufführung und in der Interpretation vom Autor. Sie ist »kulturabhängig «, von der Eingewöhnung und den Gewohnheiten bestimmt, sie ist aber dennoch »universal«. Sie bietet damit einen spezifischen Code, der gerade in der Möglichkeit der Variationen des Zusammenhangs von Regel und System einerseits, von möglichen Sinnunterstellungen, Ausdruck, Emotion und Bedeutung andererseits liegt, ohne dass man sich darüber einigen könnte, was denn mitgeteilt wird. Dennoch kann sie, wie es sich am Beispiel der Filmmusik zeigen lässt, spezifische Informationen nicht nur verstärken, sondern präpariert sie im gelungenen Fall erst heraus, ist also keineswegs nur unterstützend. Ohne die Koppelung mit den (Film-)Bildern aber »verallgemeinert « sich die Musik erneut. Mit der gleichen Musik, nun ohne die Bilder, werden individuell ganz unterschiedliche Bilder assoziiert und die Eindeutigkeit löst sich wieder auf.

$»$ Musik «, »Musik machen« und »Musik hören« nimmt so eine besondere Rolle ein. Denn einerseits ist kaum ein anderer Bereich so extrem theoretisch und praktisch formalisiert und gleichzeitig durch die Entwicklung von Technik bestimmt, man denke nur an Max Webers Analyse der Harmonielehre und seine Beschreibung der Bedeutung des Klaviers als »bürgerliches Möbel«, andererseits sind die Freiheitszuschreibungen, Erwartungen und Unterstellungen in kaum einem Bereich gesellschaftlichen und sozialen Handelns höher als gerade in der Musik. Das gilt auf der Ebene der Zuschreibung von Bedeutungen des Gehörten, die einerseits eine hohe Varianz haben und daher kaum mit Sprache verglichen werden können, andererseits gerade im Zusammenhang mit Bildern (Filmmusik), die gezielt für die Erweckung bestimmter Assoziationen, Bedeutungen und Gefühle eingesetzt werden können. Dies gilt aber auch auf der Ebene der Praxis, des Musizierens und Komponierens (in einem weiten Sinn von Vorgaben). Einerseits werden extreme Spezialisierungen ausgebildet, die mit früher Sozialisation, Ausbildung und entsprechender institutionellen Ausdifferenzierung verbunden sind, andererseits aber ist das Musizieren zumindest dann, wenn es sich von religiös-rituellen Praktiken teilweise oder ganz gelöst hat, verweltlicht und daher prinzipiell und schließlich auch tatsächlich abhängig von den sich vervielfältigenden Möglichkeiten der heute jederzeit und überall möglichen Reproduktion. Musik hat sich in ei- 
nem hohen Grade veralltäglicht. Damit aber veränderte sich erneut der europäisch ausgebildete Zusammenhang von Ton und Musik, Note, Schrift und System, Instrument und Technik. Die etwa beobachtete Rückkehr des Amateurs steht in diesem Kontext. Sie kann zwar als Banalisierung gewertet werden, aber sie ist zumindest auch anderes. Sie gehört zu einer veränderten Praxis des Hörens und Machens in Heimstudios, in ehemals industriellen Räumen, die als Proberäume und Studios, als Clubs und Treffpunkt genutzt werden und der Mischung mit anderen creative industries.

\section{Die >freie Improvisation<}

»In meiner akademischen Musikausbildung spielte Improvisation keine Rolle«, so begann kurz und prägnant ein Gespräch, das ich mit Dietmar Wiesner führte. ${ }^{10}$ Zwar lässt sich gerade in der alten Musik die Bedeutung der Improvisation zeigen, dennoch gilt, dass Text und Spielanweisungen in der europäischen Musik immer genauer wurden. Musiker werden ausgebildet, ihr Instrument, die Literatur, den Kanon und, zumindest grundlegend, die Harmonielehre bzw. -lehren zu beherrschen. Gelernt werden soll die Fähigkeit zur möglichst exakten Reproduktion einer Vorlage. Nicht Improvisation, sondern Interpretation stellt den begrenzten Raum der Möglichkeiten, den Spielraum dar. Die Fähigkeit zur Improvisation wird innerhalb des Rahmens meist als nicht geforderte, sondern als besondere individuelle Zusatzfähigkeit, die dann als zusätzlicher Ausdruck der Virtuosität gewertet wird, angesehen. Es ist wenig überraschend, dass der Herrschaft des Systems und der Reproduktion nicht die Improvisation, sondern die explizit als frei gekennzeichnete Im-

10 Ich benutze im Folgenden immer wieder Hinweise und, wenn wörtlich übernommen, durch Anführungszeichen und ohne weitere Angaben gekennzeichnete Zitate aus einem Gespräch mit dem Querflötisten und Komponisten Dietmar Wiesner, Mitbegründer (1980) und Mitglied des Ensemble Modern (siehe www.ensemble-modern.com). An einer traditionellen Musikhochschule (Detmold) ausgebildet, beschäftigt(e) er sich vor allem mit der Musik des 20. Jahrhunderts. Das Ensemble Modern ist ein unabhängiges, von den Musikern als Gesellschaftern getragenes Ensemble. Es arbeitet häufig direkt mit Komponisten (u.a. mit Heiner Goebbels, Frank Zappa, Bill Viola oder Steve Reich) zusammen und konzertiert weltweit. 
provisation gegenübergestellt wird. Diese kann als Möglichkeit in die Ausbildung aufgenommen werden und wird dann ebenso explizit mit der Forderung verbunden, die Schemata und die Systeme einmal beiseitezulassen. Die betonte, behauptete Ungebundenheit ist die andere Seite der Gebundenheit, die sie dennoch bestätigt.

Das Akademische aber kann innerhalb oder außerhalb der Institutionen durch einen persönlichen Teil ergänzt werden, durch den Versuch, sich die Möglichkeit zu schaffen, einfach mal draufloszuspielen. Eine systematische Möglichkeit hierzu bietet der Free Jazz, der ebenso mit dem zusätzlichen Hinweis darauf, frei zu sein, sich von den Standards abhebt und auch davon, sich nicht mit der Reproduktion und Variation von Skalen zu begnügen. Vorbilder sind dann etwa Archie Shepp oder Cecil Taylor. Im Fall des erfolgreichen Berufsmusikers wird dieser Übergang keineswegs nur als musikalische Befreiung, sondern auch als eine soziale beschrieben. »Dadurch, dass ich im Free Jazz aufgegangen war und das für mich, in meinem Rahmen, eine Befreiung war, war es für mich eine logische soziale Folge, das Ensemble Modern mitzugründen.« Das Betreten der anderen Seite ermöglicht als Lösung von der Konvention einen weiteren unkonventionellen und riskanten Schritt, hin zu einer Musik, die einerseits mittlerweile eine hohe Anerkennung bei Spezialisten genießt, die andererseits selbst praktisch der Improvisation nur einen sehr begrenzten Raum zur Verfügung stellt: »Ich war nie ein Freund von Standards « lässt sich auf den Jazz beziehen, aber eben auch auf das Verlassen des konventionellen Weges. Improvisation ist mit dem Verlassen des Regelhaften verbunden, nimmt es aber immer wieder auf. In der Neuen Musik aber ist sie jedoch ebenso systematisch eingeschränkt. So wird etwa ein Kästchen mit Noten und Rhythmen vorgegeben, die zu benutzen sind; es wird mit Plus- oder Minuszeichen (z.B. für lauter, leiser) gearbeitet, d.h. mit vorher festgeschriebenen Parametern. Die Improvisation kann der Erarbeitung von Material dienen, aus dem ein Stück geformt wird. Man nimmt dann Elemente des »gewussten «, schon gespielten Materials als Klischees und »arbeitet« mit ihnen. »Die Freiheit muss man sich erarbeiten.«

Allerdings spielt die Improvisation im Alltag der Neuen Musik, die ja gerade durch ihre wenn auch veränderte systematische Struktur bestimmt ist, nur eine untergeordnete Rolle. So ist es ein Kennzeichen des Ensemble Modern, nicht nur zunächst eine Partitur zu erarbeiten, sondern zum Teil mit dem Komponisten eng zusammen- 
zuarbeiten. Die notierte Fassung der Partitur kann so weiter erläutert, die Umsetzung diskutiert und die Hinweise können umgesetzt werden. Der Typus des Komponisten als Schöpfer eines Werkes, das von Musikern umgesetzt wird, wird so einerseits exemplarisch bestätigt - mündlich kann präzisiert werden, was gemeint ist -, andererseits zeigt die Praxis den größeren oder kleineren, aber immer verbleibenden Rest des Nichtnotierbaren auf.

Keineswegs typischerweise, wenn auch wiederholt und nicht zufällig, arbeitete das Ensemble Modern mit Komponisten/Musikern, bei denen Improvisationstechniken eine besondere Rolle spielen. Neben Ornette Coleman, Fred Frith und Heiner Goebbels war dies Frank Zappa. Die (Proben-)Arbeit Zappas wird im Gespräch zunächst als durchaus klischeehaft beschrieben. Bass, Schlagzeug und Klavier halten eine Grundstruktur, über die improvisiert werden kann. Ziel sei es gewesen, sich »leer zu spielen«, um dann interessantes neues Material zu entwickeln. Der »Komponist« beobachtet diesen Prozess, die Sprache des einzelnen Musikers, um dann an die Grenzen des Könnens des Einzelnen gehende Stücke zu erarbeiten. Die Improvisation ist Mittel zum Zweck, die Möglichkeiten zu erfahren, zu dokumentieren und mit ihnen zu arbeiten, sie zu strukturieren. Sie bildet in diesem Fall »den Nukleus für das kompositorische Material«. Als Beispiel kann das Stück »Get Whitey« dienen. Es hat als Basis eine lange Improvisation über C-Dur, der »Komponist « wird schließlich zum Arrangeur des improvisierten Materials. ${ }^{11}$ Die freie Improvisation, den oder die ausgebildeten oder »fertigen« Musiker oder Musikerin voraussetzend, der oder die sich von seinem/ihrem Material, seinen/ihren Spielgewohnheiten löst, ist der systematischen Arbeit nicht entgegengesetzt, sondern sie wird zu ihrem Bestandteil. Auch improvisatorisch erarbeitete Stücke sind wiederholbar und gleichen einander, sie sind dieselben, wenn sie z.B. auf einer Konzertreise Abend für Abend gespielt werden. Improvisationen haben den ihnen zugeschriebenen flüchtigen Charakter durchaus verloren. Nicht nur, weil sie sich als Technik etabliert haben und durchaus selbst einen eintönigen, sich wiederholenden Charakter bekommen können, der, mit Adorno formuliert, schließlich die Regel noch in der Abweichung bestätigt, sondern weil sie durch verfeinerte Techniken der Reproduktion zum materialen Aus-

11 Das Stück befindet sich auf: Frank Zappa und Ensemble Modern (1993): The Yellow Shark. Dirigenten: Frank Zappa und Peter Rundel. Rykodisc. 
gangspunkt der Strukturierung werden können. Ein Beispiel, wiederum aus Frank Zappas Arbeit, mag dies verdeutlichen: das Instrumentalstück »Revised Music For Guitar and Low Budget Orchestra « hat als Bestandteil einer komplexen Struktur ein improvisiertes Solo. ${ }^{12} \gg$ Er [Frank Zappa, d.V.] spielte sein Solo auf einer akustischen Ovation-Gitarre, die mit Darmsaiten bespannt war und deren Tonabnehmer direkt ins Mischpult führte. Anschließend transkribierte Bruce Fowler [Posaunist schon früherer ZappaFormationen, d.V.] das Solo Ton für Ton und verdoppelte es, indem er mittels Overdubs eine Vier-Posaunen-Harmonie daraus machte, inklusive aller gebundenen Töne. Durch diesen Effekt klang das Ganze wie eine Gitarre, aber mit Blechbläser-Sound « (Miles 2005: 309f.). ${ }^{13}$ Alles je gelungen Gespielte kann zum Material gemacht werden, wird als Probehandeln Ausgangspunkt für weiteres, für Festlegungen und Veränderungen. Aber es gilt dann auch: Die Improvisation ist die Komposition, sie ist schon im Spiel als solche angelegt und wird vor allem im Nachhinein so behandelt. Der Musiker probiert aus, beobachtet sich beim Spiel oder wird beobachtet, Entwickeltes wird verworfen oder weiterverfolgt. Das improvisierend Gefundene wird unterlegt, kann auseinandergenommen und mit anderem Material verbunden werden. Bekommt es einen Titel, ist ein Stück entstanden und es wird schließlich als »composed, arranged \& conducted by Frank Zappa « veröffentlicht. ${ }^{14}$

12 Zu hören auf: Frank Zappa (1978): Studio Tan. aufgenommen 1974-76, Bizarre.

13 Man findet in dieser interessanten Biographie genauere Beschreibungen der Arbeitsweise Zappas, die auch in ökonomischen Zusammenhängen zu sehen ist. Seine ausgedehnte Probenarbeit, der Mitschnitt der Konzerte, das Zusammenfügen der Stücke zur Veröffentlichung aus unterschiedlichen Konzerten ist gleichzeitig ökonomische und kompositorische Praxis. Auf die ausgedehnte Zappa-Literatur kann ich hier nicht eingehen. Vgl. auch Reichert 2000; als musikwissenschaftliche Untersuchung zur Struktur der Musik: Ludwig 1992 und vor allem zum Performancestil Zappas: Hitzler 1985 und 1994.

14 Ein Beispiel etwa ist das »schöne«, »eingängige« zehnminütige Stück »Watermelon In Easter Hay« (Joe's Garage, Act III. Zappa Records, CBS, 1979). Für Big Band arrangiert findet es sich auf der CD der NDR-BigBand zusammen mit Colin Towns (2005): Frank Zappa's Hot Licks (And Funny Smells) - Live 2004. Provocateur. 
Das Verhältnis von Improvisation und Komposition ist kein Gegensatz. Nicht nur der Komponist setzt sich bei der Arbeit an den Flügel, um etwas auszuprobieren, sondern Komponieren ist ein arbeitsteiliger Prozess geworden, der u.a. die zwar situativ flüchtige, aber festhaltbare und verwertbare, bearbeitbare Improvisation beinhaltet. Das »Werk « ergibt sich nicht mit der erstellten Partitur, sondern aus den Notationen, den Proben, den Aufnahmen, den Konzerten und den unterschiedlichsten Formen der Verarbeitungen und Verbindungen des Gesamtmaterials. Der Komponist, Arrangeur, Musiker, Tonmeister und Toningenieur verfügt in diesem Fall über die musikalische, nach langen rechtlichen Auseinandersetzungen schließlich unternehmerische, verlegerische und technische Kompetenz und Ausstattung, ein Werk vorzulegen, das Rock, Jazz und Neue Musik verbindet.

Dietmar Wiesner vergleicht im Gespräch die Arbeit mit Frank Zappa mit einem späteren Projekt des Ensemble Modern mit indischen Musikern. Diese haben $»$ ihre Ragas im Kopf $\ll .{ }^{15}$ Sie versuchten sie in der Zusammenarbeit als graphische Modelle, als Bilder zu beschreiben und zu vermitteln, damit ein gemeinsames Spiel möglich wurde. Allerdings handele es sich weniger um Improvisation als um ein »intelligentes Variantenwerk«, vergleichbar mit den im Kontext der Thematisierung von Improvisation gern genannten barocken Ornamenten, zu denen bereits Adorno anmerkte:

»Sieht man von der Orgelimprovisation ab, so hat sich selbst in dem von Berendt [dem Jazztheoretiker und Kritiker, d.V.] glorifizierten >Barock $<-$ nichts ist weniger Barock als die so genannte Barockmusik - die Improvisation mit der Ausführung des Generalbasses, der ornamentalen Umkleidung der Harmonie begnügen müssen, ohne je die musikalische Substanz zu ergreifen. Mit den Jazzimprovisationen steht es kaum anders. «(Adorno 1973h: 806) ${ }^{16}$

15 Wie sie in den Kopf gelangen, zeigt der Dokumentarfilm von Ronald Kurt (2006): Be a Medium. Teaching and Learning Indian Classical Music. München: Allary Film TV \& Media.

16 Eine soziologische Analyse der Auseinandersetzungen von »Modernisten« und Traditionalisten über den »Klang« der Barockmusik findet sich bei Hennion (1993). Mit seiner Bemerkung stellt sich Adorno auf die Seite der Modernisten, Barockmusik sei eine Erfindung des 19. und 20. Jahrhunderts. Die Frage ist, wie man einen Klang, den man nicht kennt, rekonstruiert? Mit Michel de Certeau ist die Rückkehr zu den Quellen immer auch eine mo- 
Für Adorno hatte sich die »große Musik, die heute noch spricht die >lebendige $<-[\ldots]$ gebildet, seitdem die Improvisation zurücktrat und dem fixierten Kunstwerk mit eindeutigem Text Raum schuf« (ebd.).

Es ist jedoch eben die behauptete, vorgestellte und zu realisieren gesuchte Eindeutigkeit, die sich als moderne Illusion erwies. Ihr wurde für eine gewisse Zeit die Illusion der freien Improvisation gegenübergestellt. Musik als notierter Text wurde dadurch keineswegs hinfällig, wohl aber ihr Anspruch auf alleinige Gültigkeit. Auch die Wege zum »Text« haben sich durch veränderte Praxis einschließlich der veränderten technischen Möglichkeiten gewandelt. Dies schließt Komponieren, Musizieren und Hören ein. Alle drei Komponenten können weiterhin getrennt durchgeführt werden. Aber das Hören heute lässt sich nicht mehr mit dem Hören bis ungefähr zur zweiten Hälfte des 20. Jahrhunderts vergleichen. Wir hören heute anders, weil wir meist schon kennen, was wir schließlich erneut, möglicherweise nun im Konzert, hören. Hören ist nicht mehr die seltene Möglichkeit, bei einer Aufführung anwesend zu sein, sondern teils oberflächliche, manchmal lästige, manchmal gewünschte Alltäglichkeit, teils bewusste Praxis des Hinhörens. Wir hören nun vergleichend, nicht mehr mit der Partitur, die im Konzert auf dem Schoß liegt und zuvor schon gelesen wurde, sondern mit dem zuvor Gehörten. Das gilt auch für den Musiker. Er wird verglichen und vergleicht selbst. Die zuvor flüchtige Improvisation kann festgehalten werden, unabhängig davon, ob sie anschließend notiert wird. Die Partitur hat ihre Stellung als alleinige Form einer allgemeinen und allgemeingültigen Weitergabe und Vorgabe auch innerhalb der akademisch-westlichen Musik verloren.

Es wäre aber falsch zu sagen, die Improvisation sei an ihre Stelle getreten. Die praktisch unbegrenzte Verfügbarkeit des einmal Gespielten verändert nicht nur die Praxis des Hörens, sondern auch des Machens, des Arrangierens, des Komponierens und des Musizierens. Man kann mit dem einmal Gespielten weiter arbeiten, es fort-

derne Haltung. Zwei moderne Fraktionen lagen im Streit: die Rekonstrukteure des »Reenactment «, der Wiederaneignung, und die Modernisten, die ein Stück so spielen, wie es ihnen heute gefällt. Aber auch die Liebe zur Musik ist keine romantische Wahl dessen, was man hört und unmittelbar liebt. »On aime la musique qu'on est prêt à aimer, que déjà on aime aimer.« (Ebd.: 34) 
setzen und verändern, zufügen und streichen, nicht mehr nur auf dem Papier, sondern vermittelt durch Technik unmittelbar am Klang. Improvisation, so Dietmar Wiesner zum Schluss des Gesprächs, gibt es vielleicht gar nicht. Es sei der zu erreichende $\mathrm{Zu}$ stand der Leere, an dem man beginnen könne, diese neu auszufüllen. Improvisieren in diesem Sinne aber könnten nur intelligente Musiker, die aus einer Abfolge von Tönen ihren Ausgangspunkt machen, der dann zum Nukleus des Weitermachens wird, nicht mehr nur zu einer Melodie, sondern nun zu einer Melodie mit Text, wie immer dieser aussehen mag. Auf das Probehandeln folge die Festlegung, auf dem Papier, bei der Aufnahme, aber auch im Sinne einer »innerlichen Festlegung«. Die Improvisation wird zur Versuchsanordnung, zu einer Art Materialschlacht, zum Austesten der Möglichkeiten. Für den Komponisten Zappa war schließlich, so Dietmar Wiesner im Gespräch, »jeder Musiker eine Taste am Klavier «. Aus diesen Tasten bildete er sein »Werk« und konnte sich zum American Composer machen. ${ }^{17}$

\section{Improvisation: (k)eine flüchtige Kunst.}

Je mehr Improvisation in die musikalische Praxis (erneut?) aufgenommen wird, löst sie sich doch als Gegenbegriff zum durch Noten vorgegebenen Spiel auf. Sie ist nicht die Freiheit von der Regel. Der Entweder-oder-Bezug der Gegenbegriffe stellt sich als Problem heraus, er beinhaltet keine Beschreibung oder gar Analyse ihres Verhältnisses. Einerseits hatte Adorno durchaus Recht, wenn er die angebliche Freiheit des Jazz als ideologisch diffamierte. »Freiheit« war nicht die Praxis des Jazz, sondern ein polemischer Gegencode

17 Der frühere Bürgerschreck Frank Zappa, der sich selbst als »pragmatischen Konservativen« bezeichnete, hat dieses Werk sehr bewusst gestaltet. Typisch bleibt aber, dass es sich nicht um eine unveränderte Fortsetzung des klassisch modernen Werkbegriffs handelt, was sich u.a. in diversen Rechtsstreitigkeiten ehemaliger Zappa-Musiker um die Urheberschaft (und daher um GEMA-Gelder) ausdrückt. Wenn eine Aufnahme zu mehr als 50\% aus Improvisationen der beteiligten Musiker besteht, können dann die Rechte an nur eine Person vergeben werden? Ist der Autor »verschwunden« und schreibt er sich illegitimerweise die Urheberschaft zu? Oder gibt es den Autor/Komponisten nur noch als rechtliche Fiktion? 
in einem Rechtfertigungsdiskurs. Anerkennungskämpfe wurden ausgetragen und soziale und politische Positionen markiert. Dabei ging es keineswegs um feine Unterschiede, sondern um grobe Differenzen, ging es nicht um Formen des Klassengeschmacks, sondern um eine sich durch den Gebrauch ausbildende Praxis, inklusive der Praxis des ästhetischen Urteils, die mit sozialer und politischer Positionierung verbunden wurde. Dies ist auch der Grund, warum Adorno andererseits Unrecht hatte. Er hat das soziologische Potential des von ihm extensiv gebrauchten Begriffs der »Dissonanz« nicht genutzt. Im Jazz wird sie ihm zur Bestätigung der Regel (und in der Zwölftonmusik machte sie keinen Sinn mehr).

Dissonanz aber kann geradezu zu einer Triebkraft werden. Sie ist nicht nur bekanntermaßen musikalisch für Spannungen verantwortlich, wenn etwa Melodie und Harmonie gegeneinander geführt werden, sondern sie kann produktiv sein. Dies gilt insbesondere für kulturelle Dissonanz, auch wenn diese meist als ungewünscht, als Mangel, als Scheitern von Integration, als aufzulösender Widerspruch, d.h. als möglichst rasch Aufzuhebendes bezeichnet und dann eben auch erfahren wird. Sie gilt dann als zu vermeidendes und gefährliches Übel. Globalisierung aber bedeutet auch ein häufiges Aufeinandertreffen nicht nur sich zufällig unterscheidender, sondern systematisch unterschiedlicher Praktiken, Orientierungen, Verhaltensweisen und Lebensformen. Anders formuliert: Es kommt zu einem dauerhaften Anstieg von Anerkennungsauseinandersetzungen und Rechtfertigungsproblemen, gleichzeitig aber auch von Kennenlernen, Kontakten, Übernahmen, Mischungen. Musik, dies kann »man « - und können nicht nur einige spezialisierte Musikethnologen - nun erfahren, kann sehr unterschiedlich sein, eben auch: systematisch unterschiedlich.

Ich möchte kurz auf ein historisches Ereignis eingehen, das sich in der Folge als äußerst produktiv und anschlussfähig erweisen sollte: die Entstehung einer in der europäischen Musik ungenutzten Tonfolge, die aber zumindest innerhalb des Systems beschreibbar war und schließlich sowohl für die Alltagsmusik, die Kunstmusik, wenn eine solche Unterscheidung auch nach Gebrauch schnell vergessen werden sollte, und die sich entwickelnde Musikindustrie als Zentrum der Kulturindustrie von grundlegender Bedeutung war.

Die Geschichte des Blues wurde häufig beschrieben; anders als die klassische Musik von Beginn an in sozialen und musikalischen Begriffen, wie dies auch im weiteren Verlauf für den sich entwi- 
ckelnden Jazz galt. ${ }^{18}$ Blues war die Musik einer bestimmten Gruppe, den segregierten ehemaligen schwarzen Sklaven, die vom Süden Amerikas (New Orleans; Mississippi) in die Städte des Nordens zogen, von Vaudeville, Minstrel-Shows und zum Teil von Kirchenliedern geprägt wurden und eine eigene musikalische Struktur hervorbrachten, die schließlich zumindest in den Formen und Parametern der harmonischen Theorie und europäischen Terminologie wenn auch als Abweichung, beschreibbar war. Dem bekannten funktionsharmonischen Schema des Blues, der Tonika-, Dominant- und Subdominantfunktion mithin und den aus dem Schema folgenden Durchgangstönen und Nebentönen, kann eine andere Lesart gegenübergestellt werden, die in der Tradition funktionaler Polyphonie, also: außereuropäischer Tradition, steht. Drei Töne, die gemeinsam gespielt werden, gelten in dieser Tradition eben nicht als Akkord im klassisch europäischen Sinn. ${ }^{19}$ In der europäischen Lesart aber, von der ich nicht behaupte, dass sie bewusst das Musizieren, die Praxis der frühen Bluesmusiker bestimmt hat, ergibt sich eine Verschiebung der Tonverhältnisse, die sich als eine praktische und kreativ genutzte »Missdeutung «, als durchaus gehörte Dissonanz verstehen lassen. ${ }^{20}$ Die Organisation der Halbtonschritte innerhalb des europäischen Dur-Moll-Tonleitersystems wurde folgenreich verändert. Die nachträglich als »Missdeutung « lesbare Verlagerung der Halbtonschritte des europäischen Systems erschloss neue Möglichkeiten, erzeugte Spannungen und positive oder negative Aufmerksamkeit.

Die Blues People, die noch gar keine waren, konnten ihre Musik nicht nur durch einen Unterschied kennzeichnen, sondern durch eine in der musikalischen Struktur ausgedrückte, bewertete Differenz. Wo der postmodern interkulturelle Blick Herkunftskultur entdeckt, entdeckte der schwarze Dichter und Schriftsteller LeRoi Jones (später: Imanu Amiri Baraka), der den Begriff der Blues People prägte,

18 Diese Beobachtung macht schon Jost (1982).

19 Interkulturell vergleichend herausgearbeitet hat dies Kubik (1999).

20 Hier ist nicht der Ort, auf diese Geschichte näher einzugehen. Es gab durchaus Musiker im frühen New Orleans, die Noten lasen. Sie waren meist kreolischer Abstammungen, unterschieden sich von den Landbluesmusikern. In der Hierarchie der Musiker standen die Pianisten ganz oben. Sie erhielten den Titel Professor (noch lange arbeitete Professor Longhair in New Orleans, der die Rockmusik beeinflussende Dr. John bezieht sich mit seinem Namen auf diese Tradition, ordnet sich ein und unter). 
in den 60er Jahren des letzten Jahrhunderts die Produktion einer kulturellen Tradition, die sich für ebendiesen Produktionsprozess Elemente der weißen Kultur auslieh und sie für sich selbst nutzte, für die Herstellung einer schwarzen Kultur, die die afrikanische und amerikanische Erfahrung zur Grundlage habe (Jones 1963). Ist es postmodern und kulturvergleichend die lange Reihe der Wurzeln, die die Ausdrucksformen bestimmt, war es der Blick der 60er Jahre des letzten Jahrhunderts, der den Jazz zum nur schwarzen, aber nicht nur afrikanischen werden ließ. Die Essays des weißen Jazzkritikers Frank Kofsky, die unter dem Titel Black Nationalism and the Revolution in Music veröffentlicht wurden (Kofsky 1969), zeigen den Gebrauch der Musik zur Herstellung eines schwarzen nationalen Bewusstseins auf. Die Gebrauchsmusik konnte zur Kunstmusik entwickelt werden und zum »Black Talk«, an orale Kommunikationsmodi anschließend, erklärt werden (vgl. Sidran 1971). Die These der »geschlossenen« Entwicklung einer schwarzen Kunstform ist jedoch eine soziale und politische Interpretation, die die Entwicklung der Musik nicht hinreichend erfassen und beschreiben kann. Neben der oralen Form gab es die notierte, Konventionen bildeten sich rasch heraus, die Musiker lernten von- und standen in harter Konkurrenz zueinander. Zudem ist Blues und Jazz Musik des 20. Jahrhunderts, im Moment ihrer Entstehung verbunden mit der Geschichte »aufgenommener « Musik, der Radiomusik, der sich mit ihr entwickelnden Schallplattenindustrie, schließlich des Starsystems und einer weiß-schwarzen Mischung: dem frühen Rhythm and Blues. $^{21}$

Es war zunächst kollektive Improvisation der meist kreolischschwarzen Bands im Süden der USA, die auf einer einfachen Struktur mit begrenzter Möglichkeit zur individuellen Improvisation basierte und ergänzt wurde durch den Individualismus des Pianisten (des Professors), führte schließlich hin zum bewunderten Solisten; die Liedkultur des Blues, die vom Land in die (nördliche) Stadt wanderte, entwickelte sich vom gitarrebegleiteten Sänger zur frühen Bluesband Chicagos mit auf kleine Takteinheiten begrenzten Improvisationsmöglichkeiten $\mathrm{zu}$ den bestimmten, keineswegs nur zwölftaktigen Harmoniewechseln; die großen Bands trennten die

21 Es waren die »Revolutionäre « des Jazz in den 40er und 50er Jahren, die zum Teil den Begriff »Jazz« ablehnten. Sie hatten einen anderen Begriff für das, was sie taten. Sie spielten »Musik des 20. Jahrhunderts«. 
Satzspieler von den virtuosen Improvisatoren. Diese Struktur war an eine Improvisation über eine feste, sich allerdings ausdifferenzierende Akkordstruktur gebunden und zudem darauf begrenzt, Hintergrundmusik in der Bar, Begleitung in der Revue oder Grundlage für das Tanzen zu sein. Zwar wurden die Arrangements professioneller und harmonisch komplexer, so etwa die von Fletcher Henderson für das weiße Benny Goodman Orchestra, aber der Zweck und die ökonomische Ausrichtung begrenzten die Möglichkeiten zur Improvisation des Solisten auf nur kurze Takteinheiten und zwangen den Satzspieler dazu, nach Noten zu spielen. Blattsicherheit, zumindest sehr gute Notenkenntnisse wurden zur Grundforderung und durch die Improvisation ergänzt.

In dieser Situation, als eine Musik sich rasch ausdifferenziert hatte, komplexer geworden war und es besser ausgebildete Musiker gab - keineswegs traf der vor allem europäische Blick auf die neue Kunst als Volkskunst die Realität des Jazz, denn dieser hatte nicht etwa den nach romantischem Ideal naturbegabten Musiker zur Voraussetzung -, entstand in den späten 30er und 40er Jahren des letzten Jahrhunderts die öffentliche Jamsession als Möglichkeit, außerhalb der Routine in kleiner Besetzung und vor ausgewähltem Publikum seine virtuosen und improvisatorischen Fähigkeiten zu zeigen.

»The jam session is symptomatic of a period where the consolidation of jazz as an improviser's art begins to clash with the dance band and other entertainment functions which economically sustain it« (Lewis 1987: 38f.).

Der Jazz wurde zur performer's art, Unterhaltung und Kunstanspruch begannen sich mit dem Bop zu trennen, Jazz wurde nun auch zu einer Musik, der man zuhörte, über die man reden und dann auch schreiben konnte und die sich umso schneller zu verändern begann. Der Gebrauch der Töne des Septimakkords (Grundton, gr. Terz, Quint, kl. Septime) wurde ergänzt, manchmal ersetzt durch die II. und IV. Stufe sowie durch den Gebrauch alterierter Erweiterungstöne (also: b9, \#9, b5, \#5) und ebenso wurden nun der zweite und der vierte Schlag betont. Das Unisonospiel kam auf. »Bop was, in the exact sense of the word a musical revolution. These men turned the jazz world upside down and sat on the top, thumbing their noses at their elders falling off the other side « (Collier in Lewis 1987: 39). Jetzt spielte man in der Konsequenz nicht mehr für Tänzer, sondern 
für Musiker. Der Bebop machte den Jazz zur performer's und das heißt zur improviser's art und damit zu einer modernen Kunst, die sich auf sich selbst bezieht, zu einer Kunst, die schwarz und modern war, weder nur das eine noch nur das andere.

Jetzt konnten zumindest die Insider in ihrem Spiel die anderen zitieren, konnten, nachdem der Aufnahmeboykott zu Beginn der 40er Jahre beendet war, die Sammler darüber reden, wer wann wie eine Note gespielt hatte und wurde die Schallplattensammlung zu dem, was die Klavierpartituren im europäischen Bürgerhaushalt sind. Die Kritiker konnten ihre Arbeit, dies geschah zunächst in Frankreich, beginnen, und es konnte sich ein Publikum von aktiven Hörern ausbilden, die nicht vor allem tranken oder tanzten, sondern dies, wenn überhaupt, nebenher auch taten. Erst jetzt gab es eine Improvisationskunst, die sich als eine von der westlich-klassischen Musik zu unterscheidende darstellen konnte, die Zwang gegen Freiheit ausspielte und, nicht zu vergessen, Schwarz gegen Weiß. Aber es waren die »Intellektuellen « unter den Spielern, diejenigen, die Substitutionsakkorde kannten und sie benutzen konnten, die sich im Kampf der Musiker in der Jamsession durchsetzten. Die Improvisationen waren nicht frei und ihre Grundlagen wurden komplexer, als sie sich von der harmonischen hin zur modalen Struktur lösten. Die improviser's art bekam eine komplexe Struktur, so dass nur weitere intensive Schulung und Übung den Einzelnen in die Lage versetzte, sich beteiligen zu können. Sie löste sich teilweise aus den ökonomischen Fesseln der Kulturindustrie. Misserfolge konnten nun als Missachtung von Kunst gewertet werden, der Musiker wurde zum Künstler, der sich im günstigen Fall eine kleinere oder größere Gemeinde schaffen konnte. Und nun konnte man auch, eine exemplarisch moderne Handlung, zu den Quellen zurückkehren; so nahm Miles Davis 1954 etwa den Titel Airegin (rückwärts gelesen mithin: Nigeria) auf. Eine autonome Kunst, die Improvisation als Stilmittel zu ihrer »Größe« erklärte und ideologisch zur Freiheit erweiterte, war entstanden, mit weltweitem Publikum, Kritikern, Zeitschriften, Schallplattenverlagen und schließlich Akademien, einer akademisierten Ausbildung und einem eigenem Markt.

Als autonome Kunst ging es nun um Selbstthematisierung. Diese konnte einen Rückzug in nur noch für Kenner nachzuvollziehende, von außen als »esoterisch« empfundene Strukturen bedeuten, aber neben Afrika wurde auch der Blues, also eine einfache musikalische Grundstruktur, nun »wiederentdeckt «, aufgenommen und in- 
tellektualisiert. Exemplarisch sei auf John Coltranes Einspielung Coltrane plays the blues hingewiesen. Seine hoch differenzierte Fassung des Bluesschemas erhielt seinen Namen, Coltrane Blues Progression. ${ }^{22}$

In den 60er Jahren, den Jahren des sogenannten New Thing, stand das Experiment neben einer Vereinfachung der Strukturen, und auch die kollektive Improvisation kam wieder zur Geltung. Der neue Stil konnte zeittypisch nicht nur mit »Freiheit« des Spiels, sondern der Befreiung von Konventionen, aber auch im politischen Sinne der Befreiungsbewegungen verstanden werden. Gleichzeitig mit diesen Tendenzen entstand die Rockmusik als eine Übernahme des schwarzen Rhythm and Blues, der Entdeckung des Blues auch hier und der Veränderung des Rock 'n' Roll. Dieser, aber schließlich auch Soul und Funk waren eine Möglichkeit, Gebrauchsmusik zu machen, zum Tanzen und für die Hitparaden zu spielen. Die die 60er Jahre bestimmenden englischen Rockbands begannen damit, Lieder der in Amerika nur für ein kleines Publikum spielenden und von den Intellektuellen des Jazz nicht anerkannten schwarzen Bluesmusiker zu spielen, eine einfache »Sprache« zunächst zu übernehmen und schließlich in unterschiedliche Richtungen weiterzuentwickeln. $\mathrm{Zu}$ improvisieren mussten sie lernen und vor allem mussten sie sich sozial durchsetzen. Diese Durchsetzung geschah in einer künstlerisch-ästhetischen Praxis, die geprägt war von einer Mischung aus Jugendlichkeit, Künstlertum und eines kollektiven »Outsidertum«. Die Musik nahm als zwar unbestimmtes, aber doch eindeutig interpretierbares Symbol bei der Ausbildung des Zusammenhangs dieses Kollektivs einen zentralen Stellenwert ein. ${ }^{23} \mathrm{Sie}$ wurde, wenn auch nicht allein, die Sprache, in der die radikalste Geste möglich war und keineswegs folgenlos blieb.

Aber der »Geist der Musik« hatte andere Folgen als gewollt. Die als »frei« missdeutete Improvisation entsprach einer Orientierung auf den Moment. Sie feierte das ins Kollektiv eingebundene Individuum. Musiker und Hörer bilden eine situative Erfahrungseinheit.

22 Siehe für weitere Informationen die Webseite www.johncoltrane.com. Coltrane Plays The Blues ist in verschiedenen Ausgaben erhältlich. Auf der Website der John Coltrane Foundation wird die Ausgabe bei Atlantic 1382, CD angegeben. Das Original erschien 1960.

23 Texte allerdings sollten nicht vergessen werden. $\mathrm{Zu}$ nennende Autoren sind u.a. Marcuse, Laing, Cooper, Castaneda, Deleuze/Guattari sowie Adorno. 
Diese Praxis ist häufiger kulturanalytisch beschrieben worden und bedeutete mehr als ein bestimmtes Mittel des Musizierens (vgl. Willis 1981; Frith 1996). Die hohe Anerkennung des jungen Musikers in der »Szene«, des als Gemeinschaft inszenierten Kollektivs von Hörern und Musikern, beruhte auf dessen exemplarischer Deutung. Er konnte so etwas wie der situative Zeremonienmeister werden. Vieles konnte man in die Musik hineinlegen, vor allem aber zeitgleich Individualität wie Zugehörigkeit. Dennoch sollte sie mehr ausdrücken: »Kein Akkord kann hässlich genug sein, um die Realität zu beschreiben«, wird Frank Zappa häufig zitiert. The Who brachten die Zertrümmerung der Instrumente auf die Bühne. Pete Townshend, Gitarrist und Kopf der Gruppe, hatte als junger Kunststudent Kontakt zu Gustav Metzger, einem Vertreter der Destruktionskunst der 60er Jahre (vgl. Kraushaar 2001, 2007). Das sich selbst zerstörende Kunstwerk ist Metzgers Ideal, Strukturen, die entstehen und im selben Prozess wieder verfallen. Der junge Kreative von der englischen Art School nimmt die Idee auf, die Klanggewitter werden zu sich auftürmenden Lärmcollagen. Die »Orgien der Gewalttätigkeit«, von denen im Rocklexikon gesprochen wird, sind Konzept (Graves 2003: 989) - zumindest in diesem Fall, denn der Gitarrist, der in Antonionis Film Blow Up (1967) als Mitglied der Yardbirds seine Gitarre unterkühlt und ohne jeden Anflug von Ekstase vor einem ebenso statisch gefilmten Publikum am Verstärker zerschlägt, Jeff Beck, der später zu einem der bedeutendsten Rockgitarristen werden sollte, erzählt eine pragmatische Variante der Geschichte: Bei den ersten Amerikatourneen seien die Verstärker für die großen Hallen zu schwach gewesen, so dass man irgendetwas tun musste, um das Publikum noch irgendwie zu erreichen.

Bei aller Collagentechnik aber bildete sich schon bald der Typus des Musikers nicht nur als Musikanten, sondern als »Schöpfer«, als »Createur « der eigenen Lieder heraus. Wie viele Arrangeure auch immer mitarbeiten oder aushelfen sollten, die Differenz von Komponist und Musiker wurde unterlaufen und aufgehoben. Man schrieb sich die Lieder selber, und auch wenn das Stuick beim Auftritt in Klangcollage und Improvisation endete, das Lied kam gerade in England, Adorno zufolge ein Land ohne Musik, zu einer neuen Geltung.

»Stellen Sie sich vor, Sie sind ein verwöhntes Kind, das auf einer Party von Erwachsenen drei Minuten Aufmerksamkeit will. Sie eröffnen mit 
einem großartigen Anfang. Wenn Sie spüren, daß die Gäste sich langweilen, bauen Sie einen Mittelteil ein. Danach kommen Sie wieder zum Hauptteil zurück, fügen aber noch eine Wendung an, um die Wiederholung zu verwischen. Danach sehen Sie zu, daß Sie so schnell wie möglich verschwinden. Das ist ein großer Popsong.«(Davies 1997: 6)

Pop- und Rocksongs sind kein »Werk «, sie sind flüchtig und situativ strukturiert. Auch wenn sie zum »Werk« zusammengebunden wurden (im widersprüchlichen Versuch der sogenannten »Rockoper«) oder improvisatorisch, zumindest im Gestus der Improvisation, verlängert wurden, bleiben sie situativ und flüchtig noch dann, wenn sie einen anderen Anspruch stellen. Diese Charakterisierung bedeutet keineswegs eine Aussage über ihren Wert bzw. eine Beurteilung als Verurteilung. Es ist vielmehr eine Aussage über ihre Form. Einmal gespielt, aufgenommen und verteilt, können sie nun verarbeitet, umgearbeitet und anders gespielt werden. Gerade wenn sie nicht nur nachgespielt werden können, sondern das Potential der Veränderung haben, erscheinen sie als besonders »wertvoll $\ll$. Es entsteht Material als Tradition, mit der gearbeitet werden kann. Sie können - wie in der heutigen Sampletechnik - als Melodieschnipsel, als Schnappschüsse wieder verwendet werden, ohne dass ihnen prinzipiell etwas angetan würde. Festgehaltene Improvisationen, mit denen man weiter arbeiten, aus denen man, wie es der »American Composer « Zappa tat, ein »Werk « machen kann. Jedes seiner späten Konzerte wurde mitgeschnitten, die Musiker einzeln zur Improvisation aufgefordert, ihre »Arbeit«, wenn sie passte, verwendet. Auch Frank Zappa, der Komponist sein wollte und wurde und Musiker war, der schließlich die Gitarre beiseite legte, um am Synklavier, einem frühen computerisierten Aufnahmegerät, das heute nur noch im Technikmuseum seinen Platz hat, aus all den einzelnen Teilen Stücke zu erarbeiten, hielt immer wieder am Lied im 4/4-Takt fest.

\section{Musik, Improvisation und die Entstehung der kreativen Klassen}

Der »Geist der Musik« des Westens in der zweiten Hälfte des Jahrhunderts war auf die Situation gerichtet und sollte sich doch institutionalisieren; er war »demokratisch «, wenn man so will, jeder sollte beteiligt sein, und bildete doch ein Starsystem aus, den Virtuosen 
als Star; er zielte auf individuelle Selbstverwirklichung und brachte zugleich das kollektive Musikerlebnis als Massenvergemeinschaftung hervor; er wollte »Gegenkultur « sein und schuf doch die Grundlage für die Ausbildung der Musikindustrie; er zielte auf Freiheit und war doch nicht nur ans System gebunden, sondern etablierte exemplarisch eine neue, kreative Klasse.

Der Musiker wurde zum Komponisten, zum ausführenden, als authentisch angesehenen Interpreten der eigenen Musik, Zeremonienmeister der Massenvergemeinschaftung und, im erfolgreichen Einzel- und Ausnahmefall, zum Verwalter seiner Rechte, zum Besitzer seiner Produktionsmittel.

Aus Jazz, Rock und Neuer Musik sehr unterschiedlich gemischt und beständig mit neuen technischen Möglichkeiten konfrontiert und sie durchaus auch selbst produzierend, muss sich die Musik nun immer wieder neu erfinden und wiederholt sich dabei beständig. Musikkonzerne suchen die Trends, können sie selten selbst kreieren. Sie brauchen die Bindung ans Kollektiv und die neue kreative Klasse, die sich keineswegs auf Musik und Musiker beschränkt. Öffnung zu Improvisation und Experiment, die potentielle Aufhebung des »Werkes«, »Kunst als Unfall«, unbestimmter Sinn und emotionale Kraft, systematischer und zufälliger Charakter, Dissonanz als Träger von Spannung, die Zuhörer als Mitproduzenten, die erst das efferveszente Ereignis des gelungenen Moments oder des gefühlten »richtigen « Tons in der solistischen Improvisation als Gemeinschaftserlebnis ausmachen; Komplexität auch auf einfacher Grundlage, die eine beständige Rückkehr zur »one chord power« ermöglicht (vgl. Laing 1985); nicht mehr nur ihre mögliche Reproduktion, sondern beständige aktuelle und nun technisch mögliche nachträgliche Variation und Veränderbarkeit - all diese Momente machen die Musik zu einer exemplarischen Kunst der kreativen Klasse, an deren Aufstieg sie ebenso exemplarisch beteiligt war (vgl. Florida 2002).

Adorno sah die zentrale Stellung der Kulturindustrie, die in der Folgezeit zu wenig systematische Beachtung und empirische Beobachtung fand. Auf ihrer Grundlage konnte England die ökonomische Basis von der klassischen Industrie auf eine postmoderne Ökonomie der kreativen Klassen, die in diesem Fall auf der Musikindustrie basierte, umstellen. Es ist aber nicht nur die Steigerung der Attraktivität eines Ortes durch eine künstlerisch kreative Szene, die in einem zweiten Schritt andere, technisch »Kreative« anlockt. We- 
der vollzog sich die totale Anpassung mittels des improvisatorischen Betrugs, noch erschloss die Improvisation das Reich der Freiheit. Sie leistete etwas ganz anderes und sehr Bedeutendes: Sie veränderte das Konzept des Verhältnisses von Regel und Handeln, von Form und Praxis. Es geht auch, aber nicht nur um Ausführung: Wir handeln in Bezügen, etwa vorherigen Handlungsentwürfen, aber wir sind nicht nur deren Ausführende und Interpreten, sondern variieren, fügen hinzu, ergänzen und verändern diese sowohl absichtsvoll bewusst wie auch in der Praxis des Handelns en passant. Improvisatorisches Handeln geschieht auf der Grundlage von Regeln, ist jedoch nicht deren Ausführung. Es verändert den klassisch modernen Versuch, Regel und Ausführung zur Deckung zu bringen.

Die Entwicklung der westlichen Musik der zweiten Hälfte des 20. Jahrhunderts steht dabei exemplarisch für die Form einer veränderten Subjektstruktur. Man darf nicht nur, man muss versuchen und ausprobieren; man darf sich nicht nur selbst entwerfen, nun wird es erwartet; man darf nicht nur improvisieren, nun muss man es können, und nicht nur in der Musik ist dies sehr voraussetzungsvoll. Die Form der Freiheit besteht in der Forderung nach situativer Prägnanz und exemplarischer Ausdeutung. Die Freiheit steht nicht der Regel gegenüber, sie ist aber ebenso wenig deren bloße subjektive Anwendung und Variation. Sie besteht in der Kompetenz, die expliziten und impliziten Regeln und das Material zu beherrschen, sie in der Praxis des Machens, des Spielens zu bestätigen und an dem Erreichten weiterzuarbeiten.

\section{* Für Lothar Jene $\dagger$}

\section{Literatur}

Adorno, Theodor W. (1973a): »Abschied vom Jazz«. In: ders. (Hg.), Gesammelte Schriften, Musikalische Schriften V, Frankfurt a.M.: Suhrkamp.

Adorno, Theodor W. (1973b): Ästhetische Theorie. Frankfurt a.M.: Suhrkamp.

Adorno, Theodor W. (1973c): Einleitung in die Musiksoziologie. Zwölf theoretische Vorlesungen. Frankfurt a.M.: Suhrkamp. 
Adorno, Theodor W. (1973d): »Juni 1927«. In: ders. (Hg.), Gesammelte Schriften 19, Musikalische Schriften VI, Frankfurt a.M.: Suhrkamp, S. 94-97.

Adorno, Theodor W. (1973e): Minima Moralia. Reflexionen aus dem beschädigten Leben: Pro domo nostra. Frankfurt a.M.: Suhrkamp.

Adorno, Theodor W. (1973f): Philosophie der neuen Musik. Frankfurt a.M.: Suhrkamp

Adorno, Theodor W. (1973g): »Über den Fetischcharakter der Musik und die Regression des Hörens«. In: ders. (Hg.), Gesammelte Schriften, Frankfurt: Suhrkamp, S. 14-49.

Bauman, Zygmunt (2003): Flüchtige Moderne. Frankfurt: Suhrkamp.

Bauman, Zygmunt (2007): Liquid Times. Living in an age of uncertainty. Cambridge: Polity Press.

Baumgartner, Thomas/Lutz, Kai/Schmidt, Conny F. et al. (2006): »The emotional power of music: How music enhances the feeling of affective pictures«. Brain Research, 1075, S. 151-164.

Bielefeld, Ulrich (2003): Nation und Gesellschaft. Selbstthematisierungen in Deutschland und Frankreich. Hamburg: Hamburger Edition.

Boltanski, Luc/Thévenot, Laurent (2007): Über die Rechtfertigung. Soziologie der kritischen Urteilskraft. Hamburg: Hamburger Edition.

Braun, Christoph (1992): Max Webers Musiksoziologie. Laaber: Laaber Verlag.

Braun, Christoph (1994): »Grenzen der Ratio, Grenzen der Soziologie. Anmerkungen zum >Musiksoziologen< Max Weber«. Archiv für Musikwissenschaft (1), S. 1-25.

Bühl, Walter L. (1994): »Musiksoziologie an der postmodernen Wende«. Soziale Welt (H.3), S. 338-362.

Collier, James L. (1978): The Making of Jazz. New York: Dell.

Davies, Ray (1997): » Kunst als Unfall<. Kinks-Chef Ray Davies über Rap, Punk, James Last und Psychopathen«. Der Spiegel, 3/1997, 24.02.1997, S. 6-11.

Florida, Richard (2002): The Rise of the Creative Class. and how it's transforming work, leisure, community and everyday life. New York: Basic Books.

Foucault, Michel (2001): »Was ist ein Autor?« In: Daniel Defert \& Francois Ewald (Hg.), Michel Foucault. Schriften in vier Bän- 
den. Band I, 1954-1969, Frankfurt a.M.: Suhrkamp, S. 10031041.

Frith, Simon (1996): Performing Rites. On the Value of Popular Music. Oxford: Oxford University Press.

Graves, Barry/Schmidt-Joos, Siegfried/Halbscheffel, Bernward (Hg.) (2003): Rocklexikon. Hamburg: Rowohlt.

Hennion, Antoine (1993): La passion musicale. Paris: Métailié.

Hennion, Antoine/Grenier, Line (2000): »Sociology of Art: New Stakes in a Post-Critical Time«. In: R. Q. Stella \& A. Sales (Hg.), The International Handbook of Sociology, London, Thousand Oaks, New Dehli: Sage, S. 341-355.

Hitzler, Ronald (1985): »Collagen eines Schelms. Zum ästhetischen Stil des Francis Vincent Zappa«. Jazzforschung/Jazz Research, Bd. 17, S. 111-133.

Hitzler, Ronald (1994): »Unbind your mind. Eine Reminiszenz anlässlich des Todes von Frank Zappa«. Ästhetik und Kommunikation, H.84, S. 4-7.

Honneth, Axel (2005): »Eine Physiognomie der kapitalistischen Lebensform. Skizze der Gesellschaftstheorie Adornos«. In: ders. (Hg.), Dialektik der Freiheit. Frankfurter Adorno Konferenz 2003, Frankfurt: Suhrkamp, S. 165-187.

Jones, LeRoi (Baraka, Imanu Amiri) (1963): Blues People. Negro Music in White America. New York: William Morrow. Dtsch.: (1969): Blues People. Schwarze und ihre Musik im weißen Amerika. Darmstadt: Melzer.

Jost, Ekkehart (1982): Jazzmusiker. Materialien zur Soziologie der afroamerikanischen Musik. Frankfurt, Berlin, Wien: Ullstein.

Kofsky, Frank (1970): Black Nationalism and the Revolution in Music. New York: Pathfinder Press.

Kraushaar, Wolfgang (2001): »Gitarrenzertrümmerung. Gustav Metzger, die Idee des autodestruktiven Kunstwerks und deren Folgen in der Rockmusik«. Mittelweg 36, Februar/März 2001, S. 2-28.

Kraushaar, Wolfgang (2007): »Selbstzerstörung als schöne Kunst betrachtet «. Frankfurter Rundschau 18.06.2007.

Kubik, Gerhard (1999): Africa and the Blues. Jackson: University Press of Mississippi.

Kurt, Ronald (2006): »Max Weber und die Musik. Perspektiven und Probleme der Kulturvergleichenden Musiksoziologie«. In: Jörn 
Rüsen (Hg.), Kulturwissenschaftliches Institut Jahrbuch 2005, Bielefeld: transcript, S. 299-312.

Laing, Dave (1985): One Chord Wonders. Power and meaning in Punk Rock. Milton Keynes, Philadelphia: Open University Press.

Lewis, Alan (1987): »The Social Interpretation of Modern Jazz«. In: Avron L. White (Hg.), Lost in Music. Culture, Style and The Musical Event. London, New York: Routledge \& Kegan Paul, S. 33-55.

Ludwig, Wolfgang (1992): Untersuchungen zum musikalischen Schaffen von Frank Zappa. Eine musiksoziologische und -analytische Studie zur Bestimmung eines musikalischen Stils. Frankfurt, Berlin, Bern et al.: Verlag Peter Lang.

Miles, Barry (2005): Frank Zappa. Berlin: Rogner \& Bernhard bei Zweitausendeins.

Radkau, Joachim (2005): Max Weber. Die Leidenschaft des Denkens. München: Carl Hanser Verlag.

Reichert, Carl-Ludwig (2000): Frank Zappa. München: Deutscher Taschenbuchverlag.

Schopenhauer, Arthur (1971): Die Welt als Wille und Vorstellung. Erster Band. Wiesbaden: Brockhaus.

Schütz, Alfred (1951): »Making music together - a study in social relationship«. Social Research, 18(1/4), S. 76-97.

Sidran, Ben (1971): Black Talk. New York: Holt, Rinehart \& Winston.

Weber, Max ( $\left.{ }^{4} 1973\right)$ : Gesammelte Aufsätze zur Wissenschaftslehre. Tübingen: Mohr Siebeck Verlag.

Weber, Max (2004 [1921]): Zur Musiksoziologie. Tübingen: Mohr Siebeck Verlag.

Willis, Paul (1981): >Profane Culture . Rocker, Hippies. Subversive Stile der Jugendkultur. Frankfurt a.M.: Syndikat. 



\title{
>ES IMPROVISIERT < IMPROVISATION IN DER NORDINDISCHEN KUNSTMUSIK
}

\author{
MARKUS SCHMIDT
}

>Menschliches Handeln als Improvisation<. Der Titel der diesem Aufsatz zugrunde liegenden Tagung hat mich spontan begeistert, da er provoziert. Die umgekehrte Formulierung >Improvisation als menschliches Handeln< hätte die Improvisation in die Nähe einer wie auch immer gearteten gesellschaftlichen oder künstlerischen Nische gerückt. So aber impliziert der Titel die wesentlich weiterreichende Frage nach einer Lebensweise des Improvisierens.

Im Folgenden werde ich versuchen, Indien, das ich tendenziell als eine Kultur der Improvisation begreife, dem Westen, den ich eher als eine Kultur der Komposition verstehe, thesenartig gegenüberzustellen. Daran anschließend möchte ich am Beispiel der klassischen nordindischen Musik diskutieren, was Improvisation in diesem Zusammenhang bedeutet, wie sie vonstatten geht und mich abschließend der Frage widmen, warum sie hier eine so große Rolle spielt.

Dass die Frage nach der Improvisation als Lebensform hier am Beispiel der klassischen indischen Musik (also doch einer Nische?) diskutiert wird, liegt einerseits daran, dass ich mich als Musikwissenschaftler und als Musiker seit 17 Jahren theoretisch und praktisch intensiv mit ihr auseinandersetze. Andererseits bildet die noch zu diskutierenden Annahme, dass in einer als >klassisch< bezeichneten Kunstform Ideale und Wertbezüge einer Gesellschaft zum Ausdruck kommen, die Grundlage meines Textes. 


\section{Indien und der Westen: Ein Kulturvergleich}

Wenn ich dem Westen eine Kultur der Komposition, Indien dagegen eine Kultur der Improvisation unterstelle, so birgt dies etliche terminologische und definitorische Gefahren in sich. Die Begriffe $>$ Westen< bzw. > westlich $<$, >Indien< bzw. >indisch $<$ und >Kultur< wurden und werden in politik-, sozial- und kulturwissenschaftlichen Kreisen leidenschaftlich diskutiert. Große Begriffe besitzen allerdings oft die unangenehme Eigenschaft, bei genauerer theoretischer Betrachtung auf der Mikroebene zu bloßen Worthülsen zu verkommen. Die insgesamt mehr als zwei Jahre, die ich bisher in Indien verbracht habe, konnten mir den Eindruck, Indien sei >irgendwie anders< aber dennoch nicht nehmen. Der Indologe Axel Michaels hat für diese Andersartigkeit ein schlüssiges Erklärungsmodell gefunden, das er als »identifikatorischen Habitus« bezeichnet:

»Die kohäsive Kraft, die die Hindu-Religionen zusammenhält und sie gegen fremde Einflüsse widerstandsfähig macht, bezeichne ich als >identifikatorischen Habitus«.« (Michaels 1998: 19)

Die kulturellen Differenzen zwischen Indien und dem Westen lassen sich sicherlich nicht monokausal erklären (man denke beispielsweise auch an klimatische Faktoren), jedoch scheint es $>$ kulturelle Motoren $<$ zu geben, die das Leben tiefer und nachhaltiger beeinflussen als andere. Dementsprechend verstehe ich $>$ westliche Kultur< als maßgeblich von Christentum und Aufklärung geprägtes Denken, Fühlen und Handeln, >indische Kultur< dagegen als maßgeblich vom Hinduismus geprägtes Denken, Fühlen und Handeln. Es würde den Rahmen dieses Aufsatzes bei weitem sprengen, die Unterschiede detailliert zu diskutieren, jedoch lassen bereits einige wichtige Schlagworte der jeweiligen geistigkulturellen Strömungen die weit reichenden Folgen dieser kulturellen Differenz erahnen.

Als einfußreiche Faktoren bzw. Ideen sehe ich auf der Seite der westlichen Kultur die christlichen Konzepte von Schuld und Sühne, von Egalität (vor Gott) und Nächstenliebe, den Jenseitsglauben, der in der Idee des jüngsten Gerichts zum Vorschein kommt, vor allem aber die in der Aufklärung propagierte Vorherrschaft der Vernunft (Rationalismus), die Subjekt-Objekt-Trennung und die in der Französischen Revolution gipfelnden Ideale von Gleichheit (poli- 
tisch), Freiheit und Brüderlichkeit. Für die weitere Betrachtung von ausschlaggebender Bedeutung ist die Konzeption des Individuums als autonomes Subjekt.

Dem stehen in der indischen Kultur ein nicht-egalitäres, hierarchisches soziales Konzept, Stichwort Kastenwesen (vgl. Michaels 1998: 176-194), die Idee der Seelenwanderung (vgl. Michaels 1998: 148-149), die Identität von Individuum und Gott bzw. Göttlichem (vgl. Michaels 1998: 85-114), sowie das Ideal der Entindividualisierung durch Initiation und/oder Askese (vgl. Michaels 119-123) entgegen. Die Kindheit, nach westlicher Vorstellung der Lebensabschnitt, aus dem der Mensch als mündiges Individuum hervorgehen sollte, ist in Indien »weitgehend Entindividualisierung und gerade dadurch vollkommene, >perfekte< (samskrta) Sozialisation « (Michaels 1998: 123).

Die Bedeutung und Bewertung des geschriebenen Wortes im Westen bzw. des gesprochenen Wortes in Indien steht in unmittelbarem Zusammenhang mit den unterschiedlichen kulturellen Prägungen. Häufig wird die Schrift als Voraussetzung für das Entstehen der westlichen Zivilisation angesehen. Das Christentum gilt als Schriftreligion, der Autor, das schreibende Subjekt, als unantastbar, die Redewendung >etwas schwarz auf weiß sehen>als Garant für Gültigkeit. In Indien kommen dem gesprochenen Wort und der mündlichen Tradierung eine ungleich höhere Bedeutung und Performanz zu. So werden beispielsweise Mantras, kurze stimmhafte Silben, die im Ritual- und Meditationskontext eine große Rolle spielen, als rituell oder spirituell wirksam empfunden. Durch korrekte Anwendung wird ein direkter Bezug zu übernatürlichen Kräften hergestellt. Michaels merkt dazu an: »Mantras sind unwiderruflich feststehende Silben oder Wortfolgen, denen gelegentlich als gefährlich empfundene Kraft zugesprochen wird « (Michaels 1998: 252). Der Veda, das älteste religiöse Schrifttum des Hinduismus, wurde zunächst Jahrhunderte lang mündlich überliefert, bevor er niedergeschrieben wurde. Die Urheberschaft wird nicht einem schöpferischen Subjekt, sondern einem Seher oder Weisen ( $r s i$ ) zugeschrieben, der das heilige Wissen nicht erfunden, sondern empfangen bzw. >gehört< hat (vgl. Michaels 1998: 68-69). $\gg$ Nicht der Autor eines Textes ist wichtig, sondern seine Schülerschaft in einer Lehrer-Schüler-Abfolge (paramparā)« befindet Michaels (ebd. 1998: 123). 
Die Skepsis gegenüber der Schrift bzw. das größere Vertrauen in mündliche Absprachen ist auch im Alltag gegenwärtig. So werden, wie ich aus eigener Erfahrung weiß, Arbeits- und Mietverträge meist nur mündlich geschlossen.

Die Begriffe >Komposition< und >Improvisation< sind ebenfalls problematisch: Musikwissenschaftliche Forschungen innerhalb der letzten 40 Jahre haben gezeigt, dass es unmöglich ist, die bis dahin vorherrschende Meinung, es handele sich hierbei um konträre, einander ausschließende Prinzipien der kreativen Gestaltung, aufrecht zu halten. Auch das Vorhandensein bzw. vermeintliche oder tatsächliche Fehlen von Schriftlichkeit in Form von Notation scheidet als Differenzierungsmerkmal aus. Vielmehr scheint der zeitliche Abstand zwischen kreativem Impuls und klanglicher Realisierung als Hauptkriterium von ausschlaggebender Bedeutung zu sein (vgl. Nettl 1998: 1-23; Reinhard 1996: 565-599).

Wesentlich interessanter und für meine These von größerer Bedeutung als die Suche nach allgemein akzeptierten Definitionen erscheint mir die Wertschätzung, die der Improvisation in den beiden Kulturräumen entgegengebracht wird. Spürt man der Bedeutung nach, in welcher der Begriff in unterschiedlichen, auch alltäglichen Kontexten verwendet wird, so drängt sich der Verdacht auf, als werde Improvisation im Westen vornehmlich als etwas Mangelhaftes betrachtet, etwas, dem zwar Respekt und Bewunderung entgegengebracht wird, das man aber lieber von sich fernhält. Einige Beispiele mögen dies veranschaulichen:

Die simprovisierten Behausungen< in den Großstadtslums der Entwicklungsländer erregen einerseits unsere Empörung, andererseits bewundern wir den Erfindungsgeist und die Tüchtigkeit der Bewohner, die es schaffen, mit >primitivsten Mitteln< ihren Wohnraum zu gestalten. Eintauschen möchten wir unsere srichtigen< Häuser dagegen jedoch keinesfalls.

Unerwarteten Besuch versorgt man mit einem >improvisierten Abendessen $<$. Der Begriff trägt die Entschuldigung für den vermeintlichen Mangel schon beinahe in sich und steht im krassen Widerspruch zu einem kostspieligen Dinner, das in den Speisekarten edler Restaurants mit Sätzen wie dem folgenden umschrieben 
wird: »eine Komposition ausgewählter Zutaten, die sorgfältig aufeinander abgestimmt werden $\ll^{1}{ }^{1}$

Fehlt bei einer Reparatur das entsprechende Spezialwerkzeug, so hört man häufig die Redewendung >dann muss eben improvisiert werden $<$. Auch hier ist der Mangel deutlich ersichtlich.

Improvisationstheater erfreut sich zwar mittlerweile in den Metropolen der westlichen Hemisphäre großer Beliebtheit, auf den großen Bühnen der Staatstheater wird man es hingegen im Spielplan vermissen. Weiterhin käme niemand ernsthaft auf die Idee, die Gorillas (ein Berliner Improvisationsensemble) mit Shakespeare, Schiller oder Brecht auf eine Stufe zu stellen.

Selbst im musikalischen Bereich, mit dem Improvisation vermutlich am ehesten assoziiert wird, ist ihre Wertschätzung zwar seit der Popularisierung des Jazz und einiger außereuropäischer Musiken gestiegen, nichtsdestotrotz wird aber vor allem die komponierte $>$ klassische Musik< weiterhin staatlich subventioniert, wohingegen die >freie Improvisationsszene< in kleinen Clubs ums künstlerische Überleben kämpft.

Komponisten, wie Bach, Mozart, Beethoven und Schubert sind in erster Linie für ihre Fugen, Sinfonien, Sonaten, Opern und Quartette bekannt, weniger für ihre vielfach belegten Improvisationen, die nicht selten die Grundlage späterer Kompositionen bildeten (vgl. Nettl 1998: 9).

In der Musikwissenschaft nimmt die Beschäftigung mit Improvisation erst seit den 1960er Jahren einen größeren Raum ein. Bis dahin galt Ernst Ferands Buch von 1938 Die Improvisation in der Musik mangels Alternativen als konkurrenzlos, wogegen den Kompositionen und Biografien der großen Meister bereits zahlreiche Monografien und Aufsätze gewidmet waren (vgl. Nettl 1998: 1).

In Indien ist Improvisation so weit verbreitet, dass es schwer fällt, sie nicht als >Indian way of life < zu betrachten. Schon die Fahrt vom Flughafen in die Innenstadt einer beliebigen indischen Metropole konfrontiert den westlichen Besucher mit zahlreichen (Im-) Provisorien. Häuser werden ohne Bauplan und Architekten errichtet, Reparaturen völlig selbstverständlich nur mit den vorhandenen, oft unzureichenden Mitteln durchgeführt, Alltagsgegenstände wie Kronkorken werden zweckentfremdet und zu Knöpfen verarbeitet

1 Auszug aus der Speisekarte des inzwischen geschlossenen Restaurants $»$ Kafka in Berlin-Kreuzberg. 
etc. Dass dies nicht nur einem materiellen Mangel geschuldet ist, zeigt ein Blick auf die finanziell potente indische Filmindustrie. >Drehbücher< werden dort üblicherweise nicht geschrieben, sondern erzählt, diskutiert, verändert und der Situation am Drehort angepasst (vgl. Ganti 2004: 78-82; Uhl/Kumar 2004: 22-24). Auch die meist in westlicher Notation geschulten Filmmusiker ziehen die praktische und persönliche Unterweisung durch den Komponisten, Arrangeur oder Dirigenten der notierten Partitur vor (vgl. Ganti 2004: 78-82; Uhl/Kumar 2004: 22-24).

In der klassischen nordindischen Musik nimmt die Improvisation viel Raum ein. Manche Musiker sprechen von bis zu 95 Prozent (vgl. Khan 1983). Gleichzeitig entspricht ihr gesellschaftlicher Status weitgehend dem ihres westlichen Pendants. Klassische Musik wird hier wie dort in großen Konzertsälen gespielt. Sie zu hören, zu spielen oder sich in ihr auszukennen, bedeutet eine, mit Bourdieu gesprochen, Steigerung des sozialen und kulturellen Kapitals.

Meine bisherigen Ausführungen sollten dazu dienen, einen scharfen, stellenweise sicher überspitzten Kontrast zwischen dem Westen und Indien zu zeichnen. Folgt man meiner Konstruktion, so findet man auf der einen Seite eine Kultur, in deren Mittelpunkt das autonome, Vernunft gesteuerte und schöpferische Subjekt steht, welches das Göttliche - so es denn überhaupt noch eine Rolle spielt - ins Jenseits verbannt hat, eine Kultur, die Schriftlichkeit mit Wahrheit und Verlässlichkeit assoziiert und ihr damit einen hohen, ja beinahe heiligen Stellenwert einräumt. Dem gegenüber steht eine Kultur, die eine Identifikation von Göttlichem und Menschlichem verlangt, die Entindividualisierung als Heilsweg versteht, die der Oralität Authentizität und performative Qualitäten zuspricht und ihr daher gegenüber dem geschriebenen Wort den Vorzug gibt.

Folgt man weiterhin meiner oben formulierten These, dass als klassisch bezeichnete Kunstformen die Ideale einer Gesellschaft zum Ausdruck bringen, so müssten sich an der Gegenüberstellung von klassischer westlicher und klassischer indischer Musik die gerade erwähnten kulturellen Merkmale nachweisen lassen.

Im Bereich der westlichen Musik werde ich mich mit einigen Andeutungen begnügen, da einerseits eine ausführliche Diskussion den Rahmen sprengen würde und andererseits der Zusammenhang zwischen westlichen Idealen und der Interpretation klassischer 
Musik als Verkörperung dieser Ideale bereits mehrfach untersucht wurde. $^{2}$

Im deutschsprachigen Raum (und vermutlich auch darüber hinaus) versteht man unter >klassischer Musik< im engeren Sinne die »in der Musik von Haydn, Mozart, Beethoven (Wiener Klassiker) geschaffene Stileinheit, deren Blüte etwa in den Zeitraum von 17701825 fällt« (dtv Lexikon Band 10 1973: 166). Im weiteren Sinne wird unter dem Begriff jedoch die gesamte $>$ Ernste Musik ${ }^{3}$ seit der Renaissance subsumiert, wobei die Musik des 20. Jahrhunderts interessanterweise gelegentlich davon ausgenommen scheint. ${ }^{4}$

Die Tatsache, dass Komponisten wie Haydn, Mozart und Beethoven sowohl die Lehrpläne des schulischen Musikunterrichts, als auch die Spielpläne der Konzerthäuser dominieren, dass sie zu Genies stilisiert wurden und dass ihre Sinfonien und Sonaten als >absolute Musik< bezeichnet wurden, mag an dieser Stelle als Indiz dafür ausreichen, dass diese Komponisten und ihre Werke als Projektionsfläche für die Ideale der westlichen Gesellschaften dienten und noch immer dienen. So ist im dtv Lexikon denn auch folgender Satz zu lesen: »Der klassische Stil der drei Wiener Meister wurde vorbildlich für die gesamte abendländische Musik« (dtv Lexikon Band 10 1973: 167). Im Geniebegriff scheint sich das

2 Frank Hentschel (2006) hat in seiner kürzlich publizierten Untersuchung gezeigt, wie klassische Musik im Sinne bürgerlicher Ideologie instrumentalisiert wurde und Geschmack und Wertvorstellungen bis heute davon geprägt werden. Merriam (1964: 241-244) und Nettl (1998: 6-10) stellen fest, dass in der öffentlichen amerikanischen Meinung Komposition, im Sinne notierter Musik, mit bürgerlichen Wertvorstellungen wie Disziplin und Verlässlichkeit assoziiert wird, Improvisation dagegen mit Antiwerten wie Unzuverlässigkeit und der Neigung zu Alkohol- und Drogenmissbrauch.

3 Der Begriff »Ernste Musik« wird als höchste und somit bestbezahlte Kategorie im Katalog der Verwertungsgesellschaft GEMA genannt. Die Kriterien, nach denen die GEMA Werke einstuft, werden in Komponistenkreisen gelegentlich als willkürlich bezeichnet. So wurde ein kürzlich von einem befreundeten Komponisten eingereichtes, streng kontrapunktisch gesetztes Gitarrenquartett kurzerhand und ohne Begründung in die Kategorie U-Musik eingeordnet.

4 Dass »Neue Musik« nicht unbedingt die Werte der Aufklärung verkörpert, wenn beispielsweise Komponisten wie John Cage den Werkcharakter einer Komposition bewusst in Frage stellen, lässt sich leicht nachvollziehen. 
Ideal des autonomen, Vernunft gesteuerten und schöpferischen Subjekts geradezu in Reinform auszudrücken, im komponierten Sonatensatz dessen notierter und somit schriftlich fixierter kreativer Ausdruck.

Der Frage, ob sich in der klassischen nordindischen Musik die Ideale der indischen Gesellschaft widerspiegeln und ob sich meine These vom Westen als einer Kultur der Komposition und von Indien als einer Kultur der Improvisation dadurch erhärten lässt, soll im Folgenden etwas detaillierter nachgegangen werden. Wie bereits angedeutet, möchte ich dazu versuchen, in der gebotenen Kürze, die Konzepte bzw. Grundprinzipen dieser Musik zu erläutern und mich anschließend dem Phänomen der Improvisation zuwenden.

\section{Grundprinzipien der klassischen nordindischen Musik}

Auf dem indischen Subkontinent existieren zwei klassische Musiktraditionen nebeneinander, die südindische, auch karnatische Musik genannt und die nordindische, die auch als Hindustān̄ bezeichnet wird. Im Rahmen dieses Aufsatzes wird lediglich die nordindische Musik behandelt, da eine Untersuchung beider Traditionen den Rahmen sprengen würde.

Dem Einwand, dass der von mir angestrebte Kulturvergleich schon im Ansatz hinke, wo doch das Attribut >klassisch $<$ ganz offensichtlich von außen (vermutlich im Verlauf der britischen Kolonialherrschaft) an die indischen Musiktraditionen herangetragen wurde, möchte ich mit dem Argument begegnen, dass indische Musiker den Terminus >Classical Indian Music < gegenüber den indischen Termini vorziehen. ${ }^{5}$

Um dem Vorwurf zu entgehen, dass ich, als zwar in dieser $\mathrm{Mu}$ sik geschulte, aber aufgrund meiner Abstammung dennoch kulturfremde Person, Dinge für wesentlich erachten könnte, die indische Musiker als zweitrangig betrachten und umgekehrt, werde ich den

5 In der Bibliothek der Sangeet Natak Academy, einem staatlichen Zentrum für die Förderung und Erforschung der klassischen indischen Kunstformen in New Delhi, findet sich unter der Rubrik >Classical Music < die Literatur zu den beiden indischen Musiktraditionen, während eine Beethovenbiografie unter der Rubrik > Worldmusic $<$ zu suchen ist. 
Inhalt eines 1983 von Radio Bremen aufgezeichneten Interviews mit dem Musiker Imrat Khan thesenartig wiedergeben, in dem dieser einem deutschen Publikum die aus seiner Sicht fundamentalen Prinzipien erläutert.

1. Klassische nordindische Musik ist alt und traditionell.

2. Klassische nordindische Musik wird in kleinen Besetzungen gespielt.

3. Klassische nordindische Musik wird oral tradiert.

4. Klassische nordindische Musik basiert auf Melodie, klassische westliche Musik auf Harmonie.

5. Klassische nordindische Musik besteht zu 90-95 Prozent aus Improvisation und nur zu fünf bis zehn Prozent aus Komposition.

6. Die Improvisation folgt den strengen Regeln von $r a \bar{g}$ und $t \bar{a} l$.

Aus Platzgründen muss auf eine ausführliche Diskussion dieser sicherlich erklärungs- und diskussionswürdigen Thesen verzichtet werden. Lediglich die für die indische Musik so zentralen Begriffe $r \bar{a} g$ und $t \bar{a} l$ sollen im Folgenden kurz erläutert werden, da sie für das Verständnis der Musik und mit ihr der Improvisation von entscheidender Bedeutung sind.

Der Begriff rāg bezeichnet das der Melodiebildung zugrunde liegende Prinzip in der indischen Kunstmusik. Es handelt sich um ein melodisches Modell mit bestimmten emotionalen bzw. spirituellen Qualitäten, das auf einer Tonskala basiert und spezifische melodische Patterns und Ornamentierungen beinhaltet, welche die Grundlage für Komposition und Improvisation bilden. Zwischen 600 und 800 rāga sind in der nordindischen Kunstmusik bekannt, von denen etwa 200 heute in Gebrauch sind. Jeder rāg folgt einer gewissen melodischen >Logik<, wobei eine melodische Balance zwischen bestimmten Tönen innerhalb der Oktave postuliert wird. Die >innere Logik< bzw. Balance eins $r a \bar{g}$ wird häufig erst nach langjähriger Praxis entdeckt und verstanden (vgl. Bor 1999: 1f.).

Beim $t \bar{a} l$ handelt es sich um das rhythmisch-metrische Konzept der klassischen indischen Musik, das dem europäischen Takt nur sehr entfernt entspricht. Die Zeitvorstellung in der indischen Musik ist zyklisch, jeder $t \bar{a} l$ beginnt und endet auf der ersten Zählzeit sam (vgl. Bor 1999: 7f.). Ob die musikalische Zeitvorstellung ihren Ursprung in der ebenfalls zyklisch gedachten kosmischen Zeitvorstel- 
lung des Hinduismus findet, ist umstritten (vgl. Clayton 2000: 1526). Dass indische und vor allem hinduistische Musiker diesen Vergleich oft bemühen, zeugt jedoch einmal mehr davon, dass Göttliches und Alltägliches auf das Engste miteinander verwoben sind (vgl. Wegner 2004: 26f.). Gebräuchlich sind in der nordindischen Kunstmusik derzeit etwa dreißig tāla unterschiedlicher Länge und Geschwindigkeit. Als Bekanntester ist tīntāl zu nennen, ein rhythmischer Zyklus mit 16 Zählzeiten (matrā) (vgl. Bor 1999: 7f.).

Eine Performance und mit ihr die Improvisation wird jedoch nicht nur durch die strikten Regeln von $r \bar{a} g$ und $t \bar{a} l$ determiniert, sondern folgt auch weniger strengen, musikalischen Konventionen. Dazu zählt das Einhalten bestimmter Formabschnitte oder $>$ Sätze $<$ in vorgegebener Reihenfolge. Üblicherweise wird mit einem vollständig improvisierten, solistisch dargebotenen und nicht metrisierten Abschnitt ( $\bar{a} l \bar{a} p$ ) begonnen, der in meditativer Weise die Melodiegestalt und den emotionalen Gehalt vorstellt. Daran schließt sich eine langsame, vom Perkussionsinstrument begleitete Komposition an, der ein bestimmter tāl zugrunde liegt. Den Abschluss bildet eine weitere schnellere Komposition. Eine andere Konvention lässt sich hieraus ableiten. Im Verlauf der Performance nimmt die musikalische Dichte mittels Steigerung von Tempo und Virtuosität kontinuierlich zu. Im Unterschied zu den Gesetzen von $r \bar{a} g$ und $t \bar{a} l$ handelt es sich bei den Konventionen jedoch nicht um Muss-, sondern um Sollbestimmungen.

Um miteinander musizieren und improvisieren zu können, müssen sich geübte Musiker lediglich auf den zu spielenden $r \bar{a} g$ und $t \bar{a} l$ verständigen, was nicht selten erst auf der Bühne, unmittelbar vor Konzertbeginn geschieht.

\section{Was bedeutet Improvisation im Kontext der klassischen nordindischen Musik?}

Wie bereits erwähnt fallen unter die musikalische bzw. musikwissenschaftliche Kategorie Improvisation so viele unterschiedliche Phänomene, dass die Frage, ob es sinnvoll sei, sie mit einem einzigen Begriff zu belegen, durchaus berechtigt erscheint (vgl. Nettl 1998: 6-12). In diesem Zusammenhang erweist es sich als vorteilhaft, dass in der klassischen nordindischen Musik Improvisation und Komposition miteinander kontrastiert werden, ja meist als einander 
ausschließende Gegenpole aufgefasst werden, so wie es auch in der abendländischen Musik lange Zeit der Fall war. Dass die Grenze zwischen Komposition und Improvisation keineswegs immer so einfach zu ziehen ist, wurde bereits diskutiert. So habe ich es auch bei meinen indischen Musiklehrern gelegentlich erlebt, dass sie zu Unterrichtszwecken aus dem Stegreif einen gat, also eine Instrumentalkomposition erfanden bzw. improvisierten/komponierten. Allerdings stellt dies den Ausnahmefall dar. Kompositionen werden üblicherweise mit größter Sorgsamkeit, oft über Jahrhunderte hinweg tradiert.

Die kurzen bandiś-es (Vokalkompositionen) und gat-s (Instrumentalkompositionen), die jeweils zu Beginn des vom Perkussionsinstrument begleiteten Formabschnitts erklingen und im Verlauf der Performance mehrfach wiederholt werden, lassen sich von einem geübten Zuhörer nach einer kurzen Einhörphase leicht identifizieren. In einer recht typischen elfminütigen Aufnahme des sitārSpielers Vilayat Khan (Khan 1982) wird die Komposition zu Beginn dreimal gespielt und im Verlauf der Aufnahme weitere fünfmal wiederholt. Insgesamt nimmt dies etwa eine Minute und 30 Sekunden in Anspruch. Der indischen Vorstellung folgend, dass Komposition und Improvisation einander ausschließende Konzepte sind, müssen die verbleibenden neuneinhalb Minuten der Improvisation zugeordnet werden, was dem angedeuteten Anteil von etwa neunzig Prozent entspricht.

Da in einem späteren Abschnitt noch detaillierter darauf einzugehen sein wird, wie sich Improvisation und Komposition voneinander und von dem dazwischen zu verortenden Konzept der Präkomposition abgrenzen lassen, soll die Frage, was Improvisation im Kontext der klassischen nordindischen Musik bedeutet, zunächst mit der zweifellos unbefriedigenden Aussage beantwortet werden, dass Improvisation all das ist, was nicht Komposition im Sinne von bandiś oder gat ist.

\section{Welche Strategien spielen bei der Improvisation eine Rolle?}

Als aufmerksamer Musikhörer muss man nur einige Konzertmitschnitte indischer Musiker hören oder sie noch besser live erleben, um zu erkennen, dass ihre Improvisationen einem einfachen, uns 
auch aus westlichen Musikstilen bekannten Prinzip folgen, nämlich dem Spiel mit Erwartungen, also einer ausgewogenen Mischung aus Erwartungserzeugung, -erfüllung und -enttäuschung. Die grundsätzliche Einfachheit des Prinzips darf jedoch nicht darüber hinwegtäuschen, dass sich dessen Ausführung äußerst komplex gestalten kann.

Erzeugt werden diese Erwartungen einerseits durch die dem Publikum wohl bekannten Rahmenbedingungen, also dem Regelwerk aus $r \bar{a} g$ und $t \overline{a l}$, sowie den sonstigen musikalischen Konventionen, andererseits mittels bestimmter musikalischer Strategien. Als einfaches Beispiel wäre hier die Wiederholung zu nennen, also die periodische Wiederkehr bestimmter Versatzstïcke, die dem Zuhörer auf der einen Seite Orientierung verleiht, auf der anderen Seite die Erwartung einer erneuten Wiederholung hervorruft.

Um zu verstehen, wie das Spiel mit den Erwartungen im Einzelnen funktioniert, bietet sich methodisch folgende Möglichkeit an. Man transkribiert zunächst eine hinreichende Anzahl von Aufnahmen, analysiert diese auf Basis der indischen Musiktheorie und konfrontiert die Ausführenden anschließend mit den Ergebnissen und Interpretationen. Vor allem der letzte Punkt ist jedoch häufig mit Schwierigkeiten verbunden, doch dazu später mehr.

Da detaillierte Transkriptionen und Analysen im Rahmen dieses Aufsatzes keinen Raum finden können, werde ich mich mit einigen wenigen Beispielen begnügen, die teils aus eigener Erfahrung stammen, teils auf Untersuchungen anderer Musikwissenschaftler basieren (vgl. Slawek 1998, 2000). Dass sich auf diese Weise keinesfalls das komplette >Improvisationsrepertoire< eines oder gar mehrerer Musiker erfassen lässt, liegt in der Natur der Sache. Die hinter der klingenden Musik vermuteten Strategien sollten sich auf diese Weise aber dennoch nachweisen lassen.

Musik ist mehr als die Summe ihrer Einzelteile. Diesem Satz würde vermutlich die überwältigende Mehrheit der Musiker und Musikliebhaber zustimmen. Es ist beinahe müßig zu erwähnen, dass Musik erst durch das komplexe Zusammenspiel vieler physikalischer, psychologischer, sozialer und kultureller Faktoren entsteht. Sie im Rahmen einer musikanalytischen Untersuchung dennoch in verschiedene Parameter zu unterteilen, erscheint mir insofern sinnvoll, als sich auf diese Weise die Komplexität musikalischer Phänomene sprachlich besser darstellen lässt.

Die Strategien, die dem Spiel mit Erwartungen zugrunde liegen, werden im Folgenden nach primären, sekundären und außermusika- 
lischen Parametern unterschieden. $\mathrm{Zu}$ den primären Parametern zähle ich die für die indische Musik fundamentalen Prinzipien von Melodie und Rhythmus, zu den sekundären die Prinzipien der klanglichen Realisierung wie Phrasierung, Dynamik, Klangfarbe usw. und zu den außermusikalischen alle Formen von interaktiven Momenten.

\section{Primäre musikalische Parameter}

Eine $r \bar{a} g$ Performance beginnt, wie bereits erwähnt, in aller Regel mit dem solistisch dargebotenen, vollständig improvisierten Formteil ālāp, der eine langsame und meditative Exposition des rāg darstellt. Viele rāga ähneln sich stark in Bezug auf ihre Melodiegestalt und beinhalten teilweise denselben Tonvorrat. In diesem Fall sind sie nur durch bestimmte melodische Phrasen und/oder die spezifische Behandlung einzelner Töne voneinander zu unterscheiden wie beispielsweise Ornamentierungen. Traditionell sollte ein $r \bar{a} g$ innerhalb der ersten paar Sekunden einer Performance eindeutig zu identifizieren sein. Um Spannung zu erzeugen, wird die Identifizierbarkeit des $r \bar{a} g$ gelegentlich bewusst hinausgezögert, indem ein Ton (bzw. ein Ornament) zurückgehalten wird. Erklingt der entscheidende Ton dann nach einiger Zeit, so löst sich die Spannung unmittelbar, was beim indischen Publikum häufig zu lautem Raunen oder begeisterten Zwischenrufe führt. Der Konzertmitschnitt des Rāg Mārū Bihāg, gespielt von dem sitār-Spieler Nikhil Banerjee liefert hierfür ein eindrückliches Beispiel (Banerjee 2004). Erst nach 6 Minuten 45 Sekunden erklingt der Identifikationston, der dem $r \bar{a} g$ zu seiner vollständigen Melodiegestalt verhilft. Bereits einige Zeit vorher ist im Publikum deutliche Unruhe zu hören, die sich an der entscheidenden Stelle zu lauten kyä bat Rufen (sinngemäß $>$ bravo $<$ ) steigert und sofort wieder konzentrierter Ruhe weicht.

Eine weitere Möglichkeit melodischer Improvisation besteht darin, einzelne Töne mittels Umspielen oder Verzieren auf unterschiedlichste Weisen zu präsentieren. Nicht selten wird hierbei ein einziger Ton über einen Zeitraum von bis zu zehn Minuten vorgestellt, ohne dass sich je eine Phrase wiederholte. Diese Form der Improvisation, die mit der (melodischen) Ausgestaltung der rāg Merkmale spielt, wird rāg-vistār, sinngemäß >Entwicklung des $r \bar{a} g$ < genannt. 
Dem ālāp folgt eine Komposition. Im Gegensatz zum ālāp ist jede Komposition metrisiert, also in einem $t \bar{a} l$ gesetzt, der vom Perkussionsinstrument tablā markiert wird. Nachdem die sich häufig nur über einen $t \bar{a} l$-Zyklus erstreckende Komposition einige Male vorgestellt wurde, beginnt die Improvisation, während die tabla weiterhin den Grundrhythmus des $t \bar{a} l$, den so genannten thek $\bar{a}$ spielt. Die tablā Begleitung dient somit zur metrischen Orientierung sowohl für den improvisierenden Musiker, als auch für die Zuhörer, von denen viele bemüht sind, den thekā mitzuklatschen.

Eine häufig angewandte Improvisationsstrategie besteht nun darin, die Zuhörer aus dem metrischen Gleichgewicht zu bringen, also die Illusion eines Metrum- oder Tempowechsels zu erzeugen, um anschließend, möglichst auf der ersten Zählzeit eines neuen $t \bar{a} l$ Zyklus erneut in den Zustand des spannungsarmen metrischen Gleichgewichts zurückzukehren.

Um dies zu erreichen, werden beispielsweise bereits bekannte musikalische Phrasen, etwa die Komposition, unter Beibehaltung der ursprünglichen Melodiegestalt gestaucht oder gestreckt. Statt auf der ersten Zählzeit beginnt die Phrase also möglicherweise auf der fünften und muss dementsprechend schneller gespielt werden, um auf der Eins des nächsten Zyklus zu landen. Präzise Rechenarbeit bzw. ein sehr gutes zeitliches Vorstellungsvermögen sind unabdingbare Voraussetzungen hierfür (vgl. Slawek 1998: 358-363).

Eine ähnliche Strategie basiert auf Betonungsverschiebungen. Normalerweise betonte Zählzeiten werden unbetont gelassen, Synkopierungen hingegen exponiert, was zu kontrametrischen Empfindungen führt und häufig selbst geübte Zuhörer zwingt, gegen den eigentlichen Puls mitzuklatschen. Nach einer gewissen Zeit der rhythmischen Improvisation kehren die Musiker wieder gemeinsam in den regulären Betonungszyklus zurück, wodurch sich die absichtlich herbeigeführte Spannung wieder auflöst.

Um einen improvisierten Abschnitt mit einer Klimax abzuschließen und gleichzeitig zur folgenden, spannungsärmeren Musik (i.d.R. der bereits bekannten Komposition) überzuleiten, hat sich eine bestimmte Improvisationsstrategie beinahe schon zur Konvention entwickelt, der tihāi. Es handelt sich hierbei um eine rhythmische Formel, die dreimal wiederholt wird und mit ihrer letzten Note auf der ersten Zählzeit eines tāl-Zyklus endet. Viele indische Musiker verbringen Jahre ihrer Ausbildung damit, unzählige tihā̄ $-s$ zu berechnen und auswendig zu lernen, die es ihnen ermöglichen, von 
jeder beliebigen Stelle im $t a \bar{l}$-Zyklus auf elegante Art und Weise zur Eins zurückzukehren.

Es lässt sich zu Recht fragen, ob hier nicht anstelle von Improvisation besser von Präkomposition zu sprechen sei. Dem soll jedoch an späterer Stelle nachgegangen werden.

\section{Sekundäre musikalische Parameter}

Wie im Bereich der primären musikalischen Parameter existiert auch bei den sekundären eine Vielzahl von Einzelstrategien, die, komplett darzustellen, ein ganzes Buch füllen würde. Anhand eines kleinen Beispiels kann aber verdeutlicht werden, was mit Improvisation in diesem Bereich gemeint ist.

Geschwindigkeit und Virtuosität sind unter indischen Musikern gefragte Fähigkeiten. Ein über mehrere $t \bar{a} l$-Zyklen gespielter oder gesungener sapāt tān, also eine virtuose Passage in rasendem Tempo über drei Oktaven, wird von den Zuhörern meist mit großem Wohlwollen quittiert. Zur besonderen Spannungsentladung kommt es jedoch, wenn die Passage ein unerwartetes Ende findet, beispielsweise durch die Verwendung einiger lang gezogener und ruhiger Töne. Anstatt mit einem virtuosen Crescendo abzuschließen (Erwartungshaltung), kann ein solches, durch Kontrastierung vor allem sekundärer musikalischer Parameter herbeigeführtes Ende (Erwartungsenttäuschung) bei gekonntem Einsatz beinahe eine emotionale Explosion seitens der Zuhörer provozieren. Der bereits erwähnte sitār-Spieler Vilayat Khan entpuppt sich auf diesem Gebiet als wahrer Meister seines Fachs. Die Publikumsreaktionen, die ich bei Konzerten beobachten bzw. bei Konzertmitschnitten hören konnte, erinnerten gelegentlich an Szenen bei Rock- oder Popkonzerten. Menschen sprangen von ihren Stühlen auf, stöhnten laut oder begannen zu weinen.

Dass den sekundären Parametern, die selbstverständlich nicht unabhängig von den primären Parametern Melodie und Rhythmus existieren können, ein separater Punkt gewidmet ist, liegt an den Möglichkeiten, die sie bieten, um das musikalische Geschehen zu variieren und interessant zu gestalten. 


\section{Außermusikalische Parameter ${ }^{6}$}

Improvisation ist in der indischen Musik undenkbar ohne interaktive Momente, wobei sich die Interaktion nicht nur auf die rein musikalische Kommunikation zwischen den Ausführenden beschränkt, sondern sich ebenso häufig zwischen Musikern und Publikum oder auch zwischen Musikern und Außenwelt vollzieht. $\mathrm{Zu}$ allen drei Aspekten lassen sich, bei Konzertmitschnitten vor indischem $\mathrm{Pu}$ blikum, zahlreiche Beispiele finden.

Die Behauptung, dass Musiker, um gemeinsam zu improvisieren, auch interagieren müssen, erscheint zunächst banal. In der klassischen indischen Musik findet man jedoch einen besonders hohen Grad an Interaktion. In der Regel wechseln sich Sänger bzw. Instrumentalist und Perkussionist beim Improvisieren ab. Auf das improvisatorische Material des Vorgängers wird dabei gerne zurückgegriffen. Häufig entstehen auf diese Weise spontane Frageund-Antwort-Spiele, Imitationen oder auch kollektive Improvisationen. Grundsätzlich wird Sängern und Instrumentalisten in ihrer musikalischen Ausbildung empfohlen, ein paar Jahre das tablāSpiel zu erlernen, um die rhythmische Fähigkeit zu schulen und adäquat auf den Begleiter reagieren zu können. In der Regel sorgt der guru dafür, dass seine Schüler bereits in einem frühen Ausbildungsstadium mit einem Trommelbegleiter üben, um die Aufmerksamkeit auf die musikalische Interaktion zu lenken.

Der sitār-Spieler Imrat Khan, der in der Vergangenheit häufig mit seinen Söhnen auftrat, merkt in dem bereits erwähnten Interview von 1983 an, dass sie nach Jahren gemeinsamen Übens in der Lage seien, »to read each others' minds « (Khan 1983). Der Konzertmitschnitt, in dessen Rahmen das Interview aufgezeichnet wurde, scheint diese Aussage auf eindrückliche Weise zu bestäti-

6 Diese auf Kommunikation und Interaktion beruhenden Parameter als außermusikalisch zu bezeichnen, mag insofern verfehlt erscheinen, als sie selbstverständlich in der Musik niederschlagen. Mit dem Begriff soll jedoch angedeutet werden, dass die Signale, auf denen die Kommunikation beruht, nicht musikalischer Natur sein müssen. Im Gegensatz zu den primären und sekundären Parametern lassen sich die Auswirkungen im klanglichen Geschehen daher auch nicht unbedingt nachweisen. So kann ein Musiker zwar beispielsweise auf die Mimik seines Kollegen musikalisch reagieren, nachvollziehen lässt sich dies anhand einer Schallaufnahme jedoch nicht. 
gen. Die drei sitār (eine für die klassische nordindische Musik ungewöhnlich große Besetzung) fügen sich hier zu einem organischen Ganzen zusammen, ohne dass der Eindruck des Einstudierten entstünde (Khan, Imrat/Khan, Nishad/Khan, Irshad/Khan, Shafaatullah 1983).

Die Positionierung der Musiker auf der Bühne ist stets so angelegt, dass sie einander im Blickfeld haben, um so möglichst schnell und spontan auf den anderen reagieren zu können. Selbst beim solistisch dargebotenen ālāp, ist der begleitende Musiker grundsätzlich mit auf der Bühne und selbst im Tonstudio hält er sich, meinen Erfahrungen nach, hinter der verglasten Studiowand im Sichtfeld des Kollegen auf, um mittels Blickkontakt mit ihm zu interagieren.

Anders als das westliche Publikum verstehen sich Inder nicht als stille Zuhörer, sondern als integrativen Bestandteil einer Darbietung klassischer Musik. Laute Zwischenrufe, bewunderndes Zischen, spontanes Klatschen und das obligatorische zustimmende Schütteln der Köpfe gehören zum Konzertalltag. Die Musiker reagieren in der Regel auf die Äußerungen des Publikums, sei es indem sie besonders gefällige Passagen immer weiter ausbauen oder die Performance kurzfristig unterbrechen, um das Publikum über die Herkunft einer besonders alten Komposition zu unterrichten. Als besondere Gefälligkeit an ein begeistertes Publikum gilt es, wenn Instrumentalisten Melodiepassagen zunächst singen, bevor sie diese auf ihrem Instrument wiedergeben. Dadurch wird der vokale Ursprung der klassischen nordindischen Musik lebendig demonstriert und unterstrichen.

Ein eindringliches Beispiel hierfür liefert ein Konzertmitschnitt des sitār-Spielers Vilayat Khan aus dem Jahr 1985 in Kolkata. Durch seinen vokalen und instrumentalen Vortrag des Rāg Bhairavī versetzt er das Publikum derart in Ekstase, dass der abschließende Applaus beinahe wie eine Erlösung klingt. Erreicht wird dies vor allem dadurch, dass er den Zuhörern Passagen, die diese zu besonderen Beifallsbekundungen hinreißen, immer wieder in neuen Varianten präsentiert (Khan 1985).

Klassische nordindische Musik zielt in erster Linie darauf $a b$, bestimmte emotionale Zustände zu kreieren. Die gesamte ästhetische Theorie der nordindischen Kunstmusik beschäftigt sich mit Fragen der Emotionalität und der Erzeugung von Stimmungen (vgl. Schmidt 2006: 1-3). Indische Musiker sind der festen Überzeugung, dass sie vor allem dann außergewöhnlich gute Konzerte spielen, 
wenn sie selbst guter Stimmung sind. Das Setting spielt daher eine große Rolle: Gute Akustik, ein geduldiger und freundlicher Tontechniker und eine bequeme und ruhige Garderobe mit bereitgestellten Getränken stellen Faktoren dar, welche die Qualität eines Konzerts beträchtlich steigern können. Dass man als Mensch mit seiner Umwelt interagiert, ist selbstverständlich, doch bei indischen $\mathrm{Mu}-$ sikern schlagen sich Einflüsse der Umgebung häufig unmittelbar in der Musik nieder. Berühmt ist beispielsweise ein Konzert Vilayat Khans aus den 1970er Jahren, bei dem die Quarte eines aus der Ferne erklingenden Martinshorns als Motiv für eine Fülle von Varianten diente. ${ }^{7}$

\section{Improvisation, Komposition und Präkomposition}

Es wurde bereits angedeutet, dass die Anwendbarkeit des Begriffs Improvisation auf die klassische nordindische Kunstmusik nicht unumstritten ist: Wenn Musiker, wie oben erwähnt, hunderte von tihā $\bar{l}-s$ berechnen und memorieren, kann von spontaner Erfindung und Realisierung ganz offensichtlich keine Rede sein. Des Weiteren weisen Widdess und Nooshin zu Recht darauf hin, dass sich in den vormodernen, musiktheoretischen Quellen kein expliziter Hinweis auf das Konzept der Improvisation findet (vgl. Widdess/Nooshin 2006: 105f.). Selbst in der zeitgenössischen indischen Musiktheorie existiert kein äquivalenter Begriff zur Improvisation ${ }^{8}$, dafür jedoch eine Reihe von Termini, die abhängig vom Stil, bestimmte Aspekte einer Performance bezeichnen, über deren Ausgestaltung das Können und die Kreativität der Musiker entscheiden. Ob diese jedoch improvisiert werden oder zu Hause minutiös geplant, memoriert und anschließend aus dem Gedächtnis gespielt werden, ist vom Höreindruck allein zunächst nicht zu entscheiden.

7 Obwohl mir diese Anekdote mehrfach von verschiedenen Leuten erzählt wurde, ist es mir leider nie gelungen, einen Mitschnitt dieses Konzertes zu hören.

8 Widdess und Nooshin erwähnen zwar den Begriff upaj (Idee, Erfindung) (vgl. Widdess/Nooshin 2006: 106). Von meinen Lehrern wurde dieser Ausdruck jedoch nie verwendet. 
Auch in der Unterrichtspraxis spielt das Diskutieren oder systematische Lehren von Improvisation keine Rolle. In den 17 Jahren meiner musikalischen Ausbildung habe ich, äußerst selten und nur dank insistierender Nachfrage, gelegentlich einen versteckten Hinweis auf die Entwicklung von Improvisationsstrategien erhalten.

Demgegenüber steht der im Kapitel über die Grundprinzipien der klassischen nordindischen Musik erwähnte und von vielen $\mathrm{Mu}$ sikern bestätigte Satz Imrat Khans, dass 90 bis 95 Prozent der nordindischen Kunstmusik improvisiert seien. Aber selbst diese Aussage erscheint insofern zweifelhaft, als indische Musiker keinen Widerspruch darin sehen, ihren Schülern vorfabrizierte tān-s und tihā̄-s zu vermitteln und diese gleichzeitig als improvisiert zu bezeichnen. Bleiben also von den stolzen 95 Prozent lediglich die wenigen von mir angeführten Beispiele über Improvisation und Interaktion übrig? ${ }^{9}$

Eingangs wurden Komposition und Improvisation in der klassischen nordindischen Musik als opponierende Konzepte vorgestellt. Es wurde weiterhin erwähnt, dass Kompositionen im Sinne von gat-s bzw. bandiś-es anhand ihrer musikalischen Struktur, ihrer Position innerhalb der Performance und der Art und Weise ihrer Tradierung verhältnismäßig leicht und eindeutig zu identifizieren seien. In diesem Sinne wurde, Imrat Khans Aussage folgend, als Improvisation all das bezeichnet, was nicht Komposition ist. Um nun $\mathrm{zu}$ einer eindeutigen Bewertung bezüglich der Improvisation zu gelangen, müssen die als improvisiert angenommenen Abschnitte auf vorgefertigte, also präkomponierte Strukturen hin untersucht werden. Die anhand der Improvisationsstrategien getroffene Einteilung der Musik in primäre, sekundäre und außermusikalische Parameter möchte ich hierzu beibehalten.

Sowohl Präkomposition als auch Improvisation beruhen in der klassischen nordindischen Musik auf dem Prinzip eines Baukastens, wie ich in meiner Unterrichtspraxis feststellen konnte. Schüler erlernen im Verlauf der Jahre von ihren Lehrern unzählige, kleine, vorgefertigte Bausteine wie beispielsweise $t \bar{a} n-s$ und tihā̄is verschiedener Länge und Geschwindigkeit, sowie zahlreiche Varianten von Tonkombinationen, Anschlagspattern usw.

9 Die Reaktion eines Publikums oder das akustische Umfeld eines Auftrittsortes lassen sich tatsächlich nur schwerlich vorhersehen. 
Zur Unterscheidung zwischen Präkomposition und Improvisation im Bereich der primären musikalischen Parameter sei daher eine graduelle Abstufung im Bereich der Flexibilität vorgeschlagen. Demnach wären als präkomponierte Strukturen solche zu verstehen, die in beiden primären musikalischen Parametern (d.h. Melodie und Rhythmus) fixiert sind, wogegen bei improvisierten Strukturen höchstens ein primärer Parameter feststeht. Während also vorfabrizierte $t \bar{a} n-s$ und tihā̄ $-s$, sprich in Melodie und Rhythmus festgelegte Pattern der Präkomposition zuzurechnen wären, bestünde Improvisation beispielsweise darin, verschiedene rhythmische und/oder melodische Varianten einer mathematischen tihāit-Formel ad hoc zu realisieren.

Das für die Improvisation entscheidende Kriterium der Spontaneität (vgl. Nettl 1998: 10-12) wird durch die Differenzierung zwischen Präkomposition und Improvisation nicht angetastet. So wäre selbst die spontane Kombination zweier präkomponierter Bausteine der Improvisation zuzurechnen, da aus der Kombination eine neue, größere Struktur entstünde, deren melodisch-rhythmische Gestalt vorher nicht abzusehen war.

Ob einzelne Passagen oder ganze Performances dem einen oder anderen Bereich zuzurechnen sind, lässt sich durch einen spontanen Höreindruck nicht entscheiden. Erst analytisches Hören (und eventuell das Transkribieren) einer größeren Anzahl von Aufnahmen ein und desselben Musikers oder noch besser die Beobachtung seiner Übungsroutine lassen Rückschlüsse auf die improvisierten bzw. präkomponierten Anteile seiner Musik zu.

Die Qualität eines Musikers ist nicht zuletzt davon abhängig, über wie viele Improvisationsbausteine er verfügt und wie flexibel er im Umgang mit dem Material ist. Bei fast allen Musikern lassen sich bestimmte Strukturen, wie beispielsweise die rhythmische Organisation von tān-s immer wieder feststellen. Dennoch überraschen manche Musiker nicht nur eingefleischte Anhänger, sondern - nach eigener Aussage - auch sich selbst immer wieder aufs Neue.

Auch Variationen im Bereich der klanglichen Gestaltung (sekundäre Parameter) werden in der Unterrichtspraxis anhand vorgefertigter Strukturen eingeübt. Mit der Zeit scheint sich durch die Kontrastierung, beispielsweise im Bereich der Dynamik, ein Gefühl dafür einzustellen, an welchen Stellen einer Performance bestimmte Strategien gut oder weniger gut funktionieren. Wie im Bereich der primären Parameter lassen sich hier im Vergleich zahlreicher 
Aufnahmen ein und desselben Musikers manche Varianten bestimmter Kontrastierungen immer wieder feststellen, was auf präkomponierte Strukturen hinweist. Da sie jedoch nicht unabhängig von den primären Parametern Melodie und Rhythmus existieren, erscheint eine separate Betrachtungsweise wenig sinnvoll.

Im Bereich der außermusikalischen Parameter scheidet die Möglichkeit der Präkomposition ohnehin fast aus, obwohl gelegentlich ein von allen Musikern simultan gespielter tihā̄, der die Performance abschließt, vorher eingeübt wird, um eine stimmige Klimax zu erreichen. Da die Ensembles in der Regel aus wechselnden Musikern bestehen, sind Absprachen aber ansonsten unüblich. Die Sensibilität, die indische Musiker im Bezug auf den Kontext der Performance beweisen, spricht daher deutlich für ihre große Flexibilität und damit für ihre improvisatorischen Fähigkeiten.

Fragt man indische Musiker, was sie eigentlich tun, wenn sie improvisieren oder konfrontiert man sie mit Analysen ihrer Aufnahmen, fallen die Antworten in den seltensten Fällen musikanalytisch verwertbar aus. So sprechen erfahrene Musiker gerne davon, dass die Musik einfach durch sie hindurch geschehe, ohne dass sie großen Anteil daran hätten oder dass sie sich beim Improvisieren in einer Art Trancezustand befinden und ihnen gar nicht bewusst ist, was mit ihnen und um sie herum geschieht (vgl. Shankar 2002: DVD1).

Dies lässt sich auf zweierlei Art deuten, entweder als Strategie, um die Musik zu mystifizieren und die Geheimnisse des Improvisierens vor dem Fragenden zu verbergen, oder aber - und dies bestätigt meinen Eindruck im Umgang mit indischen Musikern - die Improvisation vollzieht sich quasi >am Intellekt vorbei<. Durch jahrelange Übungspraxis werden Improvisationsbausteine soweit inkorporiert, dass die Entscheidung, wie eine musikalische Idee zu realisieren sei, reflexartig gefällt wird. Musikalische bzw. improvisatorische Entscheidungen laufen dadurch unbewusst ab und sind nachträglich nur schwerlich intellektuell zu erklären. Mein sitār-Lehrer Subroto Roy Chowdhury antwortete einmal auf die Frage, ob er vor einem groBen oder wichtigen Konzert aufgeregt sei, mit der erstaunten Gegenfrage, warum er aufgeregt sein solle, er übe schließlich jeden Tag mehrere Stunden. Bei Konzerten sei er vielmehr darauf gespannt, was wohl diesmal aus ihm herauskommen werde.

Die indische Unterrichtspraxis untermauert die These der Inkorporation. Von der ersten Stunde an wird Musik sinnlich erlebbar ge- 
staltet. Passagen müssen von Instrumentalschülern meist erst gesungen werden, bevor sie auf dem Instrument umgesetzt werden, Perkussionisten müssen ihre Trommelpatterns erst mit den richtigen Trommelsilben rezitieren können, bevor sie sich ans Instrument setzen dürfen. Die oft seltsam anmutenden Bewegungen, die von Sängern ausgeführt werden, sollen zum einen die Tonproduktion unterstützen, zum anderen das Gesungene gestisch unterstreichen und das körperliche Empfinden der Musik steigern. Größter Wert wird auf die korrekte Imitation der vom guru vorgegebenen Passagen gelegt. Das Fragen und Erläutern, das Planen und Abwägen sowie Diskussionen musikalischer Strukturen oder musiktheoretischer Probleme - pädagogische Konzepte, die in der westlichen Musikerausbildung als wesentlich erachtet werden - finden hier kaum Platz. In einem fortgeschrittenen Stadium beginnt der Schüler unter der Anleitung des Lehrers, einzelne, zunächst kleine Passagen zu variieren. Dabei wird er vom Lehrer so lange diskussionslos (!) korrigiert, bis dieser mit dem Ergebnis zufrieden ist. Die beinahe schon antiintellektuelle Methode der Imitation bei gleichzeitig gesteigertem sinnlichen Erlebnis der Musik scheint, so seltsam das der westlichen Vorstellung von Musikpädagogik vorkommen mag, eine äußerst effiziente Methode zu sein, die Sinne und das emotionale, unbewusste Verständnis des Schülers dafür zu schärfen, was im Rahmen eines $r a \bar{g} g$ machbar und ästhetisch ansprechend ist und was nicht.

\section{Aus welchen Gründen wird improvisiert?}

Der Frage, warum in der klassischen nordindischen Musik überhaupt improvisiert wird bzw. warum die Improvisation in ihr eine so herausragende Stellung einnimmt, ist bisher kaum nachgegangen worden. Das ist insofern nicht verwunderlich, als meines Wissens, sowohl historische als auch moderne Quellen kaum dazu Stellung nehmen. Dass ein analoger Begriff für Improvisation in der indischen Musikterminologie nicht vorhanden ist, wurde bereits erwähnt. Für die indischen Musiker der Gegenwart scheint Improvisation ein so selbstverständlicher Bestandteil ihrer musikalischen Praxis zu sein, dass auch aus dieser Richtung kaum Aufklärung zu erwarten ist. Da die Frage für meine These vom Westen als einer Kultur der Komposition und Indien als einer Kultur der Improvisation jedoch von entscheidender Bedeutung ist, werde ich versuchen, 
ihr mit einer teils auf Spekulationen, teils auf Indizien aufgebauten Argumentation nachzugehen. Die Ergebnisse möchte ich daher auch nicht als endgültige Fakten verstanden wissen, sondern als Anregung zu einer weiterführenden Diskussion.

Fünf Faktoren scheinen mir für die Stellung und Entwicklung der Improvisation in der klassischen nordindischen Musik von ausschlaggebender Bedeutung zu sein.

- (Musik-)historische Faktoren

- Sozioökonomische Faktoren

- Technische Faktoren

- Religiös-kulturelle Faktoren

- Psychologische Faktoren

Die getrennte Betrachtungsweise dieser Faktoren erfolgt aus Gründen der Übersichtlichkeit, wenngleich sie in Wirklichkeit sicherlich einander bedingen und voneinander abhängig sind.

\section{(Musik-)historische Faktoren}

Ein, wenn auch nur oberflächlicher Blick auf die Geschichte der klassischen nordindischen Musik zeigt, dass der improvisierte Anteil an der Musik keineswegs immer so hoch war wie heute, wenngleich sich in musikhistorischen Quellen nur indirekte Hinweise darauf finden lassen.

Historische Quellen belegen einerseits, dass die Performance eines $r \bar{a} g$ im 16. und 17. Jahrhundert nur einen Bruchteil der Zeit heutiger Performances in Anspruch nahm (vgl. Sanyal/Widdess 2004: 45-59). Andererseits sind von vielen heute noch gebräuchlichen Kompositionen aus dieser Zeit nur die ersten beiden von vier mündlich überlieferten Abschnitten erhalten. Zieht man also in Betracht, dass die Performances kürzer, die Kompositionen gleichzeitig länger waren, lässt sich hieraus schlussfolgern, dass der komponierte Anteil gegenüber dem improvisierten deutlich mehr Raum einnahm.

Etwa seit der Zeit des Mogulkaisers Akbar (1556-1605) wird die klassische nordindische Musik in familiären Traditionslinien (gharāna) gelehrt, die entweder nach dem jeweiligen Gründer der Tradition oder nach dem Entstehungsort benannt werden. Bis in die heutige Zeit ist die Zugehörigkeit fast aller Musiker der nordindi- 
schen Kunstmusik zu einem bestimmten gharāna anhand von musikalischen Merkmalen wie Stimmproduktion, Applikation von Melismen, Sing- und Spieltechniken, Instrumentation, Repertoire der rāga usw. zu erkennen. Es ist davon auszugehen, dass eine Spezialisierung auf bestimmte Aspekte der rāg-Performance bereits im 16 . Jahrhundert stattgefunden hat, die durch das relativ hermetische abgeschlossene gharāna-System immer weiter vorangetrieben wurde (vgl. Sanyal/Widdess 2004: 61-94). Dass diese Spezialisierung auch Einfluss auf die Entwicklung der Improvisation nahm, ist anzunehmen, da bestimmte improvisierte Formteile bzw. Improvisationstechniken in unterschiedlich starker Ausprägung in den verschiedenen gharāna existieren.

Die musikalische Form ist im älteren dhrupad-Stil insofern weit strenger als in den späteren musikalischen Formen, da sie den $\mathrm{Mu}-$ sikern deutlich weniger Gestaltungsspielraum überlässt. Die strikten musikalischen Kriterien, denen die Musiker zu folgen hatten, werden heute oftmals als Hauptgrund dafür angeführt, dass der dhrupad im 18. Jahrhundert durch den heute wesentlich populäreren $k h y \bar{a} l$-Stil abgelöst wurde (vgl. Sanyal/Widdess 2004: 53-55). Der $U r d u$-Begriff khyāl bedeutet übersetzt Imagination oder Fantasie. Der khyäl unterscheidet sich vom dhrupad vor allem dadurch, dass viele formale Kriterien aufgebrochen und außer Kraft gesetzt wurden, wodurch Raum für individuelle Ausdrucksmöglichkeiten entstand (vgl. Kuckertz 1996: 696-698). Heute ist der khyāl die am stärksten von Improvisation durchsetzte Form der klassischen nordindischen Musik.

Neben der Notwendigkeit, verloren gegangene Teile von Kompositionen zu ersetzen, scheinen also eine voranschreitende Spezialisierung und die Entwicklung neuer musikalischer Formen nachhaltigen Einfluss auf die Entfaltung der Improvisation ausgeübt zu haben.

\section{Sozioökonomische Faktoren}

Der Einfluss sozioökonomischer Faktoren auf die musikalische Praxis der klassischen nordindischen Musik wurde bisher kaum untersucht. Anhand von zwei Beispielen möchte ich andeuten, was hiermit gemeint ist.

Mit der Machtübernahme der Moguln etablierte sich in Nordindien ein komplexes und hoch spezialisiertes höfisches Herrschafts- 
system. Musiker lebten und lehrten an den Höfen als Angestellte der jeweiligen Fürsten. Die im Gegensatz zu anderen Berufsgruppen ungewöhnlich starke Fluktuation der Musiker zwischen den einzelnen Höfen und die historischen Beschreibungen der Publikumswirksamkeit einzelner Musiker werte ich als Hinweis auf die große Nachfrage nach Virtuosität und kreativem individuellen, also auch improvisatorischen Ausdruck (vgl. Sanyal/Widdess 2004: 47f.). Der sagenumwobene Hofmusiker Mian Tansen gibt das beste Beispiel hierfür ab. An Akbars Hof galt er als eines der Hofjuwelen, seine Performances wurden von den Chronisten als so hinreißend beschrieben, dass er vermutlich schon zu Lebzeiten zur Legende wurde (vgl. Sanyal/Widdess 2004: 45-49; Tyagi 1997: 137).

Die Auflösung der letzten Fürstenhöfe durch die Briten im frühen 20. Jahrhundert dürfte ebenfalls erheblichen Einfluss auf die Improvisation ausgeübt haben. Fürstlicher Protektion beraubt waren die Musiker nun gezwungen, ihr Brot als freischaffende Künstler zu verdienen und vor einem vorwiegend bürgerlichen Publikum zu bestehen (vgl. Hamilton 1989: 8-17). Gerade hier vermute ich eine starke Triebfeder für die Entwicklung der Improvisation, vor allem in Richtung Virtuosität. Der Trend ist im Vergleich von Aufnahmen des frühen und des späten 20. Jahrhunderts feststellbar und hält bis heute an. Die jüngere Generation von Musikern scheint oftmals so sehr auf Virtuosität und Geschwindigkeit fokussiert zu sein, dass einige, für klassische nordindische Musik wesentliche Aspekte, wie beispielsweise die korrekte Applikation charakteristischer Melismen dabei verloren gehen.

\section{Technische Faktoren}

Die Auswirkungen von technischen Neuerungen, wie beispielsweise der Entwicklung von Aufnahmetechniken und der Verbesserung von Instrumenten, auf die Musik sind anhand von Aufnahmen gut nachzuweisen. Je ein Beispiel mag dies illustrieren.

Der sitār-Spieler Buddhaditiya Mukherjee wird manchmal scherzhaft als bester Schüler Vilayat Khans bezeichnet, obwohl er nie Unterricht vom diesem erhalten hat. Seinen Stil, der eindeutig in dieser Tradition steht, hat er sich anhand von Schallaufnahmen erarbeitet, worüber Vilayat Khan sehr verärgert gewesen sein soll, wie ich mehrfach von indischen Musikern erfahren habe. 
Der sitār-Stil dieser Tradition, der als Besonderheit extrem viele Gleitbewegungen auf der Hauptsaite des Instruments aufweist, wurde erst durch eine Verbesserung der Instrumente Mitte des 20. Jahrhunderts möglich. Die Verwendung von Stahlsaiten und einer dickeren Decke produziert einen Ton mit langem Sustain, ohne den die vielen mikrotonalen Nuancen unmöglich zu spielen wären ( $\mathrm{vgl}$. Slawek 2000: 11-16).

\section{Religiös-kulturelle Faktoren}

Die Bedeutung und vor allem Wertschätzung der Improvisation lässt sich anhand musikhistorischer, sozioökonomischer und technischer Überlegungen allein sicherlich nicht erklären. Die unter diesen drei Punkten zusammengefassten Argumente könnten, auf den Westen angewandt und dafür leicht modifiziert, schließlich auch als Triebfedern für die Entwicklung einer Kompositionspraxis angeführt werden. ${ }^{10}$

Verstehen lässt sich Hinwendung zur Improvisation nur vor dem Hintergrund einiger musikspezifischer Überlegungen, die eine grundsätzliche kulturelle Differenz zwischen der Musikauffassung des Abendlandes und Indiens offenbaren.

Ein $r a \bar{g} g$ gilt, im Gegensatz zu einem von Menschenhand erschaffenen musikalischen Werk, als a priori existent. Er ist ein lebendiges Wesen mit menschlichen bzw. göttlichen Attributen und einem expliziten emotionalen Charakter. Als solcher kann er nicht erschaffen oder komponiert, sondern bestenfalls entdeckt und zum Vorschein gebracht werden (vgl. Schmidt 2006: 5-13). Im hinduistischen Schrifttum wird unterschieden zwischen śruti (das Gehörte, also das von Sehern offenbarte Wissen) und smrti (das Erinnerte, also das von Menschen verfasste Wissen) (vgl. Michaels 1998: 69). Der guru, der spirituelle bzw. musikalische Lehrer, wird wie ein

10 So entwickelte sich aus der Notation, die ursprünglich der Memorierbarkeit diente, eine Technik, die eine komplexe, mehrstimmige Kompositionspraxis erst ermöglichte. Überkommene Kompositionsregeln wurden im Verlauf der abendländischen Kompositionsgeschichte immer wieder verworfen, um Platz für Neuerungen zu schaffen. Auch sozioökonomische Faktoren hatten erhebliche Auswirkungen auf das kompositorische Schaffen. Man denke hierbei beispielsweise an Auftragskompositionen. 
Gott verehrt, weil ihm die Fähigkeit des >Sehens< bzw. >Hörens< von spirituellem Wissen zugesprochen wird, so auch das Entdecken und zum Vorscheinbringen eines rāg. In diesem Sinne ist die Performance eines $r \bar{a} g$, wie vor allem von Musikern des älteren dhrupad-Stils hervorgehoben wird, eher als spirituelle Praxis zu verstehen, denn als Entertainment (vgl. Marcotty 1980: 57). Durch die Performance findet eine Invokation des $r a \bar{g}$ statt, durch die dieser sich manifestieren kann (vgl. Marcotty 1980: 67). Entscheidend hierfür ist die durch korrekte Ausführung der melodischen Regeln garantierte Authentizität und Identität des $r a \bar{g}$ und zunächst weniger, ob dies durch komponierte oder improvisierte Strukturen geschieht. Theoretisch und gelegentlich auch praktisch kommt eine rāg-Performance gänzlich ohne komponierte Strukturen aus, beispielsweise wenn nur ein ālāp gesungen oder gespielt wird. ${ }^{11}$ Die Kompositionen, und hierunter verstehe ich die kurzen, sich über maximal vier tāl-Zyklen erstreckenden, bandiś-es bzw. gat-s werden demnach nicht als essentiell für die Performance betrachtet, sondern dienen in erster Linie dazu, melodische Kernaspekte und Regeln des rāg memorierbar und somit tradierbar $\mathrm{zu}$ gestalten. ${ }^{12}$ Tatsächlich zeigt eine Untersuchung der etwa 200 Kompositionen, die ich bisher erlernt habe, dass sie alle, für den $r \bar{a} g$ wesentlichen melodischen Wendungen enthalten, dass sie also quasi als Merkzettel für die musikalische Struktur fungieren.

Die Bedeutung und Stellung der Improvisation ergibt sich aus der religiös-spirituellen Auffassung von Musik. Die dezidierte Ausarbeitung, in Form von extensiven, schriftlich fixierten Kompositionen macht insofern keinen Sinn, als sie der wörtlich zu nehmenden

11 Speziell im Bereich des dhrupad bestehen Konzerte oder Schallaufnahmen häufig ausschließlich aus einem vollständig improvisierten Groß-ālāp, wie beispielsweise die Aufnahmen des rudra-vīnā-Spielers Zia Mohiuddin Dagar zeigen.

12 Dieser wenig beachtete Aspekt von Komposition in der klassischen nordindischen Musik, der von meinem Lehrer Subroto Roy Chowdhury betont wird, scheint mir für das Verständnis von Improvisation von entscheidender Bedeutung zu sein. Manjusree Tyagi widmet der Interdependenz von Komposition und Improvisation in ihrem Buch Significance of Compositional Forms in Hindustani Classical Music zwei ganze Kapitel, i.e. »The art of Improvisation« (Tyagi 1997: 118-130) und »The Art of Composing « (Tyagi 1997: 131-184). 
Lebendigkeit des $r \bar{a} g$ widerspricht. Der Musiker fungiert einerseits als Anrufer des jeweiligen $r \bar{a} g$-Wesens, andererseits als Medium, durch welches der $r \bar{a} g$ sich manifestiert und erlebbar gemacht wird (vgl. Marcotty 1980: 64). Durch die Art und Weise des Unterrichts wird der Schüler durch einen > wissenden<, also in der Invokation der rāga erfahrenen Meister vorbereitet. Einerseits inkorporiert er mittels strikter Imitation die musikalischen Gesetzmäßigkeiten des $r \bar{a} g$. Andererseits bereitet ihn die bedingungslose Hingabe an den als gottgleich angesehenen guru darauf vor, empfänglich für die Manifestation des $r \bar{a} g$ zu werden. Die leicht memorierbaren Kompositionen dienen als Garanten für die reine, unverfälschte Tradierung der rāga. Da die Invokation eines rāg stets aufs Neue, als Akt spiritueller Hingabe zu erfolgen hat (vgl. Marcotty 1980: 63-71), ist die Improvisation, im Sinne von spontaner, unmittelbarer Umsetzung kreativer Impulse, das geeignete Mittel, durch das er sich realisiert. Anders ausgedrückt lässt die Improvisation, im Gegensatz zur Komposition dem rāg genügend Freiraum, um in Erscheinung treten zu können. Folgerichtig dürfte es demnach nicht lauten >ich improvisiere<, sondern >es (bzw. er, der $r \bar{a} g$ ) improvisiert<. Tatsächlich sind Sätze, welche die Passivität des Vorgangs betonen, häufig von indischen und anderen improvisierenden Musikern zu hören (vgl. Nettl 1998: 16; Berliner 1994: 222-227).

\section{Psychologische Faktoren}

Anhand musikhistorischer und sozioökonomischer Überlegungen konnte gezeigt werden, dass die Veränderungen in der klassischen nordindischen Musik zugunsten der Improvisation mit einer Spezialisierung im Rahmen von Traditionslinien (gharāna), aber auch mit einer starken Individualisierung und Personalisierung der Musik einhergingen, wie am Beispiel Mian Tansens gezeigt wurde.

Spricht nun ein solcher >Geniekult<, wie er mit der historischen Gestalt Tansens, aber auch mit lebendigen Musikern wie Ravi Shankar betrieben wird, nicht gegen meine These vom Musiker als entindividualisiertem Medium?

Wer indische Musiker heute außerhalb des Konzertsaals erlebt, gewinnt in der Regel auch nicht gerade den Eindruck von zart besaiteten, ätherischen Wesen, sondern von starken, schöpferischen Individuen, die ihre Interessen auf einem hart umkämpften Markt 
gegenüber ihren Konkurrenten durchsetzen müssen und die alles andere als entindividualisiert wirken. Im Gespräch kann derselbe $\mathrm{Mu}$ siker, der vor einem Konzert behauptete, dass die Musik »durch ihn hindurch« geschehe, nach dem Konzert feststellen, dass er »heute wieder mal besonders gut improvisiert habe«.

Einigen indischen Musikern wird sogar der Hang zum Exzentrischen nachgesagt ${ }^{13}$, was im Westen nicht selten als Kehrseite der Genialität betrachtet wird und umso schwerer mit der Vorstellung vom Musiker als rși (Weiser mit medialen, seherischen Fähigkeiten) in Einklang zu bringen ist. Wie lässt sich nun dieser offensichtliche Widerspruch zwischen den real existierenden, starken und gelegentlich ex- bzw. egozentrischen Musikerpersönlichkeiten und dem Ideal des passiven, empfangenden Sehers in Übereinstimmung bringen?

Reinhard Andreas erklärt kreative Prozesse bei der Generierung musikalischer Strukturen mit einer »Regression im Dienste des Ich« (Andreas 1994: 525), einem Zustand, in dem der Künstler aus seinem Unbewusstem schöpft, wodurch er Zugang zu neuen Ideen findet. Anhand dieses Erklärungsmodells lassen sich interessante Schlussfolgerungen bezüglich der von mir postulierten Differenzen zwischen dem Westen und Indien einerseits und zwischen dem Typus des westlichen Komponisten und dem des indischen Improvisierenden andererseits ziehen.

Die Form des kreativen Prozesses wäre diesem Modell zufolge in beiden Kulturen identisch, wenngleich sie unterschiedlich benannt und erklärt wird. Dem Terminus »Regression im Dienste des Ich $\ll$ unterliegt ein typisch westlich-modernes, von der Freudschen Psychoanalyse geprägtes Denken. Er impliziert, dass die Idee, als kreative Keimzelle eines Musikstücks, im Unterbewussten des Künstlers lauert und dort darauf wartet entdeckt zu werden. Ein indischer Musiker würde diesen, vom Alltagsstatus verschiedenen Zustand eher als Verschmelzen mit dem rāg, auf jeden Fall aber als einen Zustand, der nicht ausschließlich innerhalb seiner selbst zustande kommt, bezeichnen. Die unterschiedliche, ja geradezu ent-

13 Die Beispiele reichen vom Harmlosen (beispielsweise der Unfähigkeit Termine einzuhalten) bis zum Gravierenden (z.B. Konzerte abzubrechen, wenn ein feindlich gesinnter Kritiker im Publikum sitzt). Mohan Nadkarni, selbst ein gefürchteter Kritiker, hat in seinem Buch Music To Thy Ears etliche solcher Anekdoten zusammengetragen (Nadkarni 2000). 
gegengesetzte Arbeitsweise in den beiden Kulturen ergibt sich hieraus beinahe von selbst. Die westliche Komposition bzw. das Werk entsteht als dezidierte Ausarbeitung der ursprünglichen, kreativen Idee des Musikers. Üblicherweise erfordert es eine lange Zeit und intensive Arbeit, bis aus einem oder zwei Motiven (kreative Idee) eine ganze Sinfonie in ihrer endgültigen, schriftlich fixierten Form hervorgegangen ist. In der klassischen nordindischen Musik steht dieser Prozess im Gegensatz dazu am Anfang. Die musikalische Struktur des rāg wird zu Hause, >im Trockenen< immer wieder geübt und dabei inkorporiert, rhythmische und melodische Passagen werden vielfach wiederholt und variiert, tihā $\bar{l}-s$ werden berechnet usw. Das Ziel dieser jahrelangen Übungspraxis ist, dass sich der $r \bar{a} g$ im Rahmen einer Performance durch den Musiker manifestieren kann. ${ }^{14}$ Der kreative Prozess, die »Regression im Dienste des Ich« bzw. die Invokation und Manifestation des als Wesen begriffenen rāg steht hier also, im Gegensatz zur westlichen Arbeitsweise, erst am Ende des künstlerischen Schaffens, wenn es improvisiert.

Erst durch den Akt des Improvisierens realisieren sich somit in der klassischen indischen Musik die spirituellen Wertvorstellungen und Ideale der hinduistisch geprägten, indischen Gesellschaft.

\section{Literatur}

Andreas, Reinhard (1994): »Generierung musikalischer Strukturen«. In: Herbert Bruhn/Rolf Oerter/Helmut Rösing (Hg.), Musikpsychologie, Ein Handbuch, Reinbek bei Hamburg: Rowohlt, S. 506-538.

Andreas, Reinhard (1996): »Improvisation, VII: Musikpsychologie«. In: Ludwig Finscher (Hg.), Die Musik in Geschichte und Gegenwart, Sachteil 4, Kassel, Basel, London et al.: Bärenreiter/Metzler, Sp. 595-599.

Berliner, Paul (1994): Thinking in Jazz. The Infinite Art of Improvisation. Chicago, London: The University of Chicago Press.

14 Nicht umsonst wird in neueren Büchern über Improvisationspraktiken der Terminus $>$ Improvisation $<$ durch den offensichtlich als besser geeignet erscheinenden Begriff >Performance< ersetzt, z.B. In the course of Performance (Nettl/Russell Hg. 1998) oder Dhrupad. Tradition and Performance in Indian Music (Sanyal/Widdess 2004). 
Bor, Joep/Miner, Allyn (1996): »Indien, 3. Das 20. Jahrhundert«. In: Ludwig Finscher (Hg.), Die Musik in Geschichte und Gegenwart, Sachteil 4, Kassel, Basel, London et al.: Bärenreiter/ Metzler, Sp. 687-695.

Bor, Joep (1999): The Raga Guide. Rotterdam: Rotterdam Conservatory of Music.

Clayton, Martin (2000): Time in Indian Music. Rhythm, Metre, and Form in North Indian Rāg Performance. New York: Oxford University Press.

Danielou, Alain (1996): Einführung in die indische Musik. Wilhelmshaven: Noetzel GmbH.

dtv-Lexikon. Ein Konversationslexikon in 20 Bänden (1973): $»$ Klassik«. Band 10, München: Deutscher Taschenbuch Verlag, S. 166-167.

Ferand, Ernst (1938): Die Improvisation in der Musik. Zürich: Rhein-Verlag.

Ganti, Tejaswini (2004): Bollywood. A Guidebook to Popular Hindi Cinema. New York, Abingdon: Routledge.

Hamilton, James Sadler (1989): Sitar Music in Calcutta. An Ethnomusicological Study. Calgary: The University of Calgary Press.

Hentschel, Frank (2006): Bürgerliche Ideologie und Musik. Politik der Musikgeschichtsschreibung in Deutschland 1776-1871. Frankfurt, New York: Campus.

Hood, Mantle (1960): »The Challenge of >Bi-Musicality««. Ethnomusicology Vol.4 No.2, S. 55-59.

Kant, Immanuel/Malter, Rudolf (1974 [1794]): Religion innerhalb der Grenzen der bloßen Vernunft. Stuttgart: Reclam.

Kuckertz, Josef (1996): »Indien, 4. Theorie und Praxis im 20. Jahrhundert«. In: Ludwig Finscher (Hg.), Die Musik in Geschichte und Gegenwart, Sachteil 4, Kassel, Basel, London et al.: Bärenreiter/Metzler, Sp. 696-704.

Marcotty, Thomas (1980): The Way-Music. How to conjure with sounds - Rudra Veen: The Theory and Technique of Tantric Music. Lugano: Decisio Editrice S.A.

Merriam, Allan P. (1964): The Anthropology of Music. Evanston: Northwestern University Press.

Michaels, Axel (1998): Der Hinduismus. Geschichte und Gegenwart. München: C.H. Beck.

Miner, Allyn (1997): Sitar and Sarod in the 18th and 19th Centuries. Delhi: Motilal Banarsidass. 
Nadkarni, Mohan (2002): Music to Thy Ears. Great Masters of Hindustani Instrumental Music. Mumbai: Somaiya Publications Pvt. Ltd.

Nettl, Bruno (1998): »An Art Neglected in Scholarship«. In: ders./ Melinda Russell (Hg.), In the Course of Performance, Chicago, London: The University of Chicago, S. 1-23.

Sanyal, Ritwik/Widdess, Richard (2004): Dhrupad. Tradition and Performance in Indian Music. Hampshire/Burlington: Ashgate.

Schmidt, Markus (2006): Ästhetik und Emotion in der nordindischen Kunstmusik. Empirische Untersuchungen zur interkulturellen Rezeption. Osnabrück: Electronic Publishing Osnabrück.

Slawek, Stephen (1998): »Keeping it going: Terms, Practices, and Processes of Improvisation in Hindustrṇ̄̄ Instrumental Music «. In: Bruno Nettl/Melinda Russell (Hg.), In the Course of Performance, Chicago, London: The University of Chicago Press, S. 335-368.

Slawek, Stephen (2000): Sitār Technique in Nibaddh Forms. Delhi: Motilal Banarsidass Publishers.

Tyagi, Manjusree (1997): Significance of Compositional Forms in Hindustani Classical Music. Delhi: Patibha Prakashan.

Uhl, Matthias/Kumar, Keval J. (2004): Indischer Film. Eine Einführung. Bielefeld: transcript Verlag.

Wegner, Gert-Matthias (2004): Vintage Tablā Repertory. Drum Compositions of North Indian Classical Music. New Delhi: Munishram Manoharlal Publishers Pvt. Ltd.

Widdess, Richard/Nooshin, Laudan (2006): »Improvisation in Iranian and Indian Music«. Journal of the Indian Musicological Society 36/37, S. 104-119.

\section{Audiovisuelle-Medien}

Banerjee, Nikhil (2004): India's Maestro of Melody, Live Concert Vol.7, Raag Marubehag. CD, Stuttgart: Chandra Dhara, CD Nr.: SNCD 71104

Chaudhuri, Debu (2003): Konzert am 24.03.2003 in Delhi, DV, Privataufnahme, Privatarchiv. 
Khan, Imrat/Khan, Nishad/Khan, Irshad/Khan, Shafaatullah (1983): Rāg Yaman, Konzert, aufgezeichnet von Radio Bremen, MC, Privater Mitschnitt, Privatarchiv.

Khan, Imrat (1983): Interview, aufgezeichnet von Radio Bremen, MC, Privater Mitschnitt, Privatarchiv.

Khan, Vilayat (1982): »Sitar-Raga Yaman Part Three, Drut Teental«, LP Raga Mood, EMI/The Grammophone Company of India, LP Nr.: 2YJE, 9002 (16-631).

Khan, Vilayat (1985): Live in Calcutta, Rag Bhairavi, MC, Privater Mitschnitt, Privatarchiv.

Shankar, Ravi (2002): In Portrait. Between Two Worlds. DVD 1, Heathfield: Opus Arte, BBC, DVD Nr.: OA 0853 D. 



\title{
IMPROVISATION: ÜBER IHREN GEBRAUCH UND IHRE FUNKTION IN DER GESCHICHTE DES JAZZ
}

\author{
KLAUS NÄUMANN
}

\begin{abstract}
»Für mich ist das Musik, in deren Zentrum die Improvisation steht. Darüber hinaus handelt es sich um eine musikalische Gattung, die etwas persönliches [sic!] von dir abverlangt, denn erst dadurch entsteht die unbeschreibliche Vielseitigkeit dieser Musik.« (Metheney in Trampert 1992: 21)
\end{abstract}

In seiner Antwort auf die Frage, wie er denn Jazz definiere, wird aus dem obigen Zitat Pat Metheneys im Rahmen eines Interviews der Fachzeitschrift Gitarre \& Bass aus dem Jahr 1992 deutlich, dass Jazzmusik für ihn unabdingbar mit dem Aspekt der Improvisation verbunden ist. Tatsächlich steht Metheney mit dieser Auffassung keineswegs alleine da, denn sowohl (Jazz-) Musikwissenschaftler, (Jazz-) Kritiker als auch (Jazz-) Musiker sind sich weitestgehend einig, dass Jazz und Improvisation in einem engen Zusammenhang stehen. Gleichwohl unterlagen beide Phänomene - und daher auch ihre Relation zueinander - in der Geschichte erheblichen Veränderungen, woraus diverse Probleme für die Gegenwart resultieren. Diese beiden Aspekte - die geschichtliche Relation zwischen Jazz und Improvisation sowie die sich daraus ergebenden Folgen für die Gegenwart - stehen im Mittelpunkt dieses Aufsatzes.

Wenn im weiteren Verlauf der Arbeit von Jazz bzw. Jazzmusik die Rede ist, dann impliziert dies neben der Musik, die den heute allgemein gebräuchlichen Jazzepochen zugerechnet wird, ebenfalls die so genannten Vorformen. ${ }^{1}$ Gleichfalls soll Musik, wie die des

1 Eine Diskussion über die vielen unterschiedlichen Theorien bezüglich Entstehung, Etymologie und Definitionen des Jazz kann hier aus Platzgründen nicht vorgenommen werden. Siehe hierzu weiterführend z.B. Dauer 1958; Jacobs 1996; Polillo 1981; Stearns 1959. 
zuvor zitierten Pat Metheney - bei dem der eine oder andere Leser eventuell einer Zuordnung zur Fusion oder Worldmusic den Vorrang einräumen würde - hier dem Jazz zugeordnet werden. ${ }^{2}$

Trotz der Vielzahl und nahezu unüberblickbaren Fülle an Definitionen für Improvisation (vgl. z.B. MGG Artikel »Improvisation« von Seedorf, Reinhard, Frisius et al. 1996: Sp. 538-611) soll im weiteren Verlauf dieser Arbeit eine Formel von Christian Kaden (1993: 47-63) als Basisdefinition dienen. Sie lautet: »so, und auch anders «. Kerngedanke seiner Definition ist, dass beim Improvisieren stets eine Wahl unter mehreren Möglichkeiten getroffen werden muss und dass dies keinen Makel, sondern vielmehr das Ideal der Improvisation darstellt. Den Gegenpol dazu bildet das »so, und nicht anders sein « - also fixierte und komponierte Musik, bei der das Veränderliche allenfalls als Randerscheinung auftritt. Kadens Kurzformel für Improvisation »so, und auch anders « erweist sich insbesondere für den Jazz als sehr geeignet, da sie nicht zu speziell ist, sondern jazzepochen- und instrumentübergreifend angewandt werden kann.

Was die Termini Gebrauch und Funktion anbelangt, so bedarf es hier ebenfalls einer kurzen Erläuterung. Beide Begriffe - auf Englisch uses and functions - spielen in Diskussionen der Ethnomusikologie eine bedeutende Rolle und wurden von einer Reihe von Ethnomusikologen thematisiert. ${ }^{3}$ Wo die Grenze zwischen diesen beiden Begriffen jedoch verläuft, ist strittig. Eine detaillierte Diskussion darüber würde jedoch den Rahmen der Arbeit sprengen und stattdessen soll eine pragmatische Definition verwendet werden.

Was den Gebrauch betrifft, so geht es in diesem Aufsatz primär um die situativen Kontexte, in denen im Jazz (bzw. dessen Vorformen) in der einen oder anderen Art und Weise improvisiert wurde. Was die Funktion anlangt, so ist hier eine übergeordnete, teilweise sich nicht auf den ersten Blick erschließende, Bedeutung einer Handlung - in diesem Fall der Improvisation - für einen einzelnen Musiker, eine Gruppe von Musikern oder Mitglieder einer Subkul-

2 Im Gegensatz dazu bezeichnete beispielsweise Louis Armstrong - den wohl jedermann dem Jazz zuordnen würde - seine Musik selten als Jazzmusik und sich selbst niemals als Jazzmusiker (vgl. Collier 1987: 62).

3 Vgl. hierzu beispielsweise zwei der prominentesten Musikethnologen der amerikanischen Schule Bruno Nettl (1983: 147-161, 1989: Kapitel 4.1.) und Alan P. Merriam (1964: 209-228); vgl. des Weiteren Neuhoff 2007: 106. 
tur bzw. Gesellschaft gemeint. Dabei können Aspekte wie beispielsweise der des Entertainments sowohl in den Bereich von Gebrauch als auch Funktion fallen (vgl. Nettl 1983: 149). Des Weiteren kann die Funktion für einen einzelnen (Musiker) gänzlich anderer Natur sein, als sie es für die Gruppe (von Musikern bzw. die Band) ist, ganz zu schweigen von der Bedeutung der Musik für eine soziale Gruppe oder eine Gesellschaft. Die Musikethnologin Anya Royce, die sich eingehend mit den Funktionen von Tänzen in verschiedenen Kulturen beschäftigt hat, äußert diesbezüglich: »A multiplicity of functions tends to be the rule rather than the exception.« (Royce 1977: 83f.) Ohne die Existenz solcher Multifunktionalitäten hier in Frage stellen zu wollen, scheint es in der Geschichte des Jazz jedoch immer wieder relativ einheitliche Funktionen gegeben $\mathrm{zu}$ haben, die für bestimmte Varianten des Jazz kennzeichnend waren. So schreibt auch der Jazztheoretiker Ekkehard Jost von Musikern...,

» [...] die sich über ihre individuelle oder biographische Ich-Identität hinaus als Mitglieder soziomusikalisch bedeutsamer Gruppen artikulierten. Dass letzten Endes individuelle und soziale Identität nicht voneinander zu trennen sind, da offenbar ein dialektischer Zusammenhang zwischen beiden besteht, wurde aus allen von mir geführten Interviews deutlich.«(Jost 1982: 8)

\section{Geschichtliche Relation zwischen Jazz und Improvisation}

\section{Vorformen des Jazz}

Als Vorformen des Jazz gelten heute im Allgemeinen die so genannten Calls, Cries, Worksongs, Spirituals und insbesondere der Blues, die alle auf die afroamerikanische Bevölkerung in den USA zurückzuführen sind. Diese primär vokalen Ausdrucksformen wurden oral tradiert und besaßen schon daher eine Nähe zur Improvisation (vgl. Jacobs 1996: 15f.). Die Differenz zwischen ihnen - unabhängig davon, ob sie geistlicher oder weltlicher Natur waren - lag weniger in den grundlegenden musikalischen Merkmalen als vielmehr in den voneinander abweichenden Funktionen (vgl. Stearns 1959: 147). So wurde im Fall der Cries gesanglich improvisiert, um eine persönliche Gefühlsbewegung (Freude oder Melancholie) mit 
der Stimme auszudrücken, bei den Calls, um eine Botschaft zu übermitteln und bei den Worksongs, um Arbeitstätigkeiten diverser Art zu begleiten oder spontan zu kommentieren (vgl. Stearns 1959: 92ff.; Jacobs 1996: 12f.). Auch bei den Spirituals und den so genannten Ring Shouts spielte der improvisatorische Aspekt eine bedeutende Rolle insofern, als Vorsänger (Prediger) und Nachsänger (Gemeinde) eine Melodie nach Gutdünken variieren konnten, was zu einer Art Kollektivimprovisation führte. Dieser improvisatorische Aspekt wurde dadurch verstärkt, dass die frühen Gesangbücher häufig nur Texte ohne Melodien beinhalteten (vgl. Dauer 1958: 63ff.; Stearns 1959: 85f., 119ff.).

Obwohl der Blues selbst eine eigene komplexe Entstehungsgeschichte besitzt - auf die hier nicht näher eingegangen werden soll kann man dennoch konstatieren, dass der Improvisation dabei von jeher eine große Bedeutung zukam. Anfangs, gleichsam überwiegend vokal und unbegleitet (vgl. Dauer 1958: 75), konnten die thematischen Inhalte eines Blues unterschiedlicher Natur sein und beispielsweise von Spötteleien, Klage und Schmerz, später der Beziehung Mann/Frau, Selbstmitleid und vielen anderen Themen handeln. Ein beträchtlicher Anteil davon wurde aus dem Stegreif gesungen und selbst dann, wenn sich bei einem Blues einmal eine relativ feste Form - quasi eine Komposition - herausgebildet hatte, wurden die Noten bzw. Töne stets umschrieben (vgl. Borneman in Polillo 1981: 38). Diese Herangehensweise beim frühen Blues jeder musikalischen Äußerung eine individuelle Note zu verleihen ist eine der Konstanten, die bis zur Gegenwart im Jazz (und natürlich ebenso im Blues) von großer Bedeutung ist.

\section{Ragtime}

Was die Improvisation betrifft, so nimmt die Phase des pianistischen Ragtime (ca. 1896-1917), der sich aus den Coon Songs der Minstrel Shows ${ }^{5}$ entwickelt hatte, in der Jazzgeschichte eine Son-

4 Dauer (1958: 63) bezeichnet dies als »improvisierte Stimmerfindung «.

5 Minstrel Shows wurden von ca. 1830 bis Anfang des 20. Jh.s auf kleinen amerikanischen Bühnen aufgeführt. Hauptakteure waren die MinstrelSänger, die in ihren Texten die schwarze Bevölkerung in teilweise bösartiger Weise verulkten. Begleitet wurden sie dabei von kleineren Ensembles 
derstellung ein. So wird der Ragtime oftmals nicht zum Bereich des Jazz gerechnet, zum einen, weil zu dieser Zeit das Wort »Jazz« noch nicht benutzt wurde, um eine Musikart zu bezeichnen und andererseits, weil bei dieser Musik scheinbar nicht improvisiert wurde. Der Grund dafür, die Improvisation auszuklammern, liegt dem Jazzforscher Marshall Stearns (1959: 138) zufolge in der geheimen Sehnsucht der Ragtime-Komponisten nach musikalischer Respektabilität »und das konnte nur eines bedeuten: Europäisches Komponieren." Allerdings verhält es sich bei einer genaueren Betrachtung so, dass Ragtime-Stücke zwar durchaus komponiert und in Schriftform fixiert waren, aber trotzdem von den Pianisten, die in der Lage dazu waren, über die festen Themen improvisiert wurde (vgl. Stearns 1959: 135). So schreibt beispielsweise Polillo hierzu:

»Auf dieser rhythmischen Basis improvisierten die besten RagtimePianisten - die nicht unbedingt die Komponisten waren - eine große Fülle von Figuren. Sie fügten nachträglich Akzente oder besondere Effekte hinzu, ließen anderes weg und schufen so recht verwickelte Darbietungen, [...]« (Polillo 1981: 56).

\section{New Orleans Jazz}

Unabhängig davon, ob man den Ragtime zur Kategorie des Jazz hinzurechnet oder nicht, war er doch eine wichtige Voraussetzung für das, was dann - auch aus heutiger Sicht der Dinge - mit Gewissheit als Jazz bezeichnet wird: der so genannte »New Orleans JazZ«.

Diese geschichtliche Phase weist hinsichtlich Gebrauch und Funktion der Improvisation einige interessante Merkmale auf. Was den geschichtlichen Kontext betrifft, so war die am Mississippi gelegene Stadt New Orleans seit ihrer Gründung im Jahr 1718 ein Schmelztiegel verschiedener Kulturen. Bereits ab ca. 1870 gab es in der Stadt eine Reihe schwarzer Blaskapellen, die bei Straßenparaden, Tanzveranstaltungen und zu Begräbnissen spielten. Was jedoch die Bezeichnung »schwarze Blaskapellen « betrifft, so muss im Hinblick auf das New Orleans dieser Tage differenziert werden zwi-

(mit Banjo, Violine, div. Perkussionsinstrumente), die u.a. Coon Songs bzw. später Ragtime-Stücke spielten (vgl. Dauer 1958: 111ff.). 
schen einerseits den Nachkommen der afroamerikanischen Bevölkerung bzw. ehemaligen Sklaven und andererseits den so genannten Kreolen. ${ }^{6}$ Letztere waren keine direkten Nachfahren der Sklaven, sondern hatten schon deutlich früher ihre Freiheit erlangt und fühlten sich daher den erst genannten überlegen. Die Blaskapellen von New Orleans setzten sich zumindest bis zum Anfang des 20. Jahrhunderts vorwiegend aus dem Kreis ehemaliger schwarzer Sklaven bzw. deren Nachfahren zusammen. ${ }^{7}$

Der Ausgangspunkt für die Gründung der zahlreichen Blaskapellen in New Orleans war das Ende des Sezessionskrieges 1856, der die Auflösung vieler Militärkapellen nach sich zog und es den Schwarzen ermöglichte, die nun nicht mehr verwendeten Instrumente günstig zu erwerben. Die Afroamerikaner waren im Gegensatz zu den höher gebildeten Kreolen in der Regel Autodidakten, verfügten zumeist über keinerlei Notenkenntnisse ${ }^{8}$ und nur über eine mittelmäßige Technik auf dem jeweiligen Instrument (vgl. Stearns 1959: 69ff.; Collier 1987: 60f., 78). Von den Kreolen unterschied sie, dass sie im Gegensatz zu ihnen improvisieren konnten, ja sogar mussten, um als »Ear Musicians « (Jost 1982: 16) in einem Verbund musizieren zu können.

Die von ihnen aufgeführte Musik bezeichnet Dauer (1958: 93f.) noch als »archaischen Jazz«, der sich erst mit dem Hinzukommen der Kreolen nach der Jahrhundertwende zum New Orleans Jazz entwickelte. Die Musik war eng verwandt mit dem Ragtime, wenngleich im Repertoire der Gruppen auch Märsche und andere Musikformen europäischen Ursprungs enthalten waren. Besonders bemerkenswert ist bezüglich der Musikformen europäischen Ursprungs,

6 Die Bezeichnung »Kreolen« ist relativ unpräzise und wird in ganz Amerika einschließlich des karibischen Raums in unterschiedlicher Weise verwendet. In diesem Kontext sind damit jedoch primär Farbige (also auch Mischlinge) gemeint, die bereits im 19. Jh. ihre Freiheit erlangten.

7 Die Kreolen kamen erst ab Anfang des 20. Jh.s hinzu und übten ab dieser Zeit einen großen Einfluss auf den so genannten New Orleans Jazz aus. Beide Gruppen - Kreolen und schwarze Afroamerikaner - näherten sich ab dieser Zeit einander an, was gleichsam zu einer musikalischen Annäherung von improvisierter und ausnotierter Musik führte (vgl. Jost 1982: 18).

8 Diese fehlenden Notenkenntnisse waren zu dieser Zeit noch kein Ausdruck einer bewussten Ablehnung von unterdrückenden Symbolen der weißen Kultur wie beispielsweise später bei Miles Davis (vgl. Magee 2007: 1f.) 
dass sie auf die Imitation weißer Blaskapellen - die ihrerseits hingegen ihre Musik nach Noten spielten - zurückzuführen sind (vgl. Dauer 1958: 93f.). So wurde diese von Schwarzen improvisierte Musik auf der Basis europäischer Vorbilder schließlich zu einem eigenen Stil, dessen musikalisches Erkennungsmerkmal es war, dass zu einer Hauptstimme (oft auf dem Kornett gespielt) die anderen Musiker der Gruppe nach Gehör dazu improvisierten (vgl. Jacobs 1996: 24f.; Collier 1987: 81). Man kann demnach sagen, dass die Improvisation hier eine Tugend war - der Wille zum Musizieren in einem Verbund -, die ursprünglich aus einer Not - fehlende Notenkenntnisse - geboren wurde (vgl. Jacobs 1996: 27).

Es erscheint fast schon kurios, dass nach dem Vorbild dieser schwarzen Blaskapellen - die ja ihrerseits weiße Blasmusik mittels der Improvisation imitierten - es in New Orleans ab 1892 vereinzelt weiße Bands gab, die wiederum versuchten, die schwarzen Marching Bands zu imitieren. Da sie beim Improvisieren im Vergleich zu den schwarzen Musikern nicht so bewandert waren, mussten sie ihre Melodielinien einstudieren, um den gewünschten »improvisatorischen Klang « zu realisieren (vgl. Dauer 1958: 110).

Darüber hinaus gab es beim Jazz in New Orleans (sowohl beim archaischen Jazz als auch beim New Orleans Jazz) noch einen weiteren Aspekt, der hier von Bedeutung ist, nämlich der des musikalischen Wettbewerbes mittels der Improvisation. Dies kam insbesondere dann zum Tragen, wenn es beim Aufeinandertreffen zweier durch die Straßen ziehender Bands, besonders während der Zeit des Karnevals, zu Duellen, den »Curting Contests«, kam. Der Hintergrund hierfür war, dass viele Gruppen für bestimmte Veranstaltungen warben und das Publikum durch die bessere oder lautere musikalische Darbietung auf die >eigene< Veranstaltung aufmerksam machen wollten. Das folgende Zitat des Klarinettisten Georg Lewis mag dies verdeutlichen:

»Wenn sich zwei Fuhrwerke begegneten, kam es zu einem >curting contest $<$. Einmal erwischten wir Buddy Petit betrunken, und unsere Band machte seine total fertig. Am nächsten Sonntag fuhren wir wieder los und sahen Buddy auf seinem Wagen sitzen, mit hängendem Kopf und kraftlos herunterbaumelnden Händen. Da setzten wir uns in Positur, um es ihnen nochmal [sic!] zu geben. Und da schlich sich plötzlich jemand heran, kettete die Räder unserer Wagen zusammen, so daß wir uns nicht davonmachen konnten, und Buddy sprang auf, reckte sich, 
und an diesem Tage haben sie uns fertiggemacht. « (Lewis in Jacobs 1996: 25)

Diese musikalischen Duelle beschränkten sich jedoch nicht nur auf Musikgruppen. In den so genannten »Bucking Sessions « (Collier 1987: 90) bzw. »Carving Contests« (Stearns 1959: 73) - improvisatorische Wettstreite - versuchten die Musiker, sich gegenseitig zu übertrumpfen. Dabei kam es zu regelrechten Fehden zwischen Einzelmusikern im Hinblick darauf, wer besser spielen bzw. improvisieren konnte. Das Publikum agierte dabei quasi als Schiedsrichter, der durch den Applaus entschied, wer der $>$ Gewinner $<$ eines solchen Duells war. So kam es beispielsweise zwischen den Kornettisten Freddie Keppard und King Oliver zu einem solchen Duell; nach dessen Ende soll der sich als siegreich fühlende Oliver bemerkt haben »Gott sei Dank, der Scheißkerl ärgert mich nun nicht mehr.« (Oliver in Polillo 1981: 73). Der Trompeter Mutt Carey soll hinsichtlich solcher Duelle sogar geäußert haben: »Wenn man einen Mann nicht mit seinem Horn niederblasen konnte, dann konnte man es ihm wenigstens über den Kopf schlagen.« (Carey in Stearns 1959: 73) Es mag dahingestellt bleiben, ob beide Musiker dies jemals so geäußert haben, dennoch wird deutlich, dass die Improvisation im Jazz unter anderem die Funktion der persönlichen Profilierung »ich bin besser als Du« oder »wir sind besser als Ihr« besaß.

\section{Kansas City und Chicago Jazz}

Das gleiche Phänomen taucht zu Zeiten des Kansas City Jazz (ca. zwischen 1933 und 1936) auf. In den Lokalen von Kansas City gab es zu dieser Zeit eine Vielzahl von Jam Sessions, die tatsächlich jedoch ebenfalls musikalische Wettkämpfe mittels Improvisation waren. Bei diesen Jam Sessions nahmen die als beste erachteten Musiker teil und setzten dabei mitunter ihren Ruf aufs Spiel. Im Rahmen einer solchen Jam Session 1934 im Cherry Blossom Club musste beispielsweise Coleman Hawkins - Mitglied des Fletcher Henderson Orchesters mit einem herausragenden Ruf als Tenorsaxophonist - gegen die angesehensten Saxophonisten der Gegend namentlich Lester Young, Ben Webster und Herschel Evans - antreten und wurde dabei nach übereinstimmenden Zeugenaussagen der Anwesenden »geschlagen« (Polillo 1981: 137). 
Dass die Improvisation im Jazz als eine Form des musikalischen Wettbewerbs eine große Bedeutung besitzt, kann man des Weiteren am Beispiel des Chicago Jazz (ca. 1925 bis 1929) beobachten. Charakteristisch für diese Phase ist, dass sich neben den bereits etablierten schwarzen Musikern, von denen viele aus New Orleans stammten (z.B. Louis Armstrong, King Oliver), in zunehmendem Maße junge weiße Musiker (z.B. Bix Beiderbecke, Frank Teschemacher und Eddie Condon) der Jazzmusik zuwandten. Diese jungen weißen Musiker, die sich gegen das Spießbürgertum der damaligen Zeit auflehnten und von ihrem Umfeld daher häufig als gesellschaftliche Außenseiter gebrandmarkt wurden, erlernten den Jazz anhand älterer Tonaufnahmen schwarzer Musiker aus New Orleans (vgl. Jost 1982: 21; Jacobs 1996: 69f., 80; Stearns: 160f.).

Da es in den USA während der 20er und 30er Jahre nach wie vor eine Barriere zwischen Schwarz und Weiß gab, musste dies wohl fast zwangsläufig zu der Frage führen, wer hierbei die höhere Kompetenz besitzt: die schwarzen Musiker, die quasi eine musikalische Urheberrolle einnahmen bzw. für sich beanspruchten, oder die weißen Musiker, die zumindest in wirtschaftlicher Hinsicht in der Regel erfolgreicher waren. Verstärkt wurde dieser Umstand dadurch, dass der Improvisator mittlerweile eine herausragende Stellung einnahm. So war zu dieser Zeit bereits nicht mehr die Kollektivimprovisation vorherrschend, ${ }^{9}$ bei der der Soloeindruck eines einzelnen Instruments dadurch erzeugt wurde, dass die anderen Instrumentalisten zwar gleichzeitig, jedoch in einer geringeren Lautstärke improvisierten (vgl. Dauer 1958: 98). Vielmehr wurde jeweils ein Solist nach dem anderen von der Band begleitet und stand dadurch besonders im Rampenlicht bzw. hatte mehr als je zuvor die Möglichkeit, sich selbst zu produzieren (vgl. Jacobs 1996: 63, 67, 85; Dauer 1958: 108f., 127).

Inwieweit die Funktion der Improvisation als ein Wettbewerb zwischen Schwarz und Weiß bei den Musikern dieser Zeit selbst eine große Bedeutung besaß, soll hier dahingestellt bleiben. Auf jeden Fall spielte sie beim Publikum eine doch erhebliche Rolle und

9 Dauer (1958: 124) führt dies auf die wirtschaftlich schwierige Situation dieser Zeit in den USA - insbesondere Chicago - zurück. Dies bewirkte ihm zufolge, dass es kaum mehr kleinere feste Ensembles gab, die aufeinander eingespielt waren und kollektiv improvisieren konnten, sondern stattdessen ständig wechselnde Besetzungen. 
spitzte sich insbesondere auf zwei Personen zu: den schwarzen Kornettisten/Trompeter Louis Armstrong und den weißen Kornettisten Bix Beiderbecke (vgl. Stearns 1959: 161f.; Polillo 1981: 110).

\section{Symphonischer Jazz und Swing}

Eine weitere interessante Phase stellt die Zeit des Symphonischen Jazz Anfang/Mitte der 20er Jahre dar, für dessen Popularität in den USA insbesondere der Arrangeur und Orchesterleiter Paul Whiteman verantwortlich war. Das Charakteristische am Symphonischen Jazz war, dass man es hierbei primär mit auskomponierter Musik wie beispielsweise George Gershwins »Rhapsody in blue « zu tun hatte, wobei im Großen und Ganzen der improvisatorische Aspekt fehlte. ${ }^{10}$ Anstatt der Improvisation wurde hingegen Gewicht darauf gelegt, die »wilde und ungezähmte Musik«, die bis zu diesem Zeitpunkt (nicht nur, aber doch) maßgeblich von der schwarzen Bevölkerung aufgeführt wurde, zu glätten und zu disziplinieren. Dies führte jedoch dazu, dass einerseits diese Musik beim schwarzen Publikum zunächst auf Ablehnung stieß, gleichzeitig der Jazz - eine Musik, die bis dahin im Kontext von Kriminalität und Prostitution gesehen wurde - in gewissen Kreisen (weiße Bevölkerungsteile der USA und vor allem europäische Komponisten der ernsten Musik) eine größere Anerkennung fand. Besonders kurios mag aus der Retrospektive anmuten, dass einige der Titel wie Gershwins »I got rhythm« oder »Summertime« sich als Jazzstücke etablierten, ja geradezu weltberühmt wurden und in der Folge vielen Jazzmusikern als Basis zur Improvisation dienten (vgl. Stearns 1959: 153ff.; Jacobs 1996: 76f.).

Analog zur steigenden Popularität des Symphonischen Jazz erfreuten sich Anfang/Mitte der 30er Jahre bis zum Ende des zweiten Weltkriegs - der so genannten Swing Ära - die Jazz Big Bands einer zunehmenden Beliebtheit. Die Besetzungen von Duke Ellington, Count Basie, aber auch von weißen Bandleadern wie Benny Goodman, der seinen Musikern fast schon in diktatorischer Manie vorschrieb, was sie zu spielen hatten (vgl. Jacobs 1996: 144) und etwas später Glenn Miller wurden nicht nur in den USA, sondern auch in

10 Zum Teil engagierten solche Orchester Instrumentalisten, die im Gegensatz $\mathrm{zu}$ vielen Orchestermusikern wirklich improvisieren konnten (vgl. z.B. Stearns 1959: 165, 182). 
Europa berühmt. Ähnlich dem Symphonischen Jazz war der Big Band Jazz primär konzertante Unterhaltungsmusik bzw. sogar Tanzmusik, die stark >geglättet< war und bei der dem Arrangement die größte Bedeutung zukam. Der improvisatorische Aspekt war abgesehen von einigen Ausnahmen - von geringer Bedeutung, obgleich er in höherem Maße als beim Symphonischen Jazz vorhanden war (vgl. Stearns 1959: 179ff.).

Insgesamt kann man sagen, dass das Fehlen des improvisatorischen Aspekts - ähnlich wie beim Ragtime - immer wieder zur Frage führte, bis zu welchem Grad bzw. ob dies überhaupt noch Jazzmusik sei. Vor allem beim Symphonischen Jazz besaß die Improvisation bzw. die Minimierung der Improvisation - das bis dahin bedeutendste Charakteristikum des Jazz - eine herausragende Funktion, nämlich die Musik aufzuwerten und sie der europäischen Kunstmusik ebenbürtig zu machen. Obschon dies bis zu einem gewissen Maße tatsächlich gelang, trugen diese Prozesse insgesamt zu einer Reaktion bei, die ins diametrale Gegenteil abdriftete, nämlich in die Phase des Bebop.

\section{Bebop}

Der Bebop entstand Anfang der 40er Jahre (vor allem ab ca. 1944) primär in New York und stellte hinsichtlich des Wandels von Gebrauch und Funktion bei der Improvisation im Jazz einen umfassenden Einschnitt dar. Bis zur Entstehung des Bebop war der Jazz wie oben bereits ausgeführt - im Laufe der Zeit primär zu einer Unterhaltungsmusik der schwarzen und weißen Bevölkerungsschichten der USA geworden (vgl. Jacobs 1996: 180). Gleichzeitig ist zu betonen, dass die schwarze Bevölkerung in den USA immer noch stark diskriminiert wurde und keineswegs gleichberechtigt war. Die Vertreter des Bebop waren nunmehr eine neue Generation junger schwarzer Musiker, die sich nichts mehr vom überwiegend weißen Musikbusiness diktieren lassen und schon gar nicht mehr als Entertainer wie beispielsweise noch ein Louis Armstrong fungieren wollten (vgl. Jost 1982: 26; Jacobs 1996: 186; Long 2006: 2).

Ab 1944 traten diese Musiker in Clubs (Mintons, Onyx) an der 52. Straße in New York immer stärker in Erscheinung und improvisierten in einer für diese Zeit gänzlich anderen Art und Weise, die selbst bei Jazzmusikern, die nicht dieser Szene angehörten auf Unverständnis stieß. Ein Zitat von Dave Tough, ein Mitglied des etab- 
lierten Woody Herman Orchester, der seinerseits ein Konzert von Dizzy Gillespie und Oscar Pettiford (zwei Vertreter dieser neuen Richtung) besuchte, verdeutlicht das Befremden, das diese Musik bei vielen hervorrief:

»Als wir hereinkamen, nahmen die Burschen da drin ihre Hörner und bliesen verrücktes Zeug. Auf einmal hörte einer ganz plötzlich auf, und ein anderer fing aus einem völlig unerfindlichen Grund an. Wir wußten nie, wann ein Solo anfing oder aufhörte. Schließlich hörten sie alle auf einmal auf und verschwanden vom Podium. Wir waren ziemlich erschrocken.« (Tough in Stearns 1959: 201)

Die wesentlichen Neuerungen beim Bebop im Vergleich zur bis dahin vorherrschenden Jazzmusik (Swing bzw. Bigband Jazz) waren die kleineren Besetzungen, ${ }^{11}$ bei denen jedoch alle Musiker auch die Rhythmusgruppe - in gewisser Weise wieder improvisierten. Eine gänzlich neue Innovation war das indessen nicht, da der Kollektivimprovisation ja bereits beim New Orleans Jazz eine zentrale Bedeutung zukam. Allerdings war die Bebop-Musik in einem sehr hohen Tempo mit abrupten Unterbrechungen (Breaks) innerhalb der Stücke. Gleichzeitig beinhalteten die Akkorde viele >dissonante< Erweiterungstöne (vor allem die verminderte Quint) in einem bis zu dieser Zeit unbekannten Ausmaß.

Diese schnellen, scheinbar >verrückten< Improvisationen von Solisten wie Charlie Parker und Dizzy Gillespie kann man als Reaktion auf den geschmeidigen Big Band Jazz und braven Swing interpretieren. So wollten die Musiker der Bebop-Bewegung eine gänzlich neue Musik erschaffen, die jedoch nicht der Unterhaltung des breiten Publikums dienen sollte, sondern bei der der intellektuelle Aspekt im Vordergrund stand. Ob das Publikum ihre Musik mochte oder nicht war ihnen zumindest nach außen hin gleichgültig. Tatsächlich bewirkten diese Prozesse, dass der Jazz ab Ende der 40er Jahre als Unterhaltungsmusik immer mehr aus der Mode kam, was sich bis zur Gegenwart im Wesentlichen nicht mehr verändert hat (vgl. Jost 1982: 26; Jacobs 1996: 219).

Das extrem hohe Tempo mit den bis dahin ungewöhnlichen Akzentsetzungen (vor allem der Schlagzeuger) hatte aber vor allem den

11 Bebop Big Bands, wie beispielsweise die von Dizzy Gillespie, waren eher Ausnahmeerscheinungen. 
Zweck, mittelmäßige, insbesondere weiße Musiker zu entmutigen und von den Jam Sessions im Mintons in New York fernzuhalten. So trafen sich einige Bebop-Musiker wie Gillespie, Monk und Clarke sogar manchmal nachmittags vor den Sessions, um komplizierte Harmonieschemen auszutüfteln. Dies sollte es den anderen Musikern erschweren, über die Progressionen zu improvisieren, um sie dadurch vom musikalischen Geschehen auszuschließen (vgl. Jacobs 1996: 194; Stearns 1959: 199; Davies/Troupe 1995: 64). Die Folge war, dass es nur sehr wenige weiße Musiker gab, die sich anfangs in dieser Szene behaupten konnten.

Was den gesellschaftlichen Aspekt angeht, so waren die »Boppers « eine nahezu sektenähnliche Gemeinschaft, die sich bewusst von der Masse unterscheiden und isolieren wollte. Neben der Musik und der Art des Improvisierens waren sie sich auch hinsichtlich ihres Lebenswandels ziemlich ähnlich, was sich in der Kleidung (Baskenmütze, große schwarze Sonnenbrille, Ziegenbart, breite Krawatte) und exzessivem Drogenkonsum ausdrückte, der vielen das Leben kostete.

Obwohl die Phase des Bebop einen großen Einfluss auf die darauf folgenden Abschnitte in der Jazzgeschichte wie u.a. den Cool Jazz (1948-1952) und Hardbop bzw. Neobop (ab 1954) ausübte, manövrierte sich diese Szene zunächst selbst ins Abseits. Begründet liegt dies in der Art, wie die Musiker sich und ihre Musik präsentierten, was in weiten Kreisen auf Ablehnung stieß und nicht zuletzt im exzessiven Lebenswandel, der ihre Zuverlässigkeit und Kreativität auf Dauer stark beeinträchtigte (vgl. z.B. Jacobs 1996: 198ff., 208, 214). Dennoch gilt es festzuhalten, dass die Improvisation bei ihnen ein Mittel war, sich zu definieren und gegenüber anderen abzugrenzen bzw. Nichtkundige - vor allem Weiße - vom musikalischen Geschehen auszuschließen. ${ }^{12}$ Gleichzeitig jedoch konnte eine gute oder sogar herausragende Improvisation im Rahmen einer Jam

12 Es gilt dennoch zu erwähnen, dass einige Verfasser über Jazzmusik (z.B. Jacobs 1996: 199) nicht der Auffassung sind, dass die Improvisation im Bebop ein Mittel war, Weiße vom musikalischen Geschehen auszuschließen. Betrachtet man sich jedoch die Zitate von einigen schwarzen Musikern so wird deutlich, dass dies insgesamt eine nicht zu unterschätzende Rolle gespielt haben muss. So äußerte beispielsweise Miles Davis: »Der Bebop war keine weiße Sache [...] Er war ausschließlich schwarz« (Davies/Troupe 1995: 143). Vgl. des Weiteren Davies/Troupe 1995: 80, 92, 194, 201. 
Session Tür und Tor zu dieser Gemeinschaft öffnen und zu einer Form von Initiationsritus werden (vgl. Jost 1982: 38; Davies/Troupe 1995: 64, 71).

\section{Jazz \& Lyric}

Der intellektuelle Aspekt der Improvisation als Ausdruck eines Gruppenbewusstseins zeigt sich ebenfalls in einem anderen Abschnitt der Jazzgeschichte. Gegen Ende der 50er Jahre, als der Konflikt zwischen Schwarz und Weiß in den USA zu eskalieren drohte, schlossen sich einige Weiße dem Schwarzen Widerstand gegen die Unterdrückung an. Die Prominentesten hierbei waren Schriftsteller wie Jack Kerouac, Allen Ginsberg, Lawrence Ferlinghetti und Gregory Corso, die sich dieser Thematik in ihren Büchern widmeten. Nicht wenige von ihnen bezeichneten sich selbst als »white negroes « und begannen mit Jazzmusikern (allerdings mehr weißen als schwarzen) zusammenzuarbeiten. Vorwiegend in kleineren Lokalen San Franciscos (insbesondere im Club »the Cellar «) hielten diese Schriftsteller Lesungen ab, die mit Jazzmusik >untermalt< oder begleitet wurden. Dabei kam der Improvisation der Solisten die Funktion zu, bestimmte Worte bzw. Sinnzusammenhänge mit ihrem Spiel zu unterstreichen und auszuschmücken. Diese Phase - improvisierte Jazzmusik mit literarischen Lesungen zu verknüpfen - war in den USA von relativ kurzer Dauer, beschränkte sich das Interesse hierfür doch nur auf einen relativ kleinen Kreis von Intellektuellen. Gleichzeitig verlor die Jazzmusik in den USA dadurch weiter an Bedeutung für ein breites Publikum. In Deutschland existiert diese Symbiose - Jazzimprovisation und literarische Lesungen -, wenn auch in geringem Umfang, bis zur Gegenwart oftmals unter der Bezeichnung Jazz \& Lyric (vgl. Viera 1992: 150). So arbeitete beispielsweise der Free-Jazz-Schlagzeuger Günther »Baby« Sommer mit Autoren wie Christa Wolf und Günther Grass zusammen.

\section{Der Einfluss diverser Aufnahmemedien}

Ein wichtiger Aspekt, der insbesondere den Gebrauch, aber auch die Funktion der Improvisation im Jazz quasi stilübergreifend und unabhängig von bestimmten Strömungen und Epochen beeinflusste, war die Erfindung und Verbesserung von Aufnahmemedien, also primär der Schellackplatte und der LP. Es wäre zu ausufernd, diese 
Prozesse hier im Detail zu beleuchten. Dennoch kann man sagen, dass sich der Gebrauch der Improvisation insofern veränderte, als der jeweilige situative Kontext - sofern es sich nicht um Liveaufnahmen handelte - ersetzt wurde durch eine mehr oder weniger sterile Studioatmosphäre. Dadurch bedingt fehlte in diesen Aufnahmesituationen gänzlich die Interaktion zwischen Musiker und Publikum (vgl. Jost 1982: 50).

Ferner beeinflusste das jeweilige Aufnahmemedium jedoch auch die Zeit eines Stückes und damit der Improvisation. War sie im Fall der Schellackplatte noch auf wenige Minuten begrenzt, so führte die Einführung der LP bzw. des Vinyls nach 1950 dazu, dass die Dauer der Improvisationen immer länger wurde (vgl. Jacobs 1996: 266; Jost 1982: 47f.). Jost (1982: 48) weist darauf hin, dass es durch die zeitliche Normierung, die diese Innovationen mit sich brachten, zu Kuriositäten kam insofern, als für einen Titel nur eine ganz bestimmte Zeit vorgesehen war (z.B. nicht länger aber auch nicht kürzer als 3 Min 12 Sek.). Es ist leicht einzusehen, dass eine solche zeitliche Fixierung für einen improvisierenden Musiker zumindest sehr gewöhnungsbedürftig ist, kann er doch bei einer gelungenen Improvisation diese nicht weiter ausdehnen bzw. sie bei einer weniger gelungenen Improvisation ohne weiteres beenden. Dies wird auch aus einem Zitat von Miles Davis ersichtlich:

»Ich hatte diesen Drei-Minuten-Krampf bei den 78er-Platten sowieso längst satt. Für wirklich freie Improvisation war da nie Raum; man musste möglichst schnell in sein Solo reinkommen, und dann war's auch schon wieder vorbei.«(Davis/Troupe 1995: 178)

Die Erfindung und Verbesserung von Aufnahmemedien beeinflusste jedoch ebenfalls die Funktion. Sie änderte sich für alle Beteiligten also den Solisten, die Begleitgruppe und sogar das Publikum (in Livesituationen) - insofern, als die Improvisation nicht mehr nur den Augenblick betraf, in der sie vollzogen wurde, sondern vielmehr ein bleibendes Zeugnis darstellte (vgl. Jost 1982: 47f.). Dadurch war es möglich, das ursprünglich Einmalige durch die technische Reproduzierbarkeit allerorts und jederzeit wieder abzurufen. 


\section{Free Jazz und Jazz Rock}

Die >radikalste< Form der Improvisation im Jazz - wenngleich nicht ohne jegliche Konventionen, wie häufig vermutet wird - begegnet einem schließlich im Free Jazz. ${ }^{13}$ Die Anfänge des Free Jazz sind einmal mehr vornehmlich auf die Metropole New York in den 60er Jahren zurückzuführen, wenngleich die Grundlagen für diese Strömung bereits früher von Musikern wie Charles Mingus und John Coltrane gelegt wurden (Jost 1975: passim). Ähnlich dem Bebop war der Free Jazz musikalisch gesehen ein Schritt zurück zur Kollektivimprovisation (keineswegs jedoch ein Rückschritt) und zur musikalischen Gleichberechtigung aller Musiker - also einer Loslösung von der Aufteilung in Rhythmus- und Melodieninstrumente. So äußerte Ornette Coleman, ein bedeutender Vertreter dieser Richtung, im Jahr 1959: »Vielleicht das wichtigste neue Element in unserer Musik ist unser Konzept einer freien Gruppen-Improvisation.« (Coleman in Jost 1975: 66)

Trotzdem war dieser Schritt zur Kollektivimprovisation im Vergleich zum Bebop deutlich radikaler aufgrund einer häufigen Abstinenz von formaler Ordnung und regelmäßigem Zeitmaß. Zudem wurde jegliche Art von Klängen bzw. Geräuschen - erzeugt durch verschiedenartigste Instrumente - verwendet (vgl. Jost 1975: 20, 224; Jacobs 1996: 285ff.).

Was die Funktion angeht, so handelte es sich um eine weitere Verstärkung dessen, was sich bereits im Bebop angekündigt und später im Hard Bop und >Literaten-Jazz fortgesetzt hatte: Eine schwarze Kampfansage bzw. Revolution, ja sogar der Befreiungskampf des afroamerikanischen Volkes auf der ganzen Welt mittels improvisierter Musik ${ }^{14}$ und gleichzeitig die Ablehnung der bis dahin

13 Die Bezeichnung »Free Jazz« geht auf die gleichnamige Platte von Ornette Coleman im Jahr 1960 zurück, wenngleich diese Musik u.a. als »free music«, »black music« oder sogar »great black music« bezeichnet wurde. $\mathrm{Zu}$ den prominentesten Vertretern gehörten Ornette Coleman, Archie Shepp, Albert Ayler, Don Cherry, Sun Ra und Cecil Taylor (vgl. Jost 1975: passim).

14 Die Tatsache, dass Einzelne - vor allem weiße Musiker - dem Free Jazz zumindest teilweise diese politische Bedeutung absprechen, soll hier nicht verschwiegen werden (vgl. z.B. Jost 1982: 146f., 159ff.; Viera 1992: 19). Gleichzeitig wird jedoch aus sehr vielen Aussagen schwarzer Musiker diese 
herrschenden musikalischen Normen und der Gesetze des Musikbusiness (vgl. Jost 1975: 11ff., 98, 208; Jacobs 1996: 275ff.; Berendt/ Huesmann 1991: 46).

Wie zuvor die Bebopper, so hegten auch die Musiker des Free Jazz keineswegs die Absicht, ihr Publikum zu unterhalten (vgl. Jost 1975: 9). Gleichzeitig manövrierten sich viele dadurch ins Abseits bzw. in die finanzielle Erfolglosigkeit. So hatten die Gruppen kaum Gelegenheit, in Clubs öffentlich aufzutreten, sondern mussten ihre Konzerte stattdessen in gemieteten Lagerhallen und Lofts selbst organisieren. Darüber hinaus hatten sie große Schwierigkeiten, ihre Musik auf Tonträgern zu veröffentlichen (vgl. Jost 1975: 78f.).

Trotz der Tatsache, dass es sich bei dieser Bewegung, vereinfacht gesagt, um eine schwarze Revolution handelte, setzte sich das Publikum primär aus Weißen zusammen (vgl. Jost 1982: 59). In den USA wurde diese Musik Anfang der 60er Jahre größtenteils ignoriert und mitunter sogar verachtet. Lediglich beim europäischen Publikum fand der Free Jazz Anerkennung und wurde als politisch bedeutsam, ja sogar als Ersatzhandlung für eine revolutionäre Tat angesehen.

Ab etwa Mitte der 70er Jahre geriet das Prinzip der freien Improvisation im Jazz in den USA zunehmend in eine Krise. Eine Reihe von bedeutenden Free Jazzern orientierte sich, was die musikalische Form anbelangt, wieder stärker an Traditionellem - insbesondere dem Bebop (vgl. Jacobs 1996: 293; Jost 1982: 151ff.). Dies ist nicht zuletzt darauf zurückzuführen, dass sich eine Menge $>$ Dilettanten< dem Prinzip der freien Improvisation im Jazz zuwandten, ohne jedoch mit den musikalischen Grundlagen vertraut zu sein. So waren viele nicht in der Lage, bei einer Improvisation über ein Harmonieschema bewusst akkordeigene Töne anzuspielen und kamen mit komplexeren Formen nicht zurecht. Einigen Arrivierten schien das nicht gefallen zu haben, da quasi der Codex - aufgrund von musikalischen und insbesondere improvisatorischen Qualitäten zu einer Gruppe zu gehören - abhanden gekommen war (vgl. Jost 1982: 83f.).

Tendenz zum Protest unverkennbar deutlich. So äußerte z.B. der Free Jazzer Archie Shepp 1968: »Er [der Jazz, d.V.] ist gegen den Vietnam-Krieg; er ist für Kuba; er ist für die Befreiung aller Völker [...] weil der Jazz selber eine Musik ist, die aus der Unterdrückung, aus der Versklavung meines Volkes hervorgegangen ist. (Shepp in Carles und Comolli 1980: 15) 
$\mathrm{Ab}$ Ende der 60er und vor allem Anfang der 70er Jahre kam es zu einer verstärkten Hybridisierung des Jazz, da vermehrt musikalische Einflüsse aus anderen Musikrichtungen (Rock, Musik anderer Kulturen) miteinbezogen wurden. Viele Gruppen erweiterten ihr Instrumentarium um elektrische bzw. elektronische Instrumente wie E-Gitarren, Keyboards oder Trompeten mit »Wah-Wah«-Effekten. Ähnlich vielseitig wie die Einflüsse und Instrumente waren die Bezeichnungen dieser hybriden Formen, von denen Jazz Rock, Rock Jazz und Fusion wohl die gängigsten sind. Als prominentester Vertreter hierbei kann Miles Davis bezeichnet werden, dessen LPs In A Silent Way und Bitches Brew für viele den Beginn des Jazz Rock markierten.

Wenngleich Jazz Rock und Free Jazz nur bedingt vergleichbar sind, so ist hinsichtlich der improvisatorischen Herangehensweise beim Jazz Rock ebenfalls eine deutliche Tendenz zum freieren Umgang und eine Loslösung von den zu Grunde liegenden harmonischen Strukturen zu beobachten. Obwohl es zu keinem gänzlichen Bruch mit den früheren Jazzformen kam - wie dies beim Free Jazz teilweise der Fall war - lautete die neue Formel >modale Spielweise $<$. Vereinfacht gesagt bedeutet dies, dass nicht mehr jeder Akkord in Form von Arpeggien ${ }^{15}$ gespielt wurde, sondern vielmehr verschiedene Tonleitern über längere Passagen verwendet wurden und dadurch die Musiker mehr Freiräume bei ihren Improvisationen besaßen.

Tatsächlich tauchte aber mit dem Beginn des Jazz Rock - häufiger als jemals zuvor - die Frage auf, ob das denn alles überhaupt noch als Jazz zu bezeichnen sei und viele sprachen sogar von einer Krise der Jazzmusik. Bis zur Gegenwart verstärkte sich dies angesichts der neuen Formen und Bezeichnungen wie u.a. Ethno Jazz (vor allem in den 80er und 90er Jahren), Hip-Hop-Jazz und Rap Jazz, Punk Jazz usw.

15 Arpeggio $=$ Töne eines Akkordes, die nicht gleichzeitig, sondern nacheinander gespielt werden. 


\section{Jazzimprovisation im Rahmen der Institutionalisierung}

Mitte der 80er Jahre kam es - zunächst in den USA, später mit dem Erstarken des europäischen Jazz ebenso in Europa - zu einer zunehmenden Institutionalisierung. ${ }^{16}$ Während die Musiker seit Anbeginn dessen, was man als Jazz bezeichnen kann, die Musik außerhalb von Institutionen erlernten, ${ }^{17}$ änderte sich dies nunmehr erheblich. Jazzmusik mit ihrem ureigensten Merkmal der Improvisation wurde an amerikanischen ${ }^{18}$ und europäischen ${ }^{19}$ Musikhochschulen bzw. Konservatorien gelehrt.

Richtet man den Blick auf Deutschland, so wird offensichtlich, dass die Institutionalisierung des Jazz auch hier eine wesentliche Rolle spielt. Derzeit gibt es etwa 20 Fachhochschulen bzw. Musikhochschulen mit einem Studiengang Jazz und darüber hinaus private Institutionen (z.B. Global Jazz Academy in Berlin, Jazz \& Pop School Darmstadt, Jazz \& Rock Schule Freiburg), deren Diplome zum Teil staatlich anerkannt sind (vgl. Heyd 2006: 1f.). Ein weiterer Ausdruck dieser Institutionalisierung ist, dass in Deutschland - wie auch in vielen anderen europäischen Ländern - etliche Veranstaltungen von öffentlicher Seite (in Deutschland u.a. vom Goetheinstitut, Kulturstiftung des Bundes) finanziell gefördert werden (vgl. Wicke 2004: 2). Nicht wenige davon sind nach dem Vorbild der

16 Bereits seit Anfang der 50er Jahre gab es an Konservatorien und Hochschulen in den USA und Europa vereinzelt und eher sporadisch Kurse über Jazzmusik, bei denen u.a. Musiker wie L. Armstrong, D. Gillespie, C. Parker als Gastdozenten mitwirkten. (vgl. Howland/Porter 2007: 1; Long 2006: 2).

17 Musikalische Grundkenntnisse wie Noten, Harmonielehre und eventuell sogar Blattspiel eigneten sich die Musiker weitestgehend in Umfeldern wie der Kirche, Schule, Vereinen oder im Privatunterricht an (vgl. Jost 1982: 31f.).

18 Bei Jost (1982: 192) wird deutlich, dass schwarzen Musikern der Zugang zu akademischen Ausbildungen bis zur >Gegenwart< aus finanziellen Gründen zumeist erschwert ist.

19 Der erste Studiengang für Jazz im deutschsprachigen Raum wurde an der Hochschule für Musik und darstellende Kunst in Graz bereits im Jahr 1965 eingerichtet (vgl. Viera 1992: 167). 
ernsten Musik, Wettbewerbe, bei denen von einer Jury Preisträger ermittelt werden. $^{20}$

Durch diese Prozesse der Institutionalisierung veränderte sich die Improvisation im Jazz hinsichtlich des Gebrauchs bzw. der situativen Kontexte zwangsläufig. So war Jazzimprovisation nunmehr ein Gegenstand bei Aufnahmeprüfungen, Vorspielen, Zwischenprüfungen und Examen an den Hochschulen und des Weiteren bei den erwähnten Preisträgerkonzerten. Dadurch wandelte sich die Funktion der Improvisation, die auf einmal ein Mittel war, einen akademischen Grad zu erwerben oder von öffentlicher Seite finanzielle $\mathrm{Zu}$ wendungen zu erhalten.

Führt man sich vor Augen - was hier in einer kurzen und keineswegs umfassenden Art und Weise dargestellt wurde -, wie vielseitig der Gebrauch und die Funktion bei der Improvisation im Jazz und eventuell sogar den Vorformen sein können, so liegen die Problematiken auf der Hand: Wie könnte man das »so, und auch anders« (nach Kadens Kurzformel für Improvisation) bewerten? Sollte man Stilechtheit, und wenn ja, aus welcher >Epoche $<$ bzw. von welchem Musiker bemessen oder etwa einen anderen wesentlichen Aspekt, nämlich den, durch Improvisation etwas Neues zu erschaffen als Ausdruck des eigenen Ich. Könnte ein Gremium gar mit Punkten oder Noten entscheiden, ob ein Jazzmusiker mittels der Improvisation seine eigenen Gefühle zum Ausdruck zu bringen in der Lage war? Erschwerend kommt bei diesem Aspekt hinzu, welcher Natur diese Gefühle eigentlich waren: Ausdruck des Protests (etwa gegen die Unterdrückung der Schwarzen in den USA), der momentanen inneren Gemütsverfassung und gar die intendierte Übermittlung einer Botschaft an das Publikum? Oder wollte das Gremium beurteilen, inwieweit der Prüfungskandidat in der Lage war, einen Konkurrenten bzw. gar eine konkurrierende Band mittels der Improvisation zu >schlagen< oder unter Umständen die Fähigkeit so kompliziert zu spielen, dass es Außenseitern nicht möglich wäre, musikalisch daran aktiv teilzunehmen. Wollte eine Jury bewerten, wie gut eine Gruppe aufeinander eingespielt ist - wie es bei der Kollektivimprovisation im New Orleans Jazz häufig der Fall war - oder wie gut sich ein

20 So gibt es beispielsweise für junge Jazzmusiker in Deutschland spezielle Fördermaßnahmen wie das Jazz-Podium Niedersachsen oder das Stipendium Jazz Berlin, wo ebenfalls eine künstlerische Bewertung der Improvisation vorgenommen wird (vgl. Wicke 2004: 2). 
Examenskandidat in einer weniger eingespielten Besetzung - wie es ab der Chicago-Zeit häufig der Fall war - musikalisch zurechtfinden kann? Ist es ein Kriterium für eine gute akademische Note, ein altes Jazz-Stück bzw. einen Standard so authentisch wie möglich vorzutragen oder nach der eigenen Persönlichkeit bzw. dem Geschmack des jeweiligen Musikers umzugestalten, wie es häufig die BebopMusiker taten. Wie bereits die geschichtliche Darstellung, so ist auch dieser kurze Fragenkatalog keineswegs umfassend, sondern soll lediglich verdeutlichen, wie groß die Problematiken für eine (objektive) Bewertung der Improvisation im Jazz sind.

Mittlerweile wird Jazzimprovisation an deutschen Musikschulen im Einzel- und Gruppenunterricht vermittelt. Dadurch bedingt spielt sie bzw. ihre Bewertung bei Prüfungen in der Unter-, Mittel- und Oberstufe im Jazz und Popularmusikbereich der Musikschulen eine erhebliche Rolle. Zudem existieren auf Landesebene Wettbewerbe für Jazzmusik wie »Jugend jazzt«, denen ebenfalls der Aspekt der >objektiven< Bewertung von Improvisation zugrunde liegt. Wenngleich an den öffentlichen Musikschulen mittels der Prüfungen keine akademischen Abschlüsse erworben werden können, so ergeben sich für die Bewertungskriterien für Jazzimprovisation doch Problematiken, die vergleichbar sind mit den zuvor erwähnten an den Musikhochschulen.

Neben Musikhochschulen und Musikschulen wird in jüngerer Zeit Jazzimprovisation sogar in den Musikunterricht an allgemein bildenden Schulen miteinbezogen (vgl. z.B. Fuchs 2006; Dethlefs 2001). In diesem Rahmen wird mit der Pentatonik über einfache harmonische Strukturen u.a. gesanglich, mit Orff Perkussionsinstrumenten oder der Blockflöte improvisiert. Was die Funktion betrifft, so erhofft man sich dadurch im engeren Sinne einen Zugang und Nähe zur zunächst fremden Jazzmusik zu schaffen und im weiteren Sinne die Akzeptanz für andere Kulturen zu vergrößern. ${ }^{21}$

21 Das Argument durch die Vermittlung von Jazzmusik die Toleranz für andere Kulturen zu fördern, taucht häufig auf neben anderen Argumenten wie »Selbstschutz vor Nationalismus und Extremismus« »Dialog und Kooperation statt Abgrenzung und Konflikt« (vgl. z.B. Eckpunktepapier der Bundeskonferenz Jazz 2007: 1). 


\section{Fazit}

Anhand der (Jazz-) Geschichte wird deutlich, dass das Verhältnis von Jazz und Improvisation hinsichtlich Gebrauch und Funktion stets großen Abweichungen unterlag in Abhängigkeit von Zeit, bestimmten Strömungen, Intentionen einer Gruppe und - das konnte hier nicht näher beleuchtet werden, da es zu ausufernd wäre - natürlich eines einzelnen Individuums. Dabei konnte nur ein sehr kleiner Teil dieses Verhältnisses beleuchtet werden, wohingegen weitere interessante Aspekte wie beispielsweise Jazz/Improvisation in Diktaturen aufgrund des Umfanges ausgeklammert werden mussten. Die Absicht war jedoch, lediglich die Mannigfaltigkeit zwischen beiden Phänomenen anzudeuten, die tatsächlich noch viel umfassender ist, als es hier dargestellt werden konnte. Aus diesem vielschichtigen Verhältnis resultieren Probleme bezüglich der Art und Weise, wie Jazzimprovisation heute (nicht nur, aber auch) in Deutschland an Musikhochschulen, Musikschulen und allgemein bildenden Schulen erstens gebraucht wird und zweitens welche Funktion dies erfüllen soll.

Am wenigsten problematisch erscheint auf den ersten Blick die Verwendung im schulischen Bereich, wo man mittels Improvisation auf einfacher Basis das gemeinsame Musizieren fördern möchte und damit ein Verständnis oder gar Interesse für andere Musikformen ja sogar Toleranz für andere Kulturen geweckt werden soll. Argumente dieser Art stoßen natürlich insbesondere bei (Kultur-) Politikern auf große Resonanz. Ohne jedoch die Sache schlecht reden zu wollen, wird man eine solche Funktion (von Jazz und Improvisation) im geschichtlichen Verlauf wohl kaum finden. Geht man vom Bebop oder Free Jazz aus, mutet diese Intention sogar wie ein Widerspruch an.

Ohne die Argumente noch einmal zu wiederholen, scheint die Verwendung an Musikhochschulen und Konservatorien am problematischsten. Zweifelsohne ist die Integration von Jazzstudiengängen an Musikhochschulen und Konservatorien eine Bereicherung, nicht nur, was die Pluralität von Musikstilen angeht, sondern auch, was die Weitervermittlung von Jazz und anderen populären Musikformen an Musikschulen betrifft und nicht zuletzt den vielen hervorragenden Jazzmusikern, die aus solchen Institutionen hervorgegangen sind. Obwohl die Vorteile insgesamt überwiegen, wird man in $\mathrm{Zu}-$ kunft jedoch immer mit einem Widerspruch leben müssen, der da 
lautet: Eine objektive Bewertung von Improvisation (nicht nur, aber vor allem) im Jazz ist nie vollständig zu realisieren aufgrund des vielschichtigen Verhältnisses beider Phänomene - Jazz und Improvisation - im Verlaufe der Geschichte.

\section{Literaturverzeichnis}

Bailey, Derek (1987 [1980]): Musikalische Improvisation. Kunst ohne Werk. Aus dem Englischen übersetzt von Hermann J. Metzler und Alexander von Schlippenbach, Hofheim: Wolke Verlag.

Berendt, Joachim-Ernst/Huesmann, Günther (1991): Das Jazzbuch. Von New Orleans bis in die achtziger Jahre. Frankfurt a.M.: Fischer Taschenbuch Verlag.

Bundeskonferenz Jazz (2007): Zur Situation des Jazz und der aktuellen improvisierten Musik in Deutschland. Eckpunktepapier. In: URL: typo3.udj.de/fileadmin/bkjazz/pdf/EckpunktepapierJazzin Deutschland2007.pdf -. [Datum des Zugriffs: 01.06.2007].

Carles, Philippe/Comolli, Jean-Louis (1980): Free Jazz - Black Power. Aus dem Französischen übersetzt von Frederica und Hansjörg Pauli, Hofheim: Buchhandlung Raymund Dilmann.

Collier, James L. (1987 [1983]): Louis Armstrong. Von New Orleans bis zur Carnegie Hall. Übersetzt von Theo Kierdorf, München: Econ Taschenbuch Verlag.

Dauer, Alfons M. $\left({ }^{2} 1958\right)$ : Der Jazz. Seine Ursprünge und seine Entwicklung. Kassel: Erich Röth-Verlag.

Davis, Miles/Troupe, Quincy (1995 [1989]): Miles Davis. Die Autobiographie. Aus dem Amerikanischen übersetzt von Brigitte Jakobeit, Hamburg: Hoffmann und Campe.

Dethelfs, Beate C. (2001): »>Basin Street Blues< Musiklernen durch ein Jazz-Evergreen und seine Geschichte«. In Musik in der Schule Heft 1, S. 21-27, 30-31.

Fuchs, Mechthild (2006): »Jazz for Beginners. Praktische Beispiele für die Einführung von Jazz in den Klassen 4-6«. In AfSMagazin Heft 21, S. 24-29. In: URL: afs-musik.de/pdf/AfSMag2106 Fuchs.pdf. [Datum des Zugriffs: 01.06.2007].

Heyd, Jörg (2006): »Ausbildung Rock Pop Jazz in Deutschland «. In: URL: www.miz.org/static/themenportale/einfuehrungstexte 
pdf/04JazzRockPop/heyd.pdf. [Datum des Zugriffs: 01.06. 2007.]

Hodeir, Andre (1975 [1956]): Jazz. Its Evolution And Essence. Übersetzt von David Noakes, New York: Da Capo Press.

Howland, John/Porter, Lewis (Hg.) (2007): »From >Perspectives in Jazz< to Jazz Perspectives«. In Jazz Perspectives Vol. 1, S. 1-3.

Jacobs, Michael (1996): All that jazz: Die Geschichte einer Musik. Stuttgart: Reclam.

Jost, Ekkehardt (1975): Free Jazz. Stilkritische Untersuchungen zum Jazz der 60er Jahre. Mainz: B. Schott's Söhne.

Jost, Ekkehardt (1982): Jazzmusiker. Materialien zur Soziologie der afro-amerikanischen Musik. Frankfurt a.M.: Verlag Ullstein $\mathrm{GmbH}$.

Kaden, Christian (1993): Des Lebens wilder Kreis. Musik im Zivilisationsprozess. Kassel: Bärenreiter Verlag.

Long, Barry (2006): Concert of Communitas: Jazz and Ritual Space from Nightclub to Concert Hall. Mount St. Mary's University. In: URL: faculty.msmary.edu/long/jazzritual_excerpt.pdf. [Datum des Zugriffs: 09.06.2007].

Magee, Jeffrey (2007): »Kinds of blue: Miles Davis, Afro-Modernism, and the Blues «. In Jazz Perspectives Vol. 1, S. 5-27.

Merriam, Alan P. (1964): The Anthropology of Music. Evanston: Northwestern University Press.

Nettl, Bruno (1983): »Music Hath Charms«. In ders., The Study Of Ethnomusicology. Twenty-Nine Issues And Concepts, Urbana und Chicago: University of Illinois Press.

Nettl, Bruno (1989): Blackfoot Musical Thought. Kent (Ohio): The Kent State University Press.

Neuhoff, Hans (2007): »Musiksoziologie heute. Eine Ortsbestimmung «. In: ders. und Helga de la Motte-Haber (Hg.), Musiksoziologie, Handbuch der Systematischen Musikwissenschaft Band 4, Laaber: Laaber-Verlag, S. 81-107.

Polillo, Arrigo (1981 [1975]): Jazz. Geschichte und Persönlichkeiten. Aus dem Italienischen übersetzt von Egino Biagioni, Mainz: Schott Musik International.

Royce, Anya Peterson (1977): The Anthropology of Dance. Bloomington: Indiana University Press.

Seedorf, Thomas/Reinhard, Andreas/Frisius, Rudolf et al. (1996): »Improvisation«. In: Ludwig Finscher (Hg.), Die Musik in Ge- 
schichte und Gegenwart, Sachteil 4, Kassel, Basel, London et al.: Bärenreiter/Metzler, Sp. 538-611.

Stearns, Marshall W. (1959 [1956]): Die Story vom Jazz. Aus dem Amerikanischen übersetzt von Hans Krammer, München: Süddeutscher Verlag.

Trampert, Lothar (1992): »[Interview mit] Pat Metheney«. In Gitarre \& Bass September 1992, S. 18-24.

Viera, Joe (1992): »Jazz. Musik unserer Zeit«. In Peter Niklas Wilson/Walter Lachenmann (Hg.), Collection Jazz Band 20, Schaftlach: Oreos Verlag GmbH.

Wicke, Peter (1992): »Jazz, Rock und Popmusik«. In Doris Stockmann (Hg.), Neues Handbuch der Musikwissenschaft Bd. 12; Volks- und Popularmusik in Europa, Laaber: Laaber-Verlag, S. 445-447.

Wicke, Peter (2004): Populäre Musik in der Bundesrepublik Deutschland. In: URL: www.miz.org/static/themenportale/einfuehrungstextepdf/04JazzRockPop/wicke.pdf. [Datum des $\mathrm{Zu}$ griffs: 11.06 .2007$]$. 



\section{MUSIKALISCHES IMPROVISIEREN: EIN AUSDRUCK DES AUGENBLICKS}

Silvana K. Figueroa-Dreher

Improvisieren als musikalischer Prozess und Improvisation als musikalisches Ergebnis dieses Prozesses sind in sämtlichen Kulturen der Welt und in allen Zeiten stärker präsent (gewesen) als Praktiken und Formen komponierter Musik. Trotzdem wurden die Sozial- und Kulturwissenschaften merkwürdigerweise nur selten auf dieses Phänomen aufmerksam, ${ }^{1}$ so dass es bisher in seinen unterschiedlichen Dimensionen und speziell aus der hier eingenommenen Perspektive kaum erforscht wurde. Dieser Aufsatz konzentriert sich auf die handlungstheoretischen Aspekte des Improvisierens und fragt, wie das Improvisieren als spezifisches Handeln zustande kommt, d.h. aufgrund welcher subjektiven Haltung diese menschliche Aktivität möglich wird. Dabei fokussiert der Artikel insbesondere Fragen der subjektiven Zeiterfahrung und der intersubjektiven Zeitkoordination während des Improvisierens, deren Thematisierung wiederum erhebliche Folgen für die handlungstheoretische Charakterisierung des Improvisierens hat. Die im Vergleich zur Ausführung komponierter Musik auftretenden Unterschiede sind ebenfalls

1 Dies mag zum Teil daran liegen, dass Improvisationen historisch schwer zu dokumentieren waren. Da beispielsweise die historischen Improvisationsanweisungen lediglich Anleitungen zum Improvisieren und keine Improvisationen als solche waren, existierten vor der Erfindung der Audioaufnahmetechnik keine reproduzierbaren Daten, die man hätte untersuchen können. Erst seit audiovisuelle Aufnahmetechniken entwickelt wurden und sich die Musikwissenschaft als Kulturwissenschaft zu verstehen beginnt und etwa vom Konstrukt der »Meisterwerkästhetik « abrückt, die nur >komponierte< Musik für betrachtenswert hielt, kann improvisierte Musik Betrachtungsgegenstand werden. 
von Relevanz für die hier diskutierten Thesen. Der Terminus Improvisieren soll unterstreichen, dass die Aufmerksamkeit dieser Reflexionen prinzipiell auf den Prozess des Spielens improvisierter Musik gerichtet ist und nicht auf das fertige Produkt des Improvisierens, die Improvisation. Bevor wir uns den genannten Fragen widmen, wird das Forschungsprojekt dargestellt, in dessen Rahmen die vorliegenden Thesen und Reflexionen entstanden sind. Der Darstellung der handlungstheoretischen Reflexionen und Fragen, die den Hintergrund der Studie bilden, folgt eine kurze Charakterisierung des Free Jazz, da mehrere der in diesem Projekt untersuchten Gruppen dieser Musikrichtung zuzurechnen sind. Danach werden die Ergebnisse und Thesen präsentiert, die sich aus ersten Analysen ergaben, sowie Reflexionen bezüglich der musikalischen Erfahrung, die Alfred Schütz (1976) unter dem Namen »Fragments on the Phenomenology of Music« notierte.

\section{Das Forschungsprojekt}

Die Thesen, die in diesem Aufsatz diskutiert werden, entstammen hauptsächlich ersten Analysen von Interviews und Improvisationsaufnahmen mit bzw. von Free Jazz-Musikern, die im Rahmen des empirischen Forschungsprojektes »Improvisation als >neuer $<$ Handlungstypus: eine handlungstheoretische Exploration der musikalischen Improvisation« durchgeführt wurden. Um das Improvisieren handlungstheoretisch zu charakterisieren - das zentrale Ziel der laufenden Studie - wurden für die Datensammlung u.a. ${ }^{2}$ drei Free JazzTrios aus Deutschland zu Improvisations-Sessions in das Tonstudio des Instituts für Komposition und Elektroakustik der Universität für Musik und darstellende Kunst Wien eingeladen. In vier Phasen wurden die Musiker audiovisuell aufgenommen. Erstens wurden sie

2 Im Rahmen des Projektes werden auch Flamenco-Trios untersucht. Die kontrastive Untersuchung beider Genres ermöglicht - indem Gemeinsamkeiten und Unterschiede der Flamenco- und Free-Jazz-Improvisationen festgestellt werden - zum »Kern« des Improvisierens - im Sinne von Alfred Schütz (vgl. 1972) - zu gelangen und seine grundlegenden Merkmale als Typus des Handelns zu erkennen, d.h. sie typologisch zu charakterisieren. Jedoch beziehen sich die Reflexionen dieses Aufsatzes ausschließlich auf die Free-Jazz-Improvisationen. 
während des Improvisierens aufgezeichnet: Diese Phase dient vor allem der Untersuchung (Charakterisierung) des Handlungstypus $>$ Improvisation< aufgrund der Analyse des Musikmaterials (Stufe I). Ummittelbar danach wurden die Musiker mit dem entstandenen Video- und Tonmaterial »konfrontiert«, wobei sie aufgefordert wurden, sich über ihre aufgezeichneten Handlungen zu äußern (Stufe II). Entsprechend des Prinzips der Grounded Theory (vgl. Strauss 1998: 40ff.) wurden die Fragen erst im Kontext der Untersuchung erarbeitet und formuliert, um Zugang zu den spontanen, »natürlichen« Äußerungen der Musiker zu gewinnen und die Interaktionsdynamik zwischen ihnen nicht zu unterbrechen (derweil sie gemeinsam die Aufnahmen betrachten und kommentieren). Diese Phase dient vor allem der Charakterisierung des Handlungstypus Improvisation, wie sie von den Musikern empfunden wird. Auf einer dritten Stufe wählten die Musiker ein Improvisationsstïck, das in ihren Augen besonders gelungen war. Dies dient vor allem als Kontrollmoment: Dadurch werden die Kriterien offen gelegt, nach denen sie die »Bewertung « improvisierter Musik vornehmen. So wurden die Sequenzen, die von den Musikern als am besten gelungen erachtet wurden, mit den betreffenden Kommentaren derjenigen Musiker verglichen, die diese Sequenzen gespielt hatten. Dies geschah im Hinblick auf die Frage der Reflexivität, um festzustellen, welche Prozesse, Situationen, Bewusstseinslagen zu ihnen führten. Auf einer vierten Stufe wurden die Musiker einzeln über ihre Improvisationen während des Spielens des gemeinsam zu analysierenden Stückes interviewt, um ihre individuellen Handlungen zu rekonstruieren, noch offene Fragen zu stellen und einen tieferen Einblick bezüglich der Improvisation zu gewinnen. Die Daten werden mit Hilfe von qualitativen Methoden - hauptsächlich Grounded Theory (vgl. Strauss 1998) und Sequenzanalyse (vgl. Soeffner 1979, 1982; Soeffner/Hitzler 1994) - und in Kooperation mit der Musikwissenschaftlerin Dr. Annegret Huber von der Universität für Musik und darstellende Kunst Wien analysiert.

\section{Handlungstheorie, Improvisation und Free Jazz}

In diesem Aufsatz ist das Augenmerk auf das Improvisieren im Free Jazz gerichtet, eines der radikalsten Improvisationsgenres in der 
Musik, das uns zum handlungstheoretischen Kern des Improvisierens zu führen vermag. ${ }^{3}$ Die Handlungstheorie befasst sich mit dem Deuten und Erklären menschlichen Handelns und versucht, seine allgemeine Struktur zu beschreiben. Handeln wird als »ein menschliches Verhalten (einerlei, ob äußeres oder inneres Tun, Unterlassen oder Dulden)« definiert, »wenn und insofern als der oder die Handelnden mit ihm einen subjektiven Sinn verbinden « (Weber 1922: 1). »Soziales Handeln aber soll ein solches Handeln heißen, welches seinem von dem oder der Handelnden gemeinten Sinn nach auf das Verhalten anderer bezogen wird und daran in seinem Ablauf orientiert ist « (ebd.). Wir handeln also insofern, als wir mit unserem Tun einen subjektiven Sinn verbinden, aber wie handeln wir? Richten wir uns immer an einem Ziel aus? Planen wir unsere Handlungen? Oder handeln wir spontan »aus dem Stegreif «? Aus der Perspektive der Soziologie sind diese Fragen insofern relevant, als eine Theorie des Handelns zum Fundament einer allgemeinen Theorie der Gesellschaft gehört (vgl. Luckmann 1992: 2), denn »zweifelsohne ist Handeln die >Grundform des gesellschaftlichen Daseins` des Menschen. Wir leben mit und unter anderen Menschen, wir handeln für und gegen andere. Auch wenn wir allein sind, beziehen wir andere in unsere Handlungen mit ein « (ebd.: 4). Innerhalb der Soziologie befasst sich insbesondere Thomas Luckmann in Anlehnung an Alfred Schütz mit den Fragen der internen Struktur des Handelns, d.h. mit seinem konkreten Verlauf. Sein Handlungsmodell ist sehr tiefgründig und detailliert und stellt die Basis für die vorliegenden Überlegungen; dennoch muss es ergänzt werden, wie im Folgenden gezeigt wird.

Thomas Luckmann bezeichnet »Handeln« - in Anlehnung an Alfred Schütz - als »den schrittweisen Vollzug einer Handlung«, al-

3 Im Rahmen des oben genannten Forschungsprojektes werden mehrere musikalische improvisatorische Genres kontrastiv untersucht, so dass einerseits die Spezifität jedes Genres zum Ausdruck kommt und andererseits die Gemeinsamkeiten bezüglich des Improvisierens aus der handlungstheoretischen Perspektive - sozusagen der handlungstheoretische Kern des Improvisierens - ergründet werden können. Es wird hier die These vertreten, dass das Improvisieren handlungstheoretisch eine Tätigkeit ist, jenseits von den unterschiedlichen Idiomen, in der diese Tätigkeit ausgeführt werden kann, ähnlich wie das Sprechen. 
so einen Vorgang in der Zeit, der sich einem bestimmten, in der Phantasie des Handelnden vorweggenommenen Ende nähert. Handlung stellt im Kontrast dazu das vollzogene Handeln dar, »das vergangene Handeln, das die Geschichte der vorangegangenen Schritte, die zu ihm führten, in sich enthält« (Luckmann 1992: 48). Luckmann behauptet, dass die handelnde Person eine Handlung vorentworfen haben muss, um überhaupt handeln zu können, so dass sich das Handeln an der entworfenen Handlung als seinem Ziel ausrichten kann (vgl. ebd.). Beim gewohnheitsmäßigen Handeln (wie beispielsweise dem Zähneputzen) bleiben jedoch die Ziele mehr oder weniger unbewusst und das Gelernte wird einfach > wie immer < wiederholt. Die Entstehung von neuen Handlungsweisen bzw. von neuen >Produkten< des Handelns bleibt beim gewohnheitsmäßigen Handeln ausgeschlossen. In >problematischen< Situationen jedoch, wenn das Ziel bzw. die Schritte ungewiss sind und die möglichen Folgen der Handlung bedeutsam werden können, müssen Entwurf und Endziel sorgfältig bedacht werden - in diesem Fall ist in unterschiedlichen Abstufungen Kreativität im Handeln gefordert. Das Handeln erfolgt gemäß Luckmann dann, wenn der Entschluss gefasst wird, den Entwurf tatsächlich zu verwirklichen. Bei routinisiertem Handeln ist der Entschluss kein schwieriger Willensakt; Entwurf und Entschluss stellen sich fast automatisch ein. Bei problematischen Handlungen jedoch wird der Entwurf bewusst vorgezeichnet und der Entschluss ist eine Angelegenheit von einigem Gewicht. Dies heißt nicht, dass die routinisierten Alltagshandlungen nicht entworfen werden, denn vor jedem Handeln steht, wie Luckmann argumentiert, ein Entwurf. Dieser tritt jedoch mit unterschiedlicher Deutlichkeit ins Bewusstsein, je nachdem, um welche Art des Handelns (problemlösendes oder routinisiertes) es geht. Bei problematischem oder unsicherem Handeln (also bei nicht routinisiertem Handeln) richtet sich der Handlungsvollzug, das Handeln, bewusst an der Aufeinanderfolge der einzelnen Schritte aus. Jeder Handlungsschritt ist ein Schritt »um-zu«: In der Zeitperspektive des Handelns konstituiert sich der aktuell-prospektive Sinn der Handlungsschritte als eine Kette von »um-zu-Motiven«, d.h. als das Erreichen-Wollen des entworfenen Ziels (vgl. ebd.: 52-57). Handeln ist somit für Luckmann eine Bewusstseinsleistung (vgl. ebd.: 38), die aufgrund von rationalen, ausgewogenen Entscheidungen stattfindet. Zielgerichtetheit - die Fähigkeit, sich an zukünftigen Zielen zu orientieren 
- kennzeichnet laut Luckmann ebenfalls das menschliche Handeln (vgl. Luckmann 1992: 6).

Die für Schütz/Luckmann definitorischen Merkmale des menschlichen Handelns - Zielgerichtetheit, reflektierende Einstellung des handelnden Subjekts - stimmen mit den prinzipiellen Annahmen der meisten sozialwissenschaftlichen Reflexionen über menschliches Handeln überein: Trotz den in konzeptionellem Sinne grundsätzlichen Unterschieden zwischen den verschiedenen soziologischen Theorien, sind diese hinsichtlich einer Definition des Handelns deutlich von einem Zweck/Mittel-Schema geprägt, ob dieses nun als individualistisch motiviert (wie im utilitaristischen Ansatz), normativ bedingt (wie bei Talcott Parsons), als idealtypisch (Max Weber) oder in der Praxis verankert (wie bei den Pragmatisten, George H. Mead, Hans Joas und Niklas Luhmann) gesehen wird (vgl. auch Fuchs-Heinritz 1995: 263). Die These des vorliegenden Aufsatzes lautet jedoch, dass andersartige Phänomene des Handelns - wie beispielsweise das musikalische Improvisieren existieren, die nicht im Sinne des rationalen, bewussten Zweck/ Mittel-Schemas erklärt werden können (vgl. auch Wahl 2000; Straub/Werbik 1999: 8). Das Improvisieren könnte einen Typus von nicht entworfenem, spontanem Handeln darstellen; daher wird es am Beispiel des Free Jazz - im Rahmen des oben genannten Projektes empirisch untersucht, um diese These zu überprüfen und das Improvisieren handlungstheoretisch zu charakterisieren.

Free Jazz kann folgendermaßen beschrieben werden:

»Insgesamt reicht die musikalische Bandbreite des Free Jazz von relativ durchkonzipierten Spielstrukturen, in welche Passagen für freie Improvisation eng eingepasst sind, bis zu völlig frei improvisierten Kommunikationsstrukturen, deren musikalischer Verlauf sich einzig aus dem Augenblick heraus ergibt, ohne vorherige Absprache der Beteiligten. Harmonische Grundgerüste, tonale Zentren oder eine bewusste Vermeidung jedes tonalen Anklangs, rhythmisch-metrisch konventionell swingende oder energiegeladene dynamische Prozesse stehen in verschiedenen Beispielen dieser Musik nebeneinander als Stilcharakteristika einiger der bedeutendsten Vertreter des free jazz.« (Knauer 1996: 1409f.; vgl. auch Jost 1974 und Noll 1977)

Anders als sonstige Musikformen, die durch Improvisation gekennzeichnet sind und beispielsweise vorkomponierte mit improvisierten Teilen kombinieren oder festgelegte Rhythmen oder melodische 
Strukturen besitzen, bestehen die meisten Free-Jazz-Performances gar nur aus Improvisationen in allen musikalischen Parametern gleichzeitig. Dieser Richtung ordnen sich die drei Trios zu, die von uns aufgenommen wurden (s.u.). Die Musiker improvisieren außerdem gleichzeitig und nicht nacheinander. Sie verfügen zwar über ein bestimmtes Repertoire an einstudierten Phrasen bzw. Wendungen, jedoch wissen sie vorab nicht, welche Sequenzen oder musikalische »Materialien « beim jeweiligen Improvisieren verwendet oder wie diese Materialien je nach musikalischer Situation und musikalischem »Bedarf « umgestaltet werden. Da die untersuchten FreeJazz-Trios auf eine radikale Art und Weise improvisieren, ist davon auszugehen, dass durch diese Fallanalyse ein Schritt zum »Kern« des Improvisierens als Handeln ${ }^{4}$ gelingen kann.

\section{Die subjektive Haltung beim Improvisieren im Free Jazz}

Im Rahmen des Forschungsprojektes wurden drei Free-Jazz-Trios ins Aufnahmestudio eingeladen. Das erste Trio (Trio TGW) besteht aus dem Bassspieler Christian Weber, dem Schlagzeuger Michael Griener und dem Saxophonisten und Klarinettisten Michael Thieke. Alle drei sind professionelle Musiker um die dreißig, die über langjährige Erfahrung im Free-Jazz-Kontext verfügen: Sie spielten mit anerkannten Musikern sowohl aus dem Free Jazz als auch aus anderen Genres, nahmen zahlreiche CDs auf und spielten auf internationalen Konzerten und Festivals in Deutschland und im Ausland. Ihr Stil ist dadurch geprägt, dass sie die stilistischen Freiheiten, die der Free Jazz als künstlerisches Konzept bietet, besonders weit ausloten. Das zweite Trio besteht aus Alexander von Schlippenbach (Klavier), Paul Lovens (Schlagzeug) und Evan Parker (Saxophon). Das Schlippenbach-Trio gilt als eines der erfahrensten und hervorragendsten in seinem Genre in Europa, die Musiker spielen seit über 35 Jahren zusammen und waren unter den ersten, die Free Jazz in

4 Obwohl innerhalb unterschiedlicher musikalischer Genres das Improvisieren sich auf verschiedene idiomspezifische »Regeln« stützen mag, wird hier davon ausgegangen, dass das Improvisieren handlungstheoretisch auf bestimmten Grundprinzipien beruht, die es zu erforschen gilt (vgl. auch Fußnote 3$)$. 
Deutschland spielten. Die dritte Formation (Investigation Routine) setzt sich zusammen aus Christoph Irmer (Geige), Klaus Treuheit (Klavier) und Günther Pitscheider (Kontrabass). Ihr Werdegang ist ebenfalls geprägt durch langjährige Erfahrung in Form von CDEinspielungen, der Teilnahme an internationalen Konzerten und Festivals sowie der Zusammenarbeit mit anderen Musikern aus Deutschland und dem Ausland. ${ }^{5}$

Auf welche Art und Weise findet das Improvisieren im Free Jazz statt? Aufgrund welcher Haltung sind die Musiker in der Lage zu improvisieren? Am Anfang einer Improvisation herrscht Ungewissheit vor, da sich die Musiker vor dem Spielen nicht absprechen, was sie spielen werden. Diese Situation wird dadurch bewältigt, dass man sich zunächst beliebiges Material vornimmt, also etwas spielt und dann schaut, »wie gut das zu dem passt, was die andern gerade anbieten « (M. Griener, Schlagzeuger), z.B. bezüglich der Klänge und Tempi, die jeder Musiker gerade spielt. Bei den Musikern sind gleichzeitig Entschiedenheit und Flexibilität erforderlich, denn es sei »Blödsinn « - so Griener -, zögernd das Material gleich zu Anfang wieder fallen zu lassen. Eher gehört es zu den »Regeln« dieses Genres, dass man das Material dann eben langsam umarbeitet bis innerhalb von Sekunden »die Linie noch klarer wird « und aus dem zufälligen und disparaten Anfang eine musikalische Koordination - nicht unbedingt einheitlich - in Tempo und Klang, eine bestimmte schlüssige, zusammenpassende Musik sich entwickeln kann, die jedoch nach sehr offenen aber dennoch komplexen ästhetischen Kriterien in dem Moment als »funktionierend « oder im Nachhinein als »gelungen « gelten kann.

Der Prozess des Improvisierens zeichnet sich durch eine starke Betonung des gegenwärtig Geschehenden aus. Die Entwicklung einer im Moment des Improvisierens als »funktionierend «, als ästhetisch schlüssig wahrgenommenen Musik geschieht nicht anhand einer Vorstellung seitens der Musiker, zu welcher Form sich diese Musik im Laufe des Improvisierens entwickeln soll, sondern aufgrund des aktuell »Passenden«. Anders als beim Spielen komponier-

5 Das Trio TGW wurde vom 27. bis zum 29. Januar 2006, Investigation Routine am 27. und 28. Mai 2006 und das Schlippenbach Trio am 13. und 14. Juli 2006 am schon erwähnten Institut für Komposition und Elektroakustik aufgenommen und von der Autorin interviewt. Alle Zitate in diesem Text stammen aus diesen Interviews. 
ter Musik existiert das als beendet imaginierte Musikstück noch nicht als handlungsleitende Vorstellung und die Musik kann sich im Prozess des Spielens in sehr unterschiedliche Richtungen entwickeln. Die Gegenwart erhält dadurch in der Wahrnehmung der Musiker ein höheres Gewicht als die Zukunft.

Für die Musiker ist Improvisieren darüber hinaus mit einem bewussten »Verlieren der Kontrolle« verbunden, »ein bewusstes Verlassen des aktiven Gestaltungswillens. Quasi wenn ich sage, ich mache meinen Plan weiter, der ist so ungefähr definiert, aber dann prallen Dinge aufeinander und dann ist es nicht mehr so kontrolliert und das kann extrem spannend oder belebend sein « (C. Weber, Kontrabassist). Der Musiker erfährt sich als Vektor einer Musik, die er nicht bewusst gestaltet, sondern die aus ihm herauskommt. Dies zu akzeptieren, muss man in der Lage sein, wie weiter geschildert wird:

»Geht auch wieder ins Thema Unfälle und Verbrechen. Also dass man Dinge quasi, die etwas außerhalb von einer Norm oder von einem Idealfall liegen, genau als solches akzeptiert und da bin ich dann auch wieder beim Alltäglichen. Also dass halt, ich geh halt auf der Straße und da ist was, nicht in jedem Fall will ich das beseitigen oder so, sondern ich nehme das halt so wie's ist.«(C. Weber, Kontrabassist)

Die Musiker empfinden, dass man in einer gewissen Weise der Situation ausgeliefert ist. Routine hilft in dieser Lage manchmal, aber nicht immer. Das Ungewisse der Situation, das nicht Planbare steht im Vordergrund. Dies betrifft jedoch nicht nur das Spiel der anderen, sondern auch das eigene Handeln ist für die Musiker im Voraus ungewiss, nicht geplant oder nicht festgelegt.

Die Haltung beim Improvisieren stellt in den Augen der Musiker einen Gegensatz zur Haltung des Übens dar. Die Improvisationshaltung ist offener, flexibler bezüglich des Handelns, sie kann beschrieben werden als Durchführung eines allgemeinen »Programms « zum Handeln, das die genaue, konkrete Ausführung der Tätigkeit offen lässt. Im Gegensatz dazu stellt Üben, handlungstheoretisch gesehen, das Erlernen von festeren, unflexibleren Handlungsweisen dar, die Optimierung einer Tätigkeit, die immer wieder in der gleichen Form reproduziert werden muss. Es handelt sich im Fall der Improvisationshaltung nicht um vorentworfene Handlungen, die Haltung beim Improvisieren ist nicht an konkreten Sequenzen bzw. Ergebnissen orientiert. Dagegen ist Üben durch konkrete 
Sequenzen bzw. Verläufe festgelegt: »Man übt ja immer anhand von konkretem Material« (C. Weber, Kontrabassist). Für die Musiker hat diese Einstellung mit dem »gemeinsamen Entstehen-Lassen der Musik« (M. Griener, Schlagzeuger) zu tun; reflexive »Kontrolleinstellungen ${ }^{6}{ }^{2}$ im Handeln werden ausgeschaltet, um die Musik geschehen zu lassen; in den Ausführungen von C. Weber (Kontrabassist) hat die Musik eine eigene Macht, »als wäre sie schon da « und müsste nur noch von den Musikern automatisch gespielt werden. Jedoch betonen sie, dass die Improvisationshaltung individuell unterschiedlich sein kann.

Wie erklären die Musiker den konkreten Prozess des Improvisierens, aufgrund welcher konkreten Prozesse wird es möglich, mit Hilfe der Improvisationshaltung spontan, unreflektiert und flexibel $\mathrm{zu}$ spielen? Eine Erklärung dafür bietet das, was die Musiker »Impuls«nennen und was unterschiedliche Konnotationen haben kann. Innerhalb der Soziologie wurde das Phänomen des Impulses kaum wahrgenommen und erforscht, ${ }^{7}$ hingegen sind in der Psychologie zahlreiche Definitionen des »Impulses « sowie »impulsiven Handelns « vorhanden, z.B. wird Impuls als »aus dem Zentralnervensystem kommender Anreiz, Anstoß oder Antrieb zu einer (meist plötzlichen) Handlung « (Red. Naturwiss. u. Medizin d. Bibliograph. Inst. 1986: 162) verstanden. Bei impulsivem Handeln werden Einfälle und Ideen »ohne weitere Bewusstseinskontrolle sofort in die Tat umgesetzt. Kinder sind impulsiv und lernen erst allmählich sich zu kontrollieren « (ebd.). Werner D. Fröhlich definiert Impuls folgendermaßen: »Anstoß bzw. Antrieb zu spontanen, heftigen und/oder unkontrollierten Verhaltensweisen « (Fröhlich 1987: 186). »Impulsive Handlung « ist für diesen Autor eine »unüberlegte, unkontrollierte, ggf. unangemessene Verhaltensweise, die rasch und heftig auftritt und (nachträglich) als Folge eines >unwiderstehlichen Dranges o.ä. interpretiert wird « (ebd.). »Impulsivität « wird als kognitiver Stil im Gegensatz zu Reflexivität und als »Eigenschaft der handlungsori-

6 Improvisieren ähnelt in dieser Hinsicht dem Brainstorming, das Assoziationen hervorruft, ohne sie reflexiv nach bestimmten Kriterien zu zensieren.

7 Möglicherweise eine Folge anthropologischer Überlegungen (etwa bei Mead, Gehlen oder Plessner), welche umgekehrt die Impulshemmung zum Charakteristikum menschlichen Daseins erklärten. Für weitere handlungstheoretische Reflexionen über impulsives Handeln siehe Figueroa-Dreher 2007. 
entierten Persönlichkeit mit ihrem Defizit an inhibitorischer Kontrolle « charakterisiert. Die Musiker - hier stellvertretend M. Griener (Schlagzeuger) - äußern sich folgendermaßen über die Funktionsweise des Impulses beim Improvisieren:

»[...] dadurch, dass ich mein Instrument und zum Beispiel auch gerade diese ganzen kleinen Becken und die anderen Spielsachen, die ich schon so lange benutze, vom Klang her so gut kenne, dass ich manchmal etwas höre, und dann den Impuls habe, ich muss jetzt sofort genau dieses Ding greifen und spielen, und erst in dem Augenblick, in dem ich draufhaue, merke, dass das genau der Klang war, der da jetzt gefehlt hat. Das war dann genau das, was ich gehört habe.«(M. Griener, Schlagzeuger)

Anders als die Psychologie, die impulsive Handlungen als negative Ereignisse betrachtet, die die Einstimmung bzw. Koordination zwischen handelnden Menschen erschweren, wird der Impuls von den Free-Jazz-Musikern als ein produktiver, positiver Mechanismus gesehen, der ihnen überhaupt erst ermöglicht, in blitzschnellem Tempo musikalisch sinnvoll ihr Handeln zu koordinieren: Von der Perspektive der Musiker her gesehen deutet der Begriff Impuls darauf hin, dass die Musiker in der Lage sind zu handeln, ohne darüber zu reflektieren, was das Ziel und die Schritte ihres Handelns sind, d.h. ohne eine Handlung vor dem Handeln zu entwerfen und auch ohne lediglich auf Routinehandlungen zurückzugreifen, die entworfene Handlungen wiederholen. ${ }^{8}$ Dies wird dadurch ermöglicht, dass sie durch intensives Üben einen hohen Grad an Spielerfahrung und dadurch an Kenntnis ihres Instruments erreichten. Das Hören der Klänge, die die anderen Musiker spielen, funktioniert als Auslöser des Impulses. Jedoch ermöglicht der Impuls als Mechanismus des Handelns nicht nur eine Art zweckmäßige, reflexartige Reaktion durchzuführen, sondern gleichzeitig eine kreative, unvorhergesehene Handlung, die nicht entworfen wurde. In der Äußerung von M.

8 Auch Keith Jarret, einer der herausragenden Jazz-Pianisten unserer Zeit, der sich seit einigen Jahren ausschließlich aufs Improvisieren verlegt hat, erklärt seine Kunst in demselben Sinne: »Wir nehmen die Improvisation als Fluss wahr, aber eigentlich besteht sie aus rasend schnellen Informationen, Impulsen, fast digital [...]. Wenn ich meine linke Hand beobachte, stelle ich fest, dass sie Dinge macht, die ich nie komponieren würde oder nie bewusst spielen könnte.« (Jarret in Heidekamp 2007: 78) 
Griener wird deutlich, dass der Impuls für ihn als musikalisches Handeln betrachtet werden kann, denn der Klang, der daraus entsteht, fügt sich sinnvoll in die Musik, die gerade gespielt wird: Es ist der Klang, »der da gefehlt hat «.

Dies wiederum betrifft den Kern der Handlungstheorien - auch der Phänomenologie Alfred Schütz' -, die größtenteils implizit oder explizit davon ausgehen, dass die Menschen vor dem Handeln ihre durchzuführenden Handlungen immer entwerfen, d.h., dass die geplante Handlung Ziel samt zugehöriger Mittel mit einschließt (vgl. Joas 1996; Figueroa-Dreher 2007). Entwurf, Ziel und Handlungsschritte sind nur in einer Zeitdimension denkbar, denn wenn ich mich an einem geplanten Ziel orientiere, orientiere ich mich automatisch am Zukünftigen. Im Falle des Improvisierens im Free Jazz jedoch scheint das nicht gegeben zu sein, sondern die Gegenwart erhält ein Gewicht an sich, da - so meine These - ein Entwurf vor dem Handeln zumeist nicht stattfindet. M. Griener (Schlagzeuger) fasst dies folgendermaßen zusammen:

»Ich hab für mich rausgefunden, dass eine gewisse Zielgerichtetheit, als Haltung, eine sehr viel zwingendere Struktur zur Folge hat, aber wenn du die durchziehst, dann machst du letztendlich nur die Musik kaputt. Das heißt, du [...] stellst sozusagen eine Behauptung auf und bist aber in jeder Sekunde trotz alledem bereit und flexibel genug, die übern Haufen zu werfen oder zumindest langsam abzuändern bis es dann irgendwie mit etwas anderem funktioniert. [...] Allein schon dadurch, dass wir uns eben nicht vorher absprechen, wär's natürlich Blödsinn, wenn jeder einfach einen Plan im Kopf hat, weil es nicht zwangsläufig der gleiche Plan ist. Egal wie lange und gut wir schon zusammenspielen. Und wenn jeder einfach seinen eigenen Plan nachvollzieht, ohne sich von den anderen beeinflussen zu lassen, dann könnte man das eigentlich auch nacheinander machen anstatt gleichzeitig. Das würde dann einfach nicht so viel Sinn machen. [...] Der Plan gilt eigentlich nie für die gesamte Zeitdauer des Stückes. Weil nicht abzusehen ist, [...] wie lang dieses Stück sein wird. Sondern, der Plan gilt eigentlich eher erstmal für einen kurzen Abschnitt, der unter Umständen das ganze Stück werden kann, falls das dann zufälligerweise schon vorbei sein sollte. Es kann auch sein, dass man irgendwie diese eine Sache durchzieht und dann ist irgendwann das Stück zu Ende, dann war das doch der Plan fürs ganze Stuick, das mag sein, aber generell ist der Plan nichts weiter als die Idee, wie fang ich jetzt dieses Stück an.«(M. Griener, Schlagzeuger) 
Die Äußerung zeigt, dass das Improvisieren nicht aufgrund eines $>$ Plans < bzw. Entwurfs durchgeführt werden kann, vielmehr wäre ein solcher Plan eine Störung der Entwicklung einer improvisierten Musik; dagegen ist Flexibilität im Handeln nötig, um die musikalische Interaktion mit den anderen Spielenden zu ermöglichen. Anders als in der herkömmlichen Handlungstheorie ${ }^{9}$ dargestellt, ist also beim Improvisieren im Free Jazz der Handlungsentwurf äußerst vage bzw. gar nicht präsent. An Stelle eines geplanten Entschlusses wird das Handeln beispielsweise durch Impulse ausgelöst, d.h. durch Anstöße zu spielen, ohne eine Vorstellung vom weiteren Verlauf der Durchführung, wie in dem Kommentar von M. Griener zu lesen ist. Je nachdem, was die Musiker hören, wird ohne Plan situativ weiter gespielt. Die Erfahrung des Improvisierens scheint der Erfahrung der Intuition im Sinne Bergsons (1993) ähnlich zu sein, insofern Vertrautheit und lange Erfahrung mit dem Instrument eine »Verschmelzung « mit dem Inneren des Objektes (des Instruments) und eine intuitive Spielart ermöglichen (vgl. Bergson 1993: 224f.).

Ein solches Handeln verlangt von den Musikern eine hoch flexible Haltung. Diese Flexibilität ermöglicht es den Musikern, ihre Klänge, Tempi etc. automatisch »neu zu justieren«, wenn »es irgendwie nicht funktioniert«. Dass Impulse das Handeln auslösen bzw. steuern können, wurde innerhalb der Phänomenologie schon von Edmund Husserl berücksichtigt, wie Bernhard Waldenfels bemerkt: »Practical intentions are founded in the intentionality of individual and social impulses (Triebintentionalität) mentioned in the posthumously published writings [of Husserl]. Actions of the subject are thus not only conditioned by trans-subjective rule-structures, they are also founded in pre-subjective impulses.« (Waldenfels 1997: 14)

Innerhalb der phänomenologischen Diskussion ist ebenfalls umstritten, ob Handeln nur als zielgerichtetes Handeln definiert werden kann. Waldenfels argumentiert beispielsweise: »Embedded in such a teleological order, action would be nothing more than a means to an end. [...] In opposition to this, the possibility of an autochthonous order of practice, originating in practice itself, may be unfolded in two steps. First, action has to be interpreted in terms of creativity in its full sense, i.e., not only executing what is possible within a cer-

9 Zur Diskussion des Zweck-Mittel-Schemas in der herkömmlichen Handlungstheorie siehe Joas 1996 und Figueroa-Dreher 2007. 
tain order, but making possible by introducing a new kind of order «. Waldenfels findet die Frage bedenkenswert, ob die Kreativität des Handelns nicht unterdeterminiert bleibt, wenn Handeln ausschließlich auf eine vorgegebene Ordnung der Ziele gegründet wird »or, in Husserl's term, rooted in a pervading teleology and rationality.« (Waldenfels 1997: 14f.)

Improvisatorisches Handeln ist nicht nur in der Musik und in der Kunst im Allgemeinen präsent, auch im Alltag unterbrechen wir unsere Entwürfe, passen uns den Plänen der anderen an. Ja wir wären überhaupt nicht in der Lage zu interagieren, richteten wir uns ausschließlich nach unseren Handlungsentwürfen, da diese mit den Entwürfen unserer Interaktionspartner nicht zwangsläufig harmonieren. Soziales Handeln nur anhand von Typisierungen, die im Wissensvorrat aufgrund vorheriger Erfahrungen zur Verfügung stehen, wäre nicht möglich, so wie die Ausübung des Rechts nicht nur aufgrund von Gesetzen möglich ist, da diese nie die konkreten Fälle bis ins Detail vorhersehen können: Ein Spielraum des Nicht-Vorhergesehenen ist immer präsent, eine Interpretation des Typischen ist immer erforderlich. Nur wenn eine gewisse Flexibilität im Handeln vorhanden ist, kann Interaktion stattfinden. Improvisation ist in diesem Sinne für die Musiker eine Art »Hyperalltag«.

Musik kann sich nur in der Zeit entfalten. Anders als z.B. Bildende Kunst kann Musik nur existieren, indem sie als Klangfolge gehört oder gedacht wird. Jedoch kann die Art und Weise, wie sie in der Zeit gespielt und wahrgenommen wird, sehr unterschiedlich sein, je nachdem, ob sie improvisiert oder komponiert wird. Komponierte Musik kann immer wieder »gleich « ausgeführt oder reproduziert werden, auch wenn die unterschiedlichen Interpretationen Differenzen zulassen können - jedenfalls können Musiker und Hörer das gleiche Musikstück erkennen. Um die Reproduzierbarkeit komponierter Musik zu ermöglichen, wurde im Abendland die Notation entwickelt, darüber hinaus ermöglichen Hilfsmittel wie das Metronom die Koordination des Tempos. Dagegen kann improvisierte Musik im extremsten Fall, wie z.B. im Free Jazz, aus der Perspektive des Musikers/der Musikerin, der/die sich nicht nach einer »Vorlage« richtet, die mit Hilfe objektiver Zeitmessungskriterien erstellt wurde, als spontanes, dialogisches bzw. interaktives »laut Denken« bezeichnet werden. Komponierte Musik hat eine zwingendere Strukturierung der Zeit zur Folge: Das Tempo und das Metrum sind in der Regel vorgegeben. An diese Vorgaben muss sich der/die 
Spieler/in halten - eventuell mit Hilfe taktgebender Instrumente wie dem Metronom -, möchte er/sie Simultaneität seines/ihres Bewusstseinstroms mit demjenigen des/der Komponisten/tin (vgl. Schütz 1976: 18) erreichen. ${ }^{10}$ Je höher der Improvisationsgrad in der Musik, desto flexibler die Zeitstrukturierung durch Tempo und Metrum, die nicht festgelegt sind. Die Möglichkeit, die z.B. der Free Jazz anbietet, sich nicht auf ein Tempo sowie auf eine bestimmte Melodie festzulegen, macht aus jedem Musikstück ein Unikat, das nicht in gleicher Form wiederholt werden kann und soll (es kann nur aufgenommen und wieder abgespielt werden). Improvisieren heißt, jedes Mal die Zeit durch die Musik anders zu strukturieren, der Improvisator passt sich nicht an eine vor-strukturierte Zeit an, sondern die Strukturierung der Zeit ergibt sich jedes Mal neu aus dem, was spontan gespielt wird.

Da die Musiker während des gemeinsamen Spielens die Musik in Echtzeit »komponieren «, gibt es normalerweise keine Zeit für Entscheidungen, was sie spielen werden, sondern das Spielen erfolgt beispielsweise über Impulse. Entscheidend im ästhetischen Sinne ist jedoch nicht, mit welchem Material man anfängt, sondern wie man damit umgeht. Das Material ist nie vor dem Spielen festgelegt:

»Also es ist jetzt durchaus nicht so, dass wir dann immer nur [...] in unsere Repertoirekiste greifen und die in immer wieder neue Reihenfolgen bringen. [...] Ich habe mein ganzes Material, das ich im Laufe meines Musikerlebens angesammelt habe, aber das Entscheidende ist eben, wie ich damit musikalisch arbeite und wie sich das verändert und es passiert immer wieder, dass man dann im Zusammenspiel Sachen spielt, die man noch nie vorher gespielt hat.«(M. Griener, Schlagzeuger)

Im Vordergrund steht beim Improvisieren im Free Jazz der Prozess des Spielens, nicht das Resultat oder die Idee eines vorher konzipierten Werkes. Es geht darum, wie die Musiker »in der Echtzeit

10 Jede musikalische Erfahrung entsteht für Schütz in der stets fließenden >innerlichen< bzw. subjektiv erlebten Zeit, d.h. im subjektiven Bewusstseinsstrom (vgl. Schütz 1976: 46). »The musical experience takes place in a specious present which, by means of recollection and expectation, includes elements of the past and the future. As an ongoing flux it shares the flux of the stream of consciousness in simultaneity« (ebd.). 
mit ihrem Material umgehen. Wo sie herkommen, was für ein Ausgangmaterial die haben, das ist eine sehr individuelle Angelegenheit« (C. Weber, Kontrabassist). Bemerkenswert ist, dass sich die Zeit- und Musikwahrnehmung der Musiker während des Improvisierens von der Wahrnehmung der gleichen Improvisationen unterscheidet, die aufgenommen und im Nachhinein gehört werden - es geht den Musikern darum, das Improvisieren zu erleben; die aufgenommene Improvisation ist nur ein Nebenprodukt, das lediglich einen Ausdruck des Augenblicks darstellt.

»The same object of our thoughts has another aspect 1) if actually experienced, 2) if looked at as an object actually experienced in a past, but now recollected, 3) if looked at later on in a third Now - as an object, actually experienced in past and previously already recollected [...]. In all three cases it is the same object, but the same object as modified, as having changed, as offering new aspects, new features, new structures of relevance.« (Schütz 1976: 39)

Die eigentliche Improvisation ist für die Musiker das Objekt, die Musik, die jetzt erlebt wird. Die Improvisationen können natürlich reproduziert werden, sind dann aber nicht mehr das, was die Musiker beim Improvisieren erfahren haben. Erlebte Erfahrung gibt es in diesem Sinne nicht als Improvisation, sondern ausschließlich als Improvisieren.

\section{Reflexionen über Alfred Schütz' »Fragments on the Phenomenology of Music « ${ }^{11}$}

Alfred Schütz' Notizen über eine Phänomenologie der Musik haben eine detaillierte Untersuchung des sinnhaften Arrangements von Tönen im Sinne eines musikalischen Themas sowie der Natur und Struktur der inneren Zeit und die Vereinigung (»synthesis«) der $d u$ rées (fluxes) zu einer lebendigen Gegenwart zum Ziel. Um dies zu erreichen, setzt sich sein Text mit der Entfaltung des musikalischen

11 Obwohl die Reflexionen von Alfred Schütz sich an der Idee des musikalischen klassischen »Werkes« orientieren und nicht am Free Jazz, bilden sie eine sinnvolle Basis, um weiter über das, was er die musikalische Erfahrung nennt, nachzudenken. 
Themas in der inneren bzw. subjektiven Zeit (durée) auseinander (vgl. Schütz 1976: 7). Schütz unterscheidet zwischen »the >inner time in which the flux of musical events unfold< and [...] a social relationship such as making music together, which occurs in >outer time $<$ and which presupposes a face-to-face relationship, a >community of space, and it is this dimension which unifies the fluxes of inner time and warrants their synchronization into a vivid present « (ebd.). $>$ Raum $<$ bedeutet in diesem Fall $\gg$ the social-cultural space of making music together, of the musical process itself« (ebd.). Schütz' »Fragments « sind insofern für die vorliegenden Reflexionen relevant, als sie sich mit der Frage der Entstehung eines »Wir«, der Basis aller Kommunikation und Koordination zwischen Musikern, auseinandersetzen. Im Folgenden werden einige der Thesen, die Schütz in seinen »Fragments « für das Hören von Musik bzw. bezüglich der »musikalischen Erfahrung « zusammenstellt, für den Fall des Musikmachens und speziell des Improvisierens diskutiert.

Eingangs erklärt Schütz, dass uns die »musikalische Erfahrung « in einen Bewusstseinszustand versetzt, in dem nicht mehr die Alltagswirklichkeit vorherrscht: ${ }^{12}$

»When the conductor raises his baton, the audience has performed a leap (in the sense of Kierkegaard) from one level of consciousness to another. They are no longer involved in the maze of activities necessary to deal with men and things. They accept the guidance of music in order to relax their tension and to surrender to its flux, a flux which is that of their stream of consciousness in inner time. «(Schütz 1976: 43)

Man darf sich fragen, was dieser »Bewusstseinssprung « aus handlungstheoretischer Sicht bedeutet, wenn die musikalische Erfahrung nicht nur des Musikhörens, sondern auch des Improvisierens, also des aktiven Musikgestaltens Thema ist. Jedoch berichten die befragten Free-Jazz-Musiker, dass sie das Improvisieren nicht oder nicht

12 Die hiermit angesprochene Theorie der »mannigfaltigen Wirklichkeiten« (vgl. Schütz 1971) knüpft an William James und Henri Bergson an. Sie konzipiert die Alltagswirklichkeit als eine unter mehreren Wirklichkeiten, denen unterschiedliche Spannungsgrade des subjektiven Bewusstseins entsprechen. Als »paramount reality« weist die Alltagswirklichkeit laut Schütz die höchste attention à la vie, die stärkste Aufmerksamkeit für die pragmatischen Verrichtungen des Lebens auf, wohingegen diese Spannung beispielsweise bei der Rezeption von Kunst - oder im Traum - schwächer ausfällt. 
durchgehend als ein aktives Tun erfahren, sondern als eine Erfahrung, wie oben schon erwähnt, in der sie »die Musik passieren« lassen. Improvisieren heißt für sie auch, dass sie sich dem Fluss der Musik hingeben, sie werden zum »Vektor « der Musik. In diesem Sinne stimmt die Erfahrung des Improvisierens mit der Beschreibung überein, die Schütz über die »musikalische Erfahrung« macht:

»The spatialized time of our daily life corresponds to the attitude of full attention to it, to the state of full awakeness. This tension hides our experiences of our inner life which become visible only if we return from full attention to life, only if we diminish the tension correlated to full awakeness necessary for our dealing with the outer world.« (ebd.: 42)

Musizieren, insbesondere improvisierendes Musizieren, ist der Rückzug vom Alltag ins innere Leben.

»Thus, a gradual withdrawal from the spatio-temporal dimension is performed together with the transgression to other levels of our conscious life, that is, to levels which are more intimate and nearer to the experience of the stream of our durée but unfit to performing in them our activities gearing to the outer world.« (ebd.: 42)

Musikmachen stellt für Schütz eine Verbindung zwischen der inneren durée und der äußeren Welt her. Musik wird also laut Schütz als ein Vorkommnis in der inneren Zeit erfahren (vgl. Schütz 1976: 38).

»When Bergson tries to convey the image of the onrolling durée, he gives the example of a melody, a melody however, not structurized as to rhythm, harmony or difference in pitch or loudness.« (ebd.: 40; vgl. Bergson 1993: 147)

Beim Improvisieren im Free Jazz kann die Erfahrung der inneren Zeit des Bewusstseinsstroms (Bergsons durée) musikalisch zum Ausdruck gebracht werden, da es keine festgelegten und verbindlichen Zeitparameter gibt, welche die Freiheit des Ausdrucks einschränken würden. ${ }^{13}$

Bemerkenswert hinsichtlich des Improvisierens im Free Jazz ist außerdem, dass die intersubjektive Zeit, die eine intersubjektive Ko-

13 Die äußere Zeit ist an die Messung räumlicher Dimensionen (wie auf der Uhr) angelehnt (vgl. Schütz 1976: 38). 
ordination ermöglicht, jedes mal neu »zusammengewürfelt« wird und nicht festgelegt ist. Vom Standpunkt der Improvisierenden aus besteht beim Spielen ein Zusammenspiel - man könnte auch sagen: eine Ambivalenz - zwischen der Dominanz der inneren bzw. subjektiven Zeit als entscheidender Parameter und der intersubjektiven Zeit: Entweder richtet sich der/die Musiker/in nach dem Tempo der anderen oder er/sie spielt den eigenen $»$ Monolog $«$. Tendenziell ergibt sich häufiger der Fall des Koordinierens mit den anderen als der Monolog. Jedoch werden beim Improvisieren im Free Jazz die abstrakten Zeitkategorien (vgl. Dreher 2004: 4), wie z.B. »Minute«, bzw. musikalische Zeitparameter, wie z.B. »2/4 Takt«, die unabhängig von der inneren Zeit der Individuen sind, ausgeblendet und die ungeformte intersubjektive Zeit wird jedes Mal durch die gespielte Musik neu strukturiert.

Improvisieren findet, wie schon angedeutet, in einer nicht reflexiven Haltung statt. Reflektieren heißt für Schütz, nicht im fortlaufenden Gedankenstrom zu schwimmen, sondern, »to step out and look back toward the past phrases of the stream of thought. Then we are no longer living in our acts directed toward their objects; we make our acts themselves objects of our reflective thinking « (Schütz 1976: 38f.). Diese reflektierende, man könnte sagen kontrollierende Einstellung muss möglicherweise beim Improvisieren »ausgeschaltet« werden, obwohl dies den Musikern ihren eigenen Aussagen zufolge nicht immer gelingt. Eine reflexive Einstellung beim Improvisieren ist deswegen kontraproduktiv, weil man sich nicht mehr auf das Objekt des Bewusstseins, auf das Hier und Jetzt der Musik, richten kann, sondern auf die vergangenen, durchgeführten Handlungen achtet. Improvisieren verlangt eine Konzentration auf die Gegenwart. Jedoch können die Musiker im Nachhinein über ihre Erfahrung beim Improvisieren berichten, so dass ein Zugang zu diesem Phänomen, das sich nicht in der paramount reality ergibt, gewährleistet ist.

Schütz geht davon aus, dass Handeln - auch musikalisches Handeln - eine Orientierung an Zukünftigem miteinschließt: »by being directed towards the objects of our acts and thoughts we are always oriented towards the future, we are always expecting certain occurrences and events « (Schütz 1976: 40). Beim Improvisieren verhält es sich jedoch anders: Die Zukunftsperspektive wird dadurch geschwächt, dass man nicht bzw. nur ansatzweise zielgerichtet han- 
delt. Wie von den befragten Musikern ausgeführt (s.o.), wirkt eine zielgerichtete Einstellung beim Improvisieren kontraproduktiv.

Eine der zentralen Thesen in Schütz' »Fragments « besagt, dass jene Bewusstseinsphänomene, die er (mit Husserl) als »retentions ${ }^{14}$ and reproductions [attached to near and remote past], protentions ${ }^{15}$ and anticipations [attached to near and remote future] « bezeichnet, »are constitutive for the interconnectedness of the stream of consciousness. They are equally constitutive for the experience of music« (ebd.: 41). Angesichts der vorgestellten Ergebnisse bezüglich der Erfahrung des Improvisierens darf man fragen, ob im Falle des Improvisierens diese Bewusstseinsphänomene immer präsent sind oder die Protentionen und Antizipationen, die sich an die nahe und entfernte Zukunft richten, nicht geschwächt oder zeitweise »ausgeschaltet« werden, da nur die Spielerfahrung und die gegenwärtig gespielte Musik beim Improvisieren zählen und nicht ein Entwurf oder nicht mal eine »Erwartung « vorhanden ist.

\section{Intersubjektive Zeit und Koordination}

Betrachtet man die individuelle Haltung der Musiker, die erforderlich ist, um improvisieren zu können, erscheint die Möglichkeit der Koordination zwischen ihnen im Handeln erschwert. Koordinieren die Musiker beim Improvisieren im Free Jazz überhaupt ihr musikalisches Handeln? Kann beim Improvisieren Intersubjektivität entstehen oder handelt es sich um gleichzeitig gespielte »Monologe «? Metaphern wie gemeinsames Atmen und Gruppenpuls geben uns Indizien dafür, dass eine Koordination zwischen den Improvisatoren stattfindet, wie im Folgenden argumentiert wird.

14 »Retention gehört innerhalb der Husserlschen Zeitanalyse des immanenten Bewusstseins zur >absolut starren Gesetzmäßigkeit<, mit der ein momentaner Eindruck noch in sfrischer $<$ Erinnerung gehalten wird, so wenn beispielsweise ein Ton, der soeben verklungen ist, noch als derselbe im Bewusstsein festgehalten wird « (Vetter 2004: 464).

15 »Protention ist bei Husserl der Titel für erwartungsartige Intentionen des Kommenden, die nicht mit der Leerintention der Erinnerung zu verwechseln sind. Als diskrete Protention setzen solche Erwartungsbildungen bereits ursprüngliche Erfahrungseinheiten voraus und schaffen diese nicht, wie im Fall der intentionalen Impression« (Vetter 2004: 438). 
Die Musiker beschreiben den Anfang einer Improvisation, die wir im Nachhinein zusammen anhören. Dieser Teil der Improvisation besteht aus musikalischen »Einheiten «, die durch gemeinsame kleine Pausen, die sie trennen, zustande kommen. M. Griener (Schlagzeuger) kommentiert: »Das sind immer so Wellen, die kommen und wieder zurückgehen «. Auf meine Frage, »Wie entstehen die Wellen? «, antwortet er: »Das ist einfach - das hat mit dem gemeinsamen Atmen zu tun letztendlich «, und C. Weber (Kontrabassist) formuliert: »Das ist ein Gruppenpuls quasi, ja?« Der Ausdruck gemeinsames Atmen verweist auf eine Dynamik, die auf einen gemeinsamen Rhythmus zurückführt, auf eine Koordination zwischen den Musikern, die nicht aus der Reflexion heraus entsteht, sondern sich wie individuelles Atmen einfach ergibt. Dass ein organischer Verlauf als Metapher gewählt wird, um das kollektive Improvisieren zu erklären, deutet darauf hin, dass eine Koordination hohen Grades erreicht wird, die gleichermaßen einverleibt ist und keine Reflexion erfordert.

Gruppenpuls ist ebenfalls eine merkwürdige Metapher: Es kann sich nur um eine solche handeln, denn der Puls ${ }^{16}$ ist per definitionem etwas Individuelles. Wie das Bild des gemeinsamen Atmens führt sie zurück auf das Gefühl der exakten, automatischen Koordination von organischen Verläufen mehrerer Individuen, auf die Einigung von natürlichen und sozialen Vorgängen durch das Spielen von Musik, aber auch auf einen gemeinsamen Rhythmus und auf das Fließen von etwas, das durch das musikalische Improvisieren zum Ausdruck gebracht wird, auf Lebendigkeit. Gruppenpuls erscheint auch als Metapher für ein hohes Maß an zeitlicher Koordination; er ermöglicht die gleiche Zeiteinteilung für alle beteiligten Musiker. Dies heißt nicht, dass sie im gleichen Tempo spielen, sondern dass sie immer wieder zusammen zu kleinen Pausen gelangen, die die Einheiten in der Improvisation ergeben. Das Improvisieren verursacht ein Schweben zwischen zwei Polen: Einerseits spielt man aus den eigenen Impulsen heraus, andererseits justiert man die eigene Musik anhand des Spiels der anderen. Beim kollektiven Ausführen komponierter Musik versucht man im Gegensatz dazu, sich

16 Puls ist: a) das Anschlagen der durch den Herzschlag fortgeleiteten Blutwelle an den Gefäßwänden; b) die Schlagader (Pulsader) am Handgelenk. 
an die vorgegebenen Zeitangaben zu halten, die eine Zeitkoordination mit den anderen Musikern ermöglichen. ${ }^{17}$

Für Schütz kommt die Koordination zwischen den Musikern bzw. zwischen Musikern und Hörern dadurch zustande, dass sich ihre durées (fluxes) durch die Musik »vereinigen«, dass sie die gleiche Zeit erleben. In diesem Aufsatz versuchte ich, darüber hinaus zu erklären, wie die Musiker selbst eine besondere, spezifische musikalische Erfahrung, das Improvisieren, beschreiben und aufgrund welcher Mechanismen dieses Phänomen zustande kommen kann. Weiterhin reflektierte ich darüber, wie die gemeinsame musikalische Koordination zustande kommt und aufgrund welcher Phänomene und Mechanismen die subjektive Haltung der Improvisierenden eine gemeinsame Koordination ermöglicht.

Meine Ausführungen argumentierten weiter, dass das Phänomen des musikalischen Improvisierens eine Herausforderung für die Erklärungsreichweite der soziologischen Handlungstheorie darstellt, für welche hier stellvertretend das Erklärungsmodell von Alfred Schütz und Thomas Luckmann behandelt wurde, da dieses sich explizit mit der internen Struktur der Handlung und dem Verlauf des Handelns auseinandersetzt. Die empirischen Betrachtungen im Rahmen meines Forschungsprojektes förderten Elemente dieses Phänomens zu Tage, die sich mit zentralen Annahmen dieses Modells (bezüglich der Zielgerichtetheit und des Entwurfcharakters von Handeln) nicht in Einklang bringen lassen. Dem damit aufgeworfenen Problem wurde mittels einer Analyse der subjektiven Zeitstrukturierung nachgegangen, wie sie im Zuge improvisierenden Musizierens beim Free Jazz stattfindet. Die vorläufigen Ergebnisse dieser Analyse legen es nahe, das Improvisieren als einen eigenständigen Typus von Handeln zu betrachten, wie er sich in der soziologischen Handlungstheorie bislang nicht adäquat abgebildet findet. In diesem Sinne intendiert die Argumentation theoretische Konsequenzen, die über den Bereich musikalischen Handelns hinausgehen.

17 Die Gegenüberstellung von komponierter und improvisierter Musik ist analytisch gedacht. Hier wird nicht behauptet, dass keine gemischten musikalischen Formen existieren würden, die Improvisation und Komposition kombinieren. Jedoch: Zum Zwecke der handlungstheoretischen Analyse ist eine idealtypische Trennung zwischen beiden sinnvoll. 


\section{Literatur}

Bailey, Derek (1992): Improvisation: Its Nature and Practice in Music. London: British Library National Sound Archive.

Bergson, Henri (1993 [1946]): Denken und schöpferisches Werden. Hamburg: Europäische Verlagsanstalt.

Dreher, Jochen (2004): »The Temporality of the Life-World. Phenomenological Reflections on the Constitution of >Time « Kongress: 2004 Annual Conference of the Society for Phenomenology and the Human Sciences (SPHS), Memphis, Tennessee, USA, 28.-30. Okt. 2004. Konstanz: Unveröffentlichtes Manuskript.

Figueroa-Dreher, Silvana K. (2007): »Vom >Impuls< zur Sozialität. Reflexionen über die >Natur< des musikalischen Improvisierens«. In: Karl-Siegbert Rehberg (Hg.), Die Natur der Gesellschaft. Verhandlungen des 33. Kongresses der Deutschen Gesellschaft für Soziologie in Kassel 2006, Frankfurt a.M.: Campus (CD-ROM erscheint demnächst).

Fröhlich, Werner D. (1987): Wörterbuch zur Psychologie. München: dtv.

Heidekamp, Konrad (2007): »Du musst nicht gut finden, was du spielst«. [Interview mit Keith Jarret], Die Zeit 20.09.07, S. 78.

Joas, Hans (1996): Die Kreativität des Handelns. Frankfurt a.M.: Suhrkamp.

Jost, Ekkehard (1975): Free Jazz. Graz: Universal.

Knauer, Wolfram (1996): »Jazz«. In: Ludwig Finscher (Hg.), Die Musik in Geschichte und Gegenwart. Allgemeine Enzyklopädie der Musik, Sachteil Bd. 4, 2., neubearb. Ausgabe, Kassel: Bärenreiter, Sp. 1384-1421.

Noll, Justus (1977): Zur Improvisation im deutschen Free Jazz. Hamburg: Wagner.

Pike, Alfred (1974): »A Phenomenology of Jazz«. Journal of Jazz Studies 2 (I), S. 88-94.

Redaktion Naturwissenschaft und Medizin des Bibliographischen Instituts (Hg.) (1986): Meyers kleines Lexikon Psychologie. Mannheim et al.: Bibliographisches Institut.

Schütz, Alfred (1971): »Über die mannigfaltigen Wirklichkeiten«. In: ders., Gesammelte Aufsätze, Bd. 1: Das Problem der sozialen Wirklichkeit, Den Haag: Nijhoff, S. 237-298. 
Schütz, Alfred (1976): »Fragments on the phenomenology of music «. Music and Man 2, S. 5-71.

Soeffner, Hans-Georg (1979): »Interaktion und Interpretation. Überlegungen zu Prämissen des Interpretierens in der Sozial- und Literaturwissenschaft«. In: ders. (Hg.), Interpretative Verfahren in den Sozial- und Textwissenschaften, Stuttgart: Metzler.

Soeffner, Hans Georg (1982): »Statt einer Einleitung: Prämissen einer sozialwissenschaftlichen Hermeneutik«. In: ders. (Hg.), Beiträge zu einer empirischen Sprachsoziologie, Tübingen: Gunter Narr, S. 9-48.

Soeffner, Hans-Georg/Hitzler, Ronald (1994): »Qualitatives Vorgehen - >Interpretation««. In: Theo Herrmann (Hg.), Methodologische Grundlagen der Psychologie. Forschungsmethoden der Psychologie, Göttingen: Hogrefe, S. 98-136.

Strauss, Anselm (1998): Grundlagen qualitativer Sozialforschung. München: Fink.

Sudnow, David (1978): Ways of the Hand. The Organisation of Improvised Conduct. Cambridge, Massachusetts: Harvard University Press.

Tucker, Mark/Jackson, Travis (2001): »Jazz«. In: Stanley Sadie (Hg.), The New Groove Dictionary of Music and Musicians, Bd. 8, New York: Macmillan, S. 903-926.

Vetter, Helmuth (Hg.) (2004): Wörterbuch der phänomenologischen Begriffe. Hamburg: Meiner.

Waldenfels, Bernhard (1997): »Action«. In: Lester Embree et al. (Hg.), Encyclopedia of Phenomenology, Dordrecht: Kluwer Academic Publishers, S. 11-15. 


\title{
IMPROVISATION ALS MERKMAL UND GegenSTAND DES MUSIKUNTERRICHTS
}

\author{
STEFAN ORGASS
}

\section{Die Kreativität des Handelns}

Eine Szene des Films In der Fremdenlegion ${ }^{1}$ spielt in einer Gefängniszelle, in der zwei von Stan Laurel und Oliver Hardy dargestellte Fremdenlegionäre eingesperrt sind. Auf einem der Betten sitzend spielt Stan versonnen mit den Fingern seiner rechten Hand an der Bespannung des Bettenrosts, dessen ersten drei >Saiten< einen Durdreiklang ergeben. Dies ist für den Häftling Anlass genug, die gesamte Bespannung $\mathrm{zu}>$ stimmen< und hernach ein Musikstück auf dieser >improvisierten Harfe< seinem Zellengenossen vorzuspielen. >Doof $<$ hat sich - wie Karl-Heinz Brodbeck sagen würde - zur Kreativität entschieden (vgl. Brodbeck 1995).

Der kleine Filmausschnitt wirft Licht auf das Thema »Menschliches Handeln als Improvisation« aus (mindestens) zwei musikpädagogischen Perspektiven: Zum einen vollzieht sich menschliches Handeln in Situationen, deren unfallfreie und in sozialer Hinsicht keinen Anstoß nehmende Bewältigung Improvisation als Prinzip - erfordert, als Anwendung vorhandener, bereits ausgebildeter passender Schemata auf unwägbare dingliche und/oder soziale Konstellationen. In der Fortsetzung der gezeigten Szene kommt es dann tatsächlich zu einem Unfall: die beiden Protagonis-

1 Vor Beginn des Vortrags im Essener Kulturwissenschaftlichen Institut am 18.01.2007, der dieser Arbeit zugrunde liegt, wurde der Anfang des 7. Kapitels (42:18 - ca. 45:15) aus dem Film In der Fremdenlegion (The Flying Deuces (1939), DVD Kinowelt 500257) mit Stan Laurel und Oliver Hardy gezeigt. 
ten verheddern sich in dem durch diese Slapstickaktion sodann zerstörten Bettenrost bzw. in der $>\mathrm{Harfe}<{ }^{2}$ Die andere musikpädagogische Perspektive eröffnet sich durch folgende Deutung des Filmausschnitts: Der Häftling scheint tatsächlich solistisch zu improvisieren, also nicht einfach ein zuvor eingeübtes Musikstück auswendig vorzutragen, sondern dergestalt zu >extemporieren $<$, dass er eine offenbar feststehende Melodie im Sinne der Dur-Moll-Tonalität frei arpeggierend harmonisiert. Improvisation wird hier zum Gegenstand - für den Produzenten wie auch für den Rezipienten.

Um Improvisation unter diesen beiden Gesichtspunkten genauer zu durchdenken, soll nach der Erläuterung wichtiger Grundbegriffe Kommunikativer Musikdidaktik (2.) ausführlicher erörtert werden, was in vorliegender Arbeit unter Improvisation verstanden werden soll. Zwei ihrer Eigenschaften sollen als Lerngegenstände legitimiert und erörtert werden (3.). Die Auffassung von Improvisation als Artikulation musikalischer Bildung ist aber nicht unproblematisch, weil sich letztere einerseits auf prinzipiell unwägbare Weise ereignet - und insofern mit improvisatorischer Unwägbarkeit zu korrespondieren scheint -, sich aber andererseits durch ein reflexives Moment auszeichnet, das für Improvisation nicht kennzeichnend ist, jedenfalls nicht in der im Bildungszusammenhang virulenten Ausprägung. Überdies ist das Verhältnis zwischen didaktischer Intentionalität und musikalischer Bildung mit Blick auf die unterrichtliche Thematisierung musikalischer Improvisation zu bestimmen (4.).

\section{Für die Thematik wichtige Grundbegriffe Kommunikativer Musikdidaktik}

Im Folgenden kann Kommunikative Musikdidaktik nicht zur Gänze als Konzeption dargestellt werden. Es seien nur für den Gedanken-

2 Diese Anwendung von Schemata kann selbst in ästhetischer Einstellung erfolgen: Martin Seels Beispiel ist die Wahrnehmung von Verkehrsampeln nicht »als imperative Signalsysteme, sondern als Generatoren purer Erscheinungen«, was sich im Straßenverkehr als durchaus unfallträchtig herausstellen kann (vgl. Seel 1996: 47). 
gang erforderliche Grundbegriffe erörtert, nämlich der Bedeutungs-, der Erfahrungs- und der Situationsbegriff.

\section{a) Bedeutung}

Zwei Aspekte einer wesentlich komplexeren Theorie ${ }^{3}$ seien hier genannt.

- Musikalische Bedeutung ist keine feststehende Größe, schon gar keine Eigenschaft des klingenden Substrats von Musik oder ihrer Niederschrift selbst, sondern sie ist ein Vollzug: Sie wird vom wahrnehmenden Individuum zugewiesen. Diese Zuweisungen beziehen sich auf Vergleiche zwischen gestalthaft wahrgenommenen Einheiten, also auf die Beziehungen zwischen Tönen, Klängen, Geräuschen und/oder Stille, die im Hören erfasst werden: Dieser Ton ist höher und kürzer als jener tiefere und längere, das erste Thema erklingt lauter als das zweite, das Saxophonspiel eines Charlie Parker klingt rauer als das eines Lee Konitz etc. Diesen Aspekt akzentuierte vor allem Peter Faltin in seiner syntaktischen Theorie musikalischer Bedeutung (vgl. Faltin 1985). Aber auch das Erfinden von Musik ist ein Zusammenhang von Handlungen, in dem musikalischem Material Bedeutungen zugewiesen werden, beim Komponieren eher im Rahmen einer Auseinandersetzung mit Form, beim Improvisieren eher durch Bedeutungen gleichsam >in Echtzeit< zuweisende klangliche Gestaltung von Formung (durch das Anwenden von Formungsprinzipien wie Wiederholung, Abwandlung und Kontrast). ${ }^{4}$

- In musikbezogenen Interaktionen emergieren neue Möglichkeiten der Bedeutungszuweisung. Diese Emergenz ist eine Folge jener $>$ doppelten Kontingenz<, von der alle Interaktionen und eben auch musikbezogene Interaktionen geprägt sind. >Doppelte Kontingenz $<$

3 Eine ältere Arbeit des Autors vorliegenden Beitrags mit dem Titel Musikalische Bildung aus bedeutungs- und interaktionstheoretischer Sicht (Orgass 2007a) wurde inzwischen durch situationstheoretische Überlegungen erweitert und erscheint noch im laufenden Jahr (Orgass 2007b: 9-123).

4 Zur Unterscheidung von Form und Formung vgl. Orgass 1995: 132-138; ferner Kühn ${ }^{2} 1995$. Kühn schlägt vor, über die Kategorien »verschieden« und »beziehungslos« das Ausmaß von Gleichheit und Ungleichheit zu charakterisieren: »Wiederholung (gleich) - Variante (ähnlich) - Verschiedenheit (anders) - Kontrast (gegensätzlich) - Beziehungslosigkeit (fremd).« (A.a.O.: Sp. 622) 
meint jene »zirkuläre Unbestimmtheit«, die durch das gegenseitige Nichtwissen der Handlungsintentionen der Interaktionspartner und das Wissen der beteiligten Interaktanten um dieses gegenseitige Nichtwissen entsteht. ${ }^{5}$ Beim Versuch, diese Unbestimmtheit handhabbar zu machen, helfen in der Regel Konventionen, Institutionen, ein bestimmter Habitus, eine bestimmte kollektive Erinnerung, eine gemeinsame Lerngeschichte, die gemeinsam gesprochene Sprache etc. Aus dem Vollzug aller musikbezogenen Umgangsweisen in Interaktionen geht, da sich diese Unbestimmtheit in der Zeit entfaltet, Neues hervor: Im Zuge der interaktiven Interpretation von Musik entstehen notwendig neue Deutungen, weil kein Interaktant die Beiträge der anderen Interaktanten vorhersehen kann, vielmehr auf die unwägbaren Beiträge der anderen seinerseits in für ihn unwägbarer, jedenfalls nicht vorhersagbarer Weise reagiert. Bei der Gruppenkomposition können die Entscheidungen darüber, wie die Musik beginnen soll und wie sie fortzusetzen und zu beenden ist, nicht auf die Intention eines Interaktanten oder die Intentionen mehrerer einzelner Interaktanten zurückgeführt werden - Handlungen sind keine Atome von Interaktionen. ${ }^{6}$ Der Sinn einer Improvisation realisiert sich geradezu in der momentanen Entstehung des musikalisch Neuen, nicht > Vorauszuhörenden .

\section{b) Erfahrung}

Während die Tätigkeit des musikbezogenen Zuweisens von Bedeutungen immer auf der Grundlage von bereits ausgebildeten Schemata erfolgt und daher auf einer Lerngeschichte beruht, mithin auf Vergangenes zurückgreift, soll der Begriff musikalischer Erfahrung konsequent auf eine Wahrnehmungsform bezogen werden, in der dem Individuum etwas musikalisch Neues und von ihm nicht Erwartbares widerfährt, das die Akkommodation der > verwendeten< musikbezogenen Schemata nahe legt. ${ }^{7}$ Das Musiklernen ist jene Tä-

5 Vgl. Kieserling 1999: 87; hier auch genauere Erläuterungen zum Terminus $>$ doppelte Kontingenz $<$.

6 Vgl. hierzu insbesondere Sutter 1997: 316; der Hinweis auf die in handlungstheoretischen Argumentationen bloß »halbierte doppelte Kontingenz« (a.a.O.: 319).

7 Vgl. die Nähe zu Wolfgang Schulz' Begriff ästhetischer Erfahrung (die kursive Hervorhebung im Original): »ästhetisch« nennt der Autor eine »Erfahrung «, »die wir so noch nicht gemacht haben und die uns gewissermaßen 
tigkeit, in der dies intentional erfolgt. Das musikalisch zu Erfahrende kommt gleichsam von der Zukunft her auf das Individuum zu (vgl. Wingert 2001), während der Versuch von dessen Assimilation an vorhandene Schemata auf Vergangenes, eben auf die je eigene musikbezogene Lerngeschichte rekurriert.

\section{c) Situation}

In der Kommunikativen Musikdidaktik wird der Situationsbegriff eingeführt, weil durch ihn die $>$ Schnittstelle $<$ zwischen den beteiligten kognitiven Systemen und dem Interaktionssystem in den Blick kommt und mit seiner Hilfe Unterricht als Abfolge von - durch die beteiligten Individuen wahrgenommenen - Situationen begriffen und beschrieben werden kann. Unterricht stellt eine >Umgebung < für Individuen dar, aber vermag - im Unterschied zum Bewusstsein und zu Interaktionen - kein System auszubilden (was hier nur als soziologische Begründung für seine prinzipielle Unvorhersagbarkeit erwähnt sei; vgl. Markowitz 1979: 178). Im Zuge der Definition einer Situation ist die Wahrnehmung der Interaktion aus Sicht eines Individuums (eines »personalen Systems«, wie der Soziologe Jürgen Markowitz sagen würde) ${ }^{8}$ - und diese Sicht ist konstitutiv für das mit dem Begriff Gemeinte - lediglich eine von mehreren Bestimmungsgrößen. Weitere solcher Bestimmungsgrößen sind eine abgrenzbare Zeit, ein abgrenzbarer Raum, die Möglichkeit der Abstufung von Aufmerksamkeiten und Einflussmöglichkeiten wie auch vor allem - die Erwartungen und die Vorbehalte, die das Individuum gegenüber der Interaktion hegt, dies alles wahrgenommen mit Hilfe des - u.a. durch die Lerngeschichte geprägten - kognitiven $>$ Haushalts< des Individuums. Insofern ist die Situation ein wahrgenommener Möglichkeitsbereich. (Die Komik im Laurel \& HardyBeispiel kommt - nach Ansicht des Autors - u.a. durch den grotesken Kontrast zwischen der restriktiven Situation des Gefängnisses und der Freiheit des ästhetisch Wahrnehmenden und Handelnden zustande, die sich der Protagonist im Film nimmt.)

>aus dem Anzug (unserer Verarbeitungsschablonen) stößt<: Wir hören, sehen, schmecken, tasten, riechen, fühlen etwas, dem wir nicht gerecht würden, wenn wir es in die Schubladen tun, die wir schon haben; [...] es verfremdet uns die bisherige Ordnung [...]«(Schulz 1997: 116f.).

8 Diese wenigen Hinweise beziehen sich in gedrängtester Form auf zwei Veröffentlichungen von Jürgen Markowitz (1979; 1986). 
Der Soziologe Hans Joas hat im Rahmen seiner nichtteleologischen Deutung der Intentionalität des Handelns den »konstitutive[n] und nicht nur kontingente[n] Situationsbezug des menschlichen Handelns« herausgestellt:

»Um handeln zu können, muss der Handelnde ein Urteil über den Charakter der Situation fällen. Jede Handlungsgewohnheit und jede Handlungsregel enthält Annahmen über den Typus von Situationen, in denen es angemessen ist, nach dieser Gewohnheit oder Regel zu verfahren. Unsere Wahrnehmung von Situationen beinhaltet im Regelfall bereits unser Urteil über die Angemessenheit bestimmter Handlungsweisen. So erklärt es sich, dass Situationen nicht nur das neutrale Betätigungsfeld für außersituativ konzipierte Intentionen sind, sondern schon in unserer Wahrnehmung bestimmte Handlungen hervorzurufen, zu provozieren scheinen. «" (Joas 1996: 235)

Für jene Intentionalität, die auch den musikalischen Handlungen eines Individuums, das solistisch oder in einer Gruppe improvisiert, hat dies entscheidende, die Improvisation überhaupt erst ermöglichende Konsequenzen:

»Wenn Intentionalität [...] als die selbstreflexive Bewusstwerdung und Beurteilung vorreflexiver Quasi-Intentionen in konkreten Situationen zu denken ist, dann sind Motive und Pläne als Produkte solcher Reflexion aufzufassen und nicht als die real wirkenden Ursachen des Handelns.« (A.a.O.: 237)

Und als ob nicht die Rede von einer allgemeinen Handlungstheorie, sondern von musikalischer Improvisation wäre, heißt es weiter:

»Die Reflexion auf die vorreflexiven Quasi-Intentionen ist allerdings auf ein Medium angewiesen. In klassischer Weise hat C. Wright Mills die Brücke zwischen dem Handlungsmodell der pragmatistischen Philosophie und der empirischen Praxis soziologischer Motivforschung geschlagen. Was als Motiv angegeben wird, ist demnach immer schon auf ein standardisiertes Vokabular möglicher und legitimer Motive bezogen.«(Ebd.)

9 Dieses Zitat gehört zum Kapitel Eine nicht-teleologische Deutung der Intentionalität des Handelns (vgl. Joas 1996: 218-244). 
Die Übertragung dieser Überlegungen auf eine handlungstheoretische Modellierung musikalischer Improvisation kann gelingen, weil sich die musikbezogenen Bedeutungszuweisungen im Rahmen von Improvisationen als »Motive« bzw. - freilich nur kurze Zeit verfolgte - »Pläne « im Sinne von Joas begreifen lassen, auf die das Individuum einerseits im Sinne von Schemata rekurrieren kann, die aber andererseits erst in der Situation der Improvisation virulent werden. Denn auch diese Bedeutungszuweisungen greifen auf ein musikbezogenes Handlungsrepertoire zurück, das sich z.B. im Jazz in den durch permanente Übung angeeigneten >scales<, >patterns< und >changes< konkretisiert. Improvisieren lässt sich als Umgang mit »Herausforderungen« begreifen:

»Unsere Wahrnehmung der Situation ist vorgeformt in unseren Handlungsfähigkeiten und unseren aktuellen Handlungsdispositionen; welche Handlung realisiert wird, entscheidet sich dann durch eine reflexive Beziehung auf die in der Situation erlebte Herausforderung.« (Joas 1996: 236)

Als Herausforderung für die musikalische Improvisation kann Vieles vom Individuum wahrgenommen werden: bisweilen ein Bettenrost in einem Gefängnis, im Rahmen solistischer Improvisation dann eher Improvisationskonzepte, aber auch Nicht-Musikalisches wie Werke der bildenden Kunst oder politische Ereignisse, im Rahmen einer Gruppenimprovisation neben den genannten >Phänomenen $<$ vor allem die musikalischen $>$ Äußerungen $<$ der Mitspieler.

\section{Können die von P. N. Wilson unterschiedenen Merkmale freier Improvisation im Musikunterricht zu Lerngegenständen werden?}

Zur »gelenkten Improvisation« vermerkt Peter Niklas Wilson:

»Oft genug ist sie ein fauler Kompromiss. Hierarchie unter dem Deckmäntelchen der Freiheit. Ohne die Verbindlichkeit detaillierter Komposition, ohne die Offenheit des freien Spiels. Im Versuch, das beste beider Welten zu haben, den Kuchen zu essen und ihn gleichzeitig zu be- 
halten, wird das Wesentliche der beiden Arten des Musikmachens, die da vereint werden sollen - Komposition und Improvisation -, preisgegeben. Hätte man doch frei improvisiert. Oder konsequent komponiert. « (Wilson 1999: 23)

Wilson bestimmt hier nicht bloß ein Problem frei improvisierter Musik, die sich ausgehend von den Impulsen des Free Jazz und den systemsprengenden Impulsen der Neuen Musik nach der Hochblüte des Serialismus in den Vereinigten Staaten wie in Europa ausgebildet hat, sondern zugleich das musikpädagogische Kernproblem: In Entsprechung zur musikpädagogischen Musik, die Theodor W. Adorno kritisierte (Adorno ${ }^{6} 1982$ : 99 und Kloppenburg 2002), ist insbesondere Improvisation im schulischen Unterricht in der permanenten Gefahr, den Anspruch, den man mit ihr in der Gegenüberstellung mit dem Komponieren verbinden muss, $\mathrm{zu}$ verniedlichen und damit zu verraten. Der Sinn des Improvisierens muss ein völlig anderer sein als der des Komponierens, sodass Versuche der Bestimmung des Begriffs der Improvisation, die unter ihr ein spontanes Komponieren »instant composition« (Wilson 1999: 12) ${ }^{10}$ begreifen oder lediglich ein Musizieren ohne Noten, das aber konzeptionell im Prinzip auch auf einer schriftlich niedergelegten Komposition beruhen könnte, abzulehnen sind.

Nun ist die Vielgestaltigkeit dessen, was als Improvisation bezeichnet wird, ausufernd, und es kann hier nicht einmal ansatzweise um eine Sichtung dieses Feldes gehen (vgl. Dahlhaus 2000; Eckhardt 1995: 174-213; Schwab 1991; Wallbaum 2000). Das ist auch vor dem Hintergrund der Absicht, Eigenschaften des Improvisierens vor allem kontrastiv zum Komponieren zu bestimmen, nicht nötig. Diese Differenzierung kann aber gut vor dem Hintergrund der Frage erfolgen, wer wann welche musikbezogenen Entscheidungen mit oder ohne Nachvollziehbarkeit durch andere trifft. Dabei wird deutlich, dass im Rahmen von Improvisationen die musikbezogenen Entscheidungen ad hoc und überdies in einer Weise getroffen werden können, die durch andere nur im Sinne unmittelbarer musikbezogener Bedeutungszuweisung nachvollziehbar sind (Begründungen ließen sich erst post hoc mit nicht-musikalischen - z.B. sprachlichen -

10 Nach Wilson prägte Jim Hall diesen Begriff, während Volker Biesenbender (1995: 3) die erste Verwendung des Begriffs »instant composing « Mischa Mengelberg (dem Sohn des Dirigenten Willem Mengelberg) zuschreibt. 
Mitteln geben); Prozess und Produkt fallen also, was den Vorgang des Treffens von Entscheidungen angeht, für Beobachter zusammen. Demgegenüber treten Prozess und Produkt hinsichtlich dieses Kriteriums durch die zeitliche Trennung (bzw. Trennbarkeit) von Hervorbringungsprozess und Produkt im Falle von Kompositionen auseinander: Indem die Entscheidungen - einerlei, ob von einem Individuum oder im Rahmen von Gruppenkompositionen von mehreren Individuen getroffen, - im Vollzug des Komponierens von der fertigen Komposition - auch für Beobachter - getrennt werden können, weil das Produkt - z.B. ein Notentext - den Entscheidungsprozess überdauert, ergibt sich Begründbarkeit in der Interaktion. Diese Differenz ist entscheidend, wenn es um die Frage nach dem Sinn und den Möglichkeiten >ästhetischer Kritik< mit Blick auf Kompositionen und Interpretationen geht (vgl. 4.). ${ }^{11}$

Im Folgenden sollen Charakteristika jener frei improvisierten Musik benannt werden, die sich nach der Phase des Serialismus in den Vereinigten Staaten und auch in Europa ausgebildet hat, und zwar in Anlehnung an jene Beschreibung, die Peter Niklas Wilson vorlegte (vgl. Wilson 1999a). ${ }^{12} \mathrm{Zu}$ den von Wilson genannten Merkmalen der Improvisation gehört einerseits ein Komplex von Charakteristika, die der Autor mit den Stichworten »Ausdruck als Intro-Spektion «; »Individualisierung des Klangs«; »nicht-musikalische Inspiration «; »Emotion, Physis, Energie« (1/7/8/10) umreißt (Merkmalskomplex a), andererseits »Gruppenimprovisation als Kairos $\ll i^{13} \gg$ multi-mindedness « (Evan Parker), Unbrauchbarkeit des Kriteriums > Verzicht auf Schriftlichkeit<als Merkmal zur Unterscheidung zwischen improvisierter und komponierter Musik (6/18;

11 Da Christopher Wallbaum die Unterscheidung zwischen Komposition und Improvisation unberücksichtigt lässt, kommen bei ihm weder im Rahmen seiner Überlegungen zur >ästhetischen Kritikく(Wallbaum 2000: 221-227), noch im Zuge der »Vergewisserung: Was heißt >ästhetisches Produkt«« (a.a.O: 230-247) diesbezügliche Differenzierungen zur Sprache.

12 Die Zahlenangaben im Klammern entsprechen der Durchnummerierung der Merkmale bei Wilson; die Seitenangaben im Haupttext beziehen sich auf diese Veröffentlichung Wilsons.

13 Also als >günstiger Augenblick <; gemeint ist, dass die Gruppenimprovisation eine ideale, >mustergültige< Realisationsform von Improvisation darstellt, nicht zuletzt wegen der durch die Interaktion - im Vergleich zur solistischen Improvisation - potenzierten Unwägbarkeit bzw. Unvorhersagbarkeit. 
Merkmalskomplex b). ${ }^{14}$ Die folgenden Ausführungen beschränken sich auf diese beiden Merkmalskomplexe.

a) Ausdruck ergibt sich in der Improvisation nicht durch deren Nutzung als »emotionales Ventil«, sondern durch Intro-Spektion, die den Musiker von der emotionalen Nabelschau wegführt und von der Selbstfindung zur Selbst-Losigkeit fortschreitet. ${ }^{15}$ Improvisatoren verwenden individuelle Vokabularen: »Die Wörter haben sich verfestigt, doch es lassen sich noch neue Sätze bilden.« (Wilson 1999a: 11) Soweit diese Vokabularen als »Spiegel der Persönlichkeit « aufgefasst werden sollen, ist der individuelle Bildungsprozess also auf Individualisierung des musikalischen Ausdrucks und seiner >materialen Träger< ausgerichtet. Dies kann unterschiedliche Formen annehmen, von der präparierten Gitarre (Keith Rowes) bis zur Hörbarmachung der Klangwelt kleiner Haushaltsgegenstände per Kontaktmikrophon (Hugh Davies). Dabei meint Virtuosität in freier Musik etwas anderes als die Perfektionierung einer gegebenen Technik (ebd.: 17); sie hängt eher mit der Fähigkeit des SichEinlassens und Hervorbringens »instantaner Magie « zusammen. ${ }^{16}$

14 Die anderen Merkmale lauten c) instantane Magie, nicht instant composition<; Ziellosigkeit als Stärke, offener Erlebnisraum; Zelebrieren des Jetzt; Retention statt Erinnerung; Offenheit der Lenkung (Beispiel: Cornelius Cardew: Treatise (2/11/12/14); d) Meta-Kommunikation über das Wie musikalischer Verständigung; Umgang mit verinnerlichten Verabredungen/ gruppeneigenen Konventionen; Umgang mit Klischees und Idiomen (3/5/9); e) Tugenden; eine Lebenshaltung (Kontingenz des Vokabulars) (4/17). Ein vollständiges Referat der insgesamt 18 Punkte, die Peter Niklas Wilson (1999a) zur Charakterisierung der freien Improvisation anführt, hätte noch die - aus didaktisch-unterrichtspraktischer Sicht, welche Möglichkeiten eigener Erprobung ins Auge fasst, weniger relevanten - folgenden zwei Eigenschaften (bzw. Komplexe von Eigenschaften) zu berücksichtigen: f) Gegen-Ritual (B. Noglik: "private Angelegenheit von öffentlicher Bedeutung «); Erobern neuer Räume (Punkte 13 und 15; a.a.O.: 22f. und 24); g) Anlass für mediale Kreativität (Punkt 16; a.a.O.: 24f.). Eine ausführliche Auseinandersetzung mit den Eigenschaften (bzw. Bündeln von Eigenschaften) c) bis e) ist - neben den vorwiegend identischen Überlegungen zu a) und b) - in einer erweiterten Fassung vorliegenden Beitrags erfolgt (Orgass 2007: 707-770).

$15 \mathrm{Vgl}$. das in der vorigen Anmerkung genannte Merkmal e).

16 Vgl. das in der vorvorigen Anmerkung genannte Merkmal c). 
Individualisierung des Klangs kann durch die Anwendung von Verfahren aus anderen Künsten inspiriert sein und so neue Musik zeitigen: Keith Rowes versetzte die Saiten seiner Gitarre mit Stricknadeln, Linealen und Metallklammern in Schwingung und legte dieses Instrument auf den Boden, später auf den Tisch. Damit orientierte er sich an Robert Rauschenberg, der Metallgegenstände auf seine Bilder applizierte, und an Jackson Pollock, der die Leinwand auf den Boden legte und den Farbauftrag gestisch dynamisierte (ebd.: 18). $\mathrm{Ob}$ dann der Ausdruck durch hohen physischen Aufwand oder durch völlig zurückgenommene Energie als ein authentischer erscheint, ist nicht ohne den jeweiligen musikalischen Zusammenhang zu entscheiden, dessen Emotionalität im Falle von »Kraftmeierei « (Peter Brötzmann) wie auch im Falle von Fragilität (beim Posaunisten/Cellisten Günter Christmann, beim Gitarristen Derek Bailey) stimmig sein muss, d.h. musikalisch wie auch personenbezogen >plausibel< (ebd.: 20).

b) Gruppenimprovisation als Kairos; multi-mindedness (Evan Parker), Unbrauchbarkeit des Kriteriums > Verzicht auf Schriftlichkeit< als Merkmal zur Unterscheidung zwischen improvisierter und komponierter Musik (6/18).

Wenngleich Soloimprovisation ohnehin eine kaum geeignete Form des schulischen Musikmachens ist, sei doch kurz erwähnt, dass in der Gruppenimprovisation - im Vergleich zur Soloimprovisation - die aufregendere, die magische Seite des Improvisierens erfahren werden kann. Derek Bailey spricht in diesem Zusammenhang von der intuitiven, telepathischen Grundlage des Improvisierens, die am ehesten in einer Gruppen-Situation erkundet werden könne. Die möglichen musikalischen Dimensionen des Gruppenspiels gingen weit über die des Solospiels hinaus (ebd.: 16), worin sich ein weiteres Mal die Kraft >doppelter Kontingenz<, nunmehr in musikalischen - und nicht bloß musikbezogenen - Interaktionen, zeigt. Andererseits ist die solistisch erprobte Improvisation die Quelle der notwendigen Selbsterfahrung, auf die in Gruppenimprovisationen zurückgegriffen wird (ebd.: 17). Dies ist zumindest zu berücksichtigen, wenn im Musikunterricht Gruppenimprovisation zum Gegenstand werden soll.

»Multi-mindedness « ist nach dem Saxophonisten Evan Parker für frei improvisierte Musik entscheidender als das Fehlen von Schriftlichkeit, von Notation (die Unterscheidung oral-literat ist 
nicht identisch mit jener zwischen improvisiert-komponiert). Es ist also nicht die Abwesenheit von Schriftlichkeit, die die freie Improvisation gegenüber komponierter Musik auszeichnet, sondern ihre Genese durch kollektive Entscheidungsprozesse. Mit dieser Bestimmung rückt, so Wilson, das improvisierte Solo mit seiner $>$ single-mindedness < wiederum ein Stück näher an den herkömmlichen Kompositionsprozess heran (ebd.: 26). Die Unterscheidung zwischen Prozess und Produkt, die in anderen Kontexten eher blass bleibt (s.o.), erweist sich nun als erkenntnisträchtig: Prozess und Produkt können in der Praxis solistischer Improvisation auseinander treten (sie müssen es freilich nicht), während sie in der Gruppenimprovisation notwendig zusammenfallen: Hier kann sich Planung seitens der einzelnen Mitspielerin bzw. des einzelnen Mitspielers höchstens auf den Beginn der Improvisation beziehen.

\section{Herleitung einer didaktischen Idee für das Unterrichten von (Gruppen-)Improvisation aus Earle Browns »Folio (1952/53)«}

Für den Unterricht bezieht sich die entscheidende didaktische Frage auf den Grad der Lenkung des zu Improvisierenden. Die differenzierte Beantwortung dieser Frage wurde in Earle Browns Zyklus Folio (1952/53), zu dem das - gerade auch im schulischen Kontext oft thematisierte ${ }^{17}$ - Stück December 1952 gehört, zum entscheidenden kompositorischen Gedanken. Auf dem Originalblatt von $D e-$ cember 1952 trug Brown ein virtuell dreidimensionales Koordinatensystem auf, auf dem jedem notierten Klangparameter eine eigene Achse zugewiesen ist. Dörte Schmidt führt aus:

17 Vgl. z.B. das Schulbuch Musik um uns, 11.-13. Schuljahr ( ${ }^{2}$ 1983: 260f.), dessen Aussage, »musikalische Graphiken« wie Browns December 1952 sollten »den Spieler mit bildästhetischen Qualitäten zu analogen Aktionen, zu analogen Klangbildern führen« (a.a.O.: 260), immer wieder aufgegriffen worden ist. In einer späteren Ausgabe desselben Unterrichtswerks heißt es noch weniger konkret: »Musikalische Grafik will die/den Spieler zu immer neuen kreativen musikalischen Aktionen anregen« vgl. Musik um uns. Sekundarbereich II (1996: 74). 
»Brown bestimmt seinen Klangraum durch ein - in der Notation selbst nicht aufscheinendes, aber für die ihr zugrundeliegende Abstraktionsbewegung ebenso wie für die Partiturlektüre der Ausführenden konstitutives - virtuell dreidimensionales Koordinatensystem, auf dem jedem notierten Klangparameter eine eigene Achse zugewiesen ist. Zusätzlich zur vertikalen und horizontalen Achse führt er für die Dynamik nun noch eine imaginäre Tiefe ein. Dieses Koordinatensystem muss der Ausführende ergänzen, um die Partitur lesbar zu machen und entscheiden zu können, wie hoch, lang und laut ein Klangereignis sein soll.« (Schmidt 2000: 196f.)

\section{Abbildung 1: Earle Brown: December 1952}

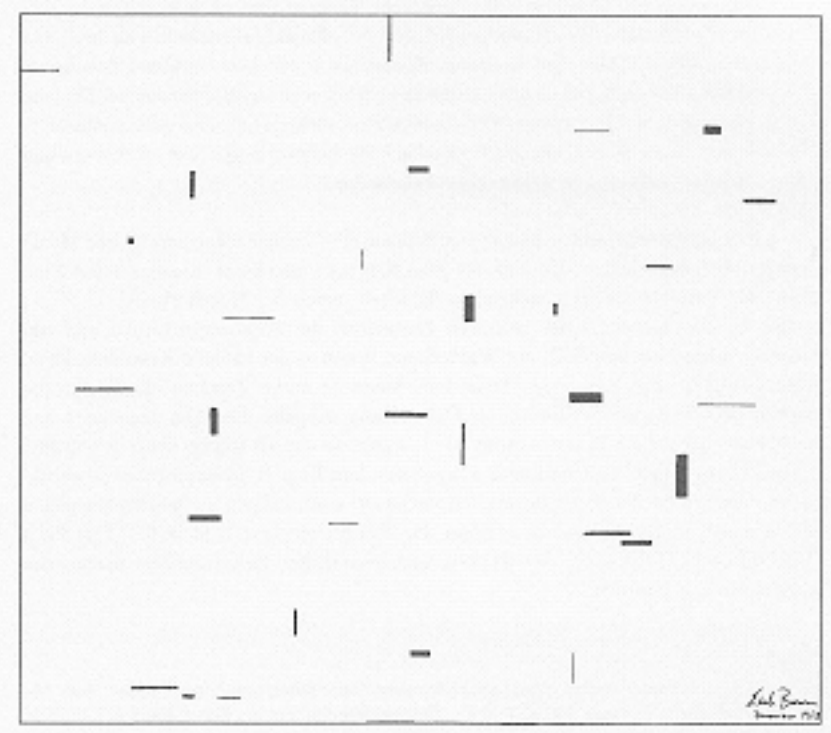

Quelle: associated music publishers. Inc., New York 1961

Nach Dörte Schmidt ist Earle Browns December 1952 also keine Anregung zur Improvisation, sondern zur je individuellen Komposition. Aber diese Einschätzung erscheint vor dem Hintergrund von Auszügen aus einem Gespräch, das John Yaffé am 25. September 1995 mit Earle Brown führte, zu rigide. Brown bemerkte dort:

»December 1952 is a rarefied, simplified thing: just sounds in space, a kind of purist finality. I had this idealistic, romantic feeling that I could, 
with a graphic score and classical musicians [...] I couldn't understand why classical musicians couldn't improvise, and why so many looked down on improvisation. The whole series of October, November and December was progressively trying to get them free of having to have every little bit of information before they had confidence enough to play. And I was convinced that, with this series, I could bring it about. ${ }^{18}$

Zumindest lässt sich an der Auseinandersetzung mit diesem Stück etwas für die Improvisation Zentrales lernen: Es ist dies die Ernsthaftigkeit, mit der Bedeutungszuweisungen zu musikalischen Graphiken erfolgen sollten. D.h. gerade wenn December 1952 als »Inspirationsquelle für spontanes Improvisieren« verwendet werden sollte, wenn also Browns Partitur im Sinne einer Vollendung der »>Verallgemeinerung< des Schriftsystems« (Schmidt 2000: 207) durch Abwesenheit von »every little bit of information « betrachtet wird, käme es auf die Wahl einer Lesart an. Z.B. - und nicht notwendiger Weise in dieser Form - ließe sich ein »Denken in Neumen« oder ein »mathematisch bestimmtes Denken nach den Koordinaten der Planimetrie $«$ in Anwendung bringen. ${ }^{19}$ Pierre Boulez hatte zwar mit diesen Hinweisen die graphische Umsetzung musikalischer Sachverhalte im Blick (Boulez 1985: 63; vgl. auch Schmidt 2000: 199), aber diese für den kompositorischen Akt relevanten Denkformen können auch als Denkformen der Lektüre einer graphisch notierten Musik begriffen werden. Jedenfalls wird im Falle einer solchen ernsthaften Auseinandersetzung sicherlich etwas anderes zu hören sein als das Eulenspiegel-Thema aus Richard Strauss' symphonischer Dichtung. ${ }^{20}$

18 Brown 1996 (die kursive Hervorhebung der Titel im Original). John Yaffé ist der Produzent der im Literaturverzeichnis angegebenen CD (in den Angaben zu Brown 1996). Zu bedenken ist, dass Folio in der Rückschau eine Umdeutung durch seinen Komponisten erfahren haben mag.

19 Planimetrie ist die Messung und Berechnung der Flächeninhalte (Geometrie der Ebene).

20 Vgl. Vogt 1982: 147, hier folgender Bericht Erhard Karkoschkas über eine Realisation von December 1952 (dort auch die kursive Hervorhebung): »Bei den Darmstädter Ferienkursen 1964 legte Brown dem Orchester dieses Blatt auf die Pulte und dirigierte. Es ist dabei wohl unbezweifelbar deutlich geworden, dass seine Arm- und Handbewegungen, nicht aber das Blatt die Musiker angeregt haben, zumal wellenartige Verläufe und sehr ausgedehnte 
Brown hat aber, wie der Partitur zu entnehmen ist, vor allem an eine Aufführung gedacht, die von einem vierdimensionalen, räumlich-zeitlichen Sinn der Graphik von December 1952 ausgeht bzw. diesen in die Partitur hineinliest, also von den Dimensionen »linksrechts«, »oben-unten«, »vorne-hinten« und »Bewegung « in der Zeit. Während in nur dreidimensional-flächiger Lesart die relative Dicke der Balken bzw. Striche (der »Ereignisse«) die relative Lautstärke und/oder den Umfang von Clusters (Tontrauben) meint, sollen in vierdimensional-räumlicher Lesart die hinsichtlich ihrer Dicke und Länge identischen »Ereignisse « als Funktionen ihrer konzeptionellen Position auf einer Ebene gedacht werden. So lassen sich mehrere parallele, »Ereignisse « anregende bzw. repräsentierende Flächen unterscheiden, von denen manche mehr im Vordergrund und manche mehr im Hintergrund stehen. Diese graphischen »Implikationen « sollen von jedem der Mitspieler musikalisch umgesetzt werden; Absprachen sollen sich nur auf die Dauer des gesamten Stücks beziehen. »Further defining of the events is not prohibited forever, provided that the imposed determinate-system is implicit in the score and in these notes « (Brown 1961, übersetzt durch den Verfasser vorliegender Arbeit). - In verallgemeinernder Zusammenfassung lässt sich sagen: Wer im Nachhinein nicht mehr beantworten könnte, welche Rolle eine $>$ Vorlage $<$ im Prinzip bei einer Improvisation aus deren Anlass gespielt hat, sollte gar nicht erst beanspruchen, sich auf diese Vorlage zu beziehen. Nach Browns Aussage hätte er sie ja auch nicht mehr nötig.

Die eigentliche >improvisationsdidaktische< Idee Browns artikuliert sich nun in dem Ansinnen, durch die fortschreitende $>$ Verallgemeinerung der Notation $<$ in der Serie von October, November und December die Musiker von der Vorstellung zu befreien, sie seien auf einen noch so kleinen Informationsfetzen angewiesen, bevor sie genug Vertrauen zum Spielen haben könnten (Brown 1996): In October 1952 fehlen die Notenschlüssel zu Beginn der beiden konventionellen fünflinigen Systeme - die Lesart als Klaviernotation mit Violinen- und Bassschlüssel ist naheliegend, aber nicht zwingend; in November 1952 sind 50 Notenlinien gesetzt, wodurch »die Rolle

Crescendi nur mit einiger Phantasie aus dem Blatt herausgelesen werden können, die auch Strauss' Eulenspiegel-Thema herauslesen kann. Was auch tatsächlich geschehen ist.«Vgl. auch Musik um uns (1982: 261). 
der Linien für die vertikale Orientierung [...] verlorengegangen« ist (Schmidt 2000: 194).

Abbildung 2: Earle Brown: October 1952, erstes System

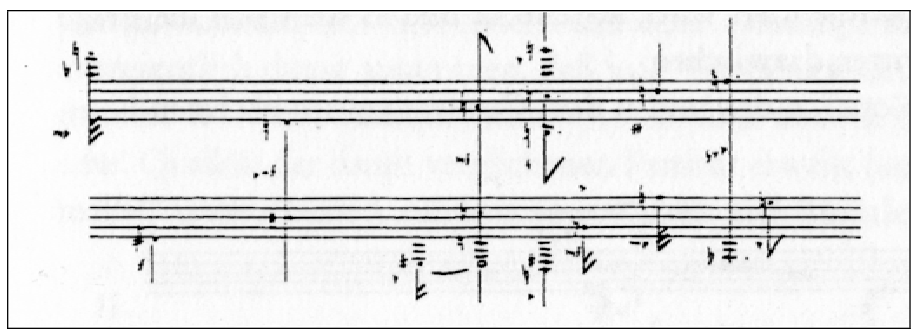

Quelle: associated music publishers, Inc., New York 1961

Abbildung 3: Earle Brown: November 1952

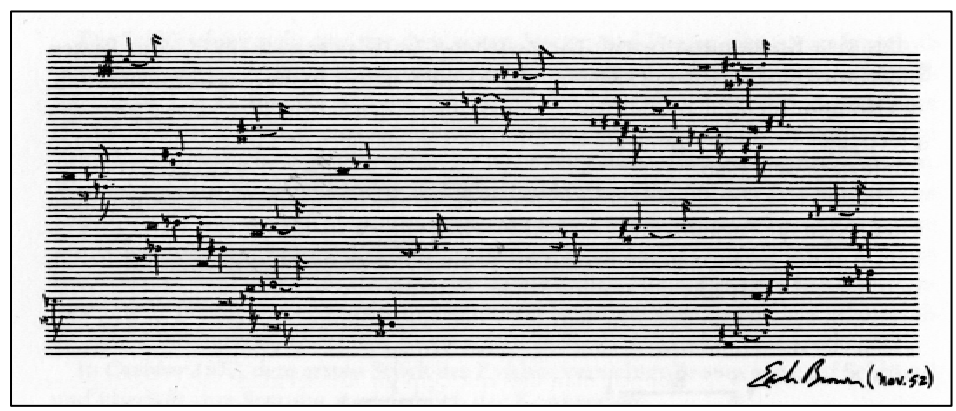

Quelle: associated music publishers, Inc., New York 1961

Diese Idee der progressiven >Befreiung < der Musiker von konventioneller Orientierung - so die These - kann helfen, entsprechende Lehr-/Lernprozesse im Hinblick auf die spezifischen, mit freier Improvisation zusammenhängenden Dimensionen Ausdruck (a) und »multi-mindedness « (b) zu strukturieren. 


\section{Didaktische Überlegungen zu den Merkmalskomplexen a) und b)}

Die genannten Eigenschaften sind nunmehr unter der Frage zu betrachten, inwiefern sie im Rahmen einer unterrichtlichen Thematisierung frei improvisierter Musik virulent werden können bzw. sollten, wobei auf Möglichkeiten selbstständig durchgeführter freier Improvisation zu achten sein wird. Ihre unterrichtliche Behandlung, die sich bspw. auf das Hören einschlägiger Tonträger beschränkte, würde einer Eigenschaft freier Improvisation von vornherein nicht gerecht, nämlich der Einmaligkeit und Flüchtigkeit dieser Kunst. Obschon Tonträger seitens der Musiker, die frei improvisieren, geduldet werden, wenn sie als >ehrliche Dokumente< ein »ungeschöntes Abbild einer Aufführung « bieten, bezeichnet Wilson es doch zu Recht als Verrat am »Primat des Hier und Jetzt«, wenn bspw. zu »bereits medial gefrorener Improvisation« improvisiert wird (Wilson 1999a: 24).

Die didaktische Reflexion kann gut vor dem Hintergrund der in den nordrhein-westfälischen Lehrplänen für das Fach Musik für die Sekundarstufe II vorgeschriebenen ersten beiden »Bereiche des Faches« (I und II) erfolgen (Lehrpläne Musik NRW 1999: 9 und 11f., hier die kursiven Hervorhebungen): »Musik gewinnt Ausdruck vor dem Hintergrund von Gestaltungsregeln « und »Musik erhält Bedeutung durch Interpretation «. Eine gewisse Kompatibilität dieser Bereiche des Faches mit den Anforderungen anderer bundesdeutscher Lehrpläne darf angenommen werden. Die didaktische Idee, die Earle Brown mit seinem Zyklus Folio verband, soll nun auf die Thematisierung der zu diskutierenden Eigenschaftsbündel a) und $b$ ) übertragen werden.

$\mathrm{Zu}$ a) Didaktische Überlegungen zum ersten Eigenschaftsbündel von Improvisation: Ausdruck als Intro-Spektion; Individualisierung des Klangs; nicht-musikalische Inspiration; Emotion, Physis, Energie.

Das von Wilson formulierte Ideal der Intro-Spektion des Ausdrucks sowie die damit zusammenhängende Individualisierung des Klangs lassen sich nicht ohne Weiteres unterrichtlich zur Geltung bringen: Weder ist klar, wie Freiräume für solche Intro-Spektion geschaffen werden sollen, noch kann eine Überprüfung durch Lehren- 
de oder durch Mitschülerinnen und Mitschüler erfolgen, wenn nicht die Fähigkeit und der Wille zur Extro-Version bei dem Lernenden, der das Ergebnis einer Intro-Spektion vorführen möchte, als bereits ausgebildet vorausgesetzt werden kann. Die unterrichtliche Arbeit hätte sich wohl zunächst auf die Entwicklung dieser basalen Fähigkeit zu beziehen.

Der Status der Gestaltungsregeln, die im Sinne des ersten Bereiches des Faches der Lehrpläne Musik NRW 1999 zu thematisieren sind, ist mit Blick auf die Improvisation, noch dazu der freien Improvisation, prekär: Sind solche Gestaltungsregeln nicht nur irgendwie bekannt, sondern verbinden sich mit ihnen auch konkrete Vorstellungen und Fähigkeiten zur Hervorbringung von ihnen entsprechenden Klanggebilden, so hat die auf sie bezogene unterrichtliche Arbeit eher mit dem Komponieren bzw. dem Erfinden von Musik im Sinne von Komposition zu tun. Zu denken wäre hier z.B. an Gestaltungsarbeiten zu >äußeren< Ausdrucksqualitäten wie >stürmisch $<$, >festlich $<$ etc. oder >innerlichen< Ausdruckqualitäten wie >entspannt<, >traurig< etc. Sind aber solche Regeln den Lernenden unklar, so dürfte das Ergebnis ihrer improvisatorischen Tätigkeit eher völlig haltlos und aus der Sicht aller Beteiligten unbrauchbar sein - wenn es vor dem Hintergrund des jeweils individuellen Wissens um die fehlende Vorbereitung und der damit einhergehenden Ängste zum Improvisieren überhaupt kommt.

Die unterrichtliche Arbeit ist mit Blick auf das Problem des Ausdrucks in freien Improvisationen so lange haltlos, wie nicht auch in der Zuordnung zum Bereich des Faches I! - zumindest in Ansätzen ausdrucksästhetische Fragen in historischer Dimensionierung thematisiert werden. Eine Theorie des Ausdrucks, die musikalischen Ausdruck im Rahmen von Improvisationen berücksichtigen könnte, müsste dergestalt handlungsorientiert sein, dass sie die Auseinandersetzung eines Individuums mit musikalischem Material ebenso im Blick hat wie die Interaktion mit anderen Individuen z.B. im Rahmen von Gruppenimprovisationen. Eine solche Theorie, die ebenso auf »konkrete situative Bezüge « abstellt wie sie die Vorstellung vom Ausdruck als Repräsentation (eines Äußeren im Sinne von Naturnachahmung oder von Darstellung der Affekte oder des Innersten des Individuums) durchbricht (vgl. Saxer 2004: 319), hat John Dewey formuliert: 
»Der Ausdruck des Selbst in einem und durch ein Medium - was das eigentliche Kunstwerk ausmacht - ist an sich eine Verlängerung einer Interaktion von etwas dem Selbst Entstammenden mit konkreten Umständen - ein Prozess, in dem beide eine Ordnung und Form annehmen, die sie vorher nicht besaßen.«(Dewey 1980: 79)

Allerdings bezieht sich Dewey auf Kunstwerke, in Sachen Musik also auf Kompositionen: »Der Ausdrucksakt, aus dem sich ein Kunstwerk entwickelt, entsteht innerhalb einer bestimmten Zeitspanne, er ist keine momentane Äußerung.« (ebd.) Dennoch lässt sich Deweys Ausdrucktheorie auch auf Improvisationen anwenden. Das Kriterium hierfür gibt der Autor selbst an:

»Unmittelbarkeit und Individualität, die das konkrete Dasein kennzeichnen, ergeben sich aus augenblicklichem Anlass; Bedeutung, Gegenstand und Inhalt ergeben sich aus dem, was von der Vergangenheit im Ich verankert ist. Ich glaube nicht, dass man Singen und Tanzen selbst bei kleinen Kindern - auf der Basis nichterlernter, ungeformter Reaktionen auf derzeit bestehende, konkrete Anlässe erklären kann. Selbstverständlich muss es in der Gegenwart etwas geben, das Glücksgefühle hervorruft. Doch ist die Handlung nur dann expressiv, wenn in ihr ein Gleichklang zwischen etwas aus vergangener Erfahrung Bewahrtem, also etwas Verallgemeinertem, und den gegenwärtigen Umständen besteht.«(A.a.O.: 87)

Damit nun das Improvisieren keinem »Wahn« erliegt, »in dem das Empfinden für ein geordnetes Schaffen subjektiv und halluziniert ist « (ebd.), empfiehlt sich die Arbeit an jenem vergangenheitsbezogenen Aspekt expressiver Handlungen, der mit der Geschichte musikalischen Ausdrucks und seiner ästhetischen Reflexion in den Blick kommt, unterrichtlich wie auch sonst selbstverständlich nur in repräsentativen Fokussierungen. Oder anders gewendet: Didaktische Intentionalität, die sich auf die Entwicklung der im Rahmen freier Improvisation erforderlichen Ausdruckskompetenzen bezieht, hat eher die »Gestaltung « als die »Hingabe« im Blick, um jene spannungsvoll im Spiel aufeinander bezogenen Dimensionen zu erwähnen, die Arnulf Rüssel in seiner Theorie des Kinderspiels unterschied. $^{21}$

21 Vgl. hierzu Rora 2001: 64-70. Rora bezieht sich auf Arnulf Rüssel ( $\left.{ }^{2} 1965\right)$ : Das Kinderspiel. Grundlinien einer psychologischen Theorie. Zu Unter- 
Die einer Geschichte musikalischen Ausdrucks zugrunde liegende Zeitverlaufsvorstellung kann durch die Angabe eines point de perfection geprägt sein (vgl. Dahlhaus 1977: 225f. sowie 247f.), repräsentiert durch ein Ausdruckskonzept, das freier Improvisation zugrunde zu liegen vermag. Eine Fortschrittsgeschichte wäre dann vom barocken Ausdruck als Darstellung über den problembeladenen Ausdruck des Innersten eines Individuums im musikalischen Sturm und Drang, in der Wiener Klassik sowie in der musikalischen Romantik - jeweils in unterschiedlichen Ausprägungen - bis zu Deweys Konzept des Ausdrucks als Interaktion als dem point de perfection zu erzählen, gefolgt von einer Verfallsgeschichte, nämlich weiter bis zur Abkehr vom Ausdrucksparadigma in der ersten Hälfte des 20. Jahrhunderts (z.B. Strawinsky) und zu deren Radikalisierung in der zweiten Hälfte des 20. Jahrhunderts (New York School). ${ }^{22}$

Vor dem Hintergrund eines Wissens darum, wes Geistes Kind man ist, wenn man meint, etwas oder sich mit spezifischen Mitteln musikalisch auszudrücken, kann dann der Weg von »Musikalischen Gestaltungsspielen «, also im Sinne Constanze Roras von musikalischen Spielen mit Spielregeln, Spielmitteln, Spieltätigkeiten und sozialen Spielstrukturen (Rora 2001: 47-83), hin zur freien Improvisation beschritten werden. Dabei sollten die Entscheidungsmöglichkeiten der Mitspielerinnen und Mitspieler immer größer werden, z.B. hinsichtlich der Wahl der Materialien wie auch hinsichtlich der Möglichkeiten, auf Mitspieler zu reagieren. Hinsichtlich der Materialien unterscheidet Rora: »fertiges Material aufgreifen/reproduzieren; fertiges Material manipulieren (Muster variieren; neben einem Schema spielen; nur den Anfang spielen); nicht von fertigem Material ausgehen, sondern eine eigene Struktur ausdenken und verwirklichen (vorgestellte Kontur spielen; vorgestellten Ton oder Harmonie ansteuern); sich beim Ausdenken eigener Strukturen und Abläufe im Material beschränken« (a.a.O.: 111f.). ${ }^{23}$ An Möglichkeiten, auf Mitspieler zu reagieren, nennt Vinco Globokar das »Imitieren, Integrieren (Folgen, im selben Sinne bewegen), Sich Zurück-

schieden zwischen »Musikalischen Gestaltungsspielen« und freien Improvisationen vgl. Rora 2001: 111ff.

22 Eine gute Grundlage hierzu bietet Saxer 2004.

23 Rora fasst hier eine umfangreichere Aufzählung Klaus-Ernst Behnes zusammen (vgl. Behne 1992: 47f.) 
halten, das Gegenteil tun, etwas Verschiedenes machen« (Globokar 1971: 59ff.; vgl. Rora 2001: 112).

Damit wird mit Blick auf die unterrichtliche Thematisierung freier Improvisation eine aus didaktischer Sicht zu konstatierende grenzwertige Situation deutlich: In dem Moment, wo freie Improvisation von Lernenden selbst gestaltet werden kann, sind Lehrhandlungen sinnlos geworden. Dies müssen Lehrende hinsichtlich der Perturbationen, mit denen sie die Entwicklung von für freie Improvisation erforderlichen Kompetenzen ermöglichen wollen, von vornherein im Blick haben, wie auch Juliane Ribke feststellt: »Nicht auf überlegenes Wissen, sondern auf ihre >Hebammenfähigkeiten< sollten die LehrerInnen sich besinnen [...] Ermutigung zur selbstbestimmten musikalischen Handlung rangiert vor der Forderung nach Materialbewältigung.« (Ribke 1999: 15)

Zu b) Didaktische Überlegungen zum zweiten Eigenschaftsbündel von Improvisation: Gruppenimprovisation als Kairos; multimindedness (Evan Parker), Unbrauchbarkeit des Kriteriums $>$ Verzicht auf Schriftlichkeit< als Merkmal zur Unterscheidung zwischen improvisierter und komponierter Musik.

Die diese Eigenschaft der freien Improvisation in den Blick nehmende unterrichtliche Arbeit kann auf Deweys Ausdruckstheorie unter besonderer Berücksichtigung jener Ausprägung »konkreter situativer Bezüge« zurückgreifen, die durch die Improvisation in der Gruppe gegeben ist. ${ }^{24}$ Die unterrichtliche Interaktion schafft selbst jene Situationen, die musikbezogene Bedeutungszuweisungen konstituieren. Es lässt sich dies als unterrichtspraktische Wendung einer »Ästhetik des Situativen« begreifen, die Sabine Sanio in Anlehnung an entsprechende Überlegungen des Linguisten Roman Jakobson thematisiert hat und die mit Rudolf Michael Brandls Überlegungen zum konstitutiven Situationsbezug musikbezogener Bedeutungszuweisungen kompatibel ist (vgl. Sanio 2004: 362f.; Brandl 1998; Orgass 2007a: Kapitel 3.1., a.a.O.: 88-98; ders. 2007b: Kapitel 4.1., a.a.O.: 108-120). In Gruppenimprovisationen bringen die jeweils anderen Spielerinnen und Spieler klangliche Bestimmungsgrößen der musikalischen Situation hervor, auf die das an der Improvisation teilnehmende Individuum reagieren muss. In Entsprechung zur un-

24 Vgl. die obigen Ausführungen zu Deweys Ausdrucktheorie sowie Saxer 2004: 319 . 
terrichtlichen Auseinandersetzung mit der Geschichte musikalischen Ausdrucks bzw. mit der Ausdrucksästhetik kann mit Blick auf die Relativierung des individuellen Ausdruckswillens durch den Gruppenbezug die Thematisierung der Genieästhetik und der mit ihr zusammenhängenden »Geniedämmerung « im 20. Jahrhundert, die mit der zunehmenden - ihrerseits problematischen - Dekonstruktion des Subjekts korrespondiert, sinnvoll und nützlich sein (Ortland 2004: 275).

Wenn erneut Earl Browns didaktische Idee aufgegriffen werden soll, so lässt sich eine in Anlehnung an Niklas Luhmanns Kunsttheorie (Luhmann 1997: 54, Anm. 65) zu konzipierende Methode der Gruppenkomposition modifizieren. In deren Rahmen werden die kontingenten Entscheidungen der Komponistin bzw. des Komponisten interaktiv rekonstruiert, um auf diese Weise den Versuch virtueller Objektivierung >doppelter Kontingenz<, als die das Kunstwerk und die Arbeit der Komponistin bzw. des Komponisten begriffen werden kann, in der Interaktion realiter nachzuvollziehen (vgl. Orgass 2007a: 63-68 und ders. 2007b: 45-50). Diese Methode lässt sich nun so modifizieren, dass die Erprobungen jeweiliger Fortsetzungsmöglichkeiten a) ein immer größeres Eigengewicht erhalten und b) in zunehmendem Maße sich vom kompositorischen Regelwerk emanzipieren, dem das >ursprünglich $<$ hinsichtlich der zugrunde liegenden Entscheidungen zu rekonstruierende Werk gehorcht.

In diesem Prozess kann sich der Musikunterricht im Rahmen des Bereiches des Faches II der Lehrpläne Musik NRW 1999 »Musik erhält Bedeutung durch Interpretation « so auf die zentrale Tätigkeit der Interpretation beziehen, dass diese sich anfangs in argumentierender, auf Nachvollziehbarkeit bedachter und daher am Notentext aufweisender Deutung vollzieht. In zunehmendem Maße realisiert sie sich aber im Gruppenmusizieren, das sich um so weiter vom Werk entfernt, wie die Bedeutungen gleichsam >in Echtzeit< durch die Hervorbringung von Musik - den musikalischen > ̈̈ußerungen $>$ der jeweiligen Mitspielerinnen und Mitspieler zugewiesen und also auch nicht mehr argumentativ gestützt werden. Auf diese Weise kann sich eine auf eine Komposition bezogene Improvisation immer mehr zu einer freien Improvisation entwickeln. - Lehrhandlungen sind in der Endphase dieses Prozesses wiederum nicht am Platze, allerdings umso mehr nach Beendigung der freien Improvisation: im Zuge der Reflexion dessen, was sich in diesem Prozess vom Interpretieren über eine Phase mit »Kollektiv-Kompositions- 
Echtzeitcharakter « (Beins 2005: 10) ${ }^{25}$ bis zum freien Improvisieren zugetragen hat. Dabei können auch bedeutungstheoretische Perspektiven, je nach dem Entwicklungsstand der Sprach- und Begründungskompetenzen der Lernenden, aufgezeigt werden. In der Phase mit »Kollektiv-Kompositions-Echtzeitcharakter« können sich Lehrhandlungen auf die materiale Differenzierung der »Module« der individuellen Klangsprache wie auch auf die kompositorischen $»$ Echtzeit «-Entscheidungen beziehen.

\section{Freie Improvisation als Artikulation musikalischer Bildung? - Überlegungen zu einem verantwortlichen unterrichtlichen Umgang mit gesteigerter Kontingenz}

Durch die Thematisierung freier Improvisation im Unterricht wird nun nicht ohne weiteres musikalische Bildung ermöglicht. Denn zur Bestimmung des Begriffs musikalischer Bildung im Sinne der Kommunikativen Musikdidaktik (Orgass 2007a; ders. 2007b) gehört, dass sie Reflexivität in mehrfacher Hinsicht als Merkmal jener interaktiven Prozesse einfordert, in denen sich musikalische Bildung als soziale Kategorie verwirklicht. Musikalische Bildung realisiert sich in der Reflexivität der differenten - durch die einzelnen Interaktanten einzubringenden - Wertbezüge; Fragen zur Sozialität der jeweiligen benennbaren Bedeutungszuweisungen zur Artikulation des Materials einer Musik, der gesellschaftlichen Bezüge einer Musik und von deren Rezeption(sbedingungen) sollen beantwortet werden; das musikalisch gebildete Individuum verfügt über jene musikalischen, musikbezogenen, sprachlichen und begründungsrelevanten Kompetenzen, die es ihm ermöglichen, an den beschriebenen in-

25 Burkhard Beins versteht darunter die Modifikation von »Modulen« der individuellen Klangsprache durch Provokation (z.B. durch das Unterlassen einer Reaktion auf soeben durch andere Musiker Gespieltes) während der Improvisation. »Indem wir Improvisation im Sinne eines AufeinanderReagierens zulassen, erhalten wir genau dieses Element der provozierenden Reaktion, das in der Komposition sonst nicht möglich ist.« (Beins 2005: 10) Die Frage nach der Unterrichtbarkeit solcher Musik wurde bislang noch kaum gestellt. 
teraktiven Prozessen musikalischer Bildung teilzunehmen. Dies alles mag sich in Gruppenkompositionen mustergültig realisieren die musikalischen (und eben nicht bloß musikbezogenen) Prozesse freier Improvisation selbst sind nicht durch diese reflexiven Dimensionen, zumindest nicht in intersubjektiv nachvollziehbarer Weise, gekennzeichnet.

Vor dem Hintergrund eines bedeutungstheoretisch fundierten Begriffs musikalischer Bildung erscheint freie Gruppenimprovisation mithin als so etwas wie eine $>$ Residualkategorie $<$ Sie darf als Tätigkeit, in der musikalische Erfahrungen gemacht werden können, ein Nischendasein führen in einem Universum strukturell vergangenheitsbezogener Bedeutungen und Bedeutsamkeiten, die als Fluidum der Unterrichtskultur fungieren. Denn die Klangaktionen der anderen Improvisatoren, die gleichsam von der Zukunft her auf das Individuum zukommen und es möglicherweise auf existenziell relevante Weise mit etwas Neuem konfrontieren, können als Anlässe musikalischer Erfahrungen zwar - wie Bedeutungen und Bedeutsamkeiten - im Nachhinein zu Gegenständen der Reflexion und also thematisierbar werden; sie sind es aber nicht im Vollzug, also in ihrer Eigenschaft als Anlässe musikalischer Erfahrungen. Bestenfalls die Improvisationsübungen und musikalischen Spiele auf dem Weg zur freien Improvisation lassen sich als bildungsrelevante Praxen ausweisen, in denen musikbezogene Schemata modifiziert - im Sinne Earle Browns also > verflüssigt < bzw. flexibilisiert - werden.

Aber andererseits - und dies ist das Entscheidende - wird die Arbeit an der Erweiterung, Differenzierung und ggf. Korrektur musikbezogener Bedeutungs- und Bedeutsamkeitszuweisungen als das unterrichtsbezogen Intendierbare und Wägbare erst im Kontext des Nicht-Intendierbaren und Unwägbaren, das in freier Improvisation virulent wird, sinnvoll bzw. - emphatisch formuliert - menschenwürdig: Ein Musikunterricht, der die Nicht-Trivialität der von ihm bestenfalls positiv beeinflussten Lern- und Hervorbringungsprozesse aus dem Auge verlöre, würde nicht nur musikalische Bildung im erläuterten Sinne verhindern, sondern auch zum Dogmatisch-Totalitären verkümmern. Wenn aber die wägbaren musikbezogenen Lehrund Lernprozesse ihren Sinn und ihre - vor dem Hintergrund der geforderten und zu fordernden Erziehung zur Demokratie auch politisch zu durchdenkende - Legitimation erst durch die unwägbaren musikbezogenen Erfahrungs- und Bildungsprozesse erhalten (vgl. Orgass 2007c: 54ff.), ist dieser Sinn auch für die Trägerinnen und 
Träger jener Lehr- und Lernprozesse im Unterricht selbst erfahrbar zu machen, weil alle unterrichtlichen Tätigkeiten ansonsten von den Beteiligten als entfremdet erfahren würden. Eben diese Sinnerfahrung kann in freier Improvisation als einer hinsichtlich ihres Vollzugs nicht zu didaktisierenden, nicht unterrichtstechnologisch zu erfassenden Tätigkeit gemacht werden.

Das Prinzip der Improvisation wird in allen Interaktionen virulent, in denen z.B. Lehrende mit der Nicht-Trivialität der Lernprozesse ihrer Schülerinnen und Schüler improvisierend zurechtzukommen versuchen. Unterricht kann sich auf die Nicht-Trivialität von Bewusstseinen und also auch von Lernprozessen (vgl. von Foerster 1993: 245-252) in zwei Weisen beziehen, deren Unterschied sich an der jeweiligen Intention festmachen lässt. Zum einen kann die soziale Orientierung der Lernprozesse das Ziel des Umgangs mit jener Nicht-Trivialität sein, d.h. jene Kommunikation, durch die Bewusstseine in Kontakt miteinander treten können mit dem Ziel der Reduktion jener Komplexität, die durch die Anwesenheit vieler kognitiv autonomer Bewusstseine gegeben ist (vgl. Schmidt ${ }^{2}$ 1996; Luhmann 1988). Zum anderen können im Unterricht auch Freiräume für (musikalische) Äußerungen der Beteiligten eröffnet werden, in denen sich die Nicht-Trivialität von zuvor absolvierten Lernprozessen im >Ausspielen< »kognitiver Autonomie « zeigt. Die Steigerung von Komplexität im Sinne einer Vergrößerung jener Kontingenz, die sich aus der musikalischen Interaktion von Schülerinnen und Schülern im Rahmen von Gruppenimprovisationen ergibt, korrespondiert dann mit der Unmöglichkeit, die individuellen Kognitionen gleichzeitig mit dem Vollzug jener Improvisation in sozialer Orientierung kommunikativ zu thematisieren.

Vor bildungstheoretischem Hintergrund erscheint es alternativlos, beide genannten Umgangsweisen mit der Nicht-Trivialität von Lernprozessen bzw. von musikbezogenen Kognitionen im Unterricht ebenso aufeinander zu beziehen, wie Lehren und Lernen auf die Ermöglichung von musikalischer (bzw. musikalisch-ästhetischer) Erfahrung und musikalischer Bildung bezogen bleiben müssen. Diese didaktische Entscheidung ist mit Klaus Schaller als eine »restdogmatische « zu bezeichnen (Schaller 1987: 88f. und 240f.; ders. 1996: 2). Die basalen Werte, die dieser Entscheidung zugrunde liegen, hängen mit der Geschichte Europas zusammen: »Parteinahme für Gemeinsamkeit« und »Achtsamkeit auf andere und Anderes«, als die sich die bürgerlichen Werte Solidarität und Ge- 
rechtigkeit im Sinne von Schallers »Pädagogik der Kommunikation« reformulieren lassen. Hinsichtlich freier Gruppenimprovisation, aber auch mit Blick auf Improvisation als Eigenschaft des Musikunterrichts bezieht sich Achtsamkeit u.a. auf das NichtWägbare, auf Phänomene der Emergenz im Zuge musikalischer und musikbezogener Interaktion, also in Gruppenimprovisationen einerseits und bspw. im Rahmen der Deutung von reproduzierter Musik oder ästhetischer Kritik von produzierter Musik andererseits. Partei soll im Zusammenhang mit Gruppenimprovisation insbesondere für jene Gemeinsamkeit ergriffen werden, die sich in der von Wilson genannten »Meta-Kommunikation über das Wie musikalischer Verständigung « (Wilson 1999a: 14) herausschälen kann, und in musikbezogener Interaktion im erwähnten Sinne bezüglich jener Gemeinsamkeiten im Bereich der Bestimmung von Sachverhalten, aufgrund derer Differenzen in strittigen Themen überhaupt wahrnehmbar werden, ${ }^{26}$ sowie hinsichtlich anthropologischer Gegebenheiten, die sich in kulturell unterschiedlichen Ausprägungen artikulieren können. ${ }^{27}$

26 Manfred Frank erläutert: »Widersprüche können in Argumentationen, die logisch korrekt gebildet sind, überhaupt nur auftreten in Form divergierender Interpretationen von Sachverhalten, die als dieselben von verschiedenen Interlokutoren gemeint sind.« (Frank 1988: 92, hier die kursive Hervorhebung)

27 Vgl. Orgass 2007 und Rüsen 1998. Aus Rüsens Idee, die »Spezifik einer Kultur als Kombination von Elementen« zu verstehen, »die von allen anderen Kulturen ebenfalls geteilt werden, dort aber anders konstelliert sind « (a.a.O.: 49) könnten Konsequenzen für die >Rekonstruktion< unterschiedlicher Konzepte von Gruppenimprovisation, wie sie bzw. im Jazz, im Bereich der Neuen Musik seit den 60er Jahren in Europa und in Amerika (der Gegenstand vorliegender Arbeit) und in nordindischer Râgamusik gegeben sind, gezogen werden. 


\section{Literatur}

Adorno, Theodor W. $\left({ }^{6} 1982\right.$ [ $\left.\left.{ }^{1} 1956\right]\right)$ : $»$ Kritik des Musikanten«. (1954) In: ders., Dissonanzen. Musik in der verwalteten Welt, Göttingen: Vandenhoeck \& Ruprecht, S. 62-101.

Behne, Klaus-Ernst (1992): »Zur Psychologie der (freien) Improvisation«. In: Walter Fähndrich (Hg.), Improvisation, Winterthur: Amadeus, S. 42-62.

Beins, Burkhard (2005): [Gesprächsbeitrag in:] »Alte Fragen neu: Form und Inhalt. Ein Gespräch von Gisela Nauck mit Annette Krebs, Andrea Neumann, Serge Baghdassarians, Burkhard Beins und Axel Dörner«. In: Gisela Nauck (Hg.), Positionen. Beiträge zur Neuen Musik 62: echtzeitmusik, Berlin: Verlag Positionen, S. 8-13.

Biesenbender, Volker (1995): »Anders üben, anders hören, anders bewegen. Vom improvisierenden Umgang mit Musik«. In: Ringgespräch über Gruppenimprovisation LXI November, S. 38.

Boulez, Pierre (1985): »Zeit, Notation und Kode». (1980) In: ders., Musikdenken heute 2, hg. von Ernst Thomas (Darmstädter Beiträge zur Neuen Musik VI), Mainz: B. Schott's Söhne, S. 63-69.

Brandl, Rudolf M. (1998): »Ein ethnosemiotischer Ansatz zum $>$ Kontext als Text< aus musikanthropologischer Sicht «. In: Hermann Danuser und Tobias Plebuch (Hg.), Musik als Text. Bericht über den Internationalen Kongress der Gesellschaft für Musikforschung, Freiburg i. Br. 1993 Bd. 1, Kassel: Bärenreiter, S. 234-245.

Brodbeck, Karl-Heinz (1995): Entscheidung zur Kreativität. Darmstadt: Wissenschaftliche Buchgesellschaft.

Brown, Earle (1961): »Prefatory Note« zu »December 1952«. In: ders. (Hg.), Folio (1952/53) and 4 Systems, New York: Associated Music Publishers, Inc.

Brown, Earle (1996): [Gespräch mit John Yaffé, im Booklet der CD:] Earle Brown: Music For Piano(s) 1951-1995. David Arden, Pianist. Castro/San Francisco: New Albion Records NA 082CD, ohne Seitenangabe.

Dahlhaus, Carl (1977): Grundlagen der Musikgeschichte. Köln: Musikverlag Hans Gerig.

Dahlhaus, Carl (2000): »Was heißt Improvisation?« (1979) In: ders., Allgemeine Theorie der Musik I: Historik - Grundlagen 
der Musik - Ästhetik, hg. von Hermann Danuser in Verbindung mit Hans-Joachim Hinrichsen und Tobias Plebuch (Gesammelte Schriften in 10 Bänden, Band 1), Laaber: Laaber, S. 405-417 und S. 643f.

Dewey, John (1980 [1934]): Kunst als Erfahrung. Frankfurt a.M.: Suhrkamp.

Eckhardt, Rainer (1995): »Improvisation in der Musikdidaktik. Eine historiographische und systematische Untersuchung«. In: Rudolf-Dieter Kraemer (Hg.), Forum Musikpädagogik Band 16, Augsburg: Wißner.

Faltin, Peter (1985): »Bedeutung ästhetischer Zeichen. Musik und Sprache«. In: Achim Eschbach u.a. (Hg.), Aachener Studien zur Semiotik und Kommunikationsforschung Band 1, Aachen: Rader.

Foerster, Heinz von (1993): »Prinzipien der Selbstorganisation im sozialen und betriebswirtschaftlichen Bereich«. In: ders., Wissen und Gewissen. Versuch einer Brücke, aus dem Amerikanischen übersetzt von Wolfram Karl Köck, Frankfurt a.M.: Suhrkamp, S. 233-268.

Frank, Manfred (1988): Die Grenzen der Verständigung. Ein Geistergespräch zwischen Lyotard und Habermas. Frankfurt a.M.: Suhrkamp.

Globokar, Vinko (1971): »Vom Reagieren«. In: Melos 2, S. 59ff.

Joas, Hans (1996 [ [1992]): Die Kreativität des Handelns. Frankfurt a.M.: Suhrkamp.

Kieserling, André (1999): Kommunikation unter Anwesenden. Studien über Interaktionssysteme. Frankfurt a.M.: Suhrkamp.

Kloppenburg, Josef (2002): »Pädagogische Musik als ästhetisches Konzept. Neue Musik und musikalische Praxis in der Schule «. In: Rudolf-Dieter Kraemer (Hg.), Forum Musikpädagogik Band 52, Augsburg: Wißner.

Kühn, Clemens ( $\left.{ }^{2} 1995\right)$ : »Form «. Musik in Geschichte und Gegenwart, zweite neubearbeitete Ausgabe, Sachteil, Band 3, Sp. 607643.

Lehrpläne Musik NRW (1999): Richtlinien und Lehrpläne für die Sekundarstufe II - Gymnasium/Gesamtschule in NordrheinWestfalen. Musik (1999). Hg. vom Ministerium für Schule und Weiterbildung, Wissenschaft und Forschung des Landes Nordrhein-Westfalen, Frechen: Ritterbach. 
Luhmann, Niklas (1988): »Wie ist Bewusstsein an Kommunikation beteiligt? «In: ders. ${ }^{2} 2005$ ( $\left.{ }^{1} 1995\right)$, Soziologische Aufklärung 6: Die Soziologie und der Mensch, Wiesbaden: Verlag für Sozialwissenschaften, S. 38-54.

Luhmann, Niklas (1997 [ $\left.\left.{ }^{1} 1995\right]\right):$ Die Kunst der Gesellschaft. Frankfurt a.M.: Suhrkamp.

Markowitz, Jürgen (1979): Die soziale Situation. Entwurf eines Modells zur Analyse des Verhältnisses zwischen personalen Systemen und ihrer Umwelt. Frankfurt a.M.: Suhrkamp.

Markowitz, Jürgen (1986): Verhalten im Systemkontext. Zum Begriff des sozialen Epigramms. Diskutiert am Beispiel des Schulunterrichts. Frankfurt a.M.: Suhrkamp.

Motte-Haber, Helga de la (Hg.) (2004): Musikästhetik (Handbuch der Systematischen Musikwissenschaft Band 1). Laaber: Laaber Verlag.

Musik um uns, 11.-13. Schuljahr (1983), 2., überarbeitete und erweiterte Auflage, hg. von Bernhard Binkowski et al., Stuttgart: J. B. Metzlersche Verlagsbuchhandlung.

Musik um uns. Sekundarbereich II (1996), hg. von Ulrich Prinz et al., Hannover: Metzler.

Orgass, Stefan (1995): »Vermittlung kategorialer Bildung durch Formanalyse im Musikunterricht der Sekundarstufe II? Zur musikdidaktischen Relevanz der bildungstheoretischen Konzeption Wolfgang Klafkis«. In: Peter W. Schatt (Hg.), Form und Kultur. Studien zur musikalischen Bildung. Folkwang-Texte Band 11, Essen: Die Blaue Eule, S. 119-178.

Orgass, Stefan (2007): Musikalische Bildung in europäischer Perspektive. Entwurf einer Kommunikativen Musikdidaktik. Hildesheim et al.: Olms.

Orgass, Stefan (2007a): »Musikalische Bildung aus bedeutungsund interaktionstheoretischer Sicht«. In: Andreas Jacob (Hg.), Musik - Bildung - Textualität, Erlangen: Universitätsbund Erlangen-Nürnberg, S. 37-110.

Orgass, Stefan (2007b): Musikalische Bildung aus bedeutungs-, interaktions- und situationstheoretischer Sicht. In: ders. 2007, S. 9-123.

Orgass, Stefan (2007c): »Unwägbarkeit als Bedingung musikalischer Bildung «. In: Johannes Bilstein/Bettina Dornberg/ Winfried Kneip (Hg.), Curriculum des Unwägbaren. I. Ästhetische Bildung im Kontext von Schule und Kultur (Pädagogik: 
Perspektiven und Theorien, Band 8), Oberhausen: Athena, S. 45-65.

Ortland, Eberhard (2004): »Genieästhetik«. In: Helga de la MotteHaber (Hg.), Musikästhetik (Handbuch der Systematischen Musikwissenschaft Band 1), Laaber: Laaber Verlag, S. 263-285.

Ribke, Juliane (1999): »Spielpläne. Zur Improvisation«. In: Üben \& Musizieren 2/1999, S. 14-21.

Rora, Constanze (2001): »Ästhetische Bildung im Musikalischen Gestaltungsspiel«. In: Rudolf-Dieter Kraemer (Hg.), Forum Musikpädagogik Band 46, Augsburg: Wißner.

Rüsen, Jörn (1998): »Theoretische Zugänge zum interkulturellen Vergleich historischen Denkens«. In: ders. et al. (Hg.), Die Vielfalt der Kulturen. Erinnerung, Geschichte, Identität 4, Frankfurt a.M.: Suhrkamp, S. 37-73.

Sanio, Sabine (2004): »Erfahrung statt Vergegenständlichung. Zum Begriff der Situation in der gegenwärtigen Ästhetik«. In: Helga de la Motte-Haber (Hg.), Musikästhetik (Handbuch der Systematischen Musikwissenschaft Band 1), Laaber: Laaber Verlag, S. 355-372.

Saxer, Marion (2004): »Die Entdeckung der >inneren Stimme< und die expressive Kultur«. In: Helga de la Motte-Haber (Hg.), Musikästhetik (Handbuch der Systematischen Musikwissenschaft Band 1), Laaber: Laaber Verlag, S. 300-329.

Schaller, Klaus (1987): Pädagogik der Kommunikation. Annäherungen - Erprobungen. Sankt Augustin: Hans Richarz.

Schaller, Klaus (1996): »Achtsamkeit auf andere und anderes«. Musik \& Bildung. Praxis Musikerziehung 28. (87.) Jahrgang, Heft 3 Mai/Juni 1996, S. 2.

Schmidt, Dörte (2000): »Schrift - Graphik - Bild. Zur Notation in Earle Browns December 1952 und dem Zyklus Folio«. In: Wolfgang Budday (Hg.), Musiktheorie. Festschrift für Heinrich Deppert zum 65. Geburtstag, Tutzing: Hans Schneider, S. 183207.

Schmidt, Siegfried J. $\left({ }^{2} 1996\right.$ [ $\left.\left.{ }^{1} 1994\right]\right)$ : Kognitive Autonomie und soziale Orientierung. Konstruktivistische Bemerkungen zum $\mathrm{Zu}$ sammenhang von Kognition, Kommunikation, Medien und Kultur. Frankfurt a.M.: Suhrkamp.

Schulz, Wolfgang (1997): Ästhetische Bildung. Beschreibung einer Aufgabe. Hg. von Gunter Otto und Gerda Luscher-Schulz, Weinheim und Basel: Beltz. 
Schwab, Alexander (1991): Improvisation und Komposition im Musikunterricht allgemeinbildender Schulen der Sekundarstufe I. Ein Beitrag zur pädagogischen Elementarisierung ausgewählter Ansätze in der Neuen Musik nach 1945. Frankfurt a.M.: Peter Lang.

Seel, Martin (1996): »Ästhetik und Aisthetik«. In: ders., Ethischästhetische Studien, Frankfurt a.M.: Suhrkamp, S. 36-69.

Sutter, Tilmann (1997): »Rekonstruktion und doppelte Kontingenz. Konstitutionstheoretische Überlegungen zu einer konstruktivistischen Hermeneutik«. In: ders., Beobachtung verstehen, Verstehen beobachten. Perspektiven einer konstruktivistischen Hermeneutik, Opladen: Westdeutscher Verlag, S. 303-336.

Vogt, Hans $\left({ }^{3} 1982\left[{ }^{1} 1972\right]\right):$ Neue Musik seit 1945. Stuttgart: Philipp Reclam jun.

Wallbaum, Christopher (2000): »Produktionsdidaktik im Musikunterricht. Perspektiven zur Gestaltung ästhetischer Erfahrungssituationen«. In: Siegmund Helms und Reinhard Schneider (Hg.), Perspektiven zur Musikpädagogik und Musikwissenschaft Band 27, Kassel: Bosse.

Wilson, Peter Niklas (1999): Hear and Now. Gedanken zur improvisierten Musik. Hofheim: Wolke.

Wilson, Peter Niklas. (1999a): »Improvisation - Stichworte zu einer flüchtigen Kunst«. In: ders., Hear and Now. Gedanken zur improvisierten Musik. Hofheim: Wolke, S. 1-26.

Wingert, Lutz (2001): »Epistemisch nützliche Konfrontation mit der Welt?« In: ders./Klaus Günther (Hg.), Die Öffentlichkeit der Vernunft und die Vernunft der Öffentlichkeit. Festschrift für Jürgen Habermas, Frankfurt a.M.: Suhrkamp, S. 77-105. 



\title{
VOM SINN DER IMPROVISATION ALS SPIEL CONSTANZE RORA
}

\author{
Spiele einen Ton \\ Höre auf, wenn Du spürst, dass Du aufhören sollst. \\ Und immer so weiter. \\ Ob Du aber spielst oder aufhörst, \\ höre immer den anderen zu. \\ Probe nicht. \\ Karlheinz Stockhausen
}

\section{Sinnzuschreibungen}

Die Rede von Improvisation ist nicht selten verbunden mit Erwartungen und Wertungen, die es rechtfertigen, von einem $>$ Mythos der Improvisation< zu sprechen (Erwe 2004). Im argumentativen Kontext dieser hohen Wertschätzung erscheint Improvisation als ein musikalisches Ereignis, das spontan und unwiederholbar, also einmalig gestaltet wird und das von Kommunikation der Ausführenden untereinander und mit dem Publikum bestimmt ist.

Den Charakter mythischer Verklärung hat dabei zweifellos die Vorstellung, Improvisation sei »voraussetzungslose Entwicklung musikalischer Kreativität« (Erwe 2004: 181), da sie verkennt, dass die Improvisation in einem Idiom (wie dem Jazz) immer Übung und Spieltechnik voraussetzt.

Daran anknüpfend stellt sich die Frage, ob es eine nicht-idiomatische (>non-idiomatic $<$ ) Improvisation geben kann, wie dies von Vertretern des Freejazz und der freien Improvisation proklamiert wird. Während Erwe diesbezüglich skeptisch bemerkt, »ob nicht auch der Freejazz - trotz aller gegenteiliger Bekundungen dazu tendiert, wiederum ein eigenes musikalisches Idiom auszuprägen, einen Stil, an dem sich die Improvisationen ausrichten« (Erwe 
2004: 185), plädiert Peter Niklas Wilson dafür, an dem Begriff einer nicht-idiomatischen Improvisation festzuhalten. Er hebt die Individualität improvisatorischer Idiome hervor, deren Addition in der Gruppenimprovisation unvorhersehbare Ergebnisse schafft:

»Die Vorstellung einer >nicht-idiomatischen< (non-idiomatic) Musik [...] meinte nicht das Neu-Erfinden des eigenen Spiels bei jedem Anlaß, die permanente tabula rasa, sondern zielte auf das vorab Unkategorisierbare des Zusammentreffens mehrerer Musiker, die ihre eigenen, oft inkompatiblen Sprachen sprechen. Mag auch jeder sein persönliches Idiom mitbringen, so ist das kollektive Ergebnis doch keineswegs vorprogrammiert.«(Wilson 1999: 18)

Aus seiner Sicht ist die freie Improvisation somit durchaus eine Situation, in der aus dem Augenblick heraus unmittelbar etwas Neues, Einmaliges > kreiert< wird.

Die folgenden Überlegungen zur Funktion der freien Improvisation in pädagogischen Kontexten lehnen sich an Wilsons >Gedanken zu improvisierter Musik griff bringt die Improvisation in Zusammenhang mit Selbstausdruck und Kommunikation. In der Improvisation als einer subjektgebundenen Sprechweise - so die implizite These - äußert sich über die musikalische Gestaltung hinaus bzw. mit ihr die Persönlichkeit des Improvisators. Wilson bringt deshalb an anderer Stelle Improvisation mit Sprache und Lebenshaltung zusammen: »Improvisation ist eine Lebenshaltung, eine Sprache mit individuellen Vokabularen. Die Wörter haben sich verfestigt, doch es lassen sich noch neue Sätze bilden.«(Wilson 1999: 11)

Wie die bei Wilson in Gesprächen erfassten Äußerungen improvisierender Musiker zeigen, liegt die Motivation für ihre musikalische Tätigkeit zu nicht unwesentlichen Teilen in diesen kommunikativen Aspekten, die als Bereicherung für das persönliche Leben auch außerhalb der musikalischen Praxis gesehen wird. Bezüge zwischen Kunst und Leben werden von den Improvisatoren vielfältig angesprochen und reichen von Statements zu den Möglichkeiten sozialen Lernens, zur Persönlichkeitsentwicklung bis zu Hinweisen auf biographische Konstellationen, die sich aus oder mit der Improvisation entwickelt haben.

So äußert sich der Saxophonist Evan Parker in einem Interview mit Wilson über Lernprozesse beim Improvisieren: 
»Man muß auch eine Fähigkeit entwickeln, potentiell verletzende Erfahrungen zu verarbeiten. Es muß einen Willen geben, der spürt, dass die Fortsetzung der musikalischen Koexistenz wichtiger ist als jede andere Überlegung. Man muß lernen, sich auf die Eigenarten und Schwächen der anderen einzustellen, und das bedarf einer bestimmten charakterlichen Einstellung.«(Parker in Wilson 1999: 126)

Der Schlagzeuger Tony Oxley betont die Bedeutung der Improvisation für die Entwicklung der Persönlichkeit:

»Ich glaube, dass man lange suchen müsste, um ein Medium oder eine Ausdrucksform zu finden, die Dir so viel Freiheit erlaubt wie die Improvisation, was die Möglichkeit angeht, das zu finden, was Deiner eigenen Persönlichkeit entspricht, und daran ernsthaft zu arbeiten.«(Oxley in Wilson 1999: 140)

Und der Pianist Paul Bley hebt bezogen auf seine biographische Situation in den 60er/70er Jahren die Einheit von musikalischem und privatem Zusammenwirken hervor:

»Carla und Annette sind zwei Frauen, mit denen ich je sieben Jahre zusammengelebt habe, und da ließ sich dann kaum noch trennen, welche Idee von wem kam. Wir tauschten unsere musikalischen Gedanken aus, und unsere Wohnung war eine wahre Brutstätte musikalischer Ideen. Ständig kamen Musiker vorbei, und wir diskutierten über die Zukunft des Jazz, der sich damals in den Sechzigern so rasend schnell veränderte. Wir konnten uns also am Mittwoch etwas ausdenken, am Donnerstag auftreten, am Freitag eine Platte machen, und am Samstag waren wir bereit, eine neue Bewegung zu gründen.«(Bley in Wilson 1999: 163)

Die Annahme eines Zusammenhangs von Kunst und Leben, d.h. der Gedanke, dass Improvisation über die musikalische Situation hinaus einen Einfluss auf die alltägliche Lebensgestaltung und -bewältigung des Improvisierenden hat, ist eine vielfach anzutreffende wiederkehrende Grundbehauptung, die zu dem >Mythos Improvisation< beiträgt und für die Begründung von Improvisation in der Musikpädagogik keine unwichtige Rolle spielt. ${ }^{1}$

1 Ähnlich äußert sich Vinco Globokar: »[Der improvisierende Musiker, d.V.] bereichert sich ständig durch Experimente, lernt zu reagieren, zu erfinden, Initiative zu ergreifen, sich beeinflussen zu lassen, die ganze Verantwortung 


\section{Erwartungen an die freie Improvisation in der Musikpädagogik}

Auf die freie Improvisation wird seit den 70er Jahren in der Musikpädagogik immer wieder Bezug genommen. Insbesondere ihre kommunikativen Aspekte weisen die freie Improvisation als besonders geeignetes Verfahren für den Musikunterricht aus. So stellt Lilli Friedemann das Musizieren von Jugendlichen im Rahmen einer Orchesterprobe dem Musizieren in einem Improvisationsensemble gegenüber, um zu verdeutlichen, wie viel mehr an Selbstbestimmung und intrinsischer Motivation im zweiten Fall zum Tragen kommt:

»Die erste Art: [...] Die Spieler sitzen dem Dirigenten zugewandt; hierdurch und durch die Notenpulte sind die Kontaktmöglichkeiten unter den Spielern erheblich vermindert. Der Beginn des Musizierens wird durch den Dirigenten bestimmt. Man spielt und rechnet damit, dass der Dirigent öfter abklopft, um etwas zu korrigieren. [...]

Die zweite Art: [...] Binnen kurzem ist eine Improvisation in konzentrierter Kommunikation unter allen Beteiligten im Gang. Man weiß kaum, wann sie begann, und noch weniger, wie lange sie dauern wird. Es gibt weder Plan noch Anführung, weder Worte noch Reflexionen verbaler Art, nur ein musikalisches Gespräch, besser gesagt: einen $\mathrm{Zu}-$ sammenschluss aller Spieler zu einer klingenden Aussage.« (Friedemann 1974: 16)

Indem die Improvisationssituation als Gruppensituation über die musikalische Gestaltung hinaus reflektiert wird, deutet sich ein Argumentationszusammenhang an, der die Zielperspektiven des Verfahrens der freien Improvisation in musikpädagogischen Kontexten betrifft. Eckhardt, der die Vielfalt musikdidaktischer Improvisationsansätze umfassend sichtet, unterscheidet vier Gruppen außermusikalischer Funktionen, die in neueren Ansätzen mit Improvisation im Unterricht verbunden werden (vgl. Eckhardt 1995: 237ff.): 
- Kreativierende Funktionen: Die musikpädagogischen Erwartungen richten sich auf die Aneignung und Steigerung einer allgemeinen Fähigkeit zur Kreativität. Anhand des Improvisierens sollen Fähigkeiten zum problemlösenden Denken, zur Umstrukturierung, zur Entdeckung von Neuem etc. entwickelt werden.

- Soziale Funktionen: In diesem umfassenden Funktionsbereich werden von Eckhardt noch Untergruppen unterschieden. Zum einen wird die Bedeutung von Improvisation für die Verbesserung von Selbstwahrnehmung, Selbstbewertung, und Selbsterkenntnis des improvisierenden Schülers hervorgehoben (IchFunktion). Zweitens wird auf die in der Improvisation zu entwickelnde Fähigkeit zur Interaktion hingewiesen. Drittens wird auf die Entwicklung von Gruppensensitivität verwiesen und schließlich wird viertens auf die Dimension einer utopischen Funktion hingewiesen, innerhalb derer Gruppenimprovisation als Modell demokratischen Verhaltens aufgefasst wird.

- Rekonvaleszenzfunktionen: In den hierzu gehörenden Argumentationslinien wird davon ausgegangen, dass Improvisieren als eine Form ganzheitlichen Handelns die Entwicklung der >gesunden< ausgeglichenen Persönlichkeit fördert.

- Unterrichtsoptimierende Funktionen: Unter dieser Funktion finden sich bei Eckhardt die Bestrebungen von musikpädagogischen Ansätzen, die die Improvisation in ihrer humanisierenden motivierenden Wirkung als wichtiges Element des Unterrichts zur institutionellen Bedingungen von Schule auffassen.

Die Verbindung von Improvisation mit außermusikalischen Zielsetzungen, die zu nicht unwesentlichen Anteilen aus den Erfahrungen von Musikern mit freier Improvisation abgeleitet werden, ist aus verschiedenen Gründen problematisch. Abgesehen davon, dass Transfereffekte musikalischer Improvisation bisher nur unzureichend empirisch bestätigt werden konnten, stellt sich die Frage, welchen Einfluss die jeweilige musikalische Qualität der musikpädagogisch initiierten Improvisationen auf die Erfüllung der hochgesteckten Erwartungen hat. Lilli Friedemann sieht in der Vernachlässigung des musikalischen Qualitätsanspruchs das Eintreten positiver außermusikalischer Effekte gefährdet:

»Als Persönlichkeitsverwirklichung werden oft schon die simpelsten Improvisationsbeiträge hierin Unerfahrener angesehen, unabhängig da- 
von, wieweit die Improvisierenden in geistiger Hinsicht entwickelt und zu Differenzierungen fähig sind. Daß sich mit der neuen Musik auch eine Art neuer Sprache entwickelt und Versuche, ohne vorausgehende musiksprachliche Übungen und Klärungen gemeinsam frei zu improvisieren, nur eine vage und undifferenzierte Form der musikalischen Kommunikation bedeuten können, wird dabei nicht erkannt. Auch wird häufig übersehen, dass gerade die von jungen Menschen neu postulierten Werte wie Kreativität, Sensibilisierung, geistige Selbständigkeit, musikalische Mündigkeit und nicht zuletzt soziale Einordnung bei einer lediglich als Befreiung von Zwängen und Aggressionen aufgefassten Gruppenimprovisation niemals entwickelt werden können. [...] Sobald die Faszination des Neuen wegfällt und die musikalische Freiheit zur Gewohnheit geworden ist, ohne dass sich dafür in sachlicher Beziehung etwas erkennbar Neues auftut, schlägt die Begeisterung leicht in klägliche innere Leere um.« (Friedemann 1973: 8)

Auch Gertrud Meyer-Denkmann stellt pädagogisch motivierte Improvisationspraktiken hinsichtlich ihres ästhetischen Anspruchs in Frage. Dabei setzt sie den Begriff des Spiels als Gegenbegriff zur Improvisation ein, indem sie die kritisierten Praktiken als >Spielkonzepte< brandmarkt, die hauptsächlich zur Illustration von Bildern und Geschichten angewendet werden:

»Diese Vorliebe für musikalische Bildbeschreibungen scheint auf jene Ratlosigkeit hinzuweisen, die nicht weiß, was denn nun mit all den neuen Klangexperimenten und improvisatorischen Freiheiten anzufangen sei, Freiheiten, die sich weder an einer üblichen Melodik und Harmonik, einem durchgehenden Beat noch am beliebten Blues-Schema orientieren wollen. Sollen Improvisationen aber über eine musische Spielbetulichkeit und ein >anything goes< hinausgehen, müssen allerdings ihre musikpädagogischen Funktionen, ihre adäquaten Klangorganisationen und schülerbezogenen Anwendungsbereiche reflektiert werden. « (Meyer-Denkmann 1996: 32)

In beiden Fällen wird an pädagogisch motivierten Improvisationspraktiken kritisiert, dass sie nicht ernsthaft, gründlich, sorgfältig genug den musikalischen Ansprüchen der Situation begegnen. Vielmehr wird festgestellt, dass die außermusikalischen Intentionen die musikalischen überlagern und hinsichtlich der musikalischen Gestaltung eine gewisse Anspruchslosigkeit zu beobachten ist. 


\section{Nähe zum Kinderspiel}

Während die Bezugnahme auf das Spiel bei Meyer-Denkmann eher ablehnend erfolgt, und sie eine deutliche Differenz zwischen $>$ Spielbetulichkeit< und >adäquater Klangorganisation< sieht, hebt Friedemann bei ihrer positiven Bezugnahme auf den Spielbegriff die Nähe von Improvisation zu kindlicher Spieltätigkeit hervor. In ihrer Darstellung einer Unterrichtssequenz mit Fünfjährigen erscheint Improvisation als Form des Kinderspiels, zu der kleine Kinder einen quasi naturwüchsigen Zugang haben:

»In der dritten Phase der Musikstunde dürfen sie zum ersten Mal in ihrem Leben an Xylophone und Glockenspiele herangehen und darauf, mit Schlegeln in beiden Händen, klingende Glocken darstellen. Sie werden von niemandem dirigiert, beginnen neugierig alle zugleich, begleiten ihr Spiel mit Jubeln und Lachen und spielen weiter und weiter. Da die Leiterin der Musikstunde es als roh empfände, dieses Musizieren abzubrechen, will sie abwarten, bis die Kinder von selbst aufhören. Aber dies erweist sich als hoffnungslos; die Kinder hören einfach nicht mehr auf.« (Friedemann 1974: 17)

In diesem Beispiel rückten die spontane Reaktion der Kinder auf das Instrumentarium und ihre Unermüdlichkeit das improvisatorische Geschehen in die Nähe des Kinderspiels. Entsprechend ihrer Überzeugung von der Verwandtschaft zwischen Spiel und Improvisation und der Möglichkeit durch die Vorgabe von Spielregeln das Improvisieren von Kindern und musikalischen Laien ästhetisch befriedigend zu gestalten, beschreibt Friedemann viele ihrer Anleitungen zu Improvisationen als Spiele.

Einen engen Bezug zwischen Spiel und Improvisation sehen auch Herwig von Kieseritzky und Matthias Schwabe. ${ }^{2}$ In ihren Erläuterungen zu den Möglichkeiten, Grundschüler mithilfe von Spielvorschlägen zu Gruppenimprovisation anzuleiten, heben Kieseritzky und Schwabe die Voraussetzungslosigkeit als Merkmal und besonderen Vorzug der freien Gruppenimprovisation hervor:

»Klänge und Geräusche lassen sich ohne Vorkenntnisse im Experiment entdecken und musikalisch handhabbar machen. Dadurch entfällt das

2 Schwabe gibt seinem improvisationspädagogischen Ansatz den Titel: Musik spielend erfinden (Schwabe 1992). 
leidige Problem der Vermittlung komplizierter Instrumentaltechnik. Klangmöglichkeiten aufzufinden wird vielmehr zu einem lustvollen Prozess.«(Kieseritzky/Schwabe 2001: 112)

Der hier von der Seite musikpädagogischer Reflexion hervorgehobene Aspekt der Voraussetzungslosigkeit weist auf den vielleicht markantesten Unterschied zwischen der improvisierenden Tätigkeit von Kindern und dem Improvisieren von Musikern hin. Die Freiheit von Vorgaben im Sinne tradierter Strukturen, klischeehafter Wendungen ist für die Musiker >freier Improvisation dezidiertes Ziel. Dennoch weisen sie in den Gesprächen mit Wilson auf die Notwendigkeit des Übens und des musikalischen Arbeitens hin. So wendet sich Tony Oxley zum Beispiel gegen die Missverständnisse, die das Wort >frei< umgeben:

»Es gibt eine Menge Dinge, die ich nicht tue, und andere Dinge, die ich sehr wohl tue. Diese Dinge werden von mir bewusst gewählt, und ich habe viele Jahre an ihnen gearbeitet. Daher kann ich mich mit der Bedeutung, die das Wort >free $<$ schließlich angenommen hat, nicht identifizieren, da sie dem Ausmaß von Arbeit und Reflexion, die in der Musik steckt, die ich spiele, nicht gerecht wird.«(Oxley in Wilson 1999: 140)

Gegen ein falsch verstandenes Attribut der Freiheit wendet sich auch der niederländische Komponist und Improvisator Misha Mengelberg, der die Möglichkeit >freier< Musik grundsätzlich bezweifelt und davon ausgeht, dass das Maximum an Freiheit erreicht ist, wenn der Improvisierende seine Beschränkung sieht und daraus seinen eigenen Spielraum ableitet. Im günstigen Fall ist er nur an seine eigenen Spielregeln gebunden, die er auch wechseln kann (vgl. Wilson 1999: 151).

Während die Improvisatoren einerseits das Durchbrechen von Strukturen, d.h. die Überwindung traditioneller Improvisationsstile intendieren und als Ausdruck persönlicher musikalischer Entwicklung sehen sowie die Offenheit des Improvisationsprozesses als Wert hervorheben, weisen sie andrerseits darauf hin, dass Üben und musikalische Arbeit als Voraussetzung notwendig sind. Auch die freie oder $>$ befreite< Improvisation ist somit nicht voraussetzungslos bzw. strebt nicht zwangsläufig Voraussetzungslosigkeit an.

Dies führt zu der Frage, ob und wie sich Musiker auf die Improvisation vorbereiten, wie sie üben. Derek Bailey unterscheidet ver- 
schiedene Arten des Übens. Neben dem allgemeinen Üben auf dem Instrument stellt er »eine Art des Übens, die mit Improvisation zu tun hat «, die das Ziel hat »mehr Gewandtheit in der Sprache zu erreichen, in der man gerade spricht.« (vgl. Wilson 1999: 108) Ähnlich beschreibt Alexander von Schlippenbach das Üben für die Improvisation:

»Ich habe bestimmte Positionen für beide Hände auf dem Klavier gefunden, in denen Sechstonreihen möglich sind, die ich dann in Akkordfolgen herausgeschrieben habe. [...] Ich will natürlich nicht einige festliegende Dinge immer wieder spielen, sondern ich will dieses Material, das ich da in den Fingern habe - das wird ja da sozusagen gespeichert parat haben, um damit wiederum in vollkommen unterschiedlichen Konstellationen, unterschiedlichen Tempi, unterschiedlichen Lagen und auch Zusammenhängen improvisieren zu können. [...] Ein freies Verfügen über das Material, das man sich erst erarbeiten muß.« (von Schlippenbach in Wilson 1999: 148)

In pädagogischen Kontexten geht die Improvisation vergleichsweise voraussetzungslos vonstatten. Entsprechend tritt die Eingrenzung der improvisatorischen Freiheit durch das Vorhandensein eingeübter Muster nicht als Problem in Erscheinung. Allerdings bedarf es im Allgemeinen der Anleitung durch Gestaltungsaufgaben, um eine Improvisation zu initiieren bzw. ein Umschlagen von der Freude an den freien Gestaltungsmöglichkeiten in >Leere< zu verhindern (s.o. Zitat Friedemann 1973: 8).

Es scheint angesichts dieser Gegenläufigkeit der Perspektiven gerechtfertigt davon zu sprechen, dass Schüler und Musiker das Reich der freien Improvisation durch zwei einander diametral entgegengesetzte Türen betreten: Die Musiker von der Seite konventioneller Strukturen, die sie überwinden wollen, die Kinder und Jugendlichen von der Seite eines Defizits an Vorkenntnissen und instrumentalen Spieltechniken.

Ausgehend von der Annahme zweier Pole, von denen aus Laien und Musiker sich der freien Improvisation annähern, entsteht die Frage, inwiefern es sinnvoll ist, eine prinzipielle Vergleichbarkeit der Erfahrungsmöglichkeiten von Schülern und Musikern in der freien Improvisation anzunehmen. Sind wir berechtigt davon auszugehen, dass sich Kinder und Jugendliche bei der Realisierung von Improvisationsaufgaben als ausdrucksvoll und kommunikativ erfahren? Ist ihre spontane musikalische Gestaltung >Spiegel der Persön- 
lichkeit<, wie Wilson dies mit Blick auf einen ausgeprägten Personalstil von der Improvisation bekannter Musiker behauptet? (Wilson: 1999: 11)

Die Vergleichbarkeit ebenso wie die Unterschiede zwischen der Improvisation von Laien und geübten Improvisatoren lassen sich darstellen, wenn man sie unter dem Begriff des Spiels analysiert. Das Spiel ist eine Form menschlichen Handelns, die nicht auf das Kindesalter beschränkt ist. Auch Erwachsene spielen. Wie die improvisationspädagogischen Bezugnahmen auf den Spielbegriff zeigen, verläuft der Übergang zwischen Spiel und Improvisation fließend, wobei auch gerade das Alter der Spielenden oder Improvisierenden keinen Hinweis darauf gibt, welcher Begriff der Situation angemessener ist.

\section{Verwandtschaft zwischen Improvisation und Spiel}

Der Entwicklungspsychologe Rolf Oerter gibt auf der Grundlage allgemeiner Spieltheorien sowie empirischer Untersuchungen des Kinderspiels eine handlungstheoretische Beschreibung des Spiels. Ausgehend von den beiden grundlegenden Merkmalen jeder Handlung - Intention und Gegenstandsbezug - kommt er zu drei Merkmalen, die für das Spiel als besondere Art des Handelns kennzeichnend sind: Wiederholung, Zweckfreiheit und Wechsel des Realitätsbezugs. Diese drei Merkmale sind kennzeichnend für das Spiel im Allgemeinen und werden von Oerter anhand von Beobachtungen des Kinderspiels konkretisiert (vgl. Oerter 1997).

\section{Wiederholung}

Das Kleinkind, das immer wieder ein Spielzeug aus dem Kinderwagen wirft und aufheben lässt, freut sich an der Wiederholung des Effekts, den es produziert. In dem Bewirken dieses Effekts liegt die Motivation für sein Spiel. Oerter sieht in der Intention, einen Effekt zu erzielen und zu wiederholen, ein Merkmal des Spiels in allen Altersgruppen. Die Eigenart des Spiels, immer neue Wiederholungen hervorzubringen, findet ihre negative Ausprägung in dem Phänomen der Spielsucht. Durch sie kann das Spiel zu einem lebensbe- 
drohlichen Medium werden, indem der Spielende über das Spiel seine soziale Realität vergisst.

»Die Freude am Effekt gibt es in allen Altersstufen, besonders im Zusammenhang mit der Meisterung von Leistungen. So will man immer wieder Bewegungsabläufe, die einen Erfolg zeitigen, durchführen: mit dem Tennisschläger den Ball übers Netz bringen, den Fußball ins Tor schießen, die Kugel in einem Geschicklichkeitsspiel zum Endpunkt befördern. Viele Partnerspiele der frühen Kindheit führen erst bei längerem Anlauf zum Effekt, sie steigern die Spannung bis zu einem Höhepunkt, dem ein plötzlicher Abfall folgt (Hoppe-hoppe Reiter, Guckguck-Spiel, Hochwerfen des Kindes). Das Kind fordert aktiv die Wiederholung des Spiels, solange bis die Bewegung abbricht oder das Kind selbst ermüdet.«(Oerter 1997: 15f.)

Nach Oerter ist es als Entwicklungsschritt zu werten, wenn aus der einfachen Wiederholung eines Effektes ein Spiel mit Varianten wird. Während bei den Übungsspielen der frühen Kindheit der Ablauf immer gleich ist, leiten ältere Kinder aus einer Spielidee viele unterschiedliche Verläufe $a b$.

»Bei komplexeren Spielen, wie den Rollenspielen im Vor- und Grundschulalter, werden Szenen mit festgelegten Handlungsabfolgen [...] oft phantasievoll variiert. So verändert ein neunjähriges Mädchen seine Rolleninterpretation im Verkaufsspiel, indem es einmal eine schwatzhafte Kundin, eine anspruchsvolle, preziöse Kundin und ein fünfjähriges Kind als Käufer spielt.«(Oerter 1997: 16)

Was bedeutet nun der Aspekt der Wiederholung für die Improvisation? Improvisation als unwiederholbares musikalisches Ereignis ist scheinbar mit diesem Merkmal kaum in Übereinstimmung zu bringen. Lediglich die Ausgangslage oder der Handlungsrahmen, dass improvisiert wird, ist wiederholbar. Auf allgemeiner Ebene wäre so gesehen Improvisieren - ebenso wie reproduktives Musizieren - eine wiederholbare Handlung, deren Verlauf jedes Mal anders ist. Der Effekt einer solchen wiederholten Handlung des miteinander Musizierens liegt im gemeinsamen Klangergebnis, welches in der Improvisation für die Musizierenden vermutlich überraschender und weniger vorhersehbar ist, als in Situationen der Reproduktion.

Auf der konkreten Ebene eines improvisierten Musikstücks wäre zu unterscheiden, ob es ein von der Situation ablösbares Konzept 
gibt, indem bestimmte Regeln festgelegt werden. Ein Beispiel für ein solches Konzept bildet der diesem Text vorangestellte Improvisationsvorschlag von Stockhausen. Er stellt einen wiederholbaren Rahmen dar, der das konkrete klangliche Ergebnis offen lässt. Vorgaben wie diese sind Spielregeln vergleichbar und rücken die improvisatorische Handlung nahe an das Regelspiel.

\section{Zweckfreiheit}

Der Aspekt der Zweckfreiheit der Spielhandlung, die wie Oerter formuliert »eine Handlung um der Handlung willen« darstellt, lohnt im Hinblick auf die Spezifik des Improvisierens genauer betrachtet zu werden. Der Selbstzweck-Charakter des Spiels, der besonders von Kant und Schiller hervorgehoben wurde, lässt sich in Bezug setzen zum Gedanken der Autonomie von Kunst. Das autonome Kunstwerk steht für sich selbst, es hat keine festgeschriebene Funktion, seine Struktur folgt keinen Gesetzen praktischer Verwendbarkeit oder Anwendung, sondern allein ästhetischen Gesichtspunkten.

Diese Loslösung von Musik aus rituellen und repräsentativen Funktionen ist das Ergebnis einer kulturhistorischen Entwicklung, die um 1800 auf ihrem Höhepunkt ist und in engem Zusammenhang mit dem humanistischen Menschen- und Bildungsideal steht (vgl. Dietrich 1998: 10). Schillers Gedanken zur ästhetischen Erziehung des Menschen verdeutlichen diesen Zusammenhang, indem das Spiel, d.h. die ästhetische Gestaltungstätigkeit des Menschen, hier zum Ausdruck menschlicher Freiheit wird: Der Mensch spielt, weil er frei ist. Das Spielvermögen des Menschen deutet auf die Möglichkeit einer Lebensführung, die weder allein auf sinnlich-emotionalen Bedürfnissen noch allein auf rationalen Überlegungen gründet, sondern im Sinne einer ganzheitlichen Versöhnung zwischen den widerstreitenden Kräften einen Ausgleich herstellt.

Innerhalb der prinzipiell zweckfreien Sphäre von Kunst lassen sich aber hinsichtlich der Absicht des künstlerisch Handelnden noch Unterscheidungen treffen. Im Hinblick auf das herzustellende Werk handelt der Künstler zweckvoll: Er arbeitet an ihm, d.h. die Handlung des Komponierens beispielsweise lässt sich nicht als >Handlung um der Handlung willen< beschreiben, sondern erfolgt zu dem Zweck, eine Komposition herzustellen. Diese Feststellung ist für die Frage einer Grenzziehung zwischen (Kinder-)Spiel und künstleri- 
scher Tätigkeit eines Komponisten, Malers, Bildhauers etc. von Bedeutung.

In Untersuchungen zum Kinderspiel wird gelegentlich zwischen dem Werkschaffen des älteren Kindes und dem planlosen Spiel (mit Material) des kleinen Kindes unterschieden. Der Spielpsychologe Arnulf Rüssel schreibt zu dem Unterschied zwischen Spiel und Arbeit bzw. Werkschaffen:

»Das objektiv sich [im Kinderspiel, d.V.] ergebende Werk, das Bauwerk, die Legung, die geknetete Form ist entweder überhaupt unbeabsichtigt entstanden und findet gar nicht oder höchstens nachträglich die Würdigung des spielenden Kindes, oder es liegt im Spielverlauf nur eine relativ vage und wenig bedeutsame Richtung auf ein Werk vor. Denn die Werkgerichtetheit und Werkbeachtung wird weitgehend zurückgedrängt durch das gestalterische Tun selbst und die Freude des Kindes an ihm.«(Rüssel 1965: 14)

Das Merkmal >Handeln um des Handelns willen< lässt sich auch als Fehlen einer Intention oder Zielausrichtung beschreiben. Der Begriff der Absichtslosigkeit wird im Zusammenhang mit diesem Spielmerkmal oft gebraucht. Arnulf Rüssel zufolge korrespondiert die Absichtslosigkeit des Kinderspiels mit seiner Unkonventionalität. Im Unterschied zu den konventionellen Gestaltungen, um die sich das ältere Kind im $>$ Werkschaffen $<-$ nicht im Spiel - absichtsvoll und planend bemüht, sind die Spielergebnisse des kleinen Kindes von subjektiven Impulsen und Zufällen bestimmt. ${ }^{3}$

Die Improvisation steht zwischen Werkschaffen und Spiel, da das Werk von dem hervorbringenden Handlungsprozess nicht ablösbar ist. Mit dem Beenden des Improvisierens ist auch die Improvisation verklungen. Das Hier und Jetzt der Improvisation ist mit dem Merkmal des Selbstzwecks verbunden, da die Improvisation Hörer wie Spieler ohne materiell fundierte Rückstände entlässt. Insofern scheint die Improvisation bei der Anwendung des Spielbegriffs auf das Musizieren von besonderer Relevanz zu sein.

Hingegen scheint der Zusammenhang von Spiel und Improvisation dort in Frage gestellt, wo die Improvisation in den Dienst des Broterwerbs gestellt und mit einem Zweck in Verbindung gebracht

3 Zu den Spielmerkmalen der Absichtslosigkeit und Nicht-Konventionalität vgl. Rora 2001: 94ff. 
wird. Dies wird für den professionellen Fußballspieler ebenso in Anschlag gebracht wie es für den bezahlten Musiker gilt. Aus vergleichbaren Gründen will Oerter die Musikausübung von Kindern nicht als Spiel gelten lassen. Da das Musizieren für Kinder häufig mit Arbeit und Lernen verbunden ist, wird es von ihnen weniger als andere Tätigkeiten als Spiel wahrgenommen (vgl. Oerter 1997: 294).

\section{Wechsel des Realitätsbezugs}

Im Kinderspiel scheint zunächst ganz offensichtlich, was mit dem Wechsel des Realitätsbezugs gemeint ist. Kinder leiten ihr Rollenspiel gern mit Formulierungen wie $>$ du wärst jetzt mal...< ein. Damit schaffen sie eine $>$ als ob Situation $<$. Wie aber lassen sich Spiele wie Hüpfspiele oder Reigenspiele mit diesem Merkmal verbinden? Oerter gibt als Beispiel das Kinderspiel Häschen in der Grube und arbeitet heraus, dass es sich bei der in diesem Spiel enthaltenen Steigerung um eine Steigerung des Selbsterlebens handelt: »Solche Spiele heben es [das Kind, d.V.] aus der Alltagswelt und Alltagserfahrung heraus, sie formieren eine Art überhöhte oder besondere Realität, die nur vorübergehend existiert.« (Oerter 1997: 11) In Äußerungen von Musikern wird das Heraustreten aus der Alltagswelt gelegentlich als veränderte Art des Zeiterlebens beschrieben. Der Gitarrist Keith Rowe z.B. beschreibt einen Zustand tranceartiger Zeitlosigkeit beim Improvisieren:

»Es ist die einzige Zeit meines Lebens, wo ich mich völlig auf das konzentriere, was ich tue. Auf der einen Ebene weiß ich, wann zwei Stunden um sind, fast auf die Minute, und auf einer anderen Ebene habe ich die Zeit völlig vergessen.«(Rowe in Wilson 1999: 136)

Auch Malcolm Goldstein hebt die Zeitlosigkeit des Improvisierens hervor:

»Und wenn ich improvisiere, kümmere ich mich überhaupt nicht um die Zeit. Ich gehe einfach von Moment zu Moment. Es geht mir um die Geste des Körpers, die Gegenwart, das Klingen-Lassen.«(Goldstein in Wilson 1999: 173) 
Ein anderer Aspekt des geänderten Realitätsbezugs in der Improvisation liegt in der Abbildfunktion des Spiels. Kinder bilden Alltagssituationen und Ereignisse, die sie miterleben, in ihrem Spiel ab und passen sie ihrem Wunschdenken an. Diese Anpassung an das Wunschdenken tritt besonders dann in Erscheinung, wenn konflikthafte oder unangenehme Situationen im Spiel nachempfunden werden. Das Kind verarbeitet im Spiel seine Erlebnisse, indem es zum Beispiel einen Rollenwechsel vornimmt, und die Rolle, die es in der Wirklichkeit hatte, eintauscht gegen eine attraktivere. Spiel birgt damit »Möglichkeiten zur Regulation des psychischen Innenraums « (Fritz 1993: 22).

Matthias Schwabe hebt die Abbildfunktion von Improvisation hervor:

»Das Eigene finden ohne mich zwangsweise an Vorbilder lehnen zu müssen, mit der Vergänglichkeit leben, Erlebtes nicht wiederholen können und doch daraus Erfahrungen für die Zukunft sammeln, Fehler zu akzeptieren und ins Positive wenden: das sind ganz elementare Merkmale nicht nur der Improvisation, sondern des realen, ganz alltäglichen Lebens. Improvisieren ist sozusagen eine Kunstform, die in ihrer ganzen Vorgehensweise das Leben abbildet wie keine andere.« (Schwabe 1997: 26)

\section{Vom Sinn der freien Improvisation als Spiel}

Die Anwendung des Spielbegriffs auf die Improvisation ergibt eine Schnittmenge gemeinsamer Merkmale, die hier ausgehend von der Darstellung Oerters als Wiederholung, Zweckfreiheit und Wechsel des Realitätsbezugs bezeichnet werden. Mit der partiellen Gleichsetzung von Improvisation und Spiel wird es möglich, die Frage nach dem Sinn von Improvisation in pädagogischen Kontexten von einer anderen Seite her aufzurollen als zuvor, da die Improvisation unter dem Spielbegriff aus der begrenzten Perspektive einer Musizierform in den Horizont alläglicher Handlungsformen gerückt wird.

Wie die umfangreiche Literatur zur Spielpädagogik zeigt, ist auch das Spiel ein Phänomen, an das sich eine Vielzahl pädagogischer Annahmen, Hoffnungen, Funktions- und Wirkungszuschreibungen anlagern. Ebenso wie in der improvisationspädagogischen 
Literatur bleibt auch hier der Nachweis dieser Zuschreibungen problematisch. Gegenüber einer eindimensionalen Vereinnahmung des Kinderspiels unter dem Aspekt seiner Nützlichkeit schlägt Jürgen Fritz vor, eher von Potentialitäten auszugehen, die sich im Spiel entfalten (vgl. Fritz 1993: 17f.). Um Potentialitäten und nicht um nachweisbare Transfereffekte handelt es sich bei den Wirkungszuschreibungen an das Spiel deshalb, weil die Handlungsmöglichkeiten, die das Spiel bereitstellt, zunächst nur innerhalb des Spiels selbst zur Realisierung kommen. Damit diese Handlungsmöglichkeiten auch außerhalb des Spiels dem Kind zur Verfügung stehen, das Spiel also auf die Lebenswirklichkeit übergreifen kann, bedarf es anderer Einflüsse als die des Spiels selbst. Übertragen auf die Improvisation bedeutet dies, dass die persönliche Bedeutsamkeit von Improvisation für Musiker ihr nicht wie ein pädagogisch verwertbares Gütesiegel anhaftet, sondern lediglich auf Erfahrungsmöglichkeiten hindeutet.

Zur Bestimmung des pädagogischen Wertes von Improvisation scheint es vielmehr sinnvoll, auf den Anteil an spielerischen Qualitäten zu achten. Was darunter jeweils zu verstehen ist, entscheidet nicht zuletzt die Motivationslage der Spieler. Ob die Improvisation aber eine Erfahrung bewirkt, die über den Moment des Improvisierens hinaus Bedeutung hat, lässt sich ausgehend von der Improvisation nicht beeinflussen. Die Improvisation erfordert Fantasie, Spontaneität und Kooperationsfähigkeit und ihre Wiederholung gibt Gelegenheit, diese Fähigkeiten im Zusammenhang mit den musikalischen Anforderungen der Improvisationssituation zu entwickeln. Die Übertragung dieser musikalischen Erfahrungen und Fähigkeiten auf die alltägliche Praxis der Lebensbewältigung bleibt Aufgabe und Teil des individuellen Selbstbildungsprozesses.

\section{Literatur}

Dietrich, Cornelie (1998): Wozu in Tönen denken. Historische und empirische Studien zur bildungstheoretischen Bedeutung musikalischer Autonomie. Kassel: Gustav Bosse.

Eckhard, Rainer (1995): Improvisation in der Musikdidaktik. Eine historiographische und systematische Untersuchung. Augsburg: Wißner. 
Erwe, Hans-Joachim (2004): »Vom Mythos der Improvisation im Jazz«. In: Claudia Bullerjahn/Wolfgang Löffler (Hg.), Musikermythen. Alltagstheorien, Legenden und Medieninszenierungen, Hildesheim: Olms, S. 163-190.

Friedemann, Lilli (1973): Einstiege in neue Klangbereiche durch Gruppenimprovisation. Wien: Universal Edition.

Friedemann, Lilli (1974): »Musizieren als unwiederholbares Geschehnis«. In: Franz Blasl (Hg.), Experimente im Musikunterricht. Eine Sammlung von Protokollen, Wien: Universal Edition, S. 16-19.

Fritz, Jürgen (1993): Theorie und Pädagogik des Spiels. Eine praxisorientierte Einführung. Weinheim: Juventa.

Kieseritzky, Herwig von/Schwabe, Matthias (2001): »Musikalische Gruppenimprovisation - Musik spielend erfinden«. In: Gundel Mattenklott/Constanze Rora (Hg.), Arbeit an der Einbildungskraft. Praxis Musisch-Ästhetischer Erziehung. Band 1: Perspektiven, Baltmannsweiler: Schneider Verl. Hohengehren, S. 107138.

Meyer-Denkmann, Gertrud (1996): »Klangexperimente und Improvisationspraktiken. Einige kritische Anmerkungen«. Musik und Unterricht 39, S. 32-34.

Oerter, Rolf (1997): Psychologie des Spiels. Weinheim: Beltz Psychologie Verlags Union.

Rora, Constanze (2001): Ästhetische Bildung im musikalischen Gestaltungsspiel. Augsburg: Wißner.

Rüssel, Arnulf (1965): Das Kinderspiel. Grundlinien einer psychologischen Theorie. Darmstadt: Wiss. Buchgesellschaft.

Schwabe, Matthias (1992): Musik spielend erfinden. Improvisieren in der Gruppe für Anfänger und Fortgeschrittene. Kassel: Bärenreiter.

Schwabe, Matthias (1997): »Risiko als Chance. Über die künstlerische und pädagogische Wirkung von Gruppenimprovisation«. Ringgespräch über Gruppenimprovisation LXII April, S. 23-26.

Wilson, Peter Niklas (1999): Hear and Now. Gedanken zur improvisierten Musik. Hofheim: Wolke. 



\section{Autorinnen Und AUtOREN}

Bielefeld, Ulrich, geb. 1951, ist Leiter des Arbeitsbereichs »Nation und Gesellschaft« am Hamburger Institut für Sozialforschung. Er lehrt als Privatdozent am Institut für Soziologie der Technischen Universität Darmstadt und ist Lehrbeauftragter der Universität Hamburg. Studium der Soziologie und Sozialpsychologie in Münster und München, Promotion und Habilitation an der TU Darmstadt. Arbeitsschwerpunkte: Soziologie der Nation, des Nationalstaats und der Demokratie, Soziologie des Fremden, Kultursoziologie.

Figueroa-Dreher, Silvana K., geb. 1966, studierte Soziologie in Buenos Aires, Argentinien. Nach ihrer Promotion (Dr. rer. soc.) an der Universität Konstanz forschte sie vor allem zur Identität in pluralistischen Gesellschaften. Aktuell leitet sie das Forschungsprojekt $\gg$ Improvisation als $>$ neuer $<$ Handlungstypus. Eine handlungstheoretische Exploration der musikalischen Improvisation«. Arbeitsschwerpunkte: Handlungstheorie, Musiksoziologie, Kultursoziologie, Argentinien, qualitative Methodologie, Identität.

Kozlarek, Oliver, geb. 1965, studierte Publizistik, Lateinamerikanistik, Soziologie und Philosophie in Berlin, Mexiko-Stadt, New York und São Paulo. Er promovierte an der FU Berlin (1997) und an der Universidad Autónoma Metropolitana in Mexiko (2001). Seit 2000 ist er Professor an der philosophischen Fakultät der Universidad Michoacana, Mexiko. Neuere Publikationen: Crítica, acción y modernidad, Mexiko-Stadt, Dríada, 2004, (Hg.), De la Teoría Crítica a una crítica plural de la modernidad, Buenos Aires, Biblos, 2007.

Kurt, Ronald, geb. 1964, studierte Soziologie, Philosophie und Germanistik in Düsseldorf, promovierte in Hagen (Dr. rer. soc.) und habilitierte in Konstanz, wo er als außerplanmäßiger Professor Soziologie lehrt. Seit 2004 ist er Fellow am Kulturwissenschaftlichen 
Institut in Essen. Arbeitsschwerpunkte: Kultur- und Wissenssoziologie, Indien, Musik, Hermeneutik, Sozialphänomenologie.

Näumann, Klaus, geb. 1969, studierte Musikpädagogik (Jazz/ Rock/Pop) und Vergleichende Musikwissenschaft. Nach seiner Promotion zum Dr. phil über »Parang-Musik in Trinidad « war er als Lehrbeauftragter an der FU Berlin, als Fellow am KWI Essen und als Gitarrenlehrer an Musikschulen tätig. Unternahm Feldforschungen in Trinidad, Venezuela und Polen; weitere Schwerpunkte: Populäre Musikformen und musikalische Akustik.

Orgass, Stefan, geb. 1960, 1990-1997 Studienrat für Musik und Geschichte an zwei Gymnasien, promovierte 1995 mit einer musikwissenschaftlichen Arbeit über J. S. Bach und ist seit 1998 Professor für Musikpädagogik an der Folkwang Hochschule (Essen). Wichtigste Publikation: Musikalische Bildung in europäischer Perspektive. Entwurf einer Kommunikativen Musikdidaktik, Hildesheim u.a., Olms, 2007. Forschungsschwerpunkte: Theorie musikalischer Bildung und musikalischer Bedeutung, Unterrichtsforschung.

Rora, Constanze, geb. 1961, Professorin für Musikpädagogik und Musikdidaktik an der Universität Leipzig, studierte Schulmusik, Germanistik, Theaterpädagogik in Berlin, promovierte zum Thema »Ästhetische Bildung im musikalischen Gestaltungsspiel «. Arbeitsschwerpunkte in den Bereichen psychologische und ästhetische Grundlagen des Musikunterrichts, Qualitative Forschung in der $\mathrm{Mu}-$ sikpädagogik.

Schmidt, Markus, geb. 1970 studierte Vergleichende Musikwissenschaft, Musikwissenschaft und Philosophie. Derzeit ist er als Wissenschaftlicher Mitarbeiter an der Freien Universität Berlin beschäftig und promoviert über Improvisation in der klassischen nordindischen Musik. Seit 1990 reist er regelmäßig nach Indien, wo er klassische indische Musik bei Subroto Roy Chowdhury (Sitar) und bei Ashish Sankrityayan (Rudra Vina) studiert. 


\section{Kultur- und Medientheorie}

Michael Schetsche, Martin Engelbrecht (Hg.)

Von Menschen und Außerirdischen

Transterrestrische Begegnungen im Spiegel der Kulturwissenschaft

Juni 2008, ca. 250 Seiten, kart., ca. $24,80 €$,

ISBN: 978-3-89942-855-1

Uwe Seifert, Jin Hyun Kim, Anthony Moore (eds.)

Paradoxes of Interactivity

Perspectives for Media

Theory, Human-Computer

Interaction, and

Artistic Investigations

Juni 2008, ca. 350 Seiten,

kart., ca. $35,80 €$,

ISBN: 978-3-89942-842-1

Christian Kassung (Hg.)

Die Unordnung der Dinge

Eine Wissens- und Mediengeschichte des Unfalls

Mai 2008, ca. 400 Seiten,

kart., zahlr. Abb., ca. 33,80 €,

ISBN: 978-3-89942-721-9

Matthias Bruhn,

Kai-Uwe Hemken (Hg.)

Modernisierung des Sehens

Sehweisen zwischen

Künsten und Medien

Mai 2008, ca. 300 Seiten,

kart., ca. $29,80 €$,

ISBN: 978-3-89942-912-1

Ulrike Haß,

Nikolaus Müller-Schöll (Hg.)

Was ist eine Universität?

Schlaglichter auf eine

ruinierte Institution

Mai 2008, ca. 16o Seiten,

kart., ca. $12,80 €$,

ISBN: 978-3-89942-907-7

\author{
Michael Dürfeld \\ Das Ornamentale \\ und die architek- \\ tonische Form \\ Systemtheoretische \\ Irritationen \\ Mai 2008, ca. 166 Seiten, \\ kart., ca. $24,80 €$, \\ ISBN: $978-3-89942-898-8$
}

Kristiane Hasselmann

Die Rituale der Freimaurer

Performative Grundlegungen eines bürgerlichen Habitus im 18. Jahrhundert

Mai 2008, ca. 300 Seiten, kart., zahlr. Abb., ca. 29,80 €, ISBN: $978-3-89942-803-2$

Ines Kappert

Der Mann in der Krise oder: Eine konservative Kapitalismuskritik in der Mainstreamkultur

Mai 2008, ca. 232 Seiten, kart., ca. $23,80 €$,

ISBN: 978-3-89942-897-1

Claudia Lillge,

Anne-Rose Meyer (Hg.)

Interkulturelle Mahlzeiten

Kulinarische Begegnungen und Kommunikation in der Literatur

Mai 2008, ca. 230 Seiten, kart., ca. $24,80 €$,

ISBN: 978-3-89942-881-o

Jan Deck, Angelika Sieburg Paradoxien des Zuschauens Die Rolle des Publikums im zeitgenössischen Theater April 2008, ca. 120 Seiten, kart., ca. $15,80 €$,

ISBN: 978-3-89942-853-7

Leseproben und weitere Informationen finden Sie unter: www.transcript-verlag.de 


\section{Kultur- und Medientheorie}

Susanne Regener

Visuelle Gewalt

Menschenbilder aus

der Psychiatrie

des 20. Jahrhunderts

April 2008, ca. 220 Seiten, kart., zahlr. Abb., ca. 25,80 €, ISBN: 978-3-89942-420-1

\section{Christa Sommerer,}

Laurent Mignonneau, Dorothée Gestrich (eds.)

\section{Interface Cultures}

Artistic Aspects of Interaction

April 2008, 350 Seiten,

kart., zahlr. Abb., ca. 32,80 €,

ISBN: 978-3-89942-884-1

Doris Kolesch, Vito Pinto, Jenny Schrödl (Hg.)

\section{Stimm-Welten}

Philosophische, medientheoretische und ästhetische Perspektiven

April 2008, ca. 216 Seiten,

kart., ca. $24,80 €$,

ISBN: 978-3-89942-904-6

Julia Pfahl

Zwischen den Kulturen zwischen den Künsten

Medial hybride Theaterinszenierungen in Québec

April 2008, ca. 350 Seiten, kart., ca. $33,80 €$,

ISBN: 978-3-89942-909-1

Alma-Elisa Kittner Visuelle Autobiographien

Sammeln als Selbstentwurf bei Hannah Höch,

Sophie Calle und

Annette Messager

April 2008, ca. 300 Seiten, kart., zahlr. Abb., ca. 29,80€, ISBN: 978-3-89942-872-8
Peter Seibert (Hg.)

Samuel Beckett und die Medien

Neue Perspektiven auf einen Medienkünstler des 20. Jahrhunderts

April 2008, 216 Seiten,

kart., $24,80 €$,

ISBN: 978-3-89942-843-8

Simone Loleit

Wahrheit, Lüge, Fiktion: Das Bad in der deutschsprachigen Literatur des 16. Jahrhunderts

April 2008, ca. 320 Seiten, kart., ca. $32,80 €$,

ISBN: 978-3-89942-666-3

Geert Lovink <zero comments>

Elemente einer kritischen Internetkultur

April 2008, ca. 300 Seiten kart., ca. $27,80 €$,

ISBN: 978-3-89942-804-9

York Kautt

Image

Zur Genealogie eines

Kommunikationscodes und zur Entwicklung des Funktionssystems Werbung April 2008, 370 Seiten, kart., zahlr. Abb., ca. 30,80€, ISBN: 978-3-89942-826-1

Dorothee Kimmich,

Wolfgang Matzat (Hg.)

Der gepflegte Umgang

Interkulturelle Aspekte der Höflichkeit in Literatur und Sprache April 2008, ca. 180 Seiten, kart., ca. $19,80 €$, ISBN: 978-3-89942-820-9

Leseproben und weitere Informationen finden Sie unter: www.transcript-verlag.de 


\section{Kultur- und Medientheorie}

Hans Dieter Hellige (Hg.) Mensch-Computer-Interface Zur Geschichte und Zukunft der Computerbedienung

April 2008, 360 Seiten,

kart., ca. $29,80 €$,

ISBN: 978-3-89942-564-2

Kati Röttger,

Alexander Jackob (Hg.)

Theater und Bild

Inszenierungen des Sehens

April 2008, ca. 250 Seiten,

kart., ca. $27,80 €$,

ISBN: 978-3-89942-706-6

\section{Bettine Menke}

\section{Das Trauerspiel-Buch}

Der Souverän - das Trauerspiel

- Konstellationen - Ruinen

April 2008, ca. 120 Seiten,

kart., ca. $14,80 €$,

ISBN: 978-3-89942-634-2

Thomas Ernst,

Patricia Gozalbez Cantó,

Sebastian Richter,

Nadja Sennewald,

Julia Tieke (Hg.)

\section{SUBversionen}

Zum Verhältnis von Politik und Ästhetik in der Gegenwart

März 2008, 406 Seiten,

kart., $30,80 €$,

ISBN: $978-3-89942-677-9$

Derrick de Kerckhove,

Martina Leeker,

Kerstin Schmidt (Hg.)

\section{McLuhan neu lesen}

Kritische Analysen zu Medien und Kultur im 21. Jahrhundert

März 2008, ca. 450 Seiten,

kart., zahlr. Abb.,

inkl. DVD, ca. $39,80 €$,

ISBN: 978-3-89942-762-2
Ronald Kurt,

Klaus Näumann (Hg.)

Menschliches Handeln

als Improvisation

Sozial- und musikwissenschaftliche Perspektiven

März 2008, 236 Seiten,

kart., $25,80 €$,

ISBN: 978-3-89942-754-7

Christian Bielefeldt,

Udo Dahmen,

Rolf Großmann (Hg.)

PopMusicology

Perspektiven der Popmusikwissenschaft

Februar 2008, 284 Seiten, kart., $26,80 €$,

ISBN: 978-3-89942-603-8

Cora von Pape

Kunstkleider

Die Präsenz des Körpers in textilen Kunst-Objekten des 20. Jahrhunderts

Februar 2008, 228 Seiten, kart., zahlr. Abb., 26,80 €, ISBN: 978-3-89942-825-4

Helge Meyer

\section{Schmerz als Bild}

Leiden und Selbstverletzung in der Performance Art

Januar 2008, 372 Seiten, kart., zahlr. Abb., 35,80 €, ISBN: 978-3-89942-868-1

Annett Zinsmeister (Hg.) welt[stadt]raum

Mediale Inszenierungen

Januar 2008, 172 Seiten,

kart., zahlr. Abb., 18,80 €,

ISBN: 978-3-89942-419-5

Leseproben und weitere Informationen finden Sie unter: www.transcript-verlag.de 
